\author{
UNIVERSIDADE DE SÃO PAULO \\ ESCOLA DE ENGENHARIA DE SÃO CARLOS \\ DEPARTAMENTO DE HIDRÁULICA E SANEAMENTO
}

Simone Pereira Casali

VARIABILIDADE TEMPORAL DA COMUNIDADE FITOPLANCTÔNICA

EM LAGOAS FACULTATIVAS DE DOIS SISTEMAS DE TRATAMENTO DE ESGOTO COM DIFERENTES CONFIGURAÇÕES (BAIXO RIBEIRA DE IGUAPE, SP).

Orientadora: Professora Titular Maria do Carmo Calijuri

São Carlos

2008 

Simone Pereira Casali

\title{
VARIABILIDADE TEMPORAL DA COMUNIDADE FITOPLANCTÔNICA EM LAGOAS FACULTATIVAS DE DOIS SISTEMAS DE TRATAMENTO DE ESGOTO COM DIFERENTES CONFIGURAÇÕES
}

(BAIXO RIBEIRA DE IGUAPE, SP).

\begin{abstract}
Dissertação apresentada à Escola de Engenharia de São Carlos da Universidade de São Paulo, como parte dos requisitos para obtenção do Título de Mestre em Hidráulica e Saneamento.
\end{abstract}

Orientadora: Professora Titular Maria do Carmo Calijuri

São Carlos

2008 
AUTORIZO A REPRODUÇÃO E DIVULGAÇÃO TOTAL OU PARCIAL DESTE TRABALHO, POR QUALQUER MEIO CONVENCIONAL OU ELETRÔNICO, PARA FINS DE ESTUDO E PESQUISA, DESDE QUE CITADA A FONTE.

Ficha catalográfica preparada pela Seção de Tratamento da Informação do Serviço de Biblioteca - EESC/USP

Casali, Simone Pereira

C334v Variabilidade temporal da comunidade fitoplanctônica em lagoas facultativas de dois sistemas de tratamento de esgoto com diferentes configurações (baixo Ribeira de Iguape, SP) / Simone Pereira Casali ; orientadora Maria do Carmo Calijuri. -- São Carlos, 2008.

Dissertação (Mestrado-Programa de Pós-Graduação e Área de Concentração em Hidráulica e Saneamento) -- Escola de Engenharia de São Carlos da Universidade de São Paulo, 2008.

1. Tratamento de esgoto. 2. Estrutura da comunidade. 3. Fitoplâncton. 
Dedico este trabalho:

Ao meu noivo Mateus, pela paciência, amor e atenção em todos os momentos; Aos meus pais Cesar e Rose, por me apoiarem e ajudarem muito durante estes anos;

Aos meus irmãos Graziela, Lavínia e Junior, pelo amor e carinho;

Ao meu sobrinho Antonio por entender meus momentos de ausência. 



\section{AGRADECIMENTO}

À Deus, pela minha existência e força nos momentos mais difíceis na realização deste trabalho.

À minha família, ao Mateus e à Marize pelo apoio, paciência, pelos momentos de descontração e por sempre acreditarem em mim.

À profa. Titular Maria do Carmo Calijuri pela orientação, discussão, amizade e por me ajudar no amadurecimento como pesquisadora.

À doutora e amiga Patrícia Bortoleto de Falco pelas idéias e auxílio na interpretação dos dados, nas coletas, na identificação do fitoplâncton e inúmeras correções não importando o dia.

À doutora e amiga Adriana C.P. Miwa por me ajudar nos relatórios, nas coletas e na estatística.

À querida Luci A. de Queiroz pela disponibilidade em ensinar e ajudar nas análises de laboratório e de campo, sem a qual não seria possível a realização deste trabalho.

Aos pesquisadores e amigos do laboratório Biotace: Ive Ciola Ferraz, Juliana Moccellin, Caroline de Andrade Gomes da Cunha, Paulo Vagner dos Santos, Rosseli Frederigi Benassi, Adriana Barbosa Costa, Ana Flávia da Silva Hoeppner e Glauce Guimarães Pereira pela constante companhia, risadas e por estenderem a mão amiga nas horas difíceis no decorrer do trabalho.

Aos examinadores dos exames de qualificação: Prof. Dr. André Cordeiro Alves dos Santos, Prof. Dr. Marcelo Pompeu, Profa. Dra. Maria Bernadete A. Varesche Silva e a Profa. Dra. Jandira L. B. Talamoni, Dra Patrícia Bortoleto de Falco, pelas pertinentes contribuições para a elaboração desta dissertação.

Aos Técnicos Waldomiro Antonio Filho e José Roberto Maramarque, com grande e indispensável experiência nos trabalhos de campo, sem vocês a realização deste trabalho seria impossível; e ao Benedito Patracon pelo cuidade, paciência e companhia durantes as coletas.

À equipe de técnicos do Laboratório de Saneamento da EESC/USP: Paulo Fragiácomo, Júlio César Trofino, pela disponibilidade em analisar e ensinar as análises de Carbono Orgânico. 
Ao Sr. Helio e sua família, por permitir a montagem do laboratório de campo em seu sítio e pelos cafezinhos.

Ao prof. Pião pela ajuda na análise estatística dos resultados.

Aos funcionários da Pós-Graduação do Departamento de Hidráulica e Saneamento Maria Auxiliadora C. Altieri Pin e Pavlovna Damião Rocha Bueno, Rosemeire A. de Jesus, Flávia G. Canova e Fernanda M. Struzziatto, obrigada pela paciência, eficiência, dicas preciosas e o mais importante, pela atenção e carinho.

A Rosemeire do A. C. Zambom da biblioteca do ICMC, pelos livros conseguidos da forma mais rápida possível.

Ao CNPq pelo auxilio concedido.

À FAPESP, pelo suporte financeiro ao Projeto Temático (02/13449-1).

À SABESP de Pariquera-Açu, Jacupiranga e Registro, principalmente ao Sr. Osvaldo Beltrame, por ceder a área de estudo.

Enfim, a todos aqueles que de alguma forma me auxiliaram durante este período de aprendizado, meu muito obrigado. 


\section{RESUMO}

CASALI, S.P. (2008). Variabilidade Temporal da Comunidade Fitoplanctônica em Lagoas Facultativas de dois Sistemas Tratamento de esgoto com diferentes configurações (Baixo Ribeira de Iguape, SP). Dissertação de Mestrado. Escola de Engenharia de São Carlos, Universidade de São Paulo, São Carlos.

Esta pesquisa foi desenvolvida nas lagoas facultativas das estações de tratamento de esgoto dos municípios de Pariquera-Açu (PA) e Jacupiranga (JA), com diferentes configurações, sendo a primeira composta por lagoa anaeróbia seguida de facultativa com chicanas e a outra por lagoa aerada mecanicamente seguida de facultativa. Estas lagoas são consideradas ambientes hipereutróficos, pois apresentam grande quantidade de matéria orgânica oriunda dos esgotos domésticos e industriais. O conhecimento da estrutura da comunidade fitoplanctônica e sua avaliação em diferentes horários do fotoperíodo são relevantes pois estes organismos são responsáveis pela produção de oxigênio necessário para a degradação da matéria orgânica. Esta pesquisa teve como objetivo principal o estudo sazonal e diário da estrutura da comunidade fitoplanctônica e da produção primária nestas lagoas. Para atingir este objetivo foi caracterizada a estrutura da comunidade, em relação a biomassa e diversidade, e determinada a produção primária com incubações in situ através do método do oxigênio dissolvido. $O$ estudo foi realizado em quatro épocas do ano (variação sazonal) no período das 7 às 16 horas, com amostragens de 3 em 3 horas (diária). Não foram observadas variações temporais e espaciais na estrutura da comunidade fitoplanctônica nas duas lagoas facultativas. Apenas as cianobactérias (principalmente a Synechocystis aquatilis e Phormidium sp) e clorofíceas (Kirchneriella lunaris, Chlorella Kessleri, Monoraphidium contortum, Monoraphidium sp, Chlamydomonas sp, Eutetramorus planctonicus e Micractinium pusillum) foram predominantes, nestas lagoas, porém em períodos alternados. Foram observados altos valores de produção primária bruta $\left(15.891 \mathrm{mgO}_{2} \mathrm{~m}^{-}\right.$ ${ }^{3} \cdot \mathrm{h}^{-1}$ em PA; $5.700 \mathrm{mgO}_{2} \mathrm{~m}^{-3} \cdot \mathrm{h}^{-1} \mathrm{em} \mathrm{JA}$ ) na interface água-sedimento das duas lagoas devido, provavelmente, ao padrão de mistura da coluna de água. Foram também observados altos valores de respiração da comunidade (abril, julho e setembro), devido à alta concentração de matéria orgânica presente nestes sistemas e, portanto, maior decomposição, indicando predominância de processos heterotróficos.

Palavras-chave: estrutura da comunidade, fitoplâncton, produção primária, variabilidade temporal, lagoa facultativa. 


\section{ABSTRACT}

CASALI, S.P. (2008). Temporal Variability of the Phytoplanktonic Community in Facultative Ponds of two Waste Water Plants with Different Setting (Baixo Ribeira de Iguape, SP). Master's Degree Dissertation. Escola de Engenharia de São Carlos, Universidade de São Paulo, São Carlos.

This research was developed in facultative ponds of the waste water treatment plant of Pariquera-Açu e Jacupiranga cities with different configurations, being the first composed by anaerobic pond followed by facultative with chicanas and the another composed by aerated mechanic pond followed by facultative. These ponds are considered hypereutrophic environments because it shows a large quantity of organic matter derived from the domestic and industrial sewage. The knowledge of phytoplanktonic community structure and its evaluation in different times of photoperiod are relevant since such organisms was responsible by production of oxygen necessary to the degrade of organic matter. This research had the main goal the seasonal and daily study of the phytoplanktonic community and the primary production in these ponds. To reach this objective the structure of the community was characterized in relation to biomass and density, and determined the primary production with incubations in situ through the dissolved oxygen method. The study was made in four periods of the year (seasonal variation) between the 7 a.m. to 4 p.m., with samplings of 3-to-3 hours (daily). It was not observed temporal and spatial variations in the phytoplanktonic community structure in the facultative ponds. Only cyanobacteria (mainly Synechocystis aquatilis and Phormidium $\mathrm{sp}$ ) and chlorophycea (Kirchneriella lunaris, Chlorella Kessleri, Monoraphidium contortum, Monoraphidium sp, Chlamydomonas sp, Eutetramorus planctonicus and Micractinium pusillum) were predominant in these ponds, however, in alternated periods. It was observed high rates of gross primary production $\left(15891 \mathrm{mgO}_{2} \mathrm{~m}^{-3} \cdot \mathrm{h}^{-1}, \mathrm{PA} ; 5700 \mathrm{mgO}_{2} \mathrm{~m}^{-}\right.$ $\left.{ }^{3} \cdot h^{-1}, J A\right)$ in the interface water-sediment of both ponds due, probably, to the standard of mixed conditions of water column. It was also observed high rates of community respiration (April, July and September), due to the high concentration of organic matter present in these systems and, therefore, greater decomposition, indicating predominance of heterotrophic processes.

Keywords: community structure, phytoplankton, primary production, temporal variability, facultative ponds. 


\section{LISTA DE FIGURAS}

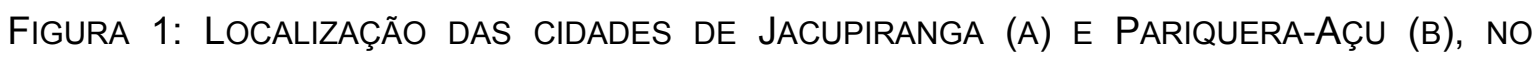
ESTADO DE SÃo PAULO. FONTE: HOEPNER (2007).

FIgURA 2: DIAGRAMA DO SISTEMA DE TRATAMENTO DE ESGOTO DOS MUNICÍPIOS DE PARIQUERA-AÇU E JACUPIRANGA, RESPECTIVAMENTE, COM REPRESENTAÇÃO DAS ESTAÇÕES DE AMOSTRAGEM. (E: ENTRADA DA LAGOA, LA: LAGOA ANAERÓBIA, LAM: LAGOA MECANICAMENTE AERADA, LF: LAGOA FACULTATIVA, LFC : LAGOA FACULTATIVA COM CHICANAS, S: SAÍDA DA LAGOA E SC: SAÍDA DA LAGOA COM CHICANA).

FiguRA 3: Sistema de TRATAMENTO DE ESgoto do MUNICÍPIO DE PARIQUERA-AÇU. 11

FIgURA 3: SISTEMA DE TRATAMENTO DE ESGOTO DO MUNICÍPIO DE PARIQUERA-AÇU. 11

FIGURA 4: CHICANAS DO SISTEMA DE TRATAMENTO DE ESGOTO DO MUNICÍPIO DE PARIQUERAAÇU.

FIgURA 5: SISTEMA DE TRATAMENTO DE ESGOTO DO MUNICÍPIO DE JACUPIRANGA. 12

FIGURA 6: DIAGRAMA DE AMOSTRAGEM.

FIGURA 7: PRECIPITAÇÕES MENSAIS (BARRAS), EM MM E TEMPERATURA MÉDIA DO AR (LINHAS), EM ${ }^{\circ} \mathrm{C}$, NO MUNICÍPIO DE PARIQUERA-AÇU.FONTE: CIIAGRO, 2008.

FIGURA 8: PRECIPITAÇÕES MENSAIS (BARRAS), EM MM E TEMPERATURA MÉDIA DO AR (LINHAS), EM ${ }^{\circ} \mathrm{C}$, NO MUNICÍPIO JACUPIRANGA. FONTE: CIIAGRO, 2008.

FIgURA 9: PRECIPITAÇÕES MENSAIS (MM) E TEMPERATURA MÉDIA DO AR $\left({ }^{\circ} \mathrm{C}\right)$ DURANTE O PERÍODO DE DEZEMBRO DE 2005 A SETEMBRO DE 2006, NO MUNICÍPIO DE PARIQUERAAÇU. OS MESES HACHURADOS REPRESENTAM OS PERÍODOS DE COLETA. FONTE: CIIAGRO, 2008.

FIGURA 10: PRECIPITAÇÕES MENSAIS (MM) E TEMPERATURA MÉDIA DO AR $\left({ }^{\circ} \mathrm{C}\right)$ DURANTE O PERÍODO DE DEZEMBRO DE 2005 A SETEMBRO DE 2006, NO MUNICÍPIO DE JACUPIRANGA. OS MESES haCHURADOS REPRESENTAM OS PERÍODOS DE COLETA. FONTE: CIIAGRO, 2008.

FIgURA 11: PRECIPITAÇÕES DIÁRIAS (MM) E TEMPERATURA MÉDIA DO AR $\left({ }^{\circ} \mathrm{C}\right)$ DURANTE OS MESES DE AMOSTRAGEM, NO MUNICÍPIO DE PARIQUERA-AÇU, NOS MESES DE JANEIRO (A), ABRIL (B), JULHO (C) E SETEMBRO (D). AS SETAS INDICAM OS DIAS DE AMOSTRAGEM. FONTE: CIIAGRO, 2006.

FIGURA 12: PRECIPITAÇÕES DIÁRIAS (MM) E TEMPERATURA MÉDIA DO AR $\left({ }^{\circ} \mathrm{C}\right)$ DURANTE OS MESES DE AMOSTRAGEM, NO MUNICÍPIO DE JACUPIRANGA, NOS MESES DE JANEIRO (A), ABRIL (B), JULHO (C) E SETEMBRO (D). AS SETAS INDICAM OS DIAS DE AMOSTRAGEM. FONTE: CIIAGRO, 2006.

FIGURA 13: PROFUNDIDADE DA ZONA EUFÓTICA (ZEUF) E DA ZONA AFÓTICA (ZAF), NAS LAGOAS FACULTATIVAS DAS ETES DE PARIQUERA-AÇU (ÀS 7H, EM SETEMBRO, A MEDIDA NÃO FOI REALIZADA) E JACUPIRANGA.

FiguRA 14: PERFIS DE TEMPERATURA DA ÁGUA $\left({ }^{\circ} \mathrm{C}\right)$, NAS LAGOAS FACULTATIVAS DAS ETES DE PARIQUERA-AÇU E JACUPIRANGA.

Figura 15: Perfis de PH, nas lagoas facultativas das ETES de Pariquera-AÇu E JACUPIRANGA.

FIGURA 16: PERFIS DE CONDUTIVIDADE ELÉTRICA $\left(\mu S . \mathrm{CM}^{-1}\right)$, NAS LAGOAS FACULTATIVAS DAS ETES DE PARIQUERA-AÇU E JACUPIRANGA.

FIGURA 17: CONCENTRAÇÕES DE N-AMONIACAL (MG.L ${ }^{-1}$ ), NAS LAGOAS FACULTATIVAS DAS ETES DE PARIQUERA-AÇU E JACUPIRANGA (SS: SUB-SUPERFICIE, M: MEIO E F: INTERFACE ÁGUA-SEDIMENTO), EM DIFERENTES ÉPOCAS DO ANO. 
FIgURA 18: CONCENTRAÇÕES DE NITROGÊNIO TOTAL KJEDAHL - NTK (MG.L - $^{-1}$ ), NAS LAGOAS FACULTATIVAS DAS ETES DE PARIQUERA-AÇU E JACUPIRANGA (SS: SUB-SUPERFÍCIE, M: MEIO E F: INTERFACE ÁGUA-SEDIMENTO), EM DIFERENTES ÉPOCAS DO ANO.

FIGURA 19: CONCENTRAÇÕES DE NITRATO (MG.L ${ }^{-1}$ ), NAS LAGOAS FACULTATIVAS DAS ETES DE PARIQUERA-AÇU E JACUPIRANGA (SS: SUB-SUPERFÍCIE, M: MEIO E F: INTERFACE ÁGUASEDIMENTO), EM DIFERENTES ÉPOCAS DO ANO.

FIGURA 20: CONCENTRAÇÕES DE NITRITO (MG.L ${ }^{-1}$ ), NAS LAGOAS FACULTATIVAS DAS ETES DE PARIQUERA-AÇU E JACUPIRANGA (SS: SUB-SUPERFÍCIE, M: MEIO E F: INTERFACE ÁGUASEDIMENTO), EM DIFERENTES ÉPOCAS DO ANO.

FIGURA 21: CONCENTRAÇÕES DE ORTOFOSFATO (MG.L-1 ${ }^{-1}$ ), NAS LAGOAS FACULTATIVAS DAS ETES DE PARIQUERA-AÇU E JACUPIRANGA (SS: SUB-SUPERFÍCIE, M: MEIO E F: INTERFACE ÁGUA-SEDIMENTO), EM DIFERENTES ÉPOCAS DO ANO.

FIGURA 22: MÉdIA DAS CONCENTRAÇÕES (N:12) DE SÓlIDOS SUSPENSOS ORGÂNICOS E INORGÂNICOS (SSO E SSI) (MG.L ${ }^{-1}$ ), NAS LAGOAS FACULTATIVAS DAS ETES DE PARIQUERA-AÇU E JACUPIRANGA, EM DIFERENTES ÉPOCAS DO ANO.

FIGURA 23: CONCENTRAÇÕES DE SÓLIDOS SUSPENSOS ORGÂNICOS - SSO (MG.L-1 ${ }^{-1}$ ), NAS LAGOAS FACULTATIVAS DAS ETES DE PARIQUERA-AÇU E JACUPIRANGA (SS: SUBSUPERFÍCIE, M: MEIO E F: INTERFACE ÁGUA-SEDIMENTO), EM DIFERENTES ÉPOCAS DO ANO.

FIGURA 24: CONCENTRAÇÕES DE SÓLIDOS SUSPENSOS INORGÂNICOS - SSI (MG.L ${ }^{-1}$ ), NAS LAGOAS FACULTATIVAS DAS ETES DE PARIQUERA-AÇU E JACUPIRANGA (SS: SUBSUPERFÍCIE, M: MEIO E F: INTERFACE ÁGUA-SEDIMENTO), EM DIFERENTES ÉPOCAS DO ANO.

FIGURA 25: CONCENTRAÇÕES DE CLOROFILA A (MG.L $\left.{ }^{-1}\right)$, NAS LAGOAS FACULTATIVAS DAS ETES DE PARIQUERA-AÇU E JACUPIRANGA (SS: SUB-SUPERFÍCIE, M: MEIO E F: INTERFACE ÁGUA-SEDIMENTO), EM DIFERENTES ÉPOCAS DO ANO.

FIGURA 26: CONCENTRAÇÕES DE FEOFITINA (MG. $L^{-1}$ ), NAS LAGOAS FACULTATIVAS DAS ETES DE PARIQUERA-AÇU E JACUPIRANGA (SS: SUB-SUPERFÍCIE, M: MEIO E F: INTERFACE ÁGUA-SEDIMENTO), EM DIFERENTES ÉPOCAS DO ANO. 


\section{LISTA DE TABELAS}

TABELA 1: DIAS DE COLETA NO PERÍODO AMOSTRADO

TABela 2: RAdiAÇÃo Solar Fotossinteticamente ATIVA $\left(\mu E \cdot M^{-2} \cdot S^{-1}\right)$ NAS ETES DE PARIQUERA-AÇU E JACUPIRANGA.

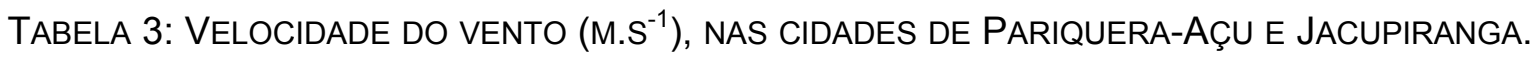

TABELA 4: VAZÃo (Q; $\left.M^{3} . D^{-1}\right)$ E TEMPO de DETENÇÃo HidRÁULICO ( $\theta T$; D) CALCULADOS PARA AS LAGOAS FACULTATIVAS DAS ETES DE PARIQUERA-AÇU E JACUPIRANGA.

TABELA 5: CONCENTRAÇÕES DE OXIGÊNIO DISSOLVIDO (MG.L ${ }^{-1}$ ), NAS LAGOAS FACULTATIVAS DAS ETES DE PARIQUERA-AÇU E JACUPIRANGA.

TABELA 6: FoRMAS DE CARBONO, ALCALINIDADE (MG.L ${ }^{-1}$ ) E PH, NA LAGOA FACULTATIVA DA ETE DE PARIQUERA-AÇU (SS: SUB-SUPERFÍCIE, M: MEIO E F: INTERFACE ÁGUASEDIMENTO).

TABELA 7: FORMAS DE CARBONO, ALCALINIDADE (MG.L ${ }^{-1}$ ) E PH, NA LAGOA FACULTATIVA DA ETE DE JACUPIRANGA (SS: SUB-SUPERFÍCIE, M: MEIO E F: INTERFACE ÁGUASEDIMENTO).

TABELA 8: RELAÇÃO C:N:P (CARBONO: NITROGÊNIO: FÓSFORO), EM MOL.L ${ }^{-1}$, NAS LAGOAS FACULTATIVAS DAS ETES DE PARIQUERA-AÇU E JACUPIRANGA (SS: SUB-SUPERFÍCIE, M: MEIO E F: INTERFACE ÁGUA-SEDIMENTO), EM DIFERENTES ÉPOCAS DO ANO

TABELA 9: GÊNEROS E ESPÉCIES DE CIANOBACTÉRIAS PRESENTES NAS LAGOAS FACULTATIVAS DAS ETES DE PARIQUERA-AÇU (PA) E JACUPIRANGA (JA).

TABELA 10: GÊNEROS E ESPÉCIES DE EUGLENOFíCEAS, BACILLARIOFÍ́CEAS E CRIPTOFíCEAS PRESENTES NAS LAGOAS FACULTATIVAS DAS ETES DE PARIQUERA-AÇU (PA) E JACUPIRANGA (JA).

TABELA 11: GÊNEROS E ESPÉCIES DE CLOROFíCEAS PRESENTES NAS LAGOAS FACULTATIVAS DAS ETES DE PARIQUERA-AÇU (PA) E JACUPIRANGA (JA).

TABELA 12: DENSIDADE FITOPLANCTÔNICA $\left(10^{5}\right.$ INDIVÍDUOS. $\left.\mathrm{ML}^{-1}\right)$, NAS LAGOAS FACULTATIVAS DAS ETES DE PARIQUERA-AÇU E JACUPIRANGA (SS: SUB-SUPERFICIE, M: MEIO E F: INTERFACE ÁGUA-SEDIMENTO), EM DIFERENTES ÉPOCAS DO ANO.

TABELA 13: CONTRIBUIÇÃO DOS GRUPOS FITOPLANCTÔNICOS (\%) NAS LAGOAS FACULTATIVAS DAS ETES DE PARIQUERA-AÇU E JACUPIRANGA, EM JANEIRO DE 2006.

TABELA 14: CONTRIBUIÇÃO DOS GRUPOS FITOPLANCTÔNICOS (\%), NAS LAGOAS FACULTATIVAS DAS ETES DE PARIQUERA-AÇU E JACUPIRANGA, EM ABRIL DE 2006.

TABELA 15: CONTRIBUIÇÃO DOS GRUPOS FITOPLANCTÔNICOS (\%), NAS LAGOAS FACULTATIVAS DAS ETES DE PARIQUERA-AÇU E JACUPIRANGA, EM JULHO DE 2006.

TABELA 16: CONTRIBUIÇÃO DOS GRUPOS FITOPLANCTÔNICOS (\%), NAS LAGOAS FACULTATIVAS DAS ETES DE PARIQUERA-AÇU E JACUPIRANGA, EM SETEMBRO DE 2006.

TABELA 17: ÍNDICES DE RIQUEZA (D), DIVERSIDADE (H'), DOMINÂNCIA (C) E EQÜIDADE (E), NA LAGOA FACULTATIVA DA ETE DE PARIQUERA-AÇU (SS: SUB-SUPERFÍCIE, M: MEIO E F: INTERFACE ÁGUA-SEDIMENTO), EM DIFERENTES ÉPOCAS DO ANO.

TABELA 18: ÍNDICES DE RIQUEZA (D), DIVERSIDADE (H'), DOMINÂNCIA (C) E EQÜIDADE (E), NA LAGOA FACULTATIVA DA ETE DE JACUPIRANGA (SS: SUB-SUPERFÍCIE, M: MEIO E F: INTERFACE ÁGUA-SEDIMENTO), EM DIFERENTES ÉPOCAS DO ANO.

TABELA 19: DENSIDADE FITOPLANCTÔNICA $\left(10^{3}\right.$ IND. $\left.\mathrm{ML}^{-1}\right)$ E BIOVOLUME $\left(10^{3} \mu \mathrm{M}^{3} . \mathrm{ML}^{-1}\right)$ DOS GÊNEROS E ESPÉCIES MAIS FREQÜENTES, NA LAGOA FACULTATIVA DA ETE DE 
PARIQUERA-AÇU, EM JANEIRO DE 2006 (SS: SUB-SUPERFÍCIE, M: MEIO E F: INTERFACE ÁGUA-SEDIMENTO).

TABELA 20: DENSIDADE FITOPLANCTÔNICA $\left(10^{3}\right.$ IND.ML $\left.{ }^{-1}\right)$ E BIOVOLUME $\left(10^{3} \mu \mathrm{M}^{3} . \mathrm{ML}^{-1}\right)$ DOS GÊNEROS E ESPÉCIES MAIS FREQÜENTES, NA LAGOA FACULTATIVA DA ETE DE PARIQUERA-AÇU, EM ABRIL DE 2006 (SS: SUB-SUPERFÍCIE, M: MEIO E F: INTERFACE ÁGUASEDIMENTO).

TABELA 21: DENSIDADE FITOPLANCTÔNICA $\left(10^{3}\right.$ IND. $\left.\mathrm{ML}^{-1}\right)$ E BIOVOLUME $\left(10^{3} \mu \mathrm{M}^{3} . \mathrm{ML}^{-1}\right)$ DOS GÊNEROS E ESPÉCIES MAIS FREQÜENTES, NA LAGOA FACULTATIVA DA ETE DE PARIQUERA-AÇU, EM JULHO DE 2006 (SS: SUB-SUPERFÍCIE, M: MEIO E F: INTERFACE ÁGUA-SEDIMENTO).

TABELA 22: DENSIDADE FITOPLANCTÔNICA $\left(10^{3}\right.$ IND. $\left.\mathrm{ML}^{-1}\right)$ E BIOVOLUME $\left(10^{3} \mu \mathrm{M}^{3} . \mathrm{ML}^{-1}\right)$ DOS GÊNEROS E ESPÉCIES MAIS FREQÜENTES, NA LAGOA FACULTATIVA DA ETE DE PARIQUERA-AÇU, EM SETEMBRO DE 2006 (SS: SUB-SUPERFICIE, M: MEIO E F: INTERFACE ÁGUA-SEDIMENTO).

TABELA 23: DENSIDADE FITOPLANCTÔNICA $\left(10^{3}\right.$ IND.ML $\left.{ }^{-1}\right)$ E BIOVOLUME $\left(10^{3} \mu \mathrm{M}^{3} . \mathrm{ML}^{-1}\right)$ DOS GÊNEROS E ESPÉCIES MAIS FREQÜENTES, NA LAGOA FACULTATIVA DA ETE DE JACUPIRANGA, EM JANEIRO DE 2006 (SS: SUB-SUPERFÍCIE, M: MEIO E F: INTERFACE ÁGUASEDIMENTO).

TABELA 24: DENSIDADE FITOPLANCTÔNICA $\left(10^{3}\right.$ IND. $\left.\mathrm{ML}^{-1}\right)$ E BIOVOLUME $\left(10^{3} \mu \mathrm{M}^{3} . \mathrm{ML}^{-1}\right)$ DOS GÊNEROS E ESPÉCIES MAIS FREQÜENTES, NA LAGOA FACULTATIVA DA ETE DE JACUPIRANGA, EM ABRIL DE 2006 (SS: SUB-SUPERFÍCIE, M: MEIO E F: INTERFACE ÁGUASEDIMENTO).

TABELA 25: DENSIDADE FITOPLANCTÔNICA $\left(10^{3}\right.$ IND.ML $\left.{ }^{-1}\right)$ E BIOVOLUME $\left(10^{3} \mu \mathrm{M}^{3} . \mathrm{ML}^{-1}\right)$ DOS GÊNEROS E ESPÉCIES MAIS FREQÜENTES, NA LAGOA FACULTATIVA DA ETE DE JACUPIRANGA, EM JULHO DE 2006 (SS: SUB-SUPERFÍCIE, M: MEIO E F: INTERFACE ÁGUASEDIMENTO).

TABELA 26: DENSIDADE FITOPLANCTÔNICA $\left(10^{3}\right.$ IND.ML $\left.{ }^{-1}\right)$ E BIOVOLUME $\left(10^{3} \mu \mathrm{M}^{3} . \mathrm{ML}^{-1}\right)$ DOS GÊNEROS E ESPÉCIES MAIS FREQÜENTES, NA LAGOA FACULTATIVA DA ETE DE JACUPIRANGA, EM SETEMBRO DE 2006 (SS: SUB-SUPERFÍCIE, M: MEIO E F: INTERFACE ÁGUA-SEDIMENTO).

TABela 27: PROduÇão PRIMÁRIA Líquida FITOPLANCTÔNICA - PPL $\left(\mathrm{MGO}_{2} \cdot \mathrm{M}^{-3} \cdot \mathrm{H}^{-1}\right)$, NAS LAGOAS FACULTATIVAS DAS ETES DE PARIQUERA-AÇU E JACUPIRANGA (SS: SUBSUPERFÍCIE, M: MEIO E F: INTERFACE ÁGUA-SEDIMENTO), EM DIFERENTES ÉPOCAS DO ANO.

TABela 28: Produção PRIMÁRIA BRUtA FITOPLANCTÔNICA - PPB $\left(\mathrm{MGO}_{2} \cdot \mathrm{M}^{-3} \cdot \mathrm{H}^{-1}\right)$, NAS LAGOAS FACULTATIVAS DAS ETES DE PARIQUERA-AÇU E JACUPIRANGA (SS: SUBSUPERFÍCIE, M: MEIO E F: INTERFACE ÁGUA-SEDIMENTO), EM DIFERENTES ÉPOCAS DO ANO.

TABELA 29: RESPIRAÇÃO DA COMUNIDADE - RC $\left(\mathrm{MGO}_{2} \cdot \mathrm{M}^{-3} \cdot \mathrm{H}^{-1}\right)$, NAS LAGOAS FACULTATIVAS DAS ETES DE PARIQUERA-AÇU E JACUPIRANGA (SS: SUB-SUPERFÍCIE, M: MEIO E F: INTERFACE ÁGUA-SEDIMENTO), EM DIFERENTES ÉPOCAS DO ANO.

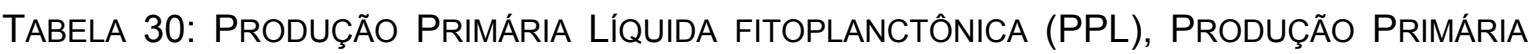
BRUTA FITOPLANCTÔNICA (PPB) E RESPIRAÇÃO DA COMUNIDADE (RC), POR ÁREA $\left(\mathrm{MGO}_{2} \cdot \mathrm{M}^{-2} \cdot \mathrm{H}^{-1}\right)$ NAS LAGOAS FACULTATIVAS DAS ETES DE PARIQUERA-AÇU E JACUPIRANGA, EM DIFERENTES ÉPOCAS DO ANO.

TABELA 31: ANÁLISE DE VARIÂNCIA FATORIAL ( $\alpha=5 \%$ ) NAS LAGOAS FACULTATIVAS DAS ETES DE PARIQUERA-AÇU E JACUPIRANGA, EM DIFERENTES ÉPOCAS DO ANO, HORÁRIOS E PROFUNDIDADES. 
TABELA 32: TESTE TURKEY ENTRE AS LAGOAS FACULTATIVAS DAS ETES DE PARIQUERA-AÇU E JACUPIRANGA. AS LETRAS PRESENTES INDICAM AS DIFERENÇAS AO NÍVEL DE 5\%. 72

TABELA 33: TESTE TURKEY ENTRE OS MESES DE AMOSTRAGEM (VARIAÇÃO SAZONAL). AS LETRAS PRESENTES INDICAM AS DIFERENÇAS AO NÍVEL DE 5\%.

TABELA 34: TESTE TURKEY ENTRE OS HORÁRIOS DE AMOSTRAGEM (VARIAÇÃO DIÁRIA). AS LETRAS PRESENTES INDICAM AS DIFERENÇAS AO NÍVEL DE 5\%.

TABELA 35: TESTE TURKEY ENTRE AS PROFUNDIDADES AMOSTRADAS (VARIAÇÃO VERTICAL); SS: SUB-SUPERFÍCIE, M: MEIO E F: INTERFACE ÁGUA-SEDIMENTO. AS LETRAS PRESENTES INDICAM AS DIFERENÇAS AO NÍVEL DE 5\%.

TABELA 36: ABUNDÂNCIA RELATIVA DOS GÊNEROS E ESPÉCIES DE CIANOBACTÉRIAS, EUGLENOFÍCEAS, CRIPTOFÍCEAS E BACILARIOFÍCEAS NA LAGOA FACULTATIVA DO SISTEMA DE PARIQUERA-AÇU, EM TRÊS PROFUNDIDADES (SS: SUB-SUPERFÍCIE, M: MEIO E F: INTERFACE ÁGUA-SEDIMENTO).

TABELA 37: ABUNDÂNCIA RELATIVA dOS GÊNEROS E ESPÉCIES DE CLOROFÍCEAS NA LAGOA FACULTATIVA DO SISTEMA DE PARIQUERA-AÇU, EM TRÊS PROFUNDIDADES (SS: SUBSUPERFÍCIE, M: MEIO E F: INTERFACE ÁGUA-SEDIMENTO).

104

TABELA 38: ABUNDÂNCIA RELATIVA dOS GÊNEROS E ESPÉCIES DE CIANOBACTÉRIAS, EUGLENOFÍCEAS, CRIPTOFICEAS E BACILARIOFÍCEAS NA LAGOA FACULTATIVA DO SISTEMA DE JACUPIRANGA, EM TRÊS PROFUNDIDADES (SS: SUB-SUPERFÍCIE, M: MEIO E F: INTERFACE ÁGUA-SEDIMENTO).

TABELA 39: ABUNDÂNCIA RELATIVA dOS GÊNEROS E ESPÉCIES DE CLOROFÍCEAS NA LAGOA FACULTATIVA DO SISTEMA DE JACUPIRANGA, EM TRÊS PROFUNDIDADES (SS: SUBSUPERFÍCIE, M: MEIO E F: INTERFACE ÁGUA-SEDIMENTO). 


\section{LISTA DE ABREVIATURAS E SIGLAS}

\begin{tabular}{|c|c|}
\hline Biov & Biovolume \\
\hline C & Carbono \\
\hline c & Dominância \\
\hline CE & Condutividade Elétrica \\
\hline CIIAGRO & Centro Integrado de Informações Agrometeorológicas \\
\hline Cinorgânico & Carbono inorgânico \\
\hline $\mathrm{CO}_{2}$ Livre & Dióxido de Carbono livre \\
\hline $\mathrm{CO}_{2}$ total & Dióxido de Carbono total \\
\hline $\mathrm{CO}_{3}^{2}$ & Carbonato \\
\hline COD & Carbono Orgânico Dissolvido \\
\hline CONAMA & Conselho Nacional de Meio Ambiente \\
\hline d & Riqueza de espécie \\
\hline Dens & Densidade \\
\hline DQO & Demanda Química de Oxigênio \\
\hline e & Eqüidade \\
\hline ETE & Estação de Tratamento de Esgoto \\
\hline f & Interface Água Sedimento \\
\hline $\mathrm{H}^{\prime}$ & Diversidade \\
\hline HCO3 & Bicarbonato \\
\hline IBGE & Instituto Brasileiro de Geografia e Estatística \\
\hline JA & Jacupiranga \\
\hline $\mathrm{m}$ & Meio \\
\hline $\mathrm{N}$ & Nitrogênio \\
\hline $\mathrm{N}$ & amoniacal \\
\hline NTK & Nitrogênio Total Kjeldahl \\
\hline OD & Oxigênio Dissolvido \\
\hline $\mathrm{P}$ & Fósforo \\
\hline PA & Pariquera-Açu \\
\hline $\mathrm{pH}$ & Potencial Hidrogeniônico \\
\hline PPB & Produção Primária Bruta \\
\hline PPL & Produção Primária Líquida \\
\hline Prof & Profundidade \\
\hline Q & Vazão \\
\hline Rc & Respiração da Comunidade \\
\hline RSFA & Radiação Solar Fotossinteticamente Ativa \\
\hline SABESP & Companhia de Saneamento Básico do Estado de São Paulo \\
\hline ss & Sub-superfície \\
\hline SSI & Sólidos Suspensos Inorgânicos \\
\hline SSO & Sólidos Suspensos Orgânicos \\
\hline SST & Sólidos Suspensos Totais \\
\hline $\mathrm{T}$ & Temperatura \\
\hline $\mathrm{TDH}(\theta \mathrm{t})$ & Tempo de Detenção Hidráulico \\
\hline Zaf & Zona Afótica \\
\hline Zeuf & Zona Eufótica \\
\hline
\end{tabular}




\section{SUMÁRIO}

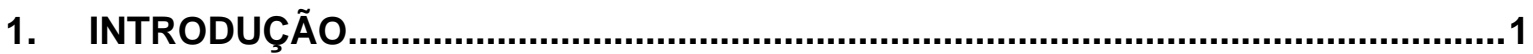

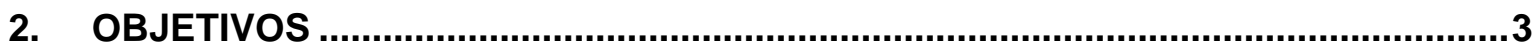

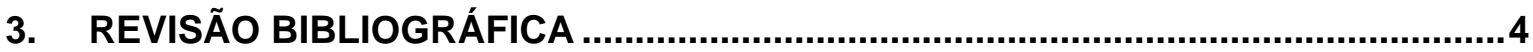

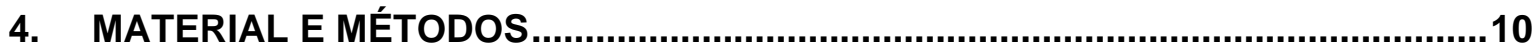

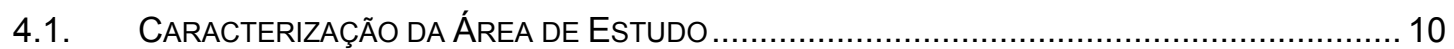

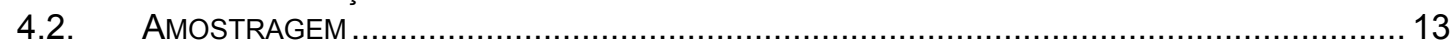

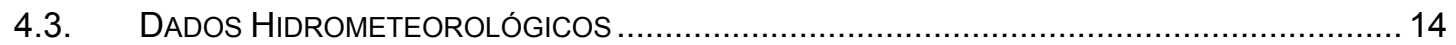

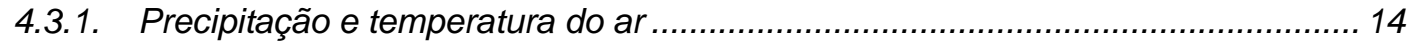

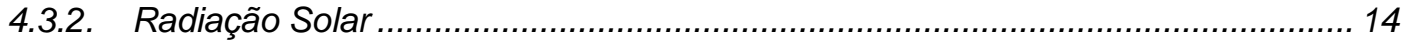

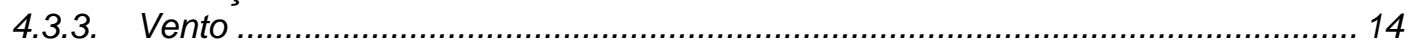

4.3.4. Vazão e Tempo de Detenção Hidráulico............................................................... 14

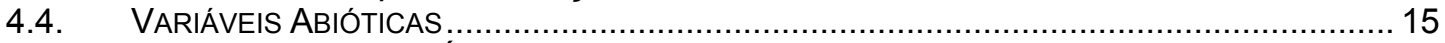

4.4.1. Temperatura da Água, $p H$, Condutividade elétrica e Oxigênio Dissolvido ............ 15

4.4.2. $\mathrm{pH}$, Alcalinidade e Formas de Carbono.............................................................. 16

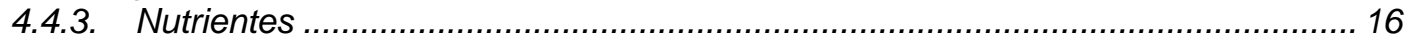

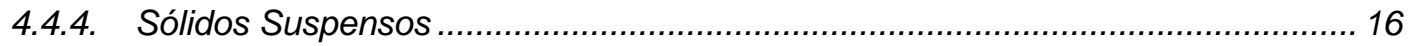

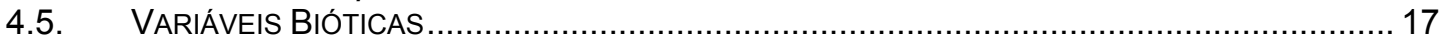

4.5.1. Determinação da biomassa fitoplanctônica por contagem direta ............................ 17

4.5.2. Determinação da biomassa fitoplanctônica por biovolume .................................. 18

4.5.3. Determinação da biomassa fitoplanctônica por concentração de pigmentos........ 18

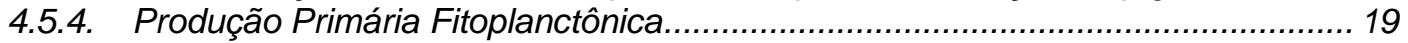

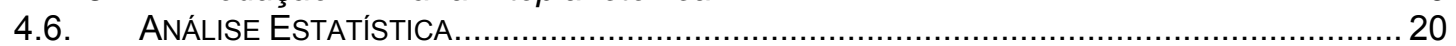

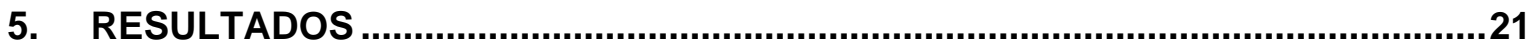

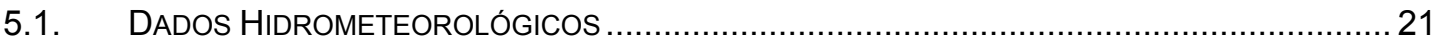

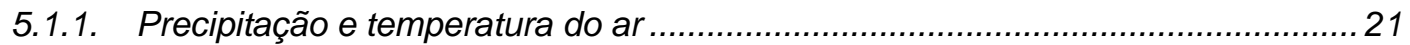

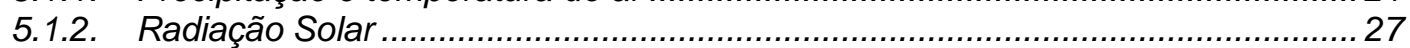

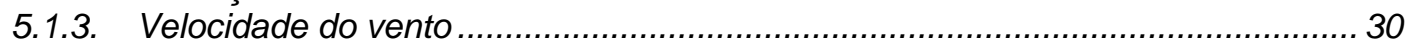

5.1.4. Vazão e tempo de detenção hidráulico ................................................................. 30

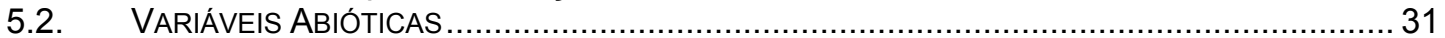

5.2.1. Temperatura da Água, $p H$, Condutividade Elétrica e Oxigênio Dissolvido............ 31

5.2.2. Alcalinidade e Formas de Carbono ................................................................. 36

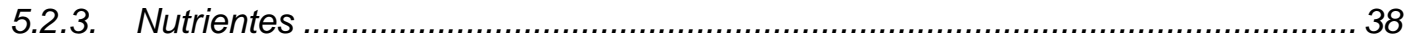

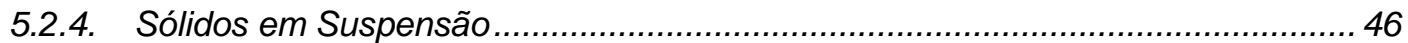

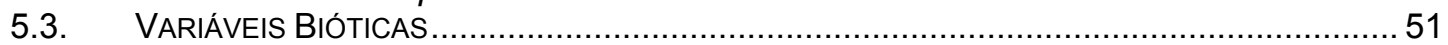

5.3.1. Determinação da biomassa fitoplanctônica por contagem direta ......................... 51

5.3.2. Determinação da biomassa fitoplanctônica - biovolume ..................................... 60

5.3.3. Determinação da biomassa fitoplanctônica - concentração clorofila a e feofitina 65

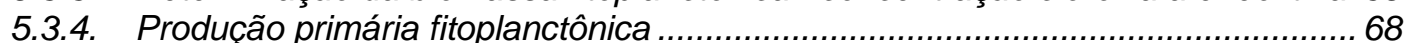

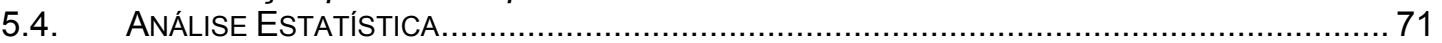

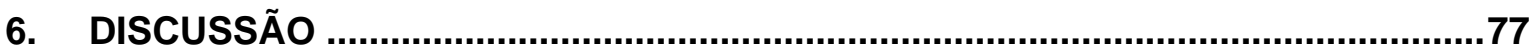

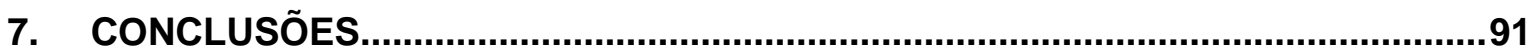

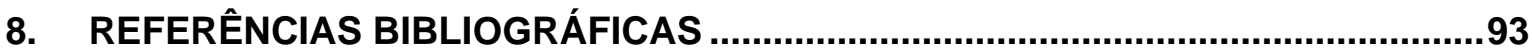

ANEXO 1 



\section{INTRODUÇÃO}

O crescimento econômico e o desenvolvimento urbano resultam no aumento significativo da quantidade de águas residuárias, de origem doméstica e industrial, lançadas diretamente nos corpos de água sem passarem por tratamento prévio adequado. Este lançamento indiscriminado tem causado sério desequilíbrio ambiental pois, geralmente, ultrapassa a capacidade máxima que o corpo de água apresenta no sentido de poder assimilar e degradar a matéria orgânica para que não ocorram conseqüências que levariam à morte da comunidade aquática local.

Para diminuir este impacto, muitos municípios aderiram a sistemas de tratamento de esgoto do tipo lagoas de estabilização, para que o efluente final destas apresente padrões assimiláveis pelos corpos de água, de acordo com a resolução CONAMA $375 / 05$, e não degradem o meio ambiente por completo.

Um método de tratamento de esgoto recomendado para regiões menos desenvolvidas e de clima tropical são os sistemas de lagoas de estabilização. Este tipo de tratamento apresenta a vantagem de ter elevada eficiência e baixos custos de construção e de operação. A simplicidade do tratamento está vinculada à utilização de processos naturais, pouco mecanizados e econômicos para a implantação e operação. No entanto, toda a simplicidade relacionada aos aspectos construtivos não exclui a necessidade de profissionais especializados para a conservação e operação destes sistemas.

As temperaturas elevadas, características de clima tropical, favorecem a degradação da matéria orgânica aumentando a velocidade das reações metabólicas necessárias para a estabilização da matéria orgânica. Por outro lado, uma das desvantagens deste sistema é a necessidade de grande área para a sua construção, que pode ser reduzida se forem utilizados sistemas de lagoas em série sendo, uma anaeróbia seguida de outra facultativa.

Estudos sobre a eficiência de tais sistemas devem considerar as condições de cada local e a qualidade que o efluente final deve atingir. HOEPPNER (2007) avaliou o desempenho e a eficiência das lagoas de estabilização dos municípios Pariquera-Açu e Jacupiranga. Porém, houve a necessidade de se conhecer a estrutura da comunidade fitoplanctônica, envolvida na estabilização da matéria orgânica, presente nestas lagoas facultativas, no sentido de auxiliar na eficiência do sistema, uma vez que se mantido o equilíbrio da comunidade os organismos presentes na lagoa não trarão problemas para a qualidade do efluente final. 
$\mathrm{Na}$ lagoa facultativa ocorrem processos biológicos responsáveis pelo tratamento do esgoto. A pequena profundidade e a extensa área do sistema são suas principais características. Com isso, pode haver maior penetração da radiação solar e, conseqüentemente, maior produtividade primária. As lagoas de estabilização são consideradas ambientes hipereutróficos devido à presença de grande quantidade de matéria orgânica oriunda dos esgotos domésticos e industriais.

O conhecimento da estrutura da comunidade fitoplanctônica e a avaliação desta em diferentes horários do fotoperíodo tornam-se relevantes na medida em que tais organismos podem representar vantagens ao sistema, pois são responsáveis pela produtividade primária e pela conseqüente produção de oxigênio, ou desvantagem, considerando-se que constituirão os "novos" sólidos do sistema, os quais resultarão, ao final do tratamento, em aumento na demanda por oxigênio dissolvido.

A produtividade primária fitoplanctônica em lagoas de estabilização, assim como em outros sistemas aquáticos, pode ser controlada pela interação de diversos fatores como a disponibilidade da radiação solar na coluna de água, a ação do vento, o tempo de detenção hidráulico, a concentração de nutrientes e a precipitação.

Um dos problemas comuns para quem estuda produção primária fitoplanctônica é a escolha do método de determinação desta. Para esta pesquisa o método escolhido foi o do oxigênio dissolvido, sendo este recomendado para ambientes eutróficos (CALIJURI e DOS SANTOS, 2004). Além disso, este método permite determinar as taxas de produção e respiração da comunidade.

Neste sentido, esta pesquisa, juntamente com outras desenvolvidas na região do Baixo Vale do Ribeira (SP), desde maio de 2004, por meio do Projeto Temático "Estudo dos sistemas naturais e artificiais redutores de cargas poluidoras para a sustentabilidade dos recursos hídricos do Baixo Ribeira do Iguape (SP)", coordenado pela Professora Titular Maria do Carmo Calijuri e financiado pela FAPESP ( $N^{\circ}$ Processo: 02/13449-1), fornece informações sobre a avaliação da produtividade primária e estrutura da comunidade fitoplanctônica e no futuro poderá auxiliar no entendimento da dinâmica destes ecossistemas aquáticos e na sustentabilidade dos recursos hídricos daquela região. 


\section{OBJETIVOS}

Esta pesquisa teve como objetivo o estudo comparativo da variabilidade temporal da estrutura da comunidade fitoplanctônica e da produção primária em duas lagoas facultativas de dois sistemas de tratamento de esgoto diferentes, sendo: um composto por lagoa anaeróbia seguida de lagoa facultativa com chicanas (município de PariqueraAçu) e outro por lagoa aerada mecanicamente seguida de lagoa facultativa (município de Jacupiranga). Para atingir este objetivo, as seguintes etapas foram necessárias:

1. Avaliar a estrutura da comunidade fitoplanctônica nas duas lagoas facultativas, em termos de biomassa (biovolume, concentração de clorofila, abundância relativa), dominância, riqueza e diversidade de espécies, em diferentes épocas do ano e horas do dia;

2. Determinar a produção primária fitoplanctônica em diferentes épocas do ano e horas do dia;

3. Relacionar a estrutura da comunidade fitoplanctônica e a produção primária com as variáveis ambientais. 


\section{REVISÃO DA LITERATURA}

As lagoas facultativas são responsáveis pela remoção de matéria orgânica através da atividade biológica (VON SPERLING, 1996). Segundo este autor, estas lagoas podem ser divididas em três zonas (profundidades) distintas: anaeróbia, facultativa e aeróbia.

A zona anaeróbia é representada pela matéria orgânica sedimentada, constituindo assim o lodo de fundo. Este lodo é decomposto pela atividade de microrganismos anaeróbios que o convertem em $\mathrm{CO}_{2}$, água, metano e outros, restando apenas a fração não biodegradável (VON SPERLING, op cit).

Na zona aeróbia, próximo à superfície da coluna de água, a matéria orgânica é oxidada pelas bactérias aeróbias facultativas (MARA; PERSON, 1986). Para que esta oxidação ocorra é necessário a presença de oxigênio, produzido e liberado pelo fitoplâncton por meio da produção primária.

Nas lagoas facultativas convencionais, a estabilização da matéria orgânica oriunda de esgoto doméstico ocorre devido às interações simbióticas entre as bactérias e o fitoplâncton. A comunidade fitoplanctônica desempenha importante papel na produção do oxigênio necessário para a degradação aeróbica bacteriana da matéria orgânica (WEATHERELL et al., 2003), sendo importante o conhecimento do metabolismo e da ecologia destes microrganismos fitoplanctônicos que atuam, portanto, de forma direta ou indireta, na estabilização da matéria orgânica.

A atividade dos microrganismos fitoplanctônicos é controlada principalmente pelas mudanças periódicas de $\mathrm{pH}$, temperatura e intensidade luminosa. Sendo assim, a eficiência dessas lagoas estão sujeitas à variação ambiental (KAYOMBO et al., 2002).

Segundo Munõz e Guieysse (2006), esta interação não é apenas benéfica para os organismos fitoplanctônicos podendo causar-lhes efeitos negativos decorrentes da liberação de substâncias, pelas bactérias, que agem como algicidas durante o processo de oxidação da matéria orgânica, prejudicando assim o desenvolvimento da comunidade fitoplanctônica. A intensa atividade fotossintética também pode interferir no crescimento das bactérias, quando esta provoca aumento no $\mathrm{pH}$, das concentrações de oxigênio dissolvido e dos agentes bactericidas.

De acordo com Arauzo et al. (2000), para se obter eficiência nos sistemas de lagoas de estabilização é muito importante manter em equilíbrio a estrutura trófica destes ambientes, pois a morte e a decomposição dos organismos fitoplanctônicos podem resultar ou criar condição semelhante à do esgoto bruto, ou seja, a presença grande quantidade de matéria orgânica. 
O estudo da comunidade fitoplanctônica, na maioria dos trabalhos pesquisados (PEARSON et al., 1987; CURTIS et al., 1994; NANDINI, 1999; KAYOMBO et al., 2002 e WEATHERELL et al., 2003), não descrevem a estrutura e a composição de espécies em lagoas de estabilização. Estes apenas apresentam a concentração de clorofila a para expressar indiretamente, a biomassa da comunidade fitoplanctônica.

Estes trabalhos determinam de forma indireta a biomassa fitoplanctônica, através da concentração de clorofila a, muito utilizada em trabalhos de monitoramento de lagoas de estabilização, pelo método de espectrofometria. Porém, este método apresenta muitos interferentes, como outros tipos de clorofila (b e c) e seus produtos de degradação, que podem superestimar as concentrações de clorofila a (Carson e Simpson, 1996). Sendo assim, torna-se evidente a importância de trabalhos que contemplem a estrutura e a composição da comunidade fitoplanctônica.

Semelhante aos sistemas aquáticos naturais, as lagoas de estabilização apresentam variabilidades temporal e espacial na estrutura da comunidade fitoplanctônica. Para Pearson et al. (1987), a distribuição vertical da densidade fitoplanctônica pode interferir no sistema como todo, pois o fitoplâncton pode vir a constituir os novos sólidos do sistema e, assim, prejudicar a qualidade do efluente final.

Sistemas abertos, como as lagoas de estabilização, estão constantemente sujeitos às flutuações das condições ambientais. Fatores climáticos como o vento, temperatura do ar, precipitação e radiação solar sofrem muitas alterações ao longo das estações do ano. Segundo Mendonça (2000) e Gurung, Dhakal e Bista (2006), precipitações intensas podem resultar na diluição da água das lagoas, pois aumentam a vazão e reduzem o tempo de detenção hidráulico e, consequentemente, há redução da diminui a densidade fitoplanctônica e das concentrações dos nutrientes.

Outro fator importante é a distribuição vertical dos organismos fitoplanctônicos na coluna de água, que pode estar relacionada à estratificação térmica, controlada principalmente pela temperatura da água e pela intensidade luminosa. Segundo König (1990), isto é comum em lagoas facultativas.

As diversas estratégias de sobrevivência encontradas no fitoplâncton estão relacionadas à variabilidade do ambiente em que vivem. Para entender as mudanças, espacial e temporal, que ocorrem na estrutura da comunidade fitoplanctônica Reynolds (1988) classificou estes organismos em três categorias, de acordo com as estratégias de sobrevivência de suas populações: as C-estrategistas (clorofíceas) são organismos pioneiros e competidores, apresentam pequenas dimensões, são adaptados a rápida reprodução e dominam ambientes com elevadas taxas de radiação e nutrientes; as $R$ estrategistas (bacilariofíceas) são adaptadas a ambientes de mistura turbulenta; e as Sestrategistas (cianobactérias) são espécies que tolerantes ao stress e sobrevivem em 
ambientes com severas restrições de nutrientes, pois são resistentes a perdas por sedimentação e predação, além de apresentarem alta capacidade de formar propágulos ou cistos e estocar nutrientes.

Vários autores descreveram os grupos fitoplanctônicos que geralmente podem ser encontrados em lagoas de estabilização: cianobactérias, clorofíceas, euglenofíceas, criptofíceas e bacilariofíceas (GLOYNA, 1973; KÖNIG, 1984; KELLNER e PIRES, 1998; ARAÚZO et al., 2000; GRANADO, 2004; e MIWA, 2007).

O estudo da estrutura e da comunidade fitoplanctônica presente nas lagoas facultativas permite a compreensão dos processos que ocorrem neste meio, já que estes são os organismos responsáveis pela produção fotossintética de oxigênio.

Das técnicas disponíveis para medir a produtividade primária fitoplanctônica, as mais comuns são a do oxigênio dissolvido e a do ${ }^{14} \mathrm{C}$. A técnica do oxigênio dissolvido é melhor aplicável em ambientes eutróficos, por outro lado, a técnica do ${ }^{14} \mathrm{C}$, considerada mais sensível, é recomendável para ambientes oligotróficos (CALIJURI e DOS SANTOS, 2004).

A técnica do oxigênio dissolvido, também conhecida como técnica dos frascos claros e escuros, consiste em estimar o oxigênio que é liberado durante a fotossíntese, pela titulação do oxigênio, segundo o método de Winkler. Esta metodologia possibilita o cálculo das taxas de produtividade primária bruta, líquida e respiração da comunidade, o que representa outra vantagem desta técnica para estudos realizados em ambientes com alto grau de trofia (CALIJURI e DOS SANTOS, 2004).

Vários autores estudaram a produtividade primária fitoplanctônica (CALIJURI; DOS SANTOS, 2001; DRAKARE et al., 2002; GÓNIAK et al., 2003; JONIAK; GOLDYN; KOZAK, 2003; WEATHERELL; ELLIOTT; CURTIS, 2003; NÕGES; KANGRO, 2005; GÓMEZ; SILVEIRA, 2006; HENRY et al., 2006; STAEHR; JESEN, 2006) e observaram que existem muitos fatores responsáveis, diretamente ou indiretamente, pelo crescimento do fitoplâncton e, conseqüentemente, pela produtividade primária em lagos, reservatórios e lagoas de estabilização. Estes fatores são: quantidade de radiação solar que penetra na coluna de água, condições nutricionais do ambiente, tempo de detenção hidráulico, turbulência produzida pela ação do vento e, conseqüentemente, a mudança na estratificação térmica da coluna de água.

A penetração da radiação solar na coluna de água, em ambientes eutrofizados como as lagoas de estabilização, apresenta grande influência na produtividade primária podendo ser considerada, neste caso, um fator limitante. Joniak, Goldyn e Kozak (2003), pesquisando a produtividade primária em um reservatório raso e hipereutrófico na Polônia, constataram que a radiação solar apresenta grande influência na produtividade. Segundo estes autores, os valores máximos de produtividade primária fitoplanctônica 
foram encontrados na superfície do reservatório, no verão, quando ocorreram maiores temperaturas e intensidade de radiação solar, características de ambientes temperados.

Henry et al. (2006) estudaram a correlação entre fatores abióticos e a produtividade primária em um reservatório localizado na cidade de São Paulo. Estes autores também verificaram a influência da intensidade de radiação solar incidente na coluna de água sobre a produtividade primária e os resultados obtidos corroboraram os dos autores citados anteriormente. Valores mais altos de produtividade primária foram obtidos quando houve maior penetração de radiação solar associada ao regime de circulação da coluna de água, que favoreceu a ressuspensão do fósforo do sedimento para a água.

Por outro lado, Ratchford e Fallowfield (2003) e Nõges e Kangro (2005) constataram que altas taxas de intensidade luminosa podem afetar de forma negativa a atividade fotossintética fitoplanctônica. Segundo os autores, em lagos estratificados, altas taxas de radiação solar na superfície da água podem causar inibição da fotossíntese, devido aos raios ultravioletas que causam danos fisiológicos às células dos organismos fitoplanctônicos. Assim, os valores mais altos de produção fotossintética foram obtidos um pouco abaixo da superfície, pois a radiação nesta profundidade não é limitante para os organismos fitoplanctônicos.

Kayombo et al (2002) e Robson (2005) observaram relação direta entre o ciclo diário da intensidade de luz, e os valores de $\mathrm{pH}$ e de oxigênio dissolvido. Durante o dia, a concentração de oxigênio é maior e seguida de aumento do $\mathrm{pH}$, provavelmente devido à grande concentração de íons hidroxila provindos da dissociação dos íons bicarbonatos ou da retirada de dióxido de carbono para a fotossíntese impedindo a formação e posterior dissociação de bicarbonato. O mesmo foi observado por Tadesse, Green e Puhakka (2004), que relacionaram as variações diurnas do oxigênio dissolvido, do pH e do carbono inorgânico às atividades biológicas (respiração e fotossíntese).

Esta variação diurna também foi observada por Ramirez e Bicudo (2005), em um reservatório raso (Lago das Garças, São Paulo). Enquanto os valores de pH e oxigênio aumentavam, os de $\mathrm{CO}_{2}$ diminuiam, principalmente durante o período de luz, o que caracterizou a atividade fotossintética e a relação inversa que ocorria no período de redução ou nenhuma radiação solar.

De acordo com Calijuri e Dos Santos (2001), que avaliaram as variações temporais da produção primária no reservatório eutrófico de Barra Bonita (SP), os tempos de detenção hidráulico determinados (TDH) durante os períodos chuvoso e seco, dependendo da principal finalidade do sistema, influíam na disponibilidade de nutrientes e na perda de biomassa. Geralmente, nos períodos de grande precipitação há perda de nutrientes e de biomassa, enquanto nos secos pode haver a reciclagem de materiais e 
maior produção. Ressalta-se, também, que em regiões tropicais como a que está localizado o reservatório de Barra Bonita, o verão é caracterizado como período chuvoso, com dias em que há menor disponibilidade de radiação solar, em decorrência da grande quantidade de nuvens presentes.

Para Gurung, Dhakal e Bista (2006) e Gómez e Silveira (2006), durantes os períodos de intensa precipitação o TDH é menor e, conseqüentemente, há maior escoamento de água e aumento na diluição dos nutrientes. O maior escoamento e a diminuição na concentração de nutrientes, juntamente com a menor transparência da coluna de água, devido à entrada de matéria alóctone, afetam diretamente o crescimento do fitoplâncton. Com o aumento do escoamento e a diminuição do TDH também ocorre o arraste do fitoplâncton, diminuindo assim a produtividade (TALLING e LEMOALLE, 1998).

Silveira, Gómez e Colli (2002) estudaram a biomassa fitoplanctônica em dois lagos rasos e mesotróficos, na Península Yucatan (Sudeste do México). Os autores confirmaram a hipótese de que longos períodos de detenção resultam no aumento da concentração de nutrientes e, portanto, da biomassa fitoplanctônica.

De acordo com Ramirez e Bicudo (2005) e Nõges e Kangro (2005), a mistura da água pelo vento é muito importante para a comunidade fitoplanctônica, pois a turbulência da água mantém a circulação de nutrientes e gases, que muitas vezes podem se tornar limitantes, na coluna de água favorecendo o aumento destes organismos.

Em lagoas de estabilização, o esgoto apresenta nutrientes em excesso e por isso geralmente estes não são limitantes para o crescimento do fitoplâncton. Para Weatherell et al. (2003), o fator mais importante na determinação da densidade do fitoplâncton nestes sistemas é a atenuação da radiação solar na coluna de água, o que difere estes ambientes dos naturais. Os autores desenvolveram um modelo para medir a concentração de algas em lagoas facultativas e de maturação. De acordo com os resultados do modelo, a disponibilidade de radiação solar subaquática foi considerada como o fator mais importante para a taxa fotossintética e, conseqüentemente, para a concentração de clorofila.

Portanto, a avaliação da produtividade primária fitoplanctônica em diferentes horários do fotoperíodo é relevante, na medida em que estes organismos são responsáveis pela produção de oxigênio a qual, por sua vez, é proporcional à intensidade luminosa.

Considerando que a atividade fotossintética é restrita ao fotoperíodo e que o processo de decomposição da matéria orgânica pode ocorrer durante as 24 horas, a taxa de produção de oxigênio deve ser maior que o seu consumo para que o sistema permaneça facultativo e a diversidade de espécies seja mantida. 
Ainda são relativamente poucos os estudos sobre produtividade primária e estrutura da comunidade fitoplanctônica realizados em lagoas de estabilização, necessitando assim de informações complementares, tais como as relativas às variações temporal e espacial, pois estes organismos são responsáveis pela produção e liberação do oxigênio utilizado pelas bactérias que degradam a matéria orgânica oriunda dos esgotos domésticos e industriais e auxiliam, portanto, no tratamento biológico. 


\section{Material e Métodos}

\subsection{Caracterização da Área de Estudo}

Os sistemas de lagoas de estabilização estão localizados no Baixo Ribeira de Iguape, Estado de São Paulo, nos municípios de Jacupiranga e Pariquera-Açu (Figura 1).

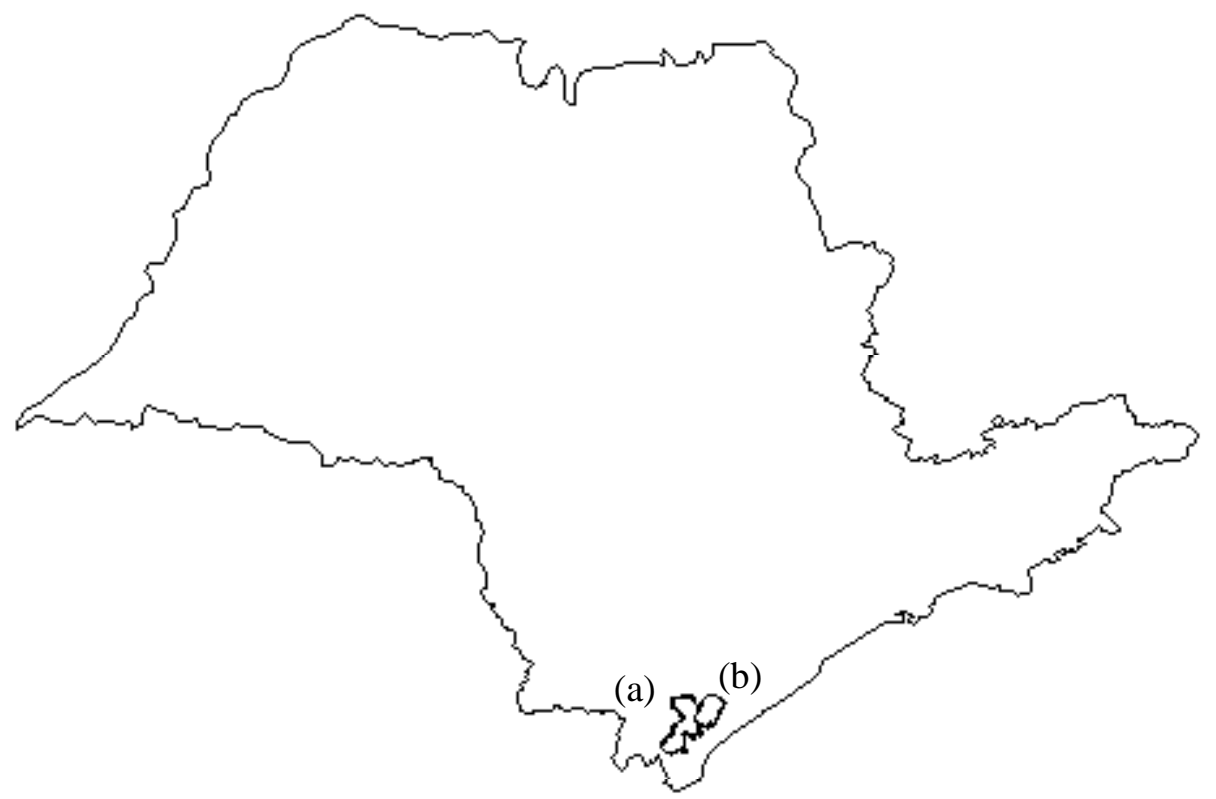

Figura 1: Localização das cidades de Jacupiranga (a) e Pariquera-Açu (b), no Estado de São Paulo. Fonte: Hoeppner (2007).

O município de Pariquera-Açu apresenta uma área de $360 \mathrm{~km}^{2}$ com população de 20.459 habitantes (66,42\% na área urbana) e o de Jacupiranga ocupa uma área de aproximadamente $708 \mathrm{~km}^{2}$, com população de 18.676 habitantes (59,95\% vivem em área urbana), segundo dados do Instituto de Geografia e Estatística - IBGE (2006).

Em ambos os municípios, $100 \%$ das casas estão ligadas à rede de abastecimento de água, sendo que em Jacupiranga $84 \%$ estão ligadas à rede de coleta de esgoto, das quais $90 \%$ são destinados ao tratamento em lagoas de estabilização; em Pariquera-Açu, $82 \%$ das residências estão ligadas à rede de coleta de esgoto e $100 \%$ deste esgoto é destinado ao tratamento em lagoas de estabilização.

As coletas foram realizadas nos Sistemas de Tratamento de Esgoto (lagoas de estabilização) destes dois municípios. Ambos os sistemas são do tipo australiano (lagoa anaeróbia seguida de lagoa facultativa) sendo que no sistema de Pariquera-Açu (Figuras 2 e 3) as lagoas estão também dispostas em paralelo e as lagoas facultativas 
apresentam chicanas (Figura 4); no sistema de Jacupiranga (Figuras 2 e 5), a lagoa anaeróbia foi transformada em lagoa aerada mecanicamente pela presença de dois aeradores. Ambos os sistemas possuem tratamento preliminar (gradeamento e caixa de areia).

Estação de Pariquera-Açu

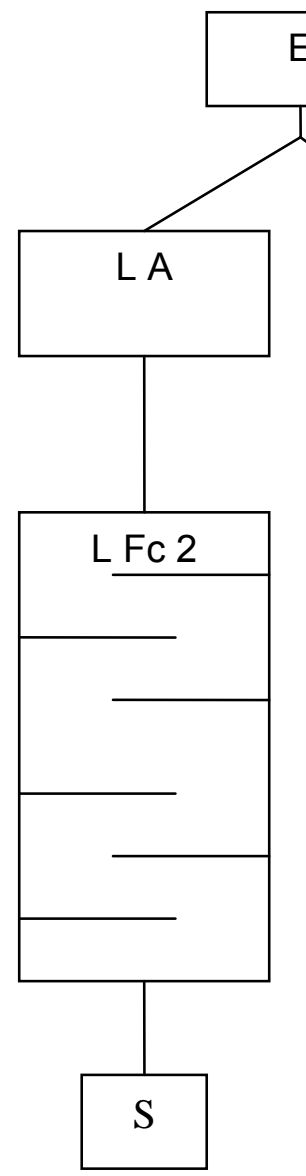

E
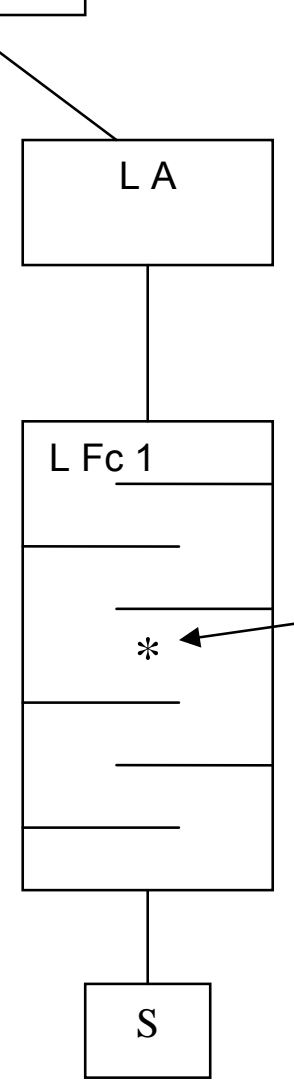

Estação de Jacupiranga

E

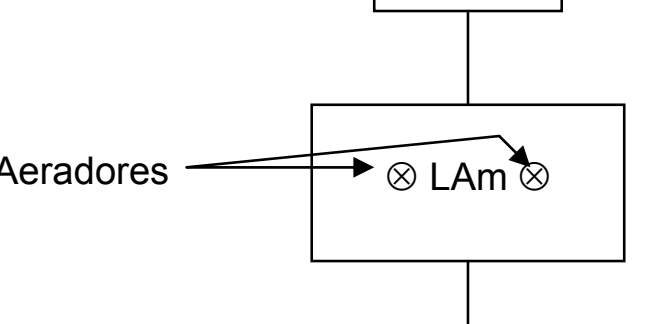

Pontos de

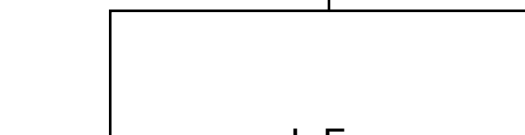

Coleta

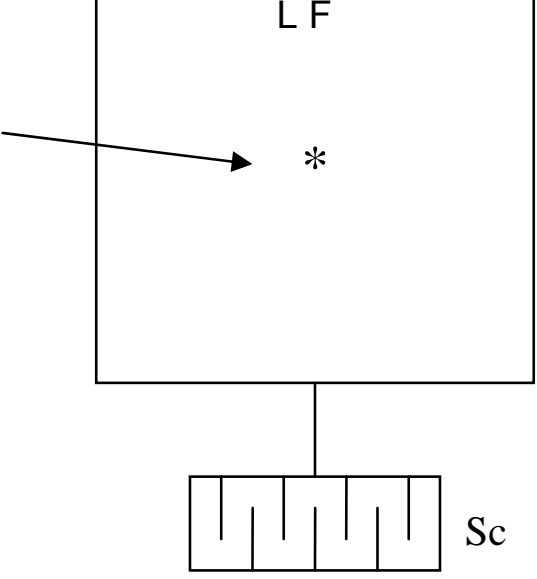

Figura 2: Diagrama do sistema de tratamento de esgoto dos municípios de Pariquera-Açu e Jacupiranga, respectivamente, com representação das estações de amostragem. (E: entrada da lagoa, LA: lagoa anaeróbia, LAm: lagoa mecanicamente aerada, LF: lagoa facultativa, LFc : lagoa facultativa com chicanas, S: saída da lagoa e Sc: saída da lagoa com chicana). 


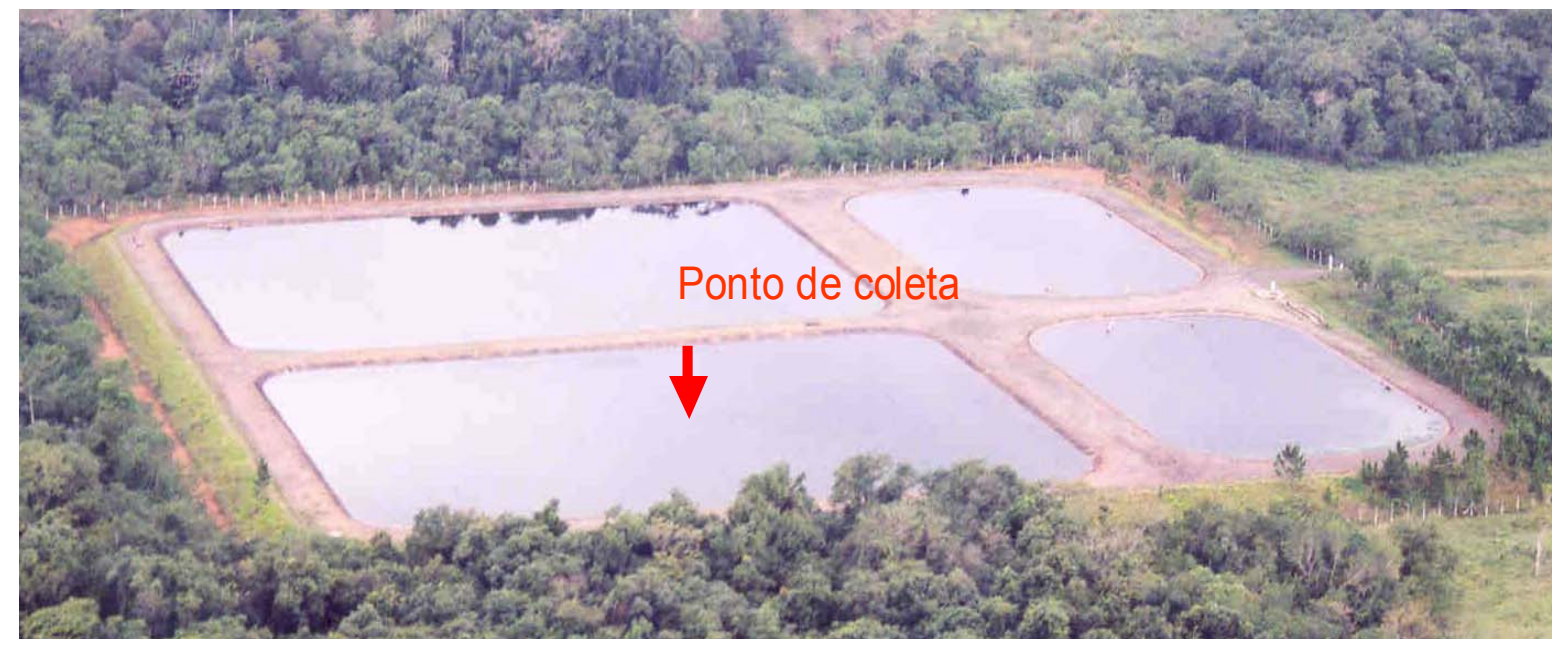

Figura 3: Sistema de Tratamento de Esgoto do município de Pariquera-Açu.

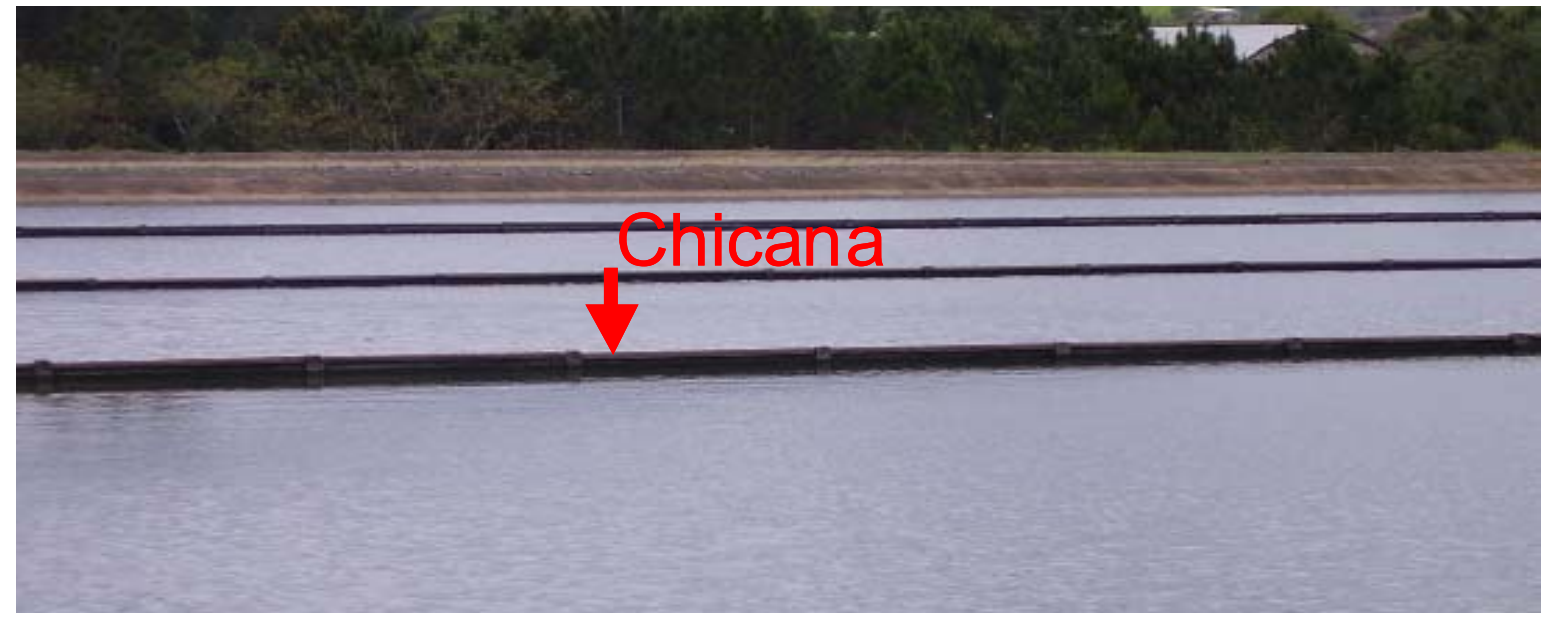

Figura 4: Chicanas do Sistema de Tratamento de Esgoto do município de Pariquera-Açu.

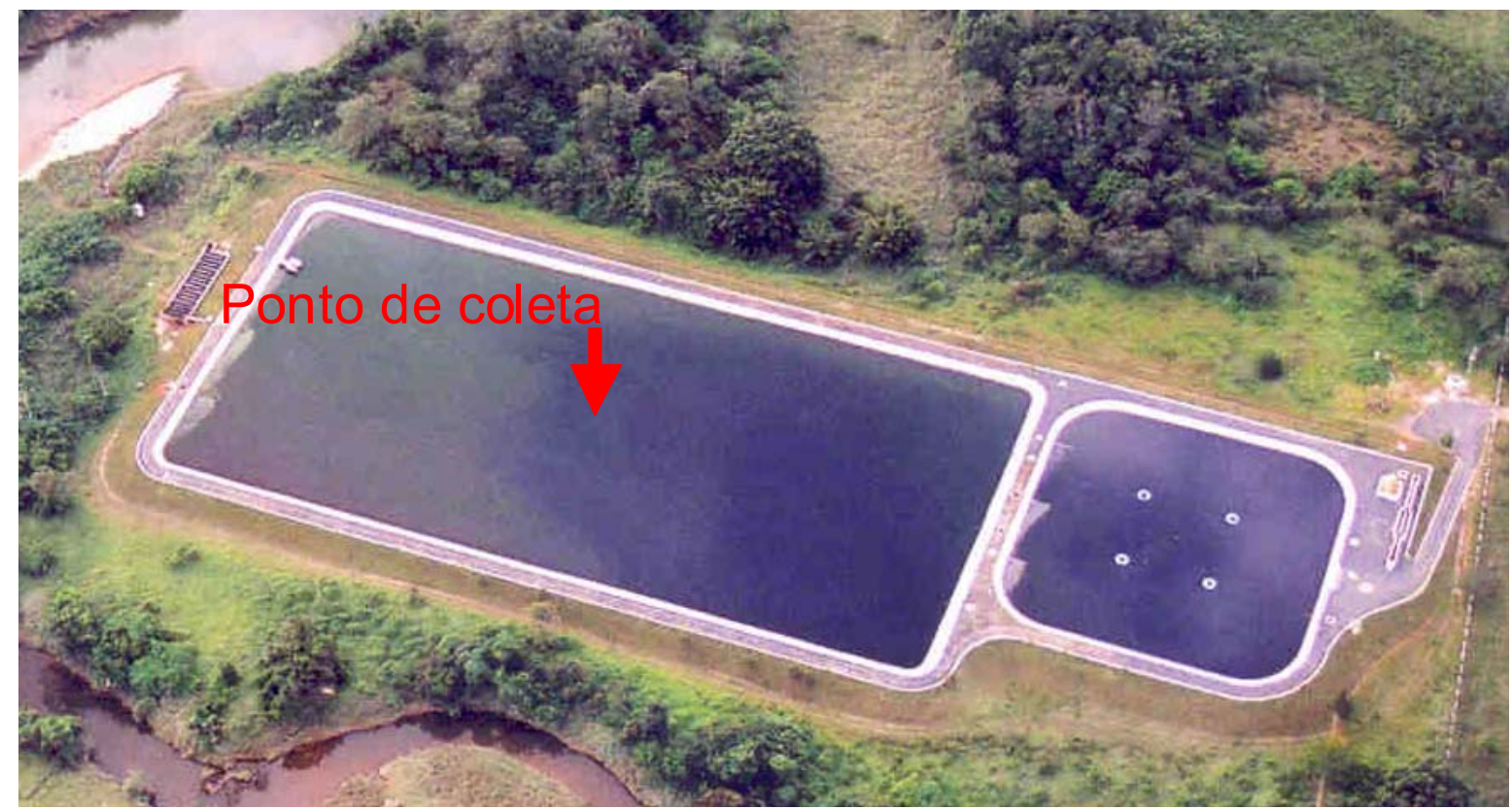

Figura 5: Sistema de Tratamento de Esgoto do município de Jacupiranga. 


\subsection{Amostragem}

Nos sistemas de lagoas de estabilização de Jacupiranga e Pariquera-Açu, as amostragens foram realizadas nas lagoas facultativas, em quatro épocas do ano (variação sazonal), durante o período de 10 horas (7 às 16h), com coletas de 3 em 3 horas (diária). As amostras foram coletadas em diferentes profundidades (sub-superfície, meio e interface água-sedimento), em apenas um ponto de cada lagoa (Figura 6). Os dias de coleta estão representados na tabela 1.

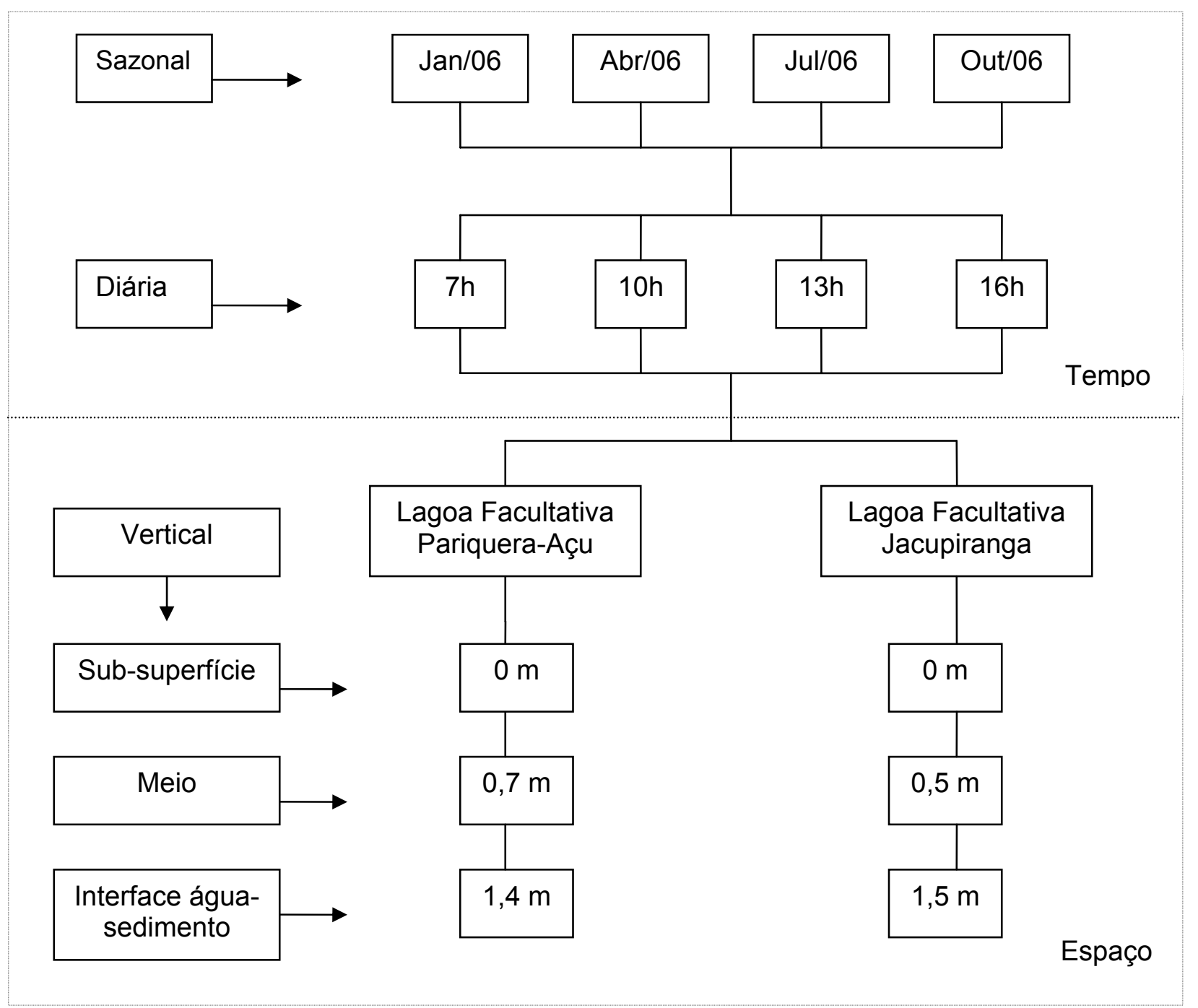

Figura 6: Diagrama de amostragem. 
Tabela 1: Dias de coleta no período de janeiro a setembro de 2006

\begin{tabular}{ccc}
\hline & Pariquera-Açu & Jacupiranga \\
Janeiro & 26 & 28 \\
Abril & 6 & 7 \\
Julho & 20 & 19 \\
Setembro & 26 & 28 \\
\hline
\end{tabular}

\subsection{Dados Hidrometeorológicos}

\subsubsection{Precipitação e temperatura do ar}

Os valores de precipitação e de temperatura do ar foram obtidos através da Base de Dados Hidrometeorológicos do Centro Integrado de Informações Agrometeorológicas - CIIAGRO, pertencente ao Instituto Agronômico de Campinas - IAC.

\subsubsection{Radiação Solar}

A radiação solar fotossinteticamente ativa, incidente e subaquática $\left(\mu \mathrm{E} \cdot \mathrm{m}^{-2} \cdot \mathrm{s}^{-1}\right)$, foi determinada in situ com radiômetro (Quanta Meter Li-Cor, LI-1.400), cuja faixa de sensibilidade está entre $400-700 \mathrm{~nm}$. A radiação solar fotossinteticamente ativa subaquática foi medida a cada $25 \mathrm{~cm}$ da coluna de água.

\subsubsection{Vento}

Os valores de velocidade do vento foram medidos na margem das lagoas, nos dias de coleta, a cerca de 1,5 m do solo, utilizando-se um anemômetro (R.Fuess) que fornece dados em quilômetros por hora.

\subsubsection{Vazão e Tempo de Detenção Hidráulico}

Os valores de vazão foram obtidos a partir da altura da lâmina de água no vertedor da saída da lagoa facultativa do sistema de Pariquera-Açu e do tanque de cloração do sistema de Jacupiranga. Foram escolhidos estes pontos, pois a vazão na saída do sistema de estabilização é constante.

A partir das alturas das laminas de água, a vazão foi obtida pela equação:

$$
Q=1,83 \times L \times H^{\frac{2}{3}}
$$


Sendo: Q: vazão $\left(\mathrm{m}^{3} . \mathrm{s}^{-1}\right)$;

$L$ : largura do vertedor $(\mathrm{m})$;

$H$ : altura da lâmina de água $(\mathrm{m})$.

$\mathrm{O}$ TDH teórico foi calculado a partir do volume de água das lagoas facultativas dos dois sistemas, obtidos através da batimetria realizada por Hoeppner (2007) e das vazões, pela equação:

$$
\theta t=\frac{V}{Q}
$$

Sendo: $\theta$ : tempo de detenção hidráulico (s);

Q: vazão $\left(\mathrm{m}^{3} \cdot \mathrm{s}^{-1}\right)$;

$\checkmark$ : volume de água $\left(\mathrm{m}^{3}\right)$.

\subsection{Variáveis Abióticas}

\subsubsection{Temperatura da Água, pH, Condutividade elétrica e Oxigênio Dissolvido}

A temperatura da água $\left({ }^{\circ} \mathrm{C}\right)$, a condutividade elétrica $\left(\mu \mathrm{S} . \mathrm{cm}^{-1}\right)$, e $\circ \mathrm{pH}$ foram medidos a cada $10 \mathrm{~cm}$ na coluna de água, nas lagoas facultativas, com equipamento multi-sonda (Yellow Springer, 556 MPS).

A concentração do oxigênio dissolvido foi determinada, de acordo com APHA (1999), pela metodologia de Winkler modificada pela azida (método 4500 O.C.). Para o cálculo do oxigênio dissolvido, em mg. $\mathrm{L}^{-1}$, utilizou-se a fórmula:

$$
O D=\frac{V_{1} \times N \times 8 \times 1000}{V_{2} \times\left(\frac{V f-4}{V f}\right)}
$$

Sendo: $V_{1}$ : volume de tiossulfato gasto na titulação;

$N$ : normalidade do tiossulfato;

8: $\mathrm{n}^{\circ}$ atômico do oxigênio;

1000: conversão de $\mathrm{mL}$ para L;

$V_{2}$ : volume da amostra titulada;

$V f$ : volume do frasco;

4: volume $(\mathrm{mL})$ de fixadores. 


\subsection{2. $\mathrm{pH}$, Alcalinidade e Formas de Carbono}

A alcalinidade foi determinada no local de coleta de acordo com a metodologia descrita em Golterman, Clymo e Ohnstad (1978). A partir dos dados de pH e alcalinidade foram calculadas as formas de carbono presentes (gás carbônico total, gás carbônico livre, bicarbonato, carbonato e carbono inorgânico) segundo Mackereth, Heron e Talling (1978).

A determinação de Carbono Orgânico foi realizada segundo a metodologia descrita APHA (1999) para Carbono Orgânico Total (método 5310 B), no laboratório de Saneamento (SHS/EESC/USP).

\subsubsection{Nutrientes}

As variáveis nitrogênio total Kjeldahl, nitrogênio amoniacal, nitrato, nitrito, fósforo total e ortofosfato foram determinadas na sub-superfície, meio e interface águasedimento das lagoas facultativas. De acordo com metodologia descrita no American Public Health Association (APHA, 1999) foram determinados: Nitrogênio Total Kjeldahl (método 4.500 B), Nitrogênio Amoniacal (método 4.500 C), Nitrato (método 4.500 D), Nitrito (método 4.500 B) e Ortofosfato (método $4.500 \mathrm{E}$ ).

As determinações foram realizadas no laboratório de Biotoxicologia de Águas Continentais e Efluentes (Biotace/EESC/USP).

Foi calculada a razão C:N:P através das massas atômicas de carbono inorgânico, nitrato mais nitrito e ortofosfato.

\subsubsection{Sólidos Suspensos}

Para a determinação dos sólidos suspensos (Totais, orgânicos e inorgânicos), as amostras foram filtradas em membranas de microfibra de vidro (Millipore AP 40; $47 \mathrm{~mm}$ de diâmetro), no local de coleta, segundo a metodologia descrita em APHA (op. cit) para Sólidos Suspensos (métodos 2.540 D e 2.540 E). 


\subsection{Variáveis Bióticas}

\subsubsection{Determinação da biomassa fitoplanctônica por contagem direta}

A análise quantitativa do fitoplâncton foi feita com o método das câmaras de sedimentação (UTHERMÖHL, 1958) e a densidade total (organismos. $\mathrm{mL}^{-1}$ ) foi calculada segundo APHA (1999), sendo a unidade fundamental de contagem o campo do microscópio, segundo a equação abaixo:

$$
D_{(o r g / m L)}=\frac{C \times A t}{A f \times F \times V}
$$

Sendo: $D$ : densidade total (organismos. $\mathrm{mL}^{-1}$ );

$C$ : número de organismos contados;

At: área total do fundo da câmara de sedimentação $\left(\mathrm{mm}^{2}\right)$;

Af: área do campo de contagem $\left(\mathrm{mm}^{2}\right)$;

$F$ : número de campos contados;

$V$ : volume da amostra sedimentada $(\mathrm{mL})$.

A abundância relativa foi calculada considerando-se o número de indivíduos de cada espécie, em relação ao total de indivíduos:

90 a $100 \%$ - organismos dominantes;

60 a $89 \%$ - organismos predominantes;

30 a $59 \%$ - organismos abundantes;

10 a $29 \%$ - organismos comuns;

1 a $9 \%$ - organismos ocasionais;

$<1 \%$ - organismos raros.

A diversidade específica, a eqüidade de SHANNON, a dominância específica e a riqueza de espécies, segundo o número de espécies presentes, foram calculadas de acordo com Odum (1988).

Para a identificação do fitoplâncton foram utilizadas chaves de classificação, bibliografias específicas (ANAGNOSTIDIS e KOMARÉK, 1986, 1988, 1989, 1998; BICUDO e MENEZES, 2005; BOURRELY, 1972, 1981, 2002; CASTRO, BICUDO e BICUDO, 1991; KOMÁREK e FOTT 1983; PARRA, GONZALEZ e DELLAROSSA, 1980, 1983; PARRA, GONZALEZ et al. 1982; SANT'ANNA et al., 2006) e consultas a sites com 
imagens e descrições de espécies fitoplanctônicas (PROTIST INFORMATION SERVIER; CYANOSITE, entre outros).

\subsubsection{Determinação da biomassa fitoplanctônica por biovolume}

Foram medidos o comprimento e a largura de células fitoplanctônicas de aproximadamente 30 indivíduos das espécies mais freqüentes. Através da comparação com formas geométricas semelhantes, o volume de cada espécie foi calculado e multiplicado pela densidade para obter-se a biomassa fitoplanctônica em $\mathrm{mm}^{3} \cdot \mathrm{mL}^{-1}$ (HILLEBRAN et al.,1999).

\subsubsection{Determinação da biomassa fitoplanctônica por concentração de pigmentos}

Para a determinação da concentração da clorofila a e feofitina, as amostras foram filtradas em membranas de microfibra de vidro (Millipore AP 20;47mm de diâmetro e 0,8$8,0 \mu \mathrm{m}$ de porosidade) e conservadas no freezer até o momento da extração. No laboratório, a extração foi feita com etanol 80\%. A análise dos extratos, em espectrofotometria, seguiu a metodologia descrita em APHA (1999) e a leitura foi realizada nos comprimentos de onda de $665 \mathrm{~nm}$ e $750 \mathrm{~nm}$. Para a determinação da clorofila a $\left(\mu \mathrm{g} \cdot \mathrm{L}^{-1}\right)$ e feofitina $\left(\mu \mathrm{g} . \mathrm{L}^{-1}\right)$ foram utilizadas as seguintes fórmulas, descritas em Nush (1980) e modificadas segundo a Norma Holandesa (Nederlandse Norm NEN 6520, 1981):

$$
\begin{aligned}
& \text { Clorofila } a=29,6 \times\left\{\left(E u_{665}-E u_{750}\right)-\left(E a_{665}-E a_{750}\right)\right\} \times \frac{v}{V \times s} \\
& \text { Feofitina }=29,6 \times\left\{\left[1,7 \times\left(E a_{665}-E a_{750}\right)\right]-\left(E u_{665}-E u_{750}\right)\right\} \times \frac{v}{V \times s}
\end{aligned}
$$

Onde: $E u$ : absorbância da amostra não acidificada;

Ea: absorbância da amostra acidificada;

$v$ : volume do extrato $(\mathrm{mL})$;

$\checkmark$ : volume da amostra filtrada $(L)$;

$S:$ espessura da cubeta $(\mathrm{cm})$;

29,6: Coeficiente de absorção especifica da clorofila a;

1,7: Razão de rendimento da clorofila a não acidificada para acidificada. 


\subsubsection{Produção Primária Fitoplanctônica}

Para a determinação da Produção Primária Fitoplanctônica foi utilizado o método do Oxigênio Dissolvido (ou técnica dos frascos claros e escuros) com incubações "in situ", durante 30 minutos, nos horários e profundidades descritos anteriormente (Figura 6). As amostras foram coletadas em garrafas de van Dorn não transparente e posteriormente colocadas em três frascos com volumes conhecidos (superior a $120 \mathrm{~mL}$ ) e tampa esmerilhada, sendo dois frascos claros e um escuro (âmbar).

No primeiro frasco claro (não incubado), após o preenchimento o oxigênio foi fixado pelo uso dos reagentes de WinKler (sulfato manganoso e azida), que fornece a concentração inicial do oxigênio dissolvido.

Os outros dois fracos (um claro e um escuro) após serem preenchidos foram colocados na posição horizontal e suspensos nas respectivas profundidades de coleta. Ao termino da incubação os fracos são retirados da água e fixados imediatamente. No laboratório as amostras foram tituladas segundo o item 4.4.1.

Após a obtenção das concentrações de oxigênio dissolvido calculou-se a respiração da comunidade $(R C)$, produtividade primária bruta (PPB) e produtividade primária líquida $(\mathrm{PPL}), \mathrm{em} \mathrm{mgO} \mathrm{O}^{2} \cdot \mathrm{m}^{-3} \cdot \mathrm{h}^{-1}$, através das fórmulas:

$$
\begin{gathered}
R C=C_{1}-C_{2} \div t \times 1000 \\
P P B=C_{3}-C_{2} \div t \times 1000 \\
P P L=P P B-R C
\end{gathered}
$$

Sendo: $C_{1}$ : concentração inicial de oxigênio na amostra $\left(\mathrm{mg} . \mathrm{L}^{-1}\right)$;

$C_{2}$ : concentração de oxigênio no frasco escuro após a incubação (mg. $\left.\mathrm{L}^{-1}\right)$;

$C_{3}$ : concentração de oxigênio no frasco claro após a incubação $\left(\mathrm{mg} \cdot \mathrm{L}^{-1}\right)$;

t: tempo de incubação;

1000: conversão de $L$ para $\mathrm{m}^{3}$.

O valor integrado da produção de oxigênio, expresso em $\mathrm{mgO}_{2} \cdot \mathrm{m}^{-2} \cdot \mathrm{h}^{-1}$, foi calculado considerando-se a profundidade de cada camada da coluna de água onde houve incubação (sub-superfície, meio e intermédia água-sedimento). 


\subsection{Análise Estatística}

Para descrever as variações dos fatores abióticos e bióticos (clorofila e densidade) nas duas lagoas facultativas, foram realizadas as análises estatísticas de variância fatorial e o teste Turkey.

As análises foram realizadas no procedimento GLM do sistema estatístico SAS (versão 9.12). Estas ferramentas foram selecionadas para verificar a existência de variação (ao nível de $5 \%$ de significância) entre as escalas de amostragem adotadas (entre os sistemas, sazonal, diária e vertical).

Foi calculado, também, o Coeficiente de correlação de Pearson, para identificar o grau de associação entre as variáveis abióticas e bióticas. 


\section{Resultados}

\subsection{Dados Hidrometeorológicos}

\subsubsection{Precipitação e temperatura do ar}

As precipitações médias mensais e temperaturas médias do ar, no período de janeiro de 2001 a dezembro de 2006, nos municípios de Pariquera-Açu e Jacupiranga estão representadas nas Figuras 7 e 8 . Comparando-se os dados com as média dos anos anteriores ao período de coleta (2006), obtidas nos mesmos períodos de amostragem, pôde-se observar que em janeiro, abril e julho de 2006 a média de precipitação foi menor do que nos últimos quatro anos, nos dois municípios; apenas em setembro os valores foram semelhantes. Porém, a temperatura manteve-se constante durante estes 6 anos. Com isso podemos dizer que, em relação à precipitação, o ano de 2006 foi relativamente mais seco.

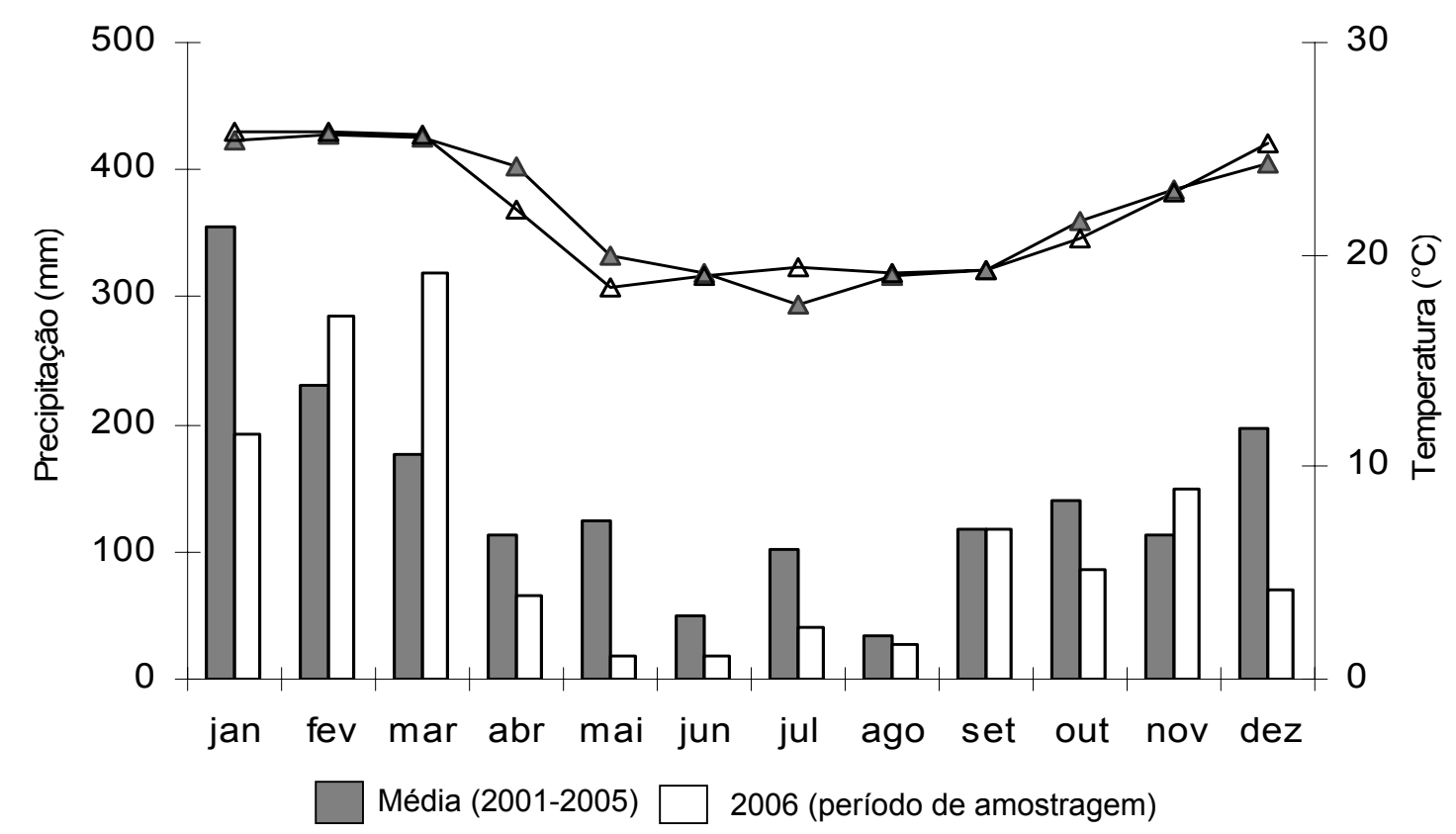

Figura 7: Precipitações mensais (barras), em mm e temperatura média do ar (linhas), em ${ }^{\circ} \mathrm{C}$, no município de Pariquera-Açu.Fonte: Ciiagro, 2008. 


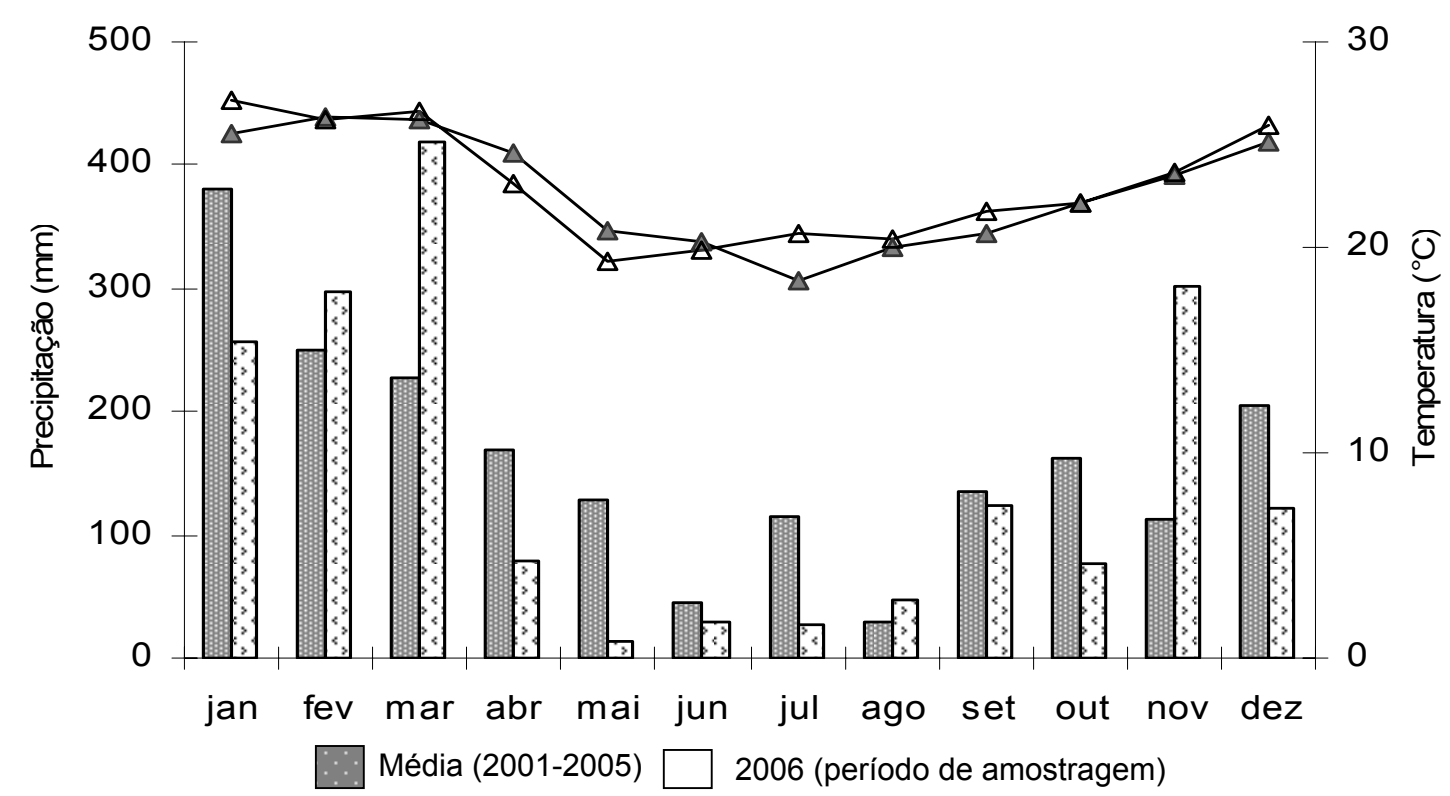

Figura 8: Precipitações mensais (barras), em mm e temperatura média do ar (linhas), em ${ }^{\circ} \mathrm{C}$, no município Jacupiranga. Fonte: Ciiagro, 2008.

As precipitações mensais e temperaturas médias do ar obtidas durante o período de estudo, nos municípios de Pariquera-Açu e Jacupiranga, estão representadas nas Figuras 9 e 10. Maiores valores de precipitação e temperatura do ar foram observados no município de Jacupiranga se comparados aos do município de Pariquera-Açu, exceto para a precipitação, nos meses de maio e julho.

As maiores precipitações ocorreram no mês de março, tanto em Pariquera-Açu como em Jacupiranga (318,2 e 419,5 mm, respectivamente) e as menores foram observadas em maio (18,5 e $14,5 \mathrm{~mm}$, respectivamente). As maiores temperaturas nestes municípios foram, respectivamente $25,87^{\circ} \mathrm{C}$ e $27,26{ }^{\circ} \mathrm{C}$ e as mínimas de $18,44^{\circ} \mathrm{C}$ e $14,5^{\circ} \mathrm{C}$. Dois períodos distintos foram observados, ou seja, um período de chuvas mais intensas, acima de $100 \mathrm{~mm}$ e altas temperaturas, acima de $25^{\circ} \mathrm{C}$ (dezembro 2005 a março 2006) e outro de pouca chuva, abaixo de $80 \mathrm{~mm}$ e temperaturas mais baixas, abaixo de $23{ }^{\circ} \mathrm{C}$ (abril a agosto de 2006). Em setembro, a temperatura também esteve abaixo de $23^{\circ} \mathrm{C}$, porém a precipitação foi maior que $100 \mathrm{~mm}$. 


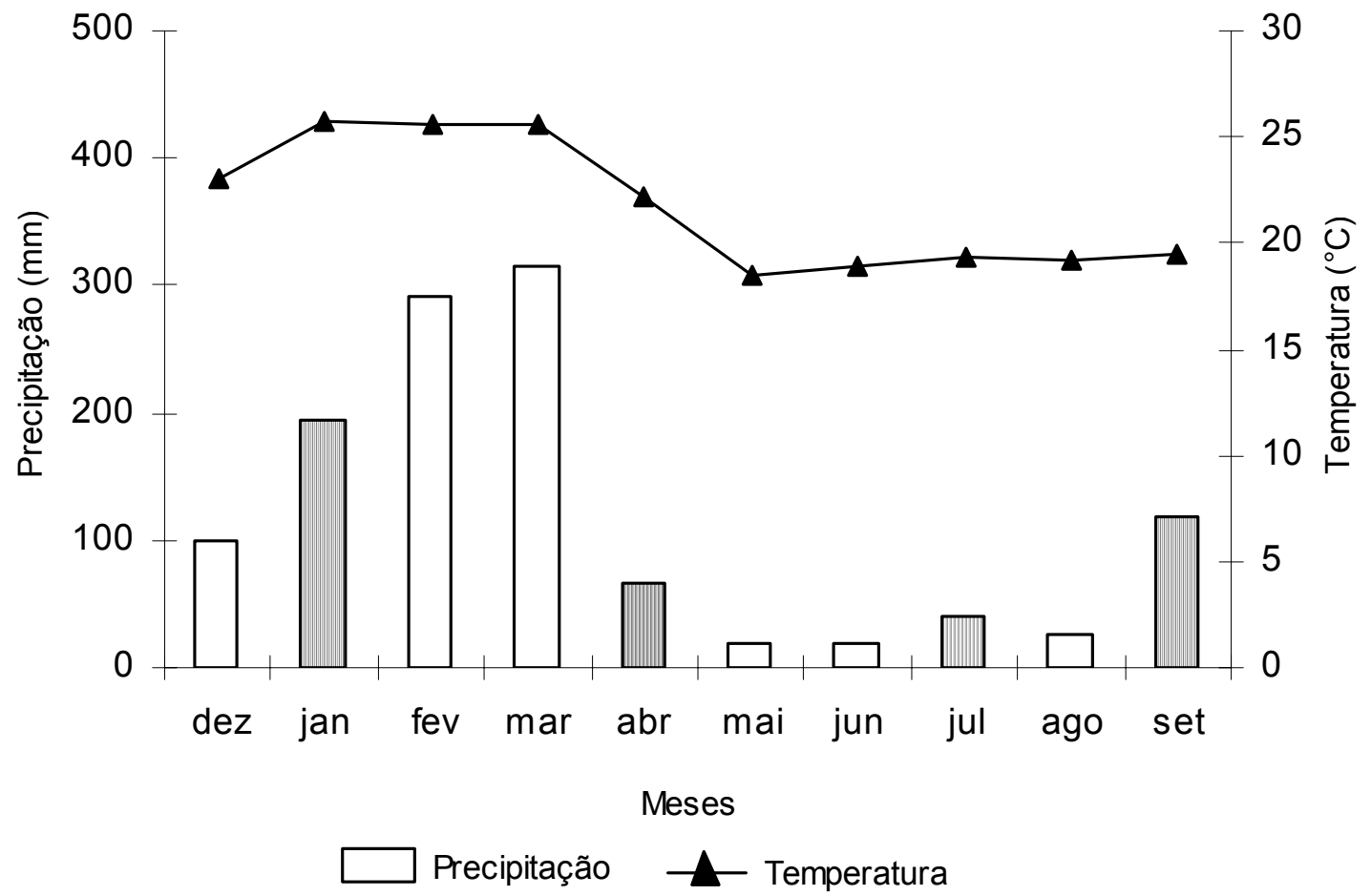

Figura 9: Precipitações mensais $(\mathrm{mm})$ e temperatura média do $\operatorname{ar}\left({ }^{\circ} \mathrm{C}\right)$ durante o período de dezembro de 2005 a setembro de 2006, no município de Pariquera-Açu. Os meses hachurados representam os períodos de coleta. Fonte: Ciiagro, 2007.

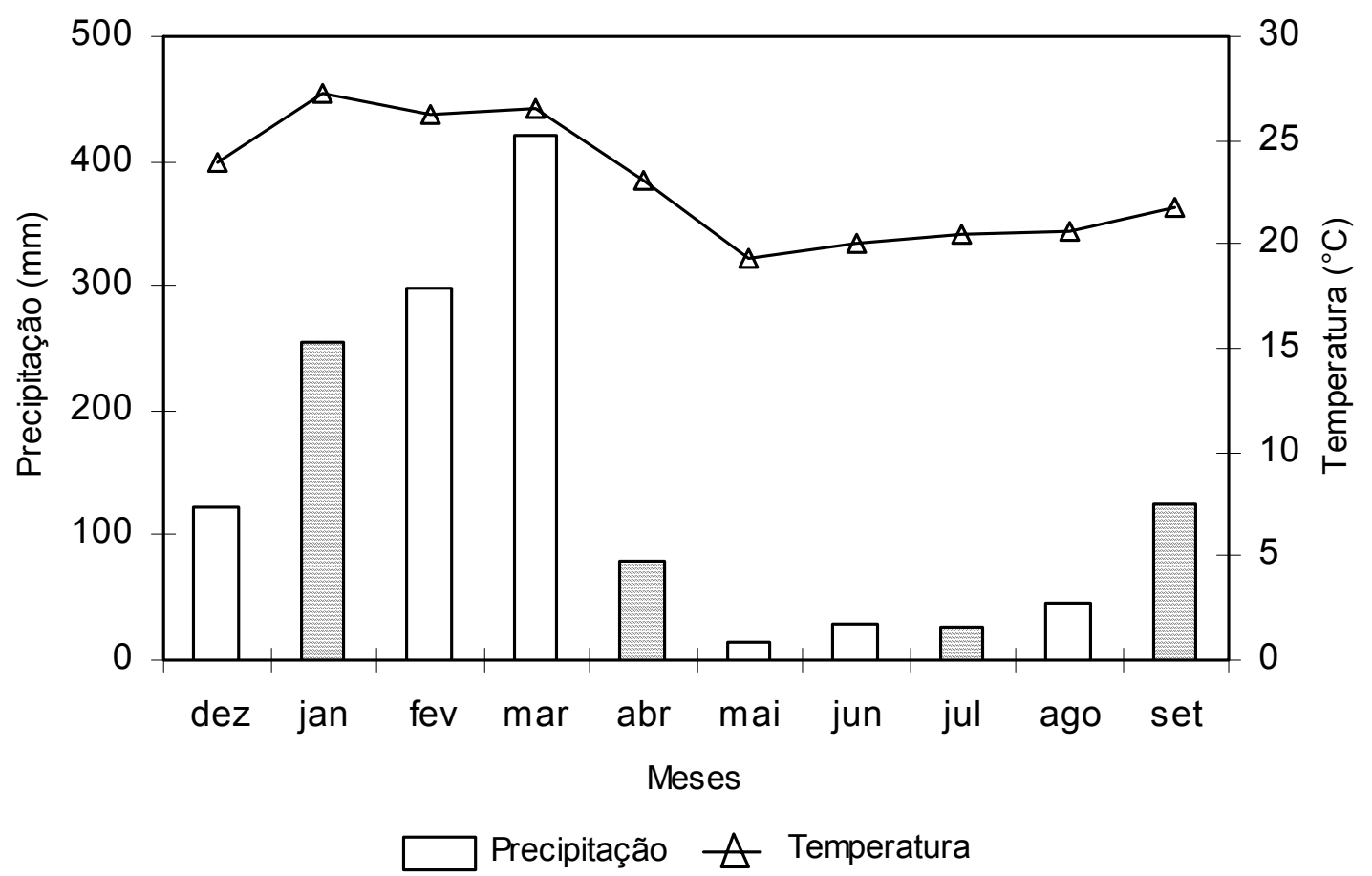

Figura 10: Precipitações mensais $(\mathrm{mm})$ e temperatura média do $\operatorname{ar}\left({ }^{\circ} \mathrm{C}\right)$ durante o período de dezembro de 2005 a setembro de 2006, no município de Jacupiranga. Os meses hachurados representam os períodos de coleta. Fonte: Ciiagro, 2007. 
Além da temperatura média e da precipitação acumulada mensais, foram obtidos, também, os valores diários destas para os meses em que ocorreram as amostragens nos municípios de Pariquera-Açu (Figura 11) e Jacupiranga (Figura 12).

Precipitações acima de 23,5 mm ocorreram no município de Pariquera-Açu, nos dias 22, 23 e 26 de janeiro. Na amostragem de abril foi observada baixa precipitação apenas três dias antes do dia de amostragem $(7,4 \mathrm{~mm})$. Comparando os quatro meses de coleta, as menores precipitações foram verificadas no mês de julho. A maior precipitação neste mês foi observada dez dias antes da coleta $(34,5 \mathrm{~mm})$. Elevadas precipitações também foram verificadas no mês de setembro, variando entre 1,4 e $41,4 \mathrm{~mm}$, porém não foram intensas antes da amostragem.

No município de Jacupiranga, foram observadas precipitações intensas, entre 5 e $56 \mathrm{~mm}$, nos 8 dias que antecederam a amostragem de janeiro, mais altas que no município de Pariquera-Açu. Em abril foi observada baixa precipitação, não ultrapassando $8,2 \mathrm{~mm}$, três dias antes da amostragem; no dia de coleta ela atingiu $11,6 \mathrm{~mm}$. No mês de julho não ocorreram precipitações próximas ao dia de coleta e em setembro ela foi elevada, variando de 11 a $40 \mathrm{~mm}$, dez dias antes da amostragem. 


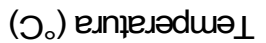

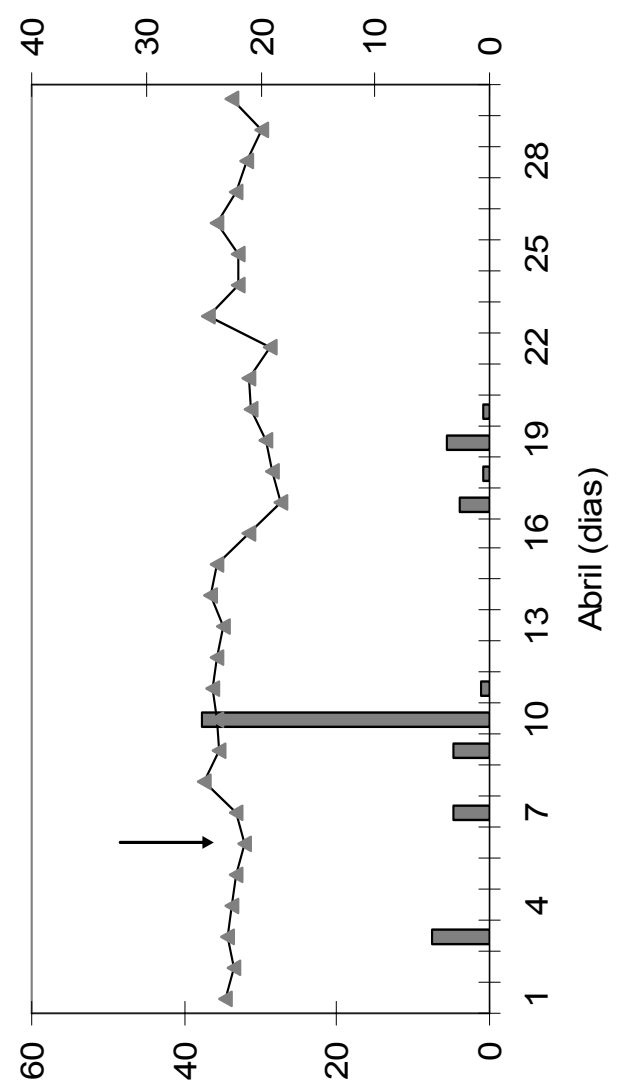

유 응

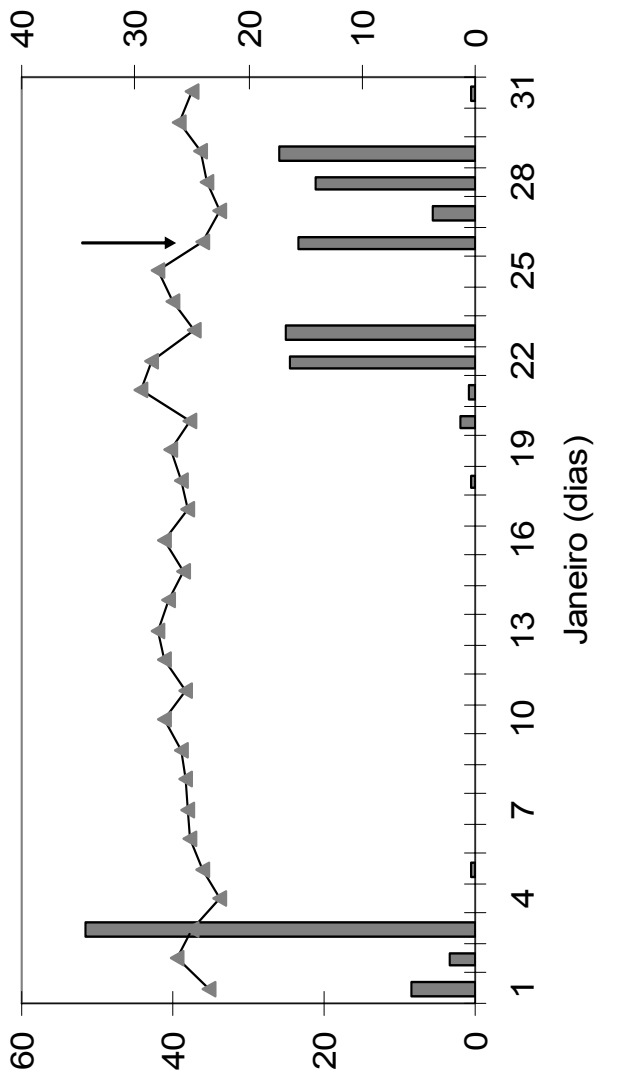

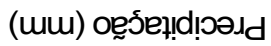

(ว。) exnłeıəduə।

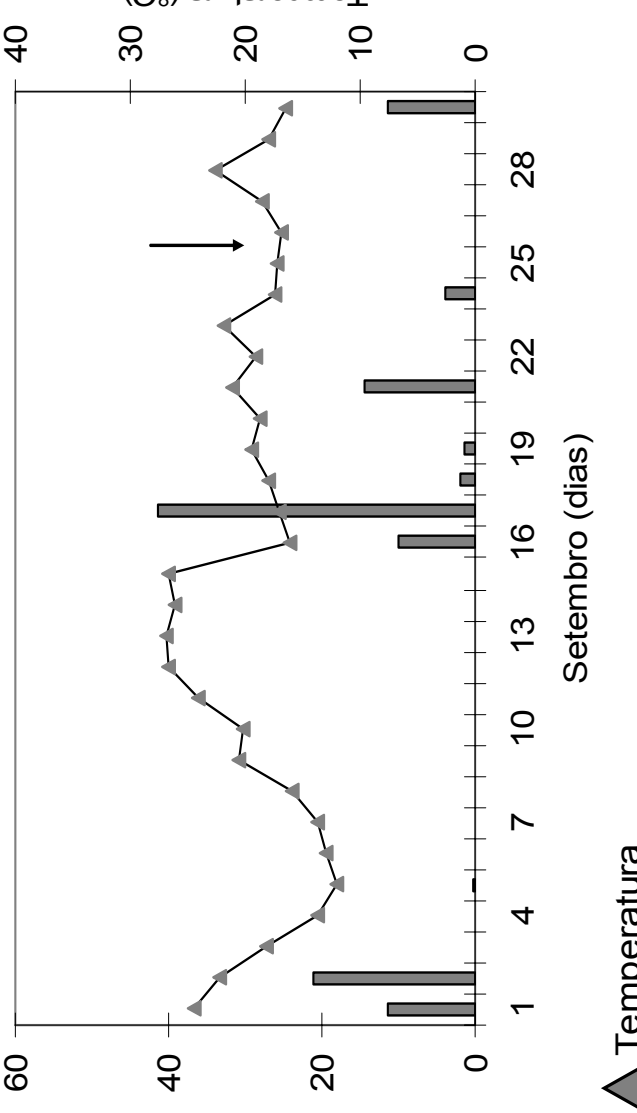

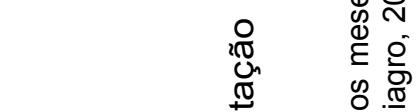
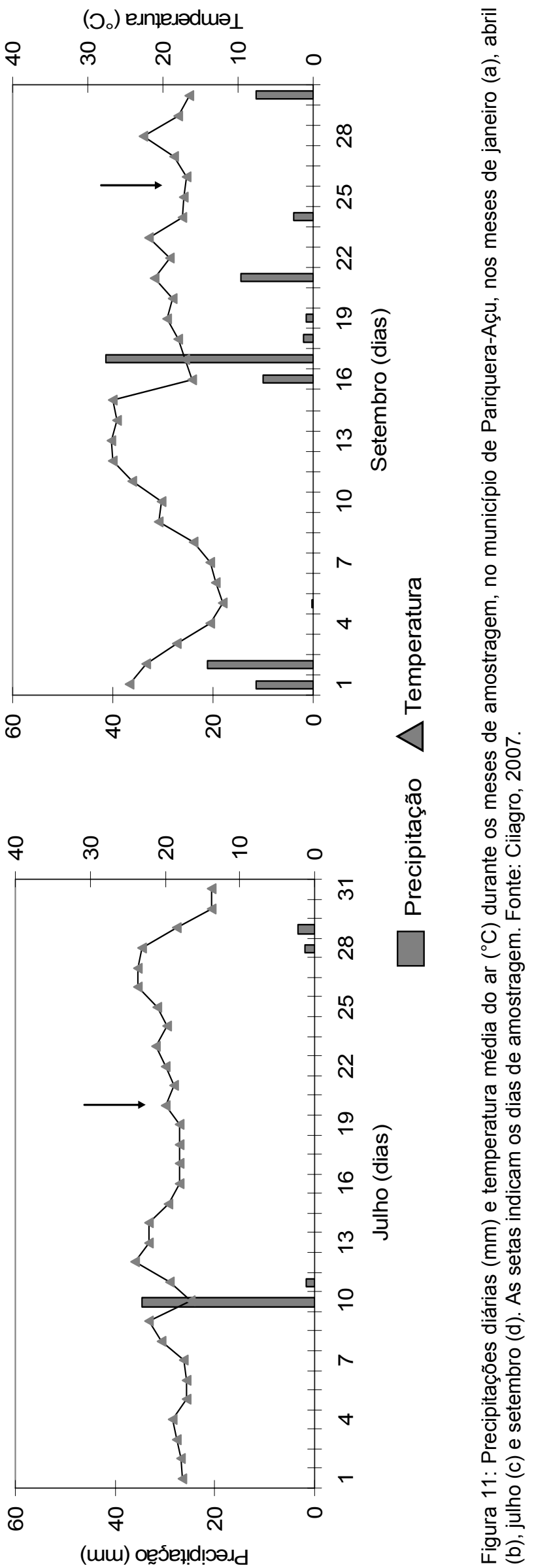

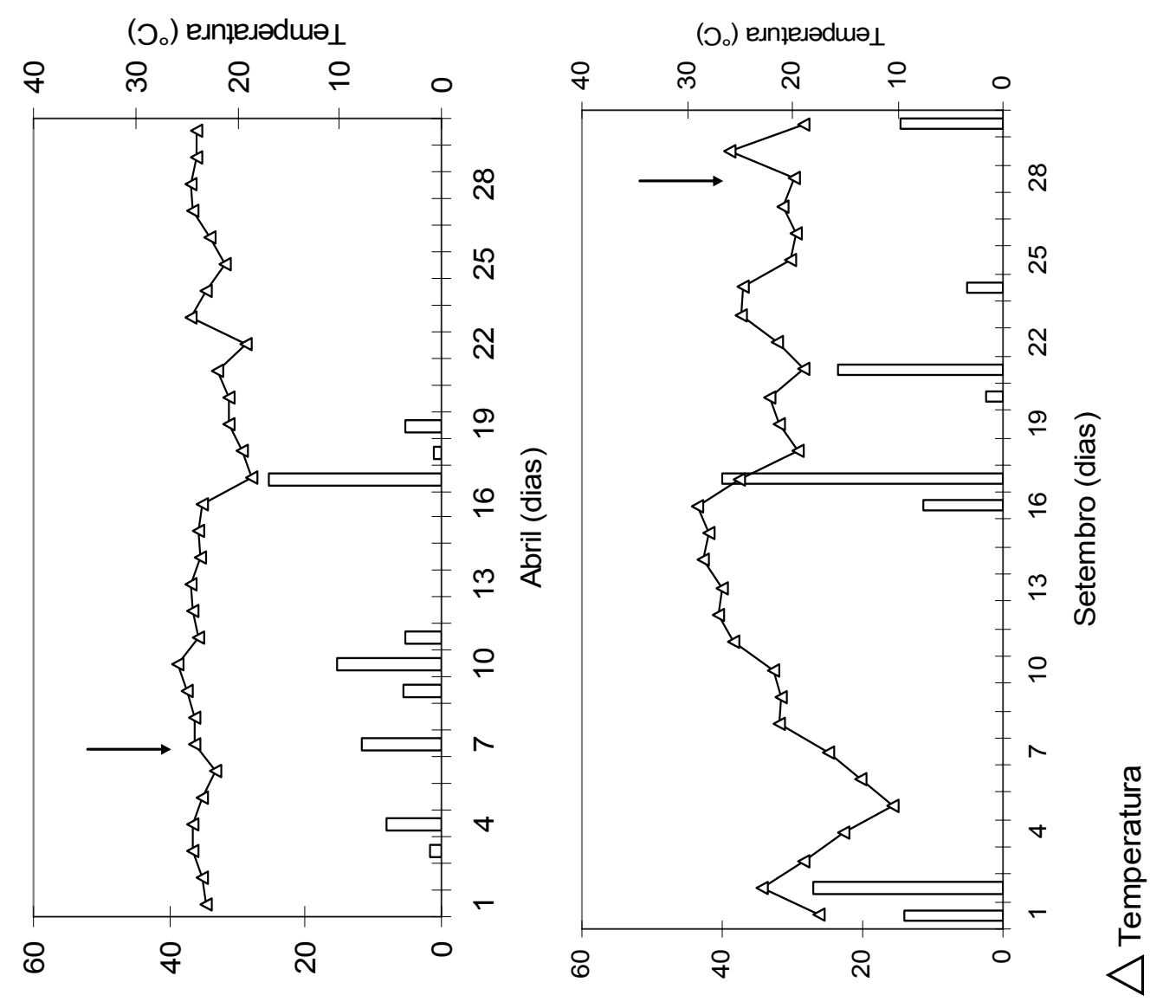

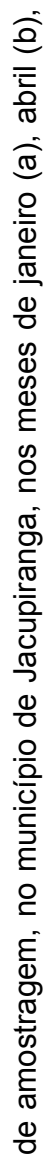
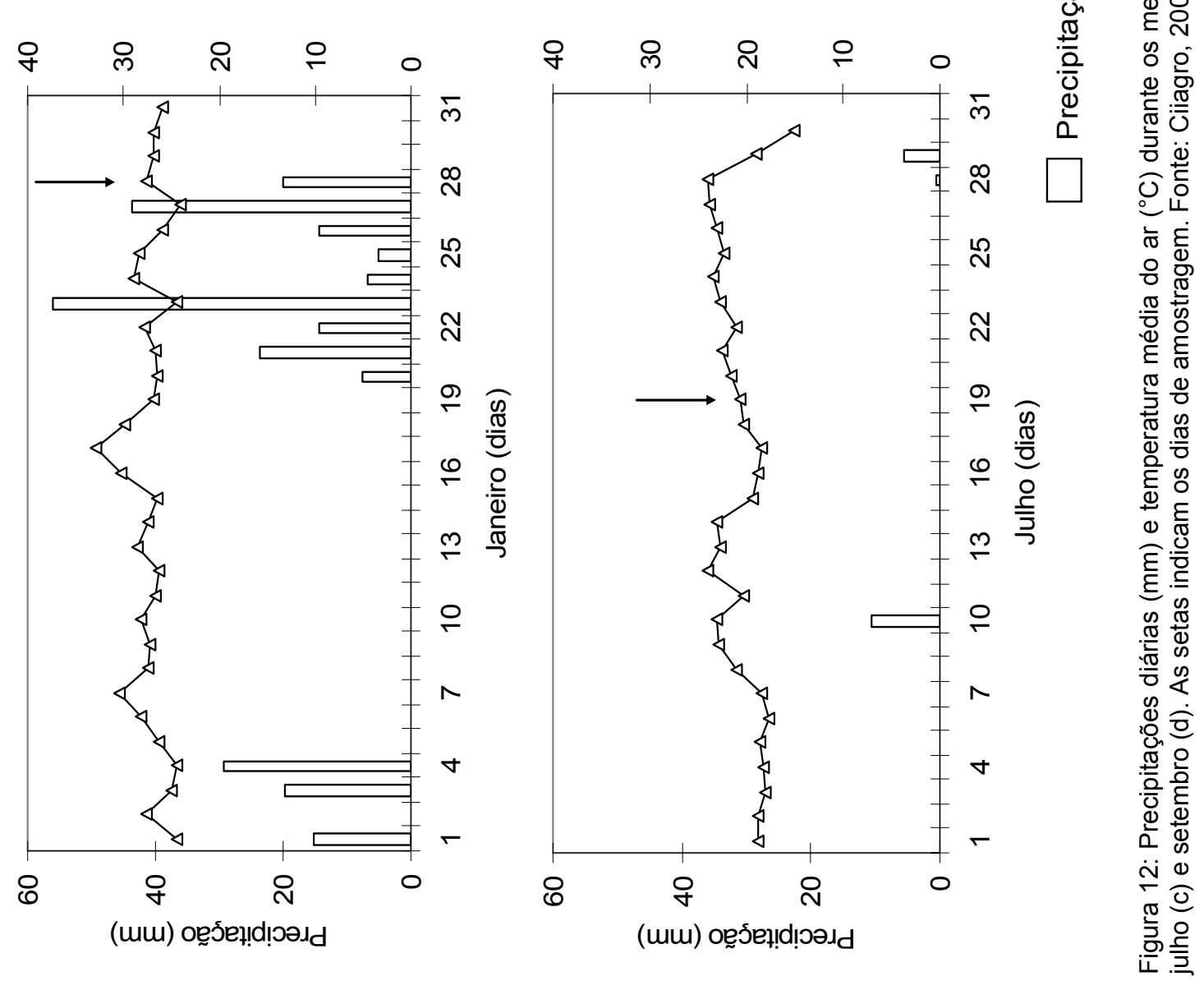


\subsubsection{Radiação Solar}

Os valores de radiação solar fotossinteticamente ativa (RSFA), incidente e subaquática, estão apresentados na Tabela 2. Comparando os quatro horários de amostragem, no sistema de Pariquera-Açu, os menores valores de RSFA incidente foram obtidos às $7 \mathrm{~h}$, na maioria dos períodos de coleta, exceto em abril. Neste horário, os valores de RSFA incidente estiveram entre $33,8 \mu \mathrm{E} \cdot \mathrm{m}^{-2} \cdot \mathrm{s}^{-1}$, em julho e $143,9 \mu \mathrm{E} \cdot \mathrm{m}^{-2} \cdot \mathrm{s}^{-1}$, em abril. Os maiores valores de RSFA ocorreram às $13 \mathrm{~h}$, em janeiro e julho (3414,0 e 1839,0 $\mu \mathrm{E} \cdot \mathrm{m}^{-2} \cdot \mathrm{s}^{-1}$, respectivamente).

Na ETE de Jacupiranga, pode-se observar variação horária da RSFA incidente, sendo que os menores valores ocorreram às $7 \mathrm{~h}$, aumentando na amostragem das $13 \mathrm{~h} e$ diminuindo às $16 \mathrm{~h}$. Este padrão só não foi observado em janeiro, quando as maiores RSFA incidentes ocorreram às $16 \mathrm{~h}$ e às $10 \mathrm{~h}$, $\left(2563,0\right.$ e $1332,0 \mu \mathrm{E} \cdot \mathrm{m}^{-2} \cdot \mathrm{s}^{-1}$, respectivamente). O menor valor de RSFA obtido neste sistema foi de $119,4 \mu \mathrm{E} \cdot \mathrm{m}^{-2} \cdot \mathrm{s}^{-1}$, às $7 \mathrm{~h}$, em abril.

Os valores de RSFA subaquática variaram entre os períodos de amostragem e entre as lagoas. Nas duas lagoas facultativas estudadas, os maiores valores de RSFA subaquática ocorreram nos períodos de janeiro e julho, sendo que na lagoa de PariqueraAçu (1113 e 926,9 $\mu \mathrm{E} \cdot \mathrm{m}^{-2} \mathrm{~s}^{-1}$, às $\left.13 \mathrm{~h}\right)$ foram maiores que os de Jacupiranga $\left(858,2 \mu \mathrm{E} \cdot \mathrm{m}^{-2} \mathrm{~s}^{-1}, 16 \mathrm{~h}\right.$ e $683,9 \mu \mathrm{E} \cdot \mathrm{m}^{-2} \mathrm{~s}^{-1}$, às $\left.13 \mathrm{~h}\right)$.

Nos dois tipos de lagoas facultativas estudadas não foi observado padrão de variação sazonal e horária na profundidade da zona eufótica (Zeuf). Na lagoa da ETE de Pariquera-Açu, o máximo valor de Zeuf ocorreu em setembro, às $13 \mathrm{~h}(0,65 \mathrm{~m})$; e os menores em abril, às 10 e 16h ( $0,05 \mathrm{~m}$, nos dois horários); e em julho, às $7 \mathrm{~h}(0,05 \mathrm{~m})$. $\mathrm{Na}$ lagoa da ETE de Jacupiranga, o máximo valor de Zeuf também ocorreu em setembro, porém às $16 \mathrm{~h}(1,05 \mathrm{~m})$; e os menores em abril, às $13 \mathrm{~h}$ e em julho, às $7 \mathrm{~h}(0,05 \mathrm{~m}$, nos dois horários). 
Tabela 2: Radiação Solar Fotossinteticamente Ativa $\left(\mu \mathrm{E} \cdot \mathrm{m}^{-2} \cdot \mathrm{s}^{-1}\right)$ nas ETEs de Pariquera-Açu e Jacupiranga.

\begin{tabular}{|c|c|c|c|c|c|c|c|c|c|c|}
\hline & & & \multicolumn{4}{|c|}{ Pariquera-Açu } & \multicolumn{4}{|c|}{ Jacupiranga } \\
\hline & & & $7 \mathrm{~h}$ & $10 \mathrm{~h}$ & $13 \mathrm{~h}$ & $16 \mathrm{~h}$ & $7 \mathrm{~h}$ & $10 \mathrm{~h}$ & $13 \mathrm{~h}$ & $16 \mathrm{~h}$ \\
\hline \multirow{7}{*}{ Janeiro } & \multirow{7}{*}{ 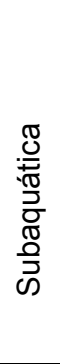 } & Incidente & 117,00 & 925,50 & 3414,00 & 927,50 & 735,90 & 1332,00 & 1153,00 & 2563,00 \\
\hline & & 0,00 & 42,24 & 226,90 & 1113,00 & 318,40 & 131,70 & 405,60 & 322,90 & 858,20 \\
\hline & & 0,25 & 2,05 & 11,16 & 116,10 & 16,29 & 41,99 & 116,70 & 99,98 & 167,40 \\
\hline & & 0,75 & 0,09 & 0,35 & 2,79 & 2,48 & 3,32 & 33,24 & 9,96 & 22,61 \\
\hline & & 1,00 & 0,01 & 0,04 & 0,21 & 0,17 & 1,83 & 7,60 & 1,52 & 3,26 \\
\hline & & 1,25 & 0,00 & 0,01 & 0,01 & 0,00 & 1,08 & 2,76 & 0,25 & 0,46 \\
\hline & & 1,50 & & 0,00 & 0,00 & & 0,38 & 2,66 & 0,09 & 0,13 \\
\hline \multirow{7}{*}{ Abril } & \multirow{7}{*}{ 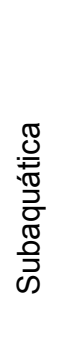 } & Incidente & 143,90 & 901,40 & 576,90 & 93,70 & 119,40 & 663,90 & 1317,00 & 361,40 \\
\hline & & 0,00 & 5,88 & 57,01 & 183,10 & 2,07 & 41,14 & 220,30 & 113,10 & 109,20 \\
\hline & & 0,25 & 1,07 & 0,68 & 14,11 & 0,31 & 8,16 & 57,90 & 29,91 & 23,81 \\
\hline & & 0,75 & 0,12 & 0,15 & 1,34 & 0,02 & 1,61 & 8,68 & 9,19 & 5,17 \\
\hline & & 1,00 & 0,03 & 0,07 & 0,17 & 0,00 & 1,40 & 1,94 & 2,95 & 1,35 \\
\hline & & 1,25 & 0,00 & 0,01 & 0,03 & & 0,35 & 0,49 & 0,64 & 0,26 \\
\hline & & 1,50 & & 0,00 & 0,00 & & 0,12 & 0,09 & 0,19 & 0,00 \\
\hline \multirow{6}{*}{ Julho } & \multirow{6}{*}{ 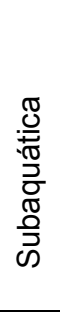 } & Incidente & 33,80 & 1743,00 & 1839,00 & 1577,00 & 124,10 & 1565,00 & 1796,00 & 1407,00 \\
\hline & & 0,00 & 21,23 & 283,40 & 926,90 & 645,50 & 53,10 & 450,40 & 683,90 & 346,20 \\
\hline & & 0,25 & 0,19 & 12,82 & 33,69 & 67,87 & 1,55 & 31,30 & 51,22 & 11,88 \\
\hline & & 0,75 & 0,00 & 0,59 & 0,37 & 3,64 & 0,06 & 1,51 & 3,05 & 1,73 \\
\hline & & 1,00 & & 0,01 & 0,01 & 0,03 & 0,01 & 0,05 & 0,10 & 0,04 \\
\hline & & 1,25 & & 0,00 & 0,00 & 0,00 & 0,00 & 0,00 & 0,01 & 0,00 \\
\hline \multirow{7}{*}{ Setembro } & \multirow{7}{*}{$\begin{array}{l}\frac{\pi}{0} \\
: \frac{0}{0} \\
\frac{\pi}{0} \\
\frac{\pi}{0} \\
\stackrel{0}{3}\end{array}$} & Incidente & - & 800,00 & 609,30 & 196,10 & 150,40 & 1537,00 & 2050,00 & 1049,00 \\
\hline & & 0,00 & - & 430,00 & 125,20 & 63,50 & 0,14 & 5,43 & 23,58 & 29,14 \\
\hline & & 0,25 & - & 40,00 & 134,40 & 12,62 & 0,06 & 5,31 & 19,00 & 25,26 \\
\hline & & 0,75 & - & 4,50 & 12,43 & 2,18 & 0,05 & 0,32 & 4,42 & 8,61 \\
\hline & & 1,00 & - & 2,50 & 2,83 & 0,25 & 0,04 & 0,15 & 1,10 & 5,09 \\
\hline & & 1,25 & - & 0,00 & 0,47 & 0,05 & 0,03 & 0,30 & 0,35 & 2,42 \\
\hline & & 1,50 & - & & 0,21 & 0,01 & 0,03 & 0,07 & 0,16 & 1,43 \\
\hline
\end{tabular}

$\overline{\text { (-) medida não realizada. }}$ 

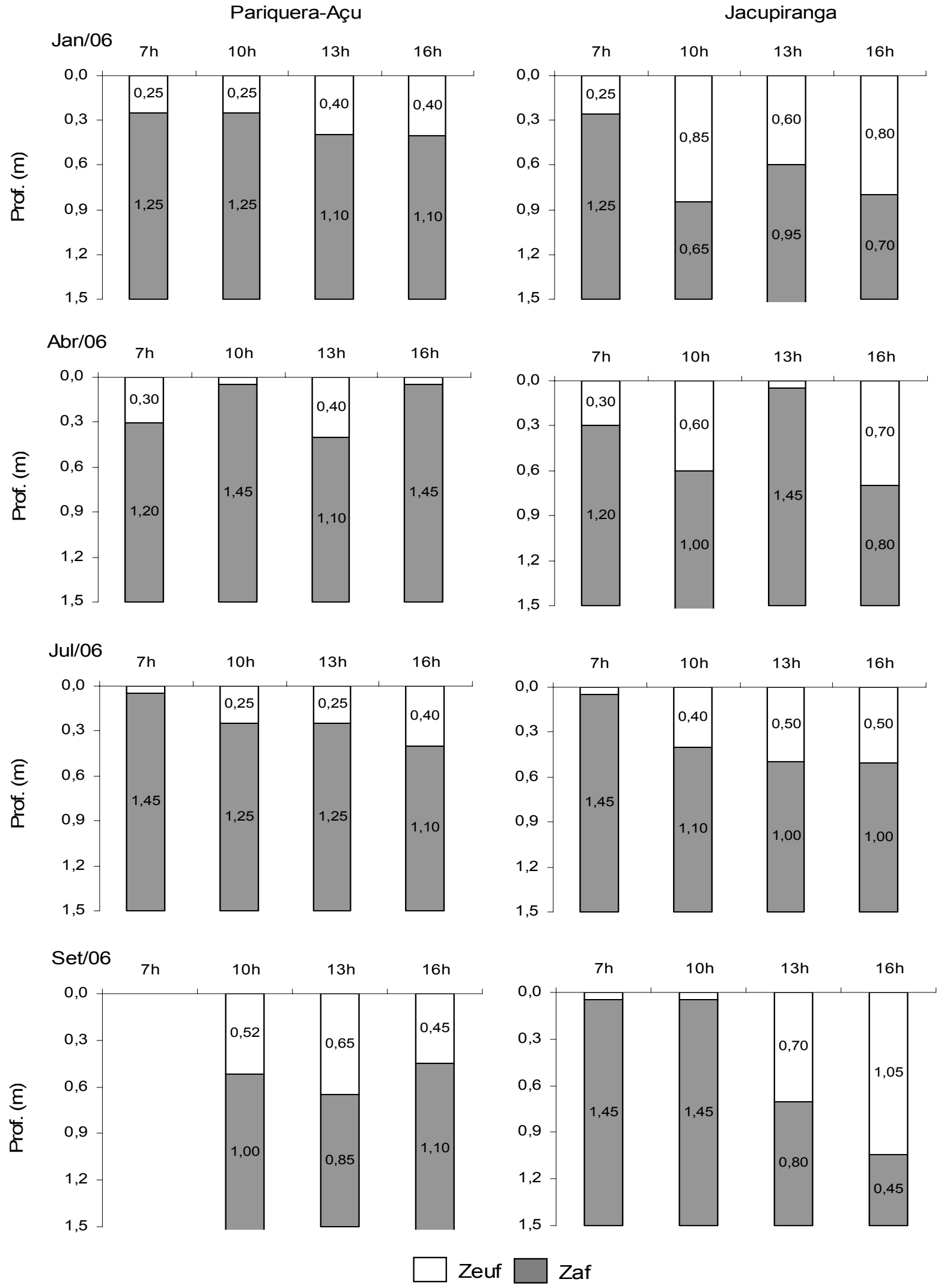

Figura 13: Profundidade da zona eufótica (Zeuf) e da zona afótica (Zaf), nas lagoas facultativas das ETEs de Pariquera-Açu (às $7 \mathrm{~h}$, em setembro, a medida não foi realizada) e Jacupiranga. 


\subsubsection{Velocidade do vento}

A maior velocidade de vento (Tabela 3), em Pariquera-Açu, ocorreu em setembro $\left(2,38 \mathrm{~m} . \mathrm{s}^{-1}\right)$ e a menor, em abril $\left(0,01 \mathrm{~m} \cdot \mathrm{s}^{-1}\right)$. Em Jacupiranga, a velocidade do vento não variou entre os dias de amostragens, ficando entre 0,72 (janeiro) e $0,13 \mathrm{~m} . \mathrm{s}^{-1}$ (abril).

\begin{tabular}{lcc}
$\begin{array}{l}\text { Tabela 3: Velocidade } \\
\text { Jacupiranga. }\end{array}$ & Pariquera-Açu & Jacupiranga \\
\hline & 1,07 & 0,72 \\
\hline Janeiro & 0,01 & nas \\
\hline Abril & 0,63 & 0,13 \\
\hline Julho & 2,68 & 0,35 \\
\hline Setembro & & 0,30 \\
\hline
\end{tabular}

\subsubsection{Vazão e tempo de detenção hidráulico}

Os valores de vazão calculados para os dois sistemas (Tabela 4) foram semelhantes e praticamente os mesmos nos três períodos em que as medidas foram realizadas $\left(624,7 \mathrm{~m}^{3} \cdot \mathrm{d}^{-1}\right)$, exceto para a ETE de Jacupiranga, em julho $(222,9$ $\left.\mathrm{m}^{3} \cdot \mathrm{d}^{-1}\right)$. Em Pariquera-Açu, o TDH foram iguais nos três períodos $(20,1 \mathrm{~d})$; no mês de setembro, este sistema não estava operando. Na ETE de Jacupiranga, o maior valor de TDH foi obtido em julho (49,7d); nos meses de janeiro e abril foi verificado o mesmo valor $(17,7 \mathrm{~d})$.

Tabela 4: Vazão $\left(Q ; \mathrm{m}^{3} \cdot \mathrm{d}^{-1}\right)$ e Tempo de Detenção Hidráulico $(\theta t ; \mathrm{d})$ calculados
para as lagoas facultativas das ETEs de Pariquera-Açu e Jacupiranga.
\begin{tabular}{cccc}
\hline & & Pariquera-Açu & Jacupiranga \\
\hline Projeto & $\theta t(\mathrm{~d})$ & 11 & 6 \\
\hline & $\mathrm{V}\left(\mathrm{m}^{3}\right)$ & 12549 & 11063 \\
\hline Janeiro & $\mathrm{Q}\left(\mathrm{m}^{3} \cdot \mathrm{d}^{-1}\right)$ & 624,7 & 624,7 \\
\hline & $\theta \mathrm{t}(\mathrm{d})$ & 20,1 & 17,7 \\
\hline Abril & $\mathrm{Q}\left(\mathrm{m}^{3} \cdot \mathrm{d}^{-1}\right)$ & 624,7 & 624,7 \\
\hline & $\theta \mathrm{t}(\mathrm{d})$ & 20,1 & 17,7 \\
\hline Julho & $\mathrm{Q}\left(\mathrm{m}^{3} \cdot \mathrm{d}^{-1}\right)$ & 624,7 & 222,9 \\
\hline & $\theta \mathrm{t}(\mathrm{d})$ & 20,1 & 49,7 \\
\hline
\end{tabular}




\subsection{Variáveis Abióticas}

\subsubsection{Temperatura da Água, pH, Condutividade Elétrica e Oxigênio Dissolvido}

Os perfis de temperatura da água são apresentados na Figura 14. Na lagoa facultativa de Pariquera-Açu não foi observada variação vertical na temperatura da água em setembro, sendo que em todos os horários a temperatura manteve-se constante em toda a coluna de água (próximo a $20^{\circ} \mathrm{C}$ ). Nesta lagoa, em janeiro, abril e julho, ocorreram estratificações térmicas nas amostragens das 13 e 16h, enquanto que nos primeiros horários amostrados (7 e 10h), a temperatura permaneceu homogênea na coluna de água, exceto às $7 \mathrm{~h}$, em janeiro, quando ocorreu variação de $0,06^{\circ} \mathrm{C}$, nos primeiros $10 \mathrm{~cm}$. O maior valor de temperatura da água foi de $30,29{ }^{\circ} \mathrm{C}$, em janeiro (16h) e o menor de $19,75^{\circ} \mathrm{C}$, em julho (13h).

Estratificação térmica foi observada em todos os períodos estudados, na lagoa facultativa do sistema de Jacupiranga, principalmente nas amostragens das 13 e 16h. Em setembro, às $10 \mathrm{~h}$, foi observada variação de $1,17^{\circ} \mathrm{C}$ na superfície da coluna de água. $\mathrm{O}$ maior valor de temperatura da água foi de $31,48{ }^{\circ} \mathrm{C}$ e o menor de $20,01{ }^{\circ} \mathrm{C}$, ambos em setembro, às $16 \mathrm{~h}$ (sub-superfície e na interface água-sedimento, respectivamente).

$\mathrm{Na}$ Figura 15 estão apresentados os perfis de $\mathrm{pH}$ obtidos na lagoa facultativa dos sistemas de Jacupiranga e de Pariquera-Açu. De modo geral, os perfis de $\mathrm{pH}$ seguiram o mesmo padrão observado para a temperatura da água. Foi possível observar variações horárias, ou seja, o $\mathrm{pH}$ aumentou no período compreendido entre as amostragens das 7 e 16h, de aproximadamente 7 para 8, em janeiro; e de 7 para 9,58, em abril, na lagoa facultativa de Pariquera-Açu. Em Jacupiranga, a variação foi de 7,23 para 8,62, em janeiro; e de 7,58 para 8,36, em abril.

$\mathrm{Na}$ amostragem de abril, na lagoa da ETE de Pariquera-Açu, ocorreu variação vertical do $\mathrm{pH}$ em todos os horários. Em julho, a variação foi de 8,04 a 6,28 , na subsuperfície, nas amostragens de 13 e $16 \mathrm{~h}$.

$\mathrm{Na}$ lagoa da ETE de Jacupiranga, a maior variação de $\mathrm{pH}$ ocorreu em janeiro, às 16h, de 8,69 (0,30 m) e 6,95 (1,5m). Porém em setembro (13 e 16h), foram observados os maiores valores de $\mathrm{pH}$ na sub-superfície, próximo a 9, e em seguida diminuíram na interface água-sedimento para 6,61 e 6,58, respectivamente. 


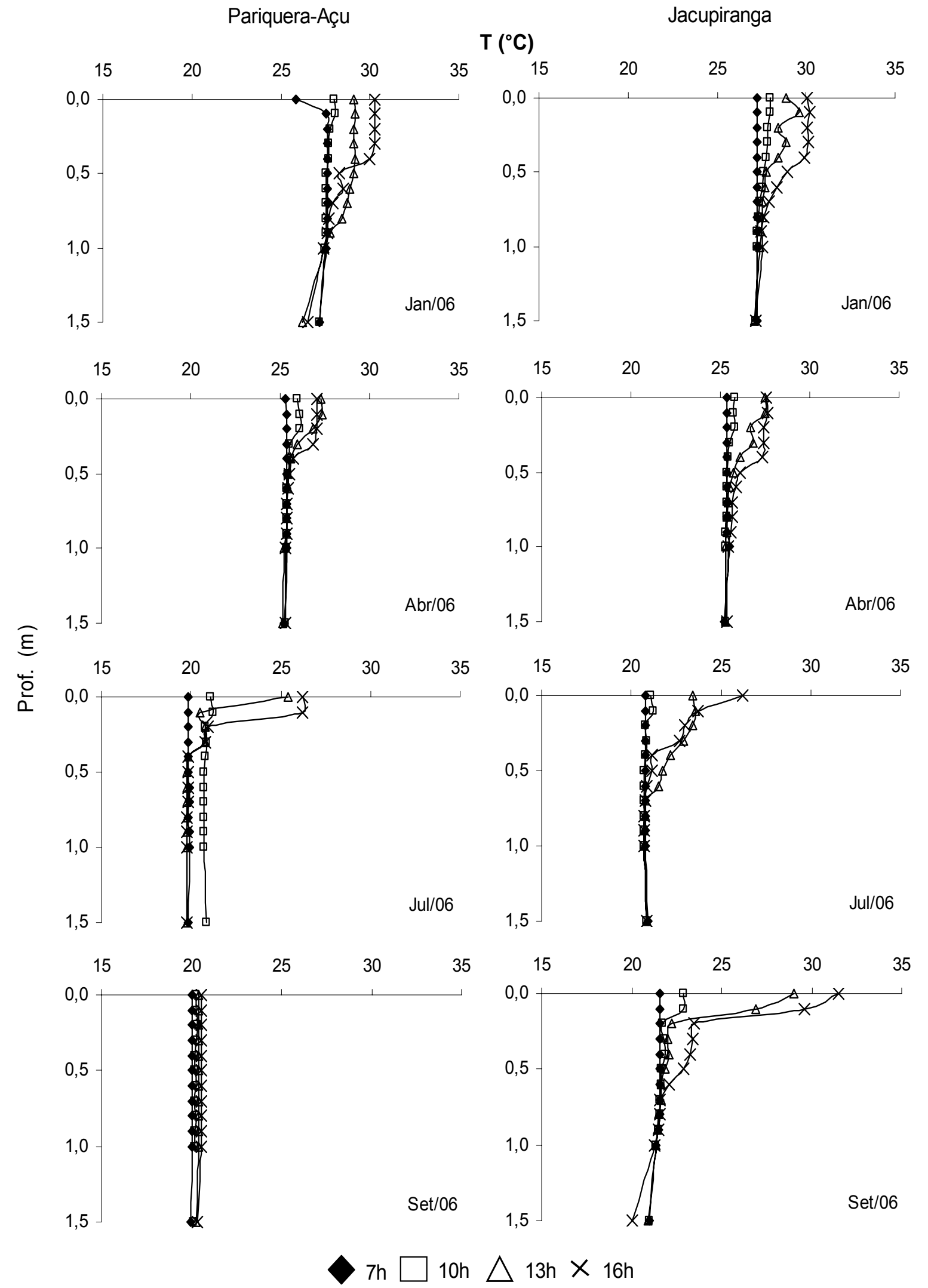

Figura 14: Perfis de temperatura da água $\left({ }^{\circ} \mathrm{C}\right)$, nas lagoas facultativas das ETEs de Pariquera-Açu e Jacupiranga. 


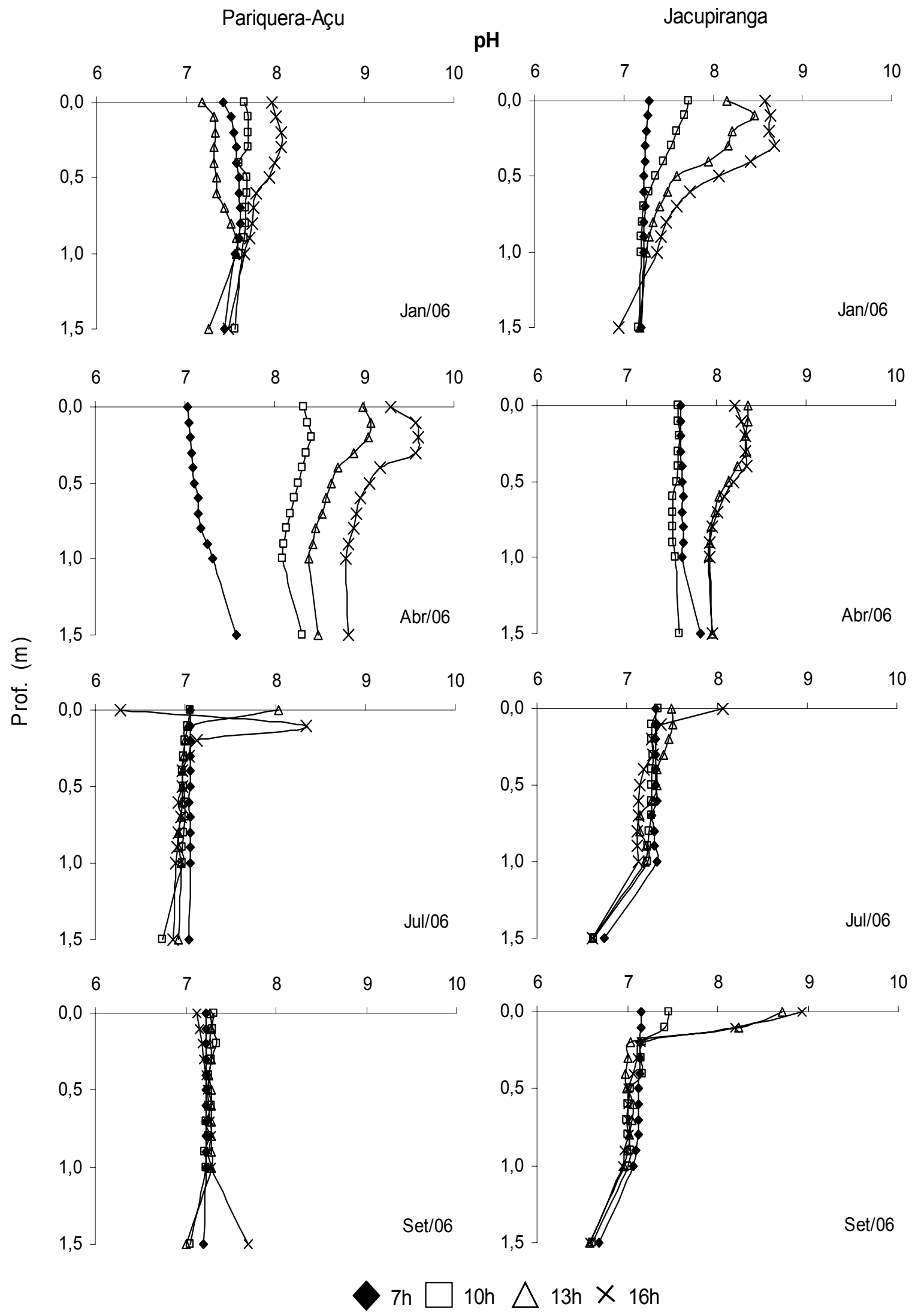

Figura 15: Perfis de pH, nas lagoas facultativas das ETES de Pariquera-Açu e Jacupiranga. 
Na lagoa facultativa de Pariquera-Açu, os valores de condutividade, às $16 \mathrm{~h}$, foram maiores no mês de julho, entre $566(1,5 \mathrm{~m})$ e $604 \mu \mathrm{S} . \mathrm{cm}^{-1}(1,50$ e $0,10 \mathrm{~m}$, respectivamente) e os menores no mês de abril, entre 302 e $375 \mu \mathrm{S} . \mathrm{cm}^{-1}(0,10$ e 1,5 m, respectivamente). Na amostragem de janeiro e abril, próximo a interface água-sedimento, observou-se aumento de aproximadamente $20 \mu \mathrm{S} . \mathrm{cm}^{-1}$, em todos os horários. Em julho e setembro, a condutividade manteve-se constante em quase toda a coluna de água, exceto na sub-superfície, às 13 e $16 \mathrm{~h}$.

Com relação aos valores de condutividade elétrica (CE) na lagoa de Jacupiranga, foi observado aumento maior próximo a interface água-sedimento se comparado à de Pariquera-Açu, principalmente em janeiro, período em que a condutividade manteve-se constante em toda a coluna de água. Os maiores valores desta variável, com exceção da interface água-sedimento, foram observados em julho (entre 527 a $564 \mu$ S.cm ${ }^{-1}$; meio e sub-superfície, respectivamente), e os menores, no mês de abril (374 a $396 \mu$ S.cm ${ }^{-1}$; ambos no meio da coluna de água).

$\mathrm{Na}$ Tabela 5 estão representadas as concentrações de OD obtidas nas lagoas facultativas de Pariquera-Açu e Jacupiranga. Para esta variável, foram observadas variabilidades sazonais, horárias e verticais, no período estudado.

$\mathrm{Na}$ lagoa facultativa da ETE de Pariquera-Açu, na amostragem de abril, foram observadas as maiores variações horária e vertical. As concentrações de OD variaram entre 22,21 (13h, sub-superfície) e 0,36 mg. $\mathrm{L}^{-1}$ ( $7 \mathrm{~h}$, meio). No mês de julho, também foi observada variação vertical de OD às $16 \mathrm{~h}$, porém, esta foi menor que a citada acima $\left(17,47\right.$ a 4,56 mg. $\left.\mathrm{L}^{-1}\right)$.

Nesta lagoa, em setembro, não foi observada variação vertical de oxigênio dissolvido nos horários amostrados, exceto às $10 \mathrm{~h}$, quando as concentrações variaram de 4,90 a 1,26 mg. $\mathrm{L}^{-1}$. Neste mesmo período, as concentrações de OD observadas às 13 e $16 \mathrm{~h}$ mantiveram-se praticamente constantes.

Como foi observado na lagoa facultativa de Pariquera-Açu, também houve variabilidade temporal na distribuição vertical de OD na lagoa facultativa de Jacupiranga. Em setembro, foram observadas as maiores variações as $13\left(29,00\right.$ a 20,94 mg. $\left.\mathrm{L}^{-1}\right)$ e $16 \mathrm{~h}$ $\left(31,48\right.$ a $\left.20,01 \mathrm{mg} \cdot \mathrm{L}^{-1}\right)$. Nos outros meses amostrados, as maiores concentrações de OD também ocorreram às 13 e $16 \mathrm{~h}$, porém foram mais baixas que as observadas em setembro. 


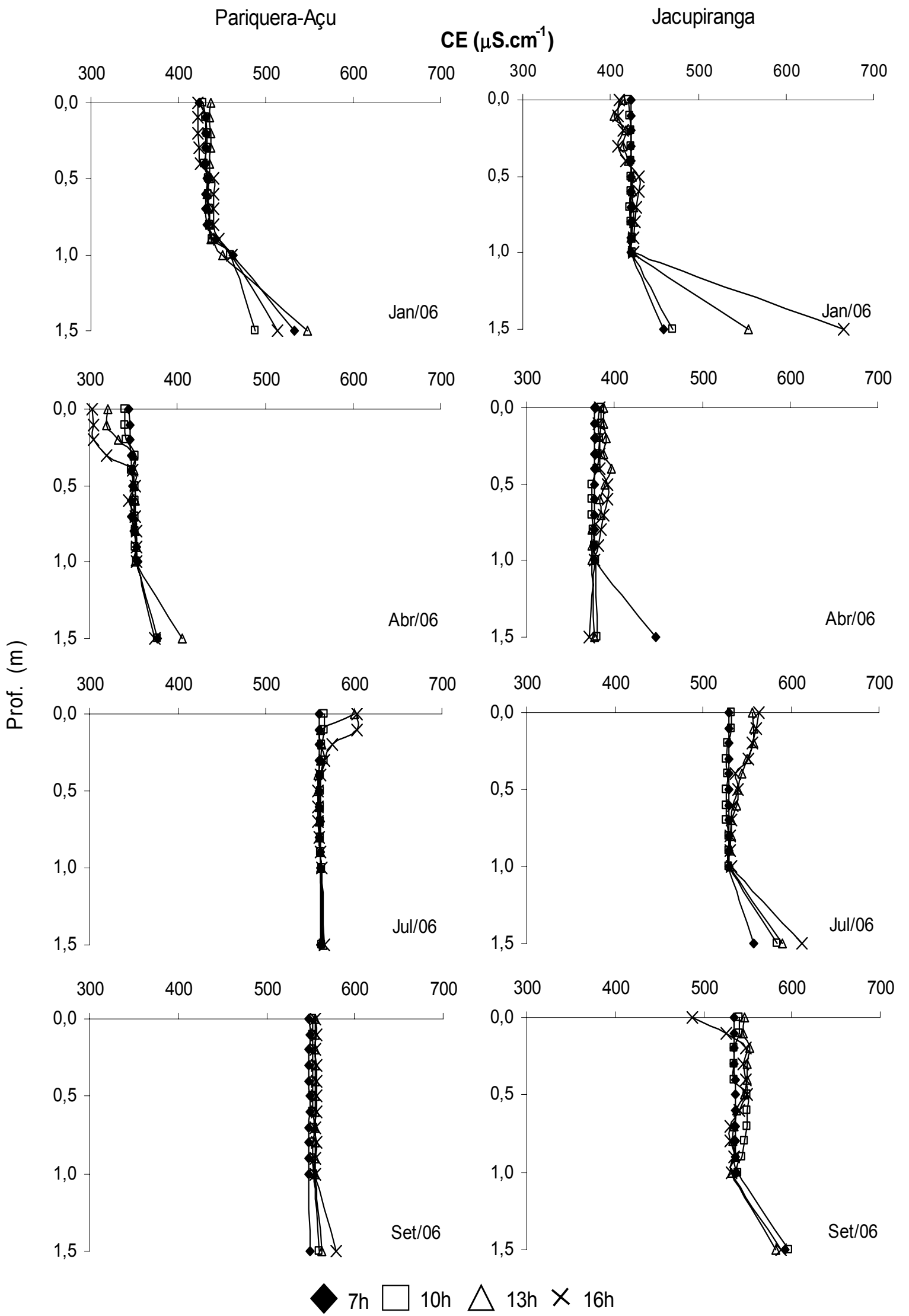

Figura 16: Perfis de condutividade elétrica $\left(\mu \mathrm{S} . \mathrm{cm}^{-1}\right)$, nas lagoas facultativas das ETEs de Pariquera-Açu e Jacupiranga. 
Tabela 5: Concentrações de oxigênio dissolvido (mg. $\mathrm{L}^{-1}$ ), obtidas nas lagoas facultativas das ETEs de Pariquera-Açu e Jacupiranga.

\begin{tabular}{|c|c|c|c|c|c|c|c|c|c|}
\hline & & \multicolumn{4}{|c|}{ Pariquera-Açu } & \multicolumn{4}{|c|}{ Jacupiranga } \\
\hline & & $7 \mathrm{~h}$ & $10 \mathrm{~h}$ & $13 \mathrm{~h}$ & $16 \mathrm{~h}$ & $7 \mathrm{~h}$ & $10 \mathrm{~h}$ & $13 \mathrm{~h}$ & $16 \mathrm{~h}$ \\
\hline \multirow{3}{*}{ Janeiro } & SS & - & 5,19 & 1,64 & 7,38 & 0,64 & 8,54 & 16,03 & 15,43 \\
\hline & M & - & - & 0,99 & - & 0,58 & 1,42 & 0,49 & 10,42 \\
\hline & $F$ & - & - & - & - & 0,35 & 3,33 & 11,38 & 2,89 \\
\hline \multirow{3}{*}{ Abril } & SS & 0,47 & 9,65 & 22,21 & 12,68 & - & 3,71 & 14,75 & 12,79 \\
\hline & $M$ & 0,36 & 5,87 & 0,52 & 1,13 & - & 3,95 & 0,97 & 6,57 \\
\hline & $\mathrm{F}$ & - & - & 0,40 & 0,58 & - & - & 2,23 & 0,50 \\
\hline \multirow{3}{*}{ Julho } & SS & - & - & 14,61 & 17,47 & - & - & 4,38 & 8,63 \\
\hline & $M$ & - & - & - & 9,35 & - & - & - & - \\
\hline & $\mathrm{F}$ & - & - & - & 4,56 & - & - & - & 0,47 \\
\hline \multirow{3}{*}{ Setembro } & SS & 0,35 & 4,90 & 3,18 & 3,25 & - & 5,38 & 17,82 & 28,54 \\
\hline & $M$ & 0,35 & 2,13 & 3,31 & 3,28 & - & 1,12 & 29,52 & - \\
\hline & $\mathrm{F}$ & 0,19 & 1,26 & 2,75 & 3,26 & - & 1,56 & - & 0,35 \\
\hline
\end{tabular}

\subsubsection{Alcalinidade e Formas de Carbono}

As concentrações de bicarbonato $\left(\mathrm{HCO}_{3}{ }^{-}\right)$, dióxido de carbono total $\left(\mathrm{CO}_{2}\right.$ total), carbono inorgânico ( $\mathrm{C}_{\text {-inorgânico}}$ ), carbono orgânico dissolvido (COD), dióxido de carbono livre $\left(\mathrm{CO}_{2}\right.$ livre $)$ e Carbonato $\left(\mathrm{CO}_{3}{ }^{-2}\right)$, alcalinidade e os valores de $\mathrm{pH}$ na lagoa facultativa de Pariquera-Açu estão apresentados na Tabela 6 e os de Jacupiranga, na Tabela 7.

$\mathrm{Na}$ lagoa facultativa de Pariquera-Açu, as concentrações de $\mathrm{HCO}_{3}{ }^{-}, \mathrm{CO}_{2}$ total, Cinorgânico, $\mathrm{COD}, \mathrm{CO}_{2}$ livre e $\mathrm{CO}_{3}^{-2}$ e a alcalinidade mantiveram-se as mesmas nas três profundidades e nos quatro horários amostrados, exceto o COD, em setembro. Neste período, a concentração de COD foi maior na sub-superfície $\left(173,80 \mathrm{mg} \cdot \mathrm{L}^{-1}\right)$ e menor na interface água-sedimento $\left(41,53 \mathrm{mg} \cdot \mathrm{L}^{-1}\right)$, às $7 \mathrm{~h}$.

Em setembro, observou-se aumento de aproximadamente $40 \%$, nas formas de carbono (exceto COD) e na alcalinidade, em relação aos outros períodos.

$\mathrm{Na}$ lagoa facultativa do sistema de Jacupiranga, as formas de carbono $\left(\mathrm{HCO}_{3}{ }^{-}\right.$, $\mathrm{CO}_{2}$ total, $\mathrm{C}_{\text {-inorgânico, }} \mathrm{COD}$ e $\mathrm{CO}_{3}{ }^{-2}$ ) e a alcalinidade não variaram, tanto vertical como temporalmente em janeiro, abril e julho. Em setembro, observou-se aumento nos valores destas variáveis (aproximadamente $35 \%$ em relação aos outros meses). Para o $\mathrm{CO}_{2}$ total

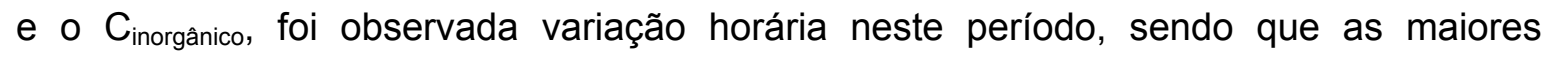
concentrações foram medidas às $7 \mathrm{~h}$ e as menores, às 16h. Neste ultimo horário 
ocorreram também, variações verticais de 104 a $170 \mathrm{mg} \cdot \mathrm{L}^{-1}$ para o $\mathrm{CO}_{2}$ total; e de 28 a 46

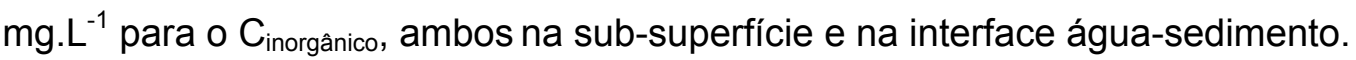

O COD também variou nas amostragens horária e vertical, em setembro, sendo que a maior concentração foi observada na sub-superfície $\left(138,90 \mathrm{mg} \cdot \mathrm{L}^{-1}\right)$ e a menor, na interface água-sedimento $\left(17,61 \mathrm{mg} \cdot \mathrm{L}^{-1}\right)$, ambas às $13 \mathrm{~h}$.

Tabela 6: Formas de carbono, alcalinidade $\left(\mathrm{mg}_{\mathrm{L}} \mathrm{L}^{-1}\right)$ e $\mathrm{pH}$, na lagoa facultativa da ETE de Pariquera-Açu (SS: sub-superfície, M: meio e $\mathrm{F}$ : interface água-sedimento).

\begin{tabular}{|c|c|c|c|c|c|c|c|c|c|c|c|c|}
\hline & \multicolumn{3}{|c|}{ Janeiro } & \multicolumn{3}{|c|}{ Abril } & \multicolumn{3}{|c|}{ Julho } & \multicolumn{3}{|c|}{ Setembro } \\
\hline & SS & $\mathrm{M}$ & $\mathrm{F}$ & SS & $\mathrm{M}$ & $\mathrm{F}$ & SS & $\mathrm{M}$ & $\mathrm{F}$ & SS & $\mathrm{M}$ & $\mathrm{F}$ \\
\hline \multicolumn{13}{|c|}{$\mathrm{HCO}_{3}{ }^{-}$} \\
\hline $7 \mathrm{~h}$ & 119 & 120 & 128 & 114 & 112 & 120 & 119 & 120 & 128 & 174 & 170 & 170 \\
\hline $10 \mathrm{~h}$ & 113 & 118 & 131 & 110 & 114 & 114 & 113 & 117 & 131 & 170 & 172 & 170 \\
\hline $13 \mathrm{~h}$ & 117 & 118 & 124 & 108 & 112 & 117 & 115 & 118 & 124 & 171 & 167 & 169 \\
\hline $16 \mathrm{~h}$ & 114 & 114 & 124 & 86 & 113 & 116 & 110 & 114 & 124 & 168 & 167 & 169 \\
\hline \multicolumn{13}{|c|}{$\mathrm{CO}_{2}$ total } \\
\hline $7 \mathrm{~h}$ & 97 & 98 & 111 & 90 & 87 & 96 & 94 & 96 & 102 & 137 & 132 & 131 \\
\hline $10 \mathrm{~h}$ & 92 & 97 & 112 & 81 & 87 & 89 & 90 & 91 & 104 & 131 & 133 & 132 \\
\hline $13 \mathrm{~h}$ & 95 & 98 & 109 & 80 & 87 & 93 & 85 & 91 & 99 & 132 & 127 & 130 \\
\hline $16 \mathrm{~h}$ & 88 & 88 & 103 & 68 & 86 & 92 & 82 & 87 & 96 & 128 & 128 & 129 \\
\hline \multicolumn{13}{|c|}{ C-inorg. } \\
\hline $7 \mathrm{~h}$ & 26 & 27 & 30 & 25 & 24 & 26 & 26 & 26 & 28 & 37 & 36 & 36 \\
\hline $10 \mathrm{~h}$ & 25 & 26 & 30 & 22 & 24 & 24 & 25 & 25 & 28 & 36 & 36 & 36 \\
\hline $13 \mathrm{~h}$ & 26 & 27 & 30 & 22 & 24 & 25 & 23 & 25 & 27 & 36 & 35 & 35 \\
\hline $16 \mathrm{~h}$ & 24 & 24 & 28 & 19 & 23 & 25 & 22 & 24 & 26 & 35 & 35 & 35 \\
\hline \multicolumn{13}{|l|}{$C O D$} \\
\hline $7 \mathrm{~h}$ & 14,68 & 12,58 & 14,23 & 28,13 & 28,99 & 19,19 & 19,18 & 16,58 & 17,26 & 173,80 & 65,88 & 41,53 \\
\hline $10 \mathrm{~h}$ & 17,18 & 15,84 & 16,24 & 22,76 & 24,71 & 27,81 & 19,72 & 15,52 & 14,87 & 31,46 & 28,60 & 58,07 \\
\hline $13 \mathrm{~h}$ & 22,80 & 16,80 & 12,81 & 24,07 & 23,24 & 26,32 & 18,44 & 15,51 & 47,31 & 28,67 & 77,62 & 19,53 \\
\hline $16 \mathrm{~h}$ & 17,65 & 14,96 & 14,70 & 19,90 & 21,17 & 16,49 & 13,82 & 12,91 & 15,46 & 20,81 & 16,10 & 15,76 \\
\hline \multicolumn{13}{|c|}{$\mathrm{CO}_{2}$ livre } \\
\hline $7 \mathrm{~h}$ & 10,90 & 11,11 & 18,82 & 7,74 & 5,76 & 9,13 & 8,82 & 8,91 & 9,44 & 11,29 & 9,87 & 8,05 \\
\hline $10 \mathrm{~h}$ & 10,62 & 11,87 & 16,80 & 1,35 & 5,06 & 6,38 & 8,26 & 6,37 & 9,42 & 8,04 & 8,89 & 9,16 \\
\hline $13 \mathrm{~h}$ & 10,72 & 12,26 & 18,94 & 0,63 & 5,64 & 8,47 & 1,65 & 5,25 & 8,99 & 8,43 & 6,56 & 7,77 \\
\hline $16 \mathrm{~h}$ & 5,52 & 5,79 & 13,57 & 0,08 & 3,93 & 8,28 & 0,60 & 4,69 & 6,22 & 7,14 & 7,12 & 7,18 \\
\hline \multicolumn{13}{|c|}{$\mathrm{CO}_{3}^{-2}$} \\
\hline $7 \mathrm{~h}$ & 0,12 & 0,12 & 0,08 & 0,15 & 0,20 & 0,14 & 0,14 & 0,14 & 0,15 & 0,23 & 0,25 & 0,31 \\
\hline $10 \mathrm{~h}$ & 0,11 & 0,11 & 0,09 & 0,80 & 0,23 & 0,18 & 0,14 & 0,19 & 0,16 & 0,31 & 0,29 & 0,27 \\
\hline $13 \mathrm{~h}$ & 0,12 & 0,10 & 0,08 & 1,64 & 0,20 & 0,14 & 0,73 & 0,24 & 0,15 & 0,30 & 0,37 & 0,32 \\
\hline $16 \mathrm{~h}$ & 0,21 & 0,21 & 0,10 & 8,07 & 0,29 & 0,14 & 1,81 & 0,25 & 0,22 & 0,34 & 0,34 & 0,34 \\
\hline \multicolumn{13}{|c|}{ Alcalinidade } \\
\hline $7 \mathrm{~h}$ & 107 & 109 & 115 & 103 & 102 & 109 & 107 & 109 & 115 & 157 & 153 & 154 \\
\hline $10 \mathrm{~h}$ & 102 & 106 & 119 & 101 & 103 & 103 & 102 & 106 & 119 & 154 & 156 & 154 \\
\hline $13 \mathrm{~h}$ & 105 & 107 & 112 & 100 & 102 & 106 & 105 & 107 & 112 & 155 & 151 & 153 \\
\hline $16 \mathrm{~h}$ & 103 & 103 & 112 & 92 & 102 & 105 & 103 & 103 & 112 & 152 & 151 & 153 \\
\hline \multicolumn{13}{|l|}{$p H$} \\
\hline $7 \mathrm{~h}$ & 7,20 & 7,20 & 7,00 & 7,35 & 7,47 & 7,30 & 7,32 & 7,32 & 7,32 & 7,39 & 7,44 & 7,53 \\
\hline $10 \mathrm{~h}$ & 7,19 & 7,16 & 7,06 & 8,09 & 7,53 & 7,43 & 7,32 & 7,45 & 7,33 & 7,53 & 7,49 & 7,47 \\
\hline $13 \mathrm{~h}$ & 7,20 & 7,15 & 6,98 & 8,41 & 7,48 & 7,32 & 8,02 & 7,53 & 7,32 & 7,51 & 7,61 & 7,54 \\
\hline $16 \mathrm{~h}$ & 7,48 & 7,46 & 7,13 & 9,20 & 7,64 & 7,33 & 8,44 & 7,57 & 7,47 & 7,58 & 7,58 & 7,58 \\
\hline
\end{tabular}

$\mathrm{HCO}_{3}{ }^{-}$: bicarbonato; $\mathrm{CO}_{2}$ total: dióxido de carbono total; C-inorg.: carbono inorgânico; COD; carbono orgânico dissolvido; $\mathrm{CO}_{2}$ livre: dióxido de carbono livre $; \mathrm{CO}_{3}{ }^{-2}$ : carbonato. 
Tabela 7: Formas de carbono, alcalinidade $\left(\mathrm{mg}^{\mathrm{L}} \mathrm{L}^{-1}\right)$ e $\mathrm{pH}$, na lagoa facultativa da ETE de Jacupiranga (SS: sub-superfície, M: meio e F: interface água-sedimento).

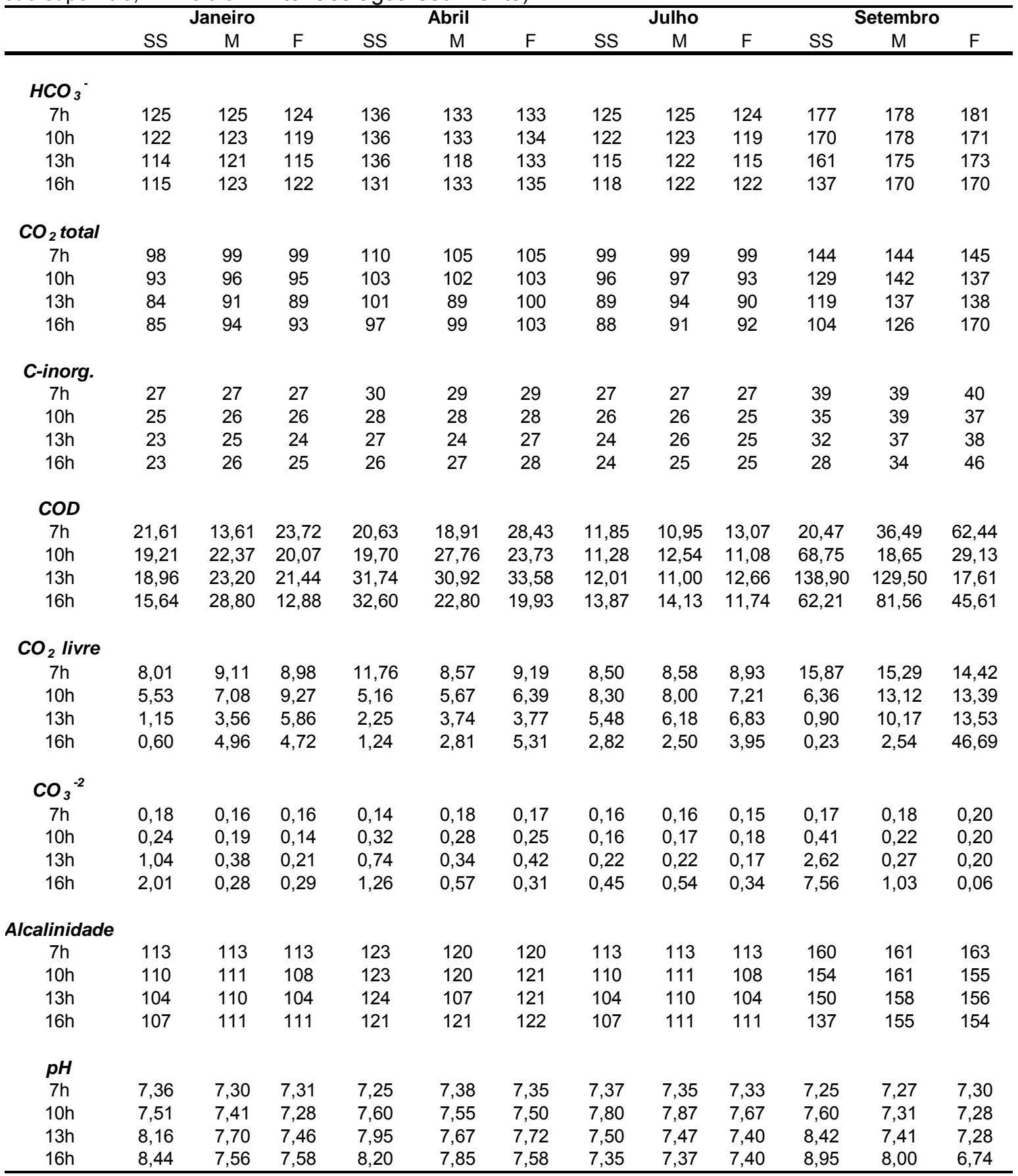

$\mathrm{HCO}_{3}{ }^{-}$: bicarbonato; $\mathrm{CO}_{2}$ total: dióxido de carbono total; C-inorg: carbono inorgânico; COD: carbono orgânico dissolvido; $\mathrm{CO}_{2}$ livre: dióxido de carbono livre $; \mathrm{CO}_{3}^{-2}$ : carbonato.

\subsubsection{Nutrientes}

As concentrações de nitrogênio amoniacal ( $\mathrm{N}$-amoniacal) permaneceram semelhantes nas amostragens de janeiro e abril, com concentrações que variaram entre 6 e $11 \mathrm{mg} \cdot \mathrm{L}^{-1}$ na lagoa de Pariquera-Açu; e entre 10 e $14 \mathrm{mg} \cdot \mathrm{L}^{-1}$, na de Jacupiranga. Nas amostragens de julho e setembro seguiram os mesmos padrões observados anteriormente, ou seja, as concentrações de $\mathrm{N}$-amoniacal não variaram nestes períodos, 
porém foram mais altas que em janeiro e abril (entre 17 e $21 \mathrm{mg} \cdot \mathrm{L}^{-1}$ em Pariquera-Açu e 14 e 20 mg. L $^{-1}$ em Jacupiranga).

Não foram observadas variações horária e vertical entre os períodos de amostragens, exceto às $13 \mathrm{~h}$, na interface água-sedimento da lagoa facultativa da ETE de Jacupiranga. Neste horário, na interface água-sedimento, foi observada a menor concentração de $\mathrm{N}$-amoniacal, em julho $\left(7 \mathrm{mg} \cdot \mathrm{L}^{-1}\right)$, se comparada aos outros horários amostrados. Em setembro, neste horário, foi observado pico de $36 \mathrm{mg} \cdot \mathrm{L}^{-1}$ (interface águasedimento).

As concentrações de nitrogênio total Kjeldahl (NTK), apresentada na Figura 18, seguiram o mesmo padrão observado para as de $\mathrm{N}$-amoniacal, ou seja, as menores concentrações ocorreram em janeiro e abril, e as maiores em julho e setembro, nas duas lagoas estudadas. As concentrações de NTK em janeiro e abril estiveram entre $11 \mathrm{e}$ 18,76 mg.L - $^{-1}$ em Pariquera-Açu; e entre 14,09 e 19,51 mg. L $^{-1}$ em Jacupiranga. Nos outros períodos (julho e setembro), essas concentrações estiveram entre 19,51 e 27,23 mg.L-1 em Pariquera-Açu; e entre 23,15 e 29,45 mg. $\mathrm{L}^{-1}$ em Jacupiranga. Também não foram observadas variações entre os horários e as profundidades amostradas.

As maiores concentrações de nitrato foram observadas em setembro, nas duas lagoas amostradas; concentrações ligeiramente mais elevadas ocorreram na lagoa facultativa de Jacupiranga. Também não foram observadas variações horárias e verticais nos períodos amostrados (Figura 19). No mês de janeiro, na lagoa facultativa de Pariquera-Açu, foram obtidas as menores concentrações desta variável (entre 0,41 e 0,62 $\mathrm{mg} \cdot \mathrm{L}^{-1}$ ) e no mês de setembro, as maiores (entre 2,44 e 2,64 mg. $\mathrm{L}^{-1}$ ). Na lagoa facultativa de Jacupiranga, as menores concentrações foram observadas em abril (entre 0,57 e 0,62 $\left.\mathrm{mg} \cdot \mathrm{L}^{-1}\right)$ e as maiores, em setembro chegando próximo de $3 \mathrm{mg} \cdot \mathrm{L}^{-1}$.

$\mathrm{Na}$ Figura 20 podem ser observadas as concentrações de nitrito, obtidas nas duas lagoas. Variações sazonal e diária foram verificadas em ambas.

$\mathrm{Na}$ lagoa de Pariquera-Açu, as concentrações de nitrito foram menores que as de Jacupiranga, exceto às $7 \mathrm{~h}$, em abril. Em janeiro, julho e setembro, as concentrações de nitrito não ultrapassaram a concentração de $5 \mathrm{mg} \cdot \mathrm{L}^{-1}$, enquanto que em abril houve variação de 1,91 a $14,94 \mathrm{mg} \cdot \mathrm{L}^{-1}$.

$\mathrm{Na}$ lagoa de Jacupiranga, foram observadas as maiores concentrações de nitrito, sendo que a máxima foi obtida na interface água-sedimento da lagoa, em julho, às $7 \mathrm{~h}$ $\left(20,04 \mathrm{mg} \cdot \mathrm{L}^{-1}\right)$ e a mínima, em setembro, na sub-superfície, às $10 \mathrm{~h}\left(5,24 \mathrm{mg} \cdot \mathrm{L}^{-1}\right)$. Nesta lagoa observou-se variação sazonal, mas não horária e vertical. No mês de julho, as concentrações de nitrito estiveram próximas à $15,05 \mathrm{mg} \cdot \mathrm{L}^{-1}$, seguido por janeiro e abril, quando estiveram próximos à $10 \mathrm{mg} \cdot \mathrm{L}^{-1}$; em setembro, estiveram abaixo de $6,30 \mathrm{mg} \cdot \mathrm{L}^{-1}$. 


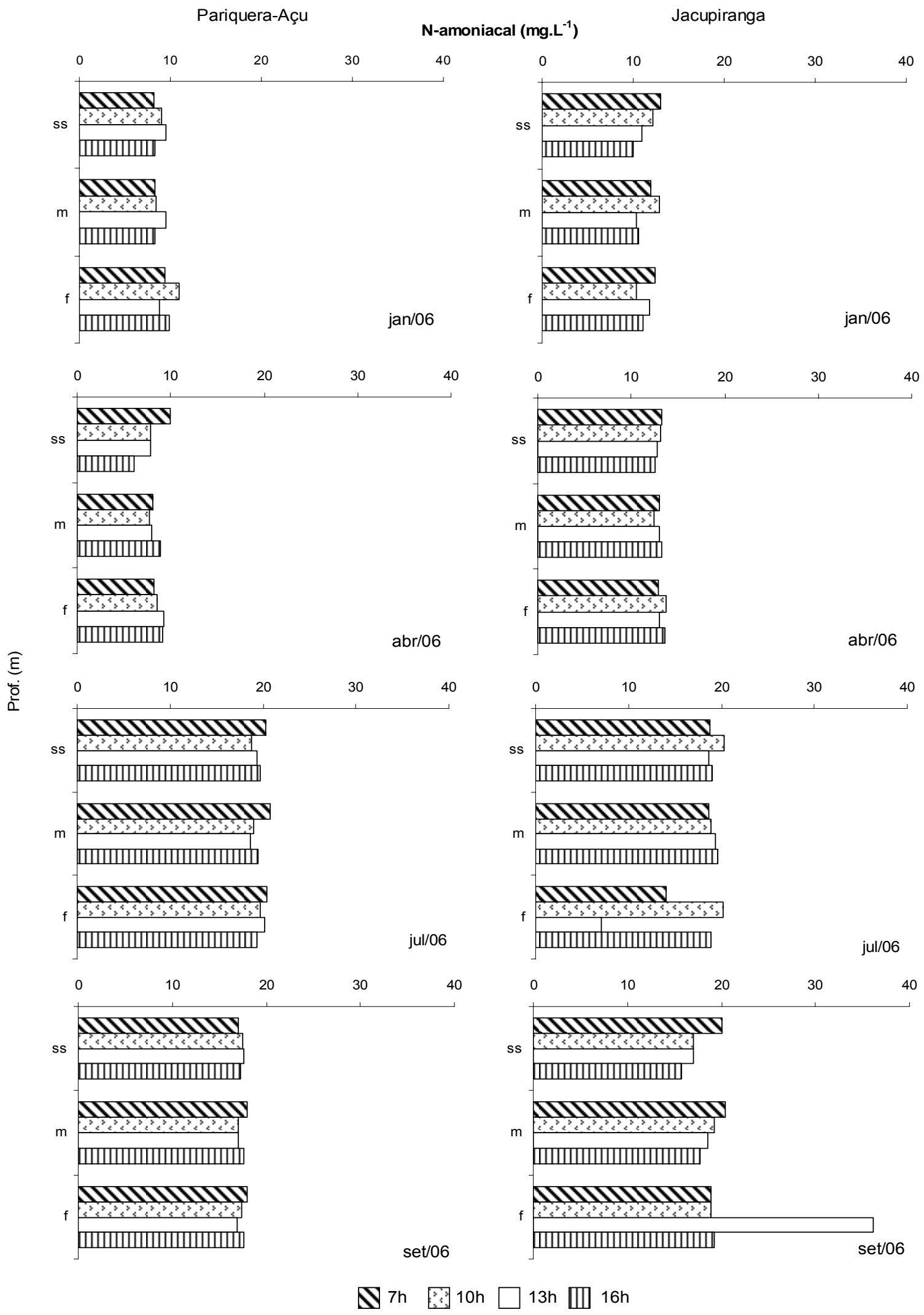

Figura 17: Concentrações de $\mathrm{N}$-amoniacal $\left(\mathrm{mg} \cdot \mathrm{L}^{-1}\right)$, nas lagoas facultativas das ETEs de Pariquera-Açu e Jacupiranga (ss: sub-superfície, m: meio e f: interface água-sedimento), em diferentes épocas do ano. 


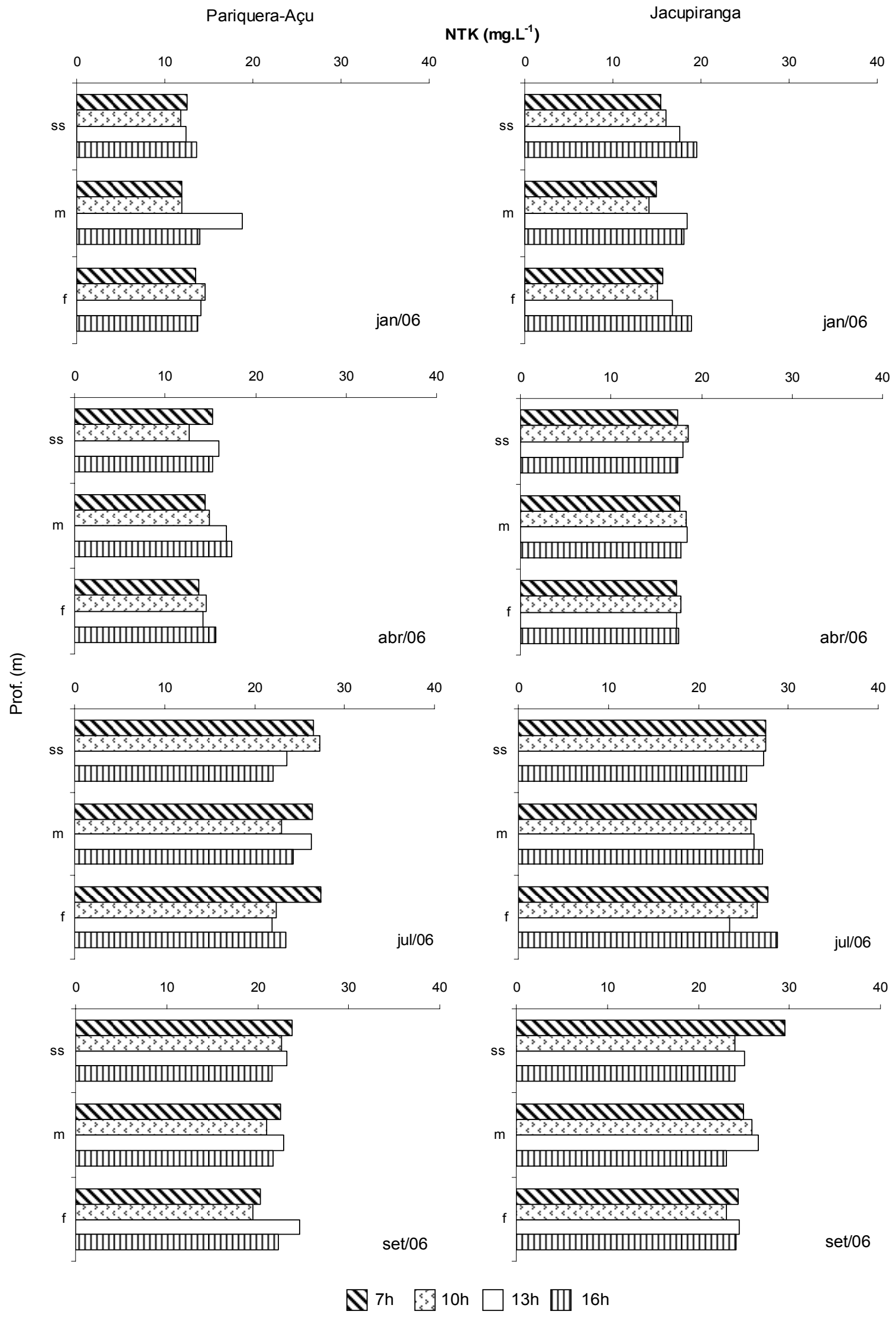

Figura 18: Concentrações de Nitrogênio Total Kjedahl - NTK $\left(\mathrm{mg} \cdot \mathrm{L}^{-1}\right)$, nas lagoas facultativas das ETEs de Pariquera-Açu e Jacupiranga (ss: sub-superfície, m: meio e f: interface água-sedimento), em diferentes épocas do ano. 


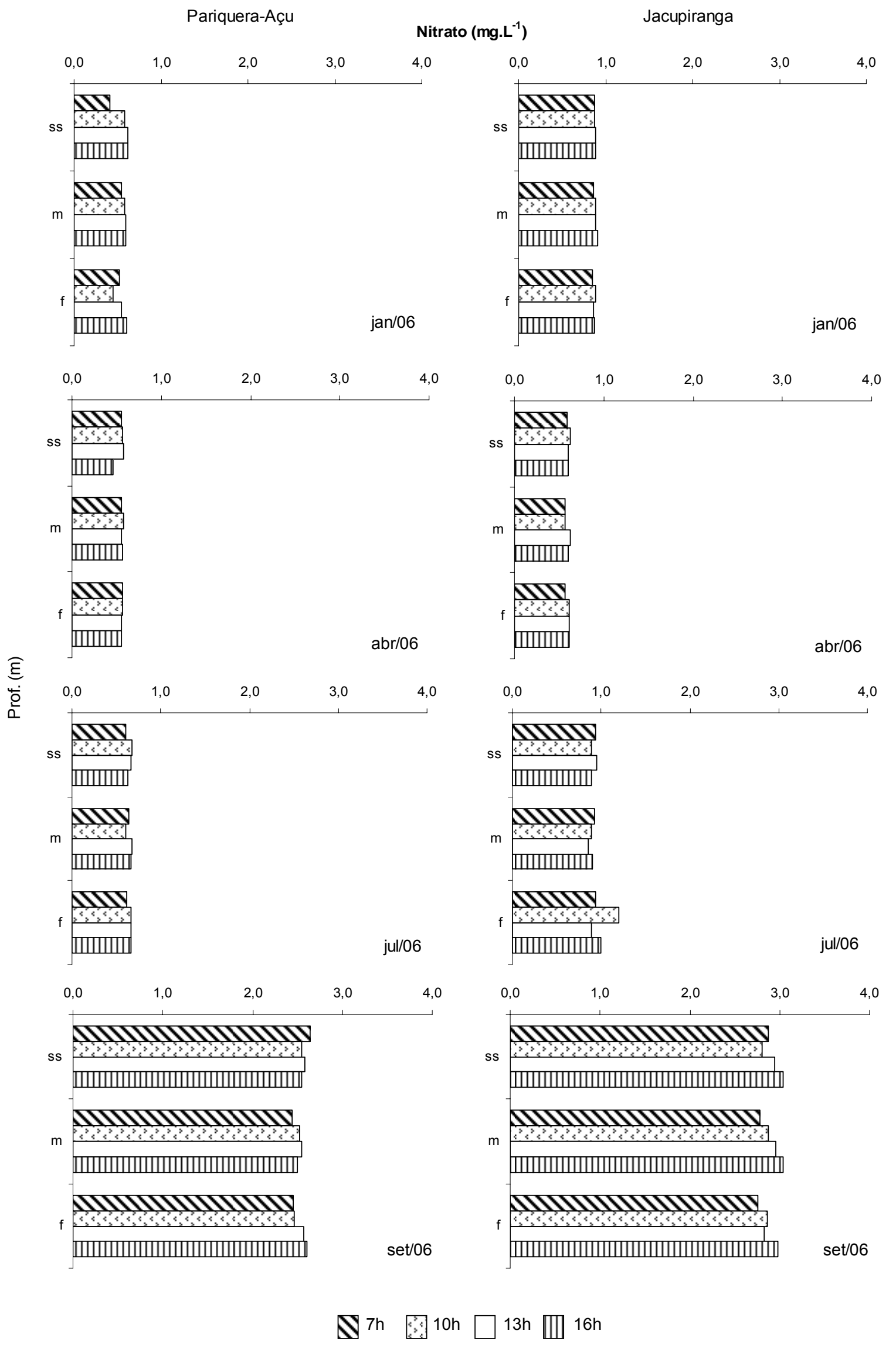

Figura 19: Concentrações de Nitrato $\left(\mathrm{mg}^{-\mathrm{L}^{-1}}\right)$, nas lagoas facultativas das ETEs de Pariquera-Açu e Jacupiranga (ss: sub-superfície, m: meio e f: interface água-sedimento), em diferentes épocas do ano. 


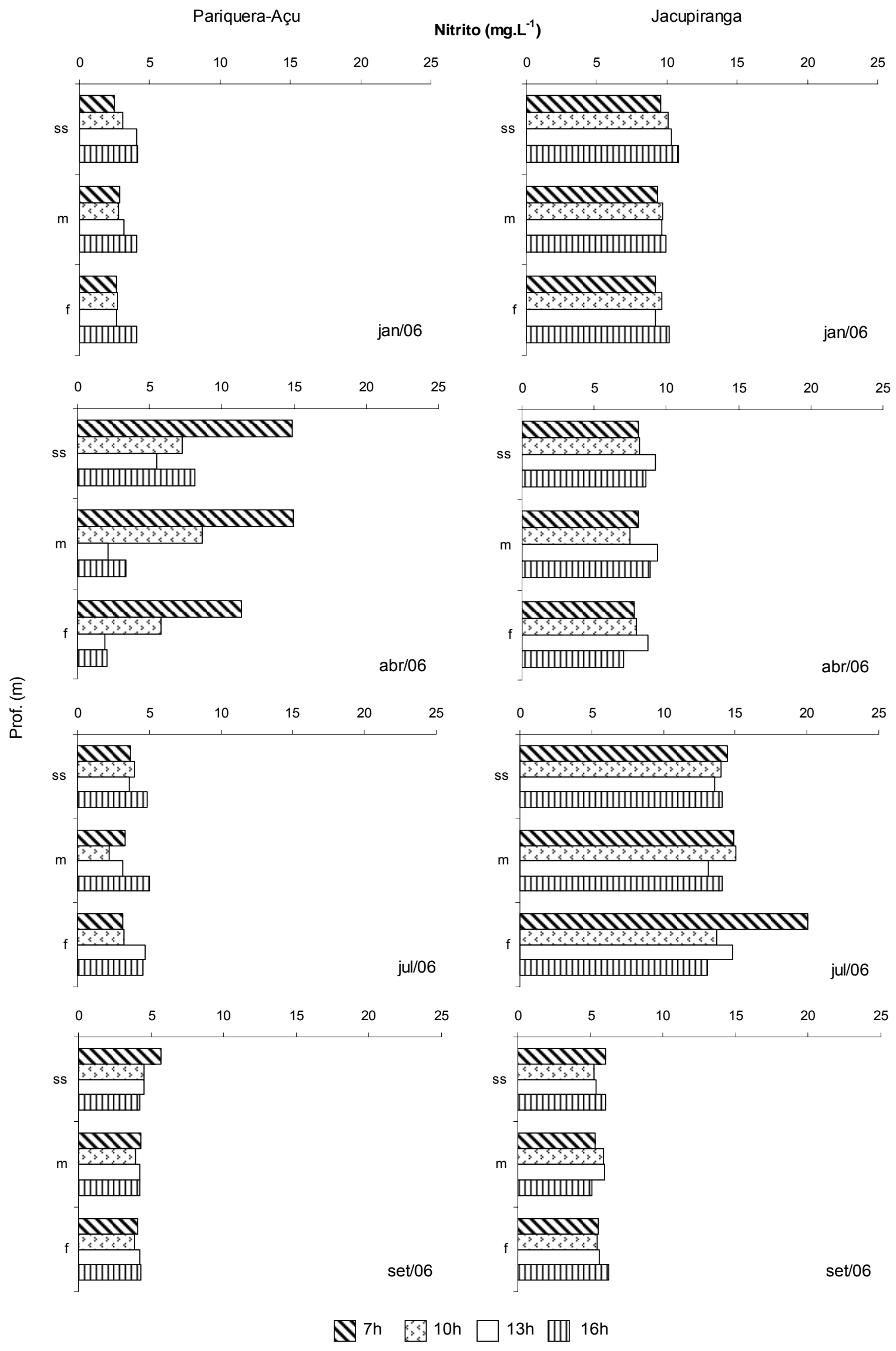

Figura 20: Concentrações de Nitrito $\left(m g \cdot \mathrm{L}^{-1}\right)$, nas lagoas facultativas das ETEs de Pariquera-Açu e Jacupiranga (ss: sub-superfície, m: meio e f: interface água-sedimento), em diferentes épocas do ano. 
Em janeiro e setembro, na lagoa de Pariquera-Açu, variações sazonais, horárias e verticais foram observadas para as concentrações de ortofosfato; e em julho e setembro, para a lagoa de Jacupiranga.

Na lagoa facultativa do sistema de Pariquera-Açu, setembro foi o período no qual foram observadas as maiores concentrações de ortofosfato (entre 0,44 e 1,47 mg. $\mathrm{L}^{-1}$, no meio, às $10 \mathrm{~h}$ e $13 \mathrm{~h}$, respectivamente). As menores concentrações foram observadas em abril, entre 0,20 e $0,44 \mathrm{mg} \cdot \mathrm{L}^{-1}$, às $13 \mathrm{~h}$, na interface água-sedimento e no meio da coluna de água, respectivamente. Foram observadas variações verticais às $16 \mathrm{~h}$, em janeiro $\left(1,11 ; 0,84\right.$ e $\left.0,61 \mathrm{mg} \cdot \mathrm{L}^{-1}\right)$ e em todas as amostragens de setembro, exceto às $7 \mathrm{~h}$.

$\mathrm{Na}$ lagoa de Jacupiranga, as maiores concentrações de ortofosfato foram verificadas em julho, entre 0,87 (meio, 10h) e 1,65 mg. $\mathrm{L}^{-1}$ (sub-superfície, 16h); e as menores ocorreram em janeiro, entre 0,35 (interface água-sedimento, 13h) e 0,49 mg. $\mathrm{L}^{-1}$ (sub-superfície, 16h). Em julho, verificou-se variação vertical, às 16h, e em setembro, às 10, 13 e $16 \mathrm{~h}$.

Na Tabela 8 estão apresentadas as proporções de C:N:P obtidas nas lagoas facultativas de Pariquera-Açu e Jacupiranga. Entretanto, é preciso considerar que a proporção apresentada foi estimada usando-se as concentrações dissolvidas dos nutrientes. Na lagoa facultativa de Pariquera-Açu, em abril, foram observadas as maiores relações de C:N:P, entre 415:39:1 e 1034:21:1 (16h, ss e 13h, f; respectivamente); e em setembro as menores entre 188:8:1 e 655:26:1 (m, 13h e 10h, respectivamente).

Enquanto que na lagoa facultativa de Jacupiranga, as maiores relações de C:N:P, foram em setembro, entre 272:19:1(16h, ss) e 791:37:1 (7h, f); e em julho as menores entre 116:15:1 (16h, ss) e 241:30:1 (10h, m). 


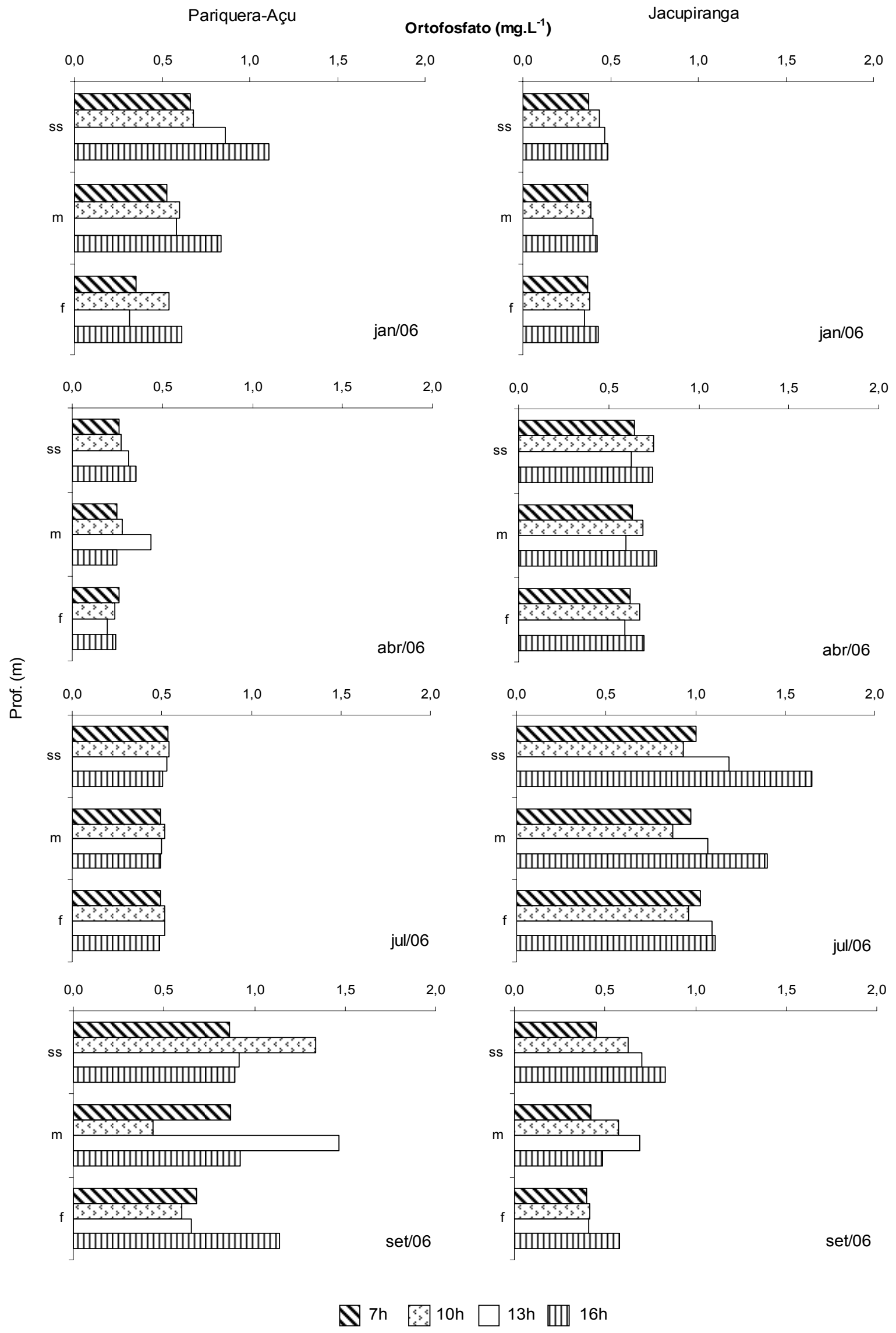

Figura 21: Concentrações de Ortofosfato $\left(m g \cdot \mathrm{L}^{-1}\right)$, nas lagoas facultativas das ETEs de Pariquera-Açu e Jacupiranga (ss: sub-superfície, m: meio e f: interface água-sedimento), em diferentes épocas do ano. 
Tabela 8: Relação C:N:P (Carbono: Nitrogênio: Fósforo), em mol.L-1 ${ }^{-1}$, nas lagoas facultativas das ETEs de Pariquera-Açu e Jacupiranga (ss: sub-superfície, $\mathrm{m}$ : meio e f: interface água-sedimento), em diferentes épocas do ano

\begin{tabular}{|c|c|c|c|c|c|c|c|}
\hline & & \multicolumn{3}{|c|}{ Pariquera-Açu } & \multicolumn{3}{|c|}{ Jacupiranga } \\
\hline & & SS & $M$ & $\mathrm{~F}$ & SS & $\mathrm{M}$ & $\mathrm{F}$ \\
\hline \multirow{4}{*}{ Janeiro } & $7 \mathrm{~h}$ & $318: 7: 1$ & $403: 11: 1$ & $682: 15: 1$ & $571: 46: 1$ & $584: 45: 1$ & $578: 44: 1$ \\
\hline & $10 \mathrm{~h}$ & 296:9:1 & $350: 9: 1$ & $415: 10: 1$ & $466: 41: 1$ & $537: 45: 1$ & $540: 45: 1$ \\
\hline & $13 \mathrm{~h}$ & $239: 9: 1$ & $364: 11: 1$ & $752: 17: 1$ & $391: 39: 1$ & $499: 43: 1$ & $545: 46: 1$ \\
\hline & $16 \mathrm{~h}$ & $172: 7: 1$ & 229:9:1 & $366: 13: 1$ & $380: 39: 1$ & $480: 42: 1$ & $467: 42: 1$ \\
\hline \multirow{4}{*}{ Abril } & $7 \mathrm{~h}$ & $757: 96: 1$ & 756:100:1 & $812: 75: 1$ & $370: 22: 1$ & $359: 22: 1$ & $370: 22: 1$ \\
\hline & $10 \mathrm{~h}$ & $646: 47: 1$ & $677: 54: 1$ & $810: 44: 1$ & $300: 19: 1$ & $320: 19: 1$ & $332: 21: 1$ \\
\hline & $13 \mathrm{~h}$ & $556: 32: 1$ & $431: 10: 1$ & $1034: 21: 1$ & $349: 26: 1$ & $323: 27: 1$ & $366: 26: 1$ \\
\hline & $16 \mathrm{~h}$ & 415:39:1 & $760: 27: 1$ & 818:18:1 & $282: 20: 1$ & $281: 20: 1$ & $321: 18: 1$ \\
\hline \multirow{4}{*}{ Julho } & $7 \mathrm{~h}$ & 382:13:1 & 421:13:1 & 448:13:1 & 213:25:1 & $220: 26: 1$ & 209:33:1 \\
\hline & $10 \mathrm{~h}$ & $363: 14: 1$ & $381: 9: 1$ & $440: 13: 1$ & $224: 26: 1$ & $241: 30: 1$ & $210: 25: 1$ \\
\hline & $13 \mathrm{~h}$ & $351: 14: 1$ & $397: 13: 1$ & 419:17:1 & $163: 20: 1$ & $192: 21: 1$ & 179:23:1 \\
\hline & $16 \mathrm{~h}$ & $351: 18: 1$ & $382: 19: 1$ & 430:18:1 & $116: 15: 1$ & $141: 17: 1$ & $180: 21: 1$ \\
\hline \multirow{4}{*}{ Setembro } & $7 \mathrm{~h}$ & $344: 17: 1$ & $329: 14: 1$ & $417: 17: 1$ & $695: 35: 1$ & $743: 34: 1$ & $791: 37: 1$ \\
\hline & $10 \mathrm{~h}$ & 213:9:1 & $655: 26: 1$ & $478: 19: 1$ & $447: 23: 1$ & $534: 27: 1$ & $718: 35: 1$ \\
\hline & $13 \mathrm{~h}$ & $313: 14: 1$ & 188:8:1 & 433:19:1 & $367: 21: 1$ & $427: 23: 1$ & $735: 36: 1$ \\
\hline & $16 \mathrm{~h}$ & $312: 13: 1$ & $302: 13: 1$ & $246: 11: 1$ & $272: 19: 1$ & $566: 30: 1$ & $636: 28: 1$ \\
\hline
\end{tabular}

\subsubsection{Sólidos em Suspensão}

A média das concentrações de SST está representada na Figura 22. A fração orgânica (SSO) representou a maior parte dos sólidos presentes em ambas as lagoas (entre 82 e 98\%). Na lagoa facultativa de Pariquera-Açu, as maiores concentrações de SSO ocorreram em janeiro $\left(64,1 \mathrm{mg} \cdot \mathrm{L}^{-1}\right)$ e julho $\left(66,8 \mathrm{mg} \cdot \mathrm{L}^{-1}\right)$, e as menores em abril $\left(44,2 \mathrm{mg} \cdot \mathrm{L}^{-1}\right)$ e setembro $\left(45,4 \mathrm{mg} \cdot \mathrm{L}^{-1}\right)$.

As concentrações da fração inorgânica (SSI) foram maiores em janeiro, abril e julho (9,6; 9,9 e 6,6 mg. $\mathrm{L}^{-1}$, respectivamente) e menor em setembro $\left(1,1 \mathrm{mg} \cdot \mathrm{L}^{-1}\right)$.

$\mathrm{Na}$ lagoa de Jacupiranga foi observada variação sazonal nas concentrações de SSO e SSI. As maiores concentrações destas variáveis foram observadas em julho e setembro. Nestes períodos, a fração orgânica esteve entre 76,3 e 95,2 mg.L $\mathrm{L}^{-1}$ e a inorgânica entre 5,2 e 11,8 mg. $\mathrm{L}^{-1}$. Por outro lado, as menores concentrações foram observadas em janeiro e abril, sendo que a fração orgânica esteve entre 48,2 e $43,2 \mathrm{mg} \cdot \mathrm{L}^{-1}$; e a inorgânica entre 4,3 e $1,7 \mathrm{mg} \cdot \mathrm{L}^{-1}$. 


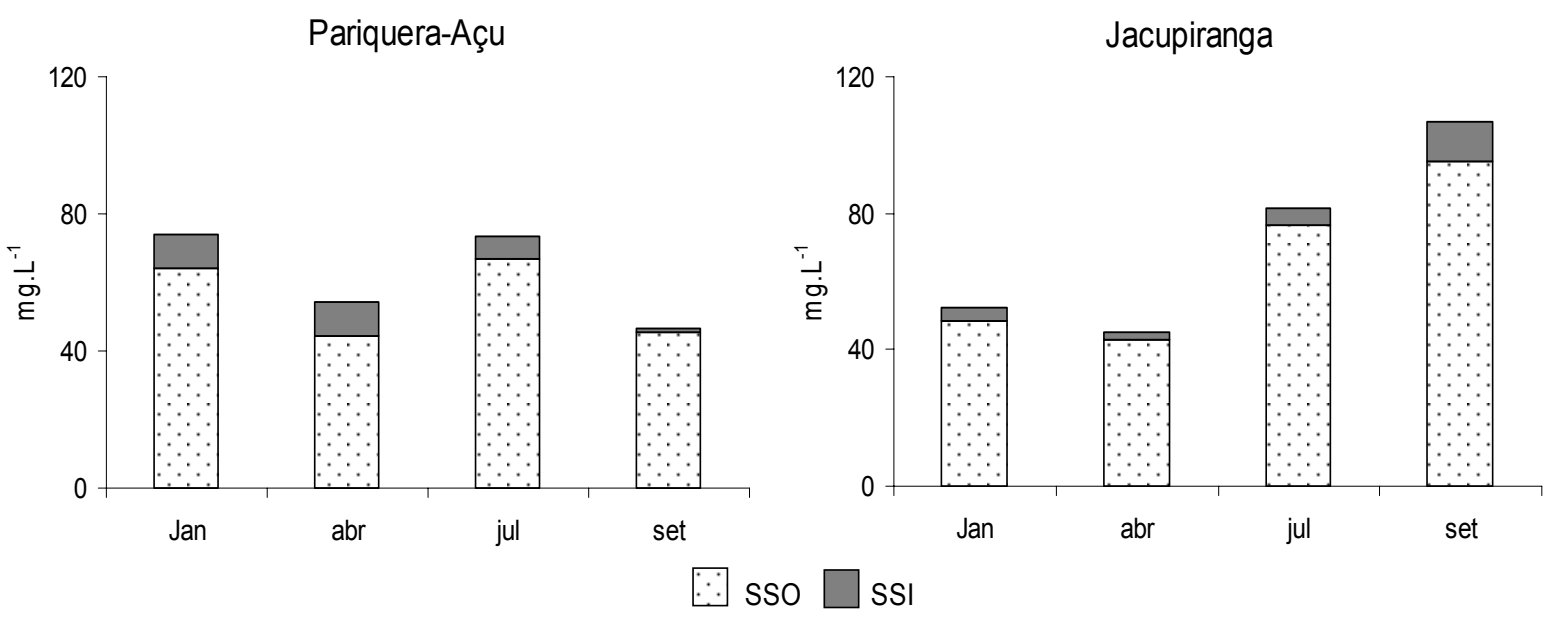

Figura 22: Média das concentrações (n:12) de Sólidos Suspensos Orgânicos e Inorgânicos (SSO e SSI) (mg. $\mathrm{L}^{-1}$ ), nas lagoas facultativas das ETEs de Pariquera-Açu e Jacupiranga, em diferentes épocas do ano.

A distribuição dos sólidos suspensos orgânicos (SSO) na coluna de água e nos diferentes horários é mostrada na Figura 23. Foram observadas variações sazonais nas concentrações desta fração, enquanto que as variações horária e vertical ocorreram apenas em abril, na lagoa de Pariquera-Açu. Neste período, a menor concentração de SSO foi observada às $7 \mathrm{~h}$ (14 mg. $\mathrm{L}^{-1}$, interface água-sedimento) e a maior, às $16 \mathrm{~h}$ (85 $m g . L^{-1}$, na sub-superfície). Nos meses de julho e setembro não foram observadas variações horária e vertical e as concentrações ficaram entre 52 e $78,5 \mathrm{mg} \cdot \mathrm{L}^{-1}$ e entre 40,5 e $56 \mathrm{mg} \cdot \mathrm{L}^{-1}$, respectivamente, ocorrendo apenas pico de $91 \mathrm{mg} \cdot \mathrm{L}^{-1}$, às $13 \mathrm{~h}$ (meio), em julho.

$\mathrm{Na}$ lagoa de Jacupiranga também foram observadas variações sazonais de SSO em todo o período amostrado e variação horária, principalmente em janeiro. Neste período, a menor concentração foi obtida às $7 \mathrm{~h}\left(35,5 \mathrm{mg} \cdot \mathrm{L}^{-1}\right.$, meio) e a maior, às $16 \mathrm{~h} \mathrm{(66}$ $m g \cdot L^{-1}$, sub-superfície). Em abril não ocorreram variações horária e vertical e as concentrações variaram entre 37,5 (7h) e 49,5 mg. $\mathrm{L}^{-1}$ (16h), ambas na sub-superfície. Em julho e setembro, não foi observada variação vertical e as concentrações estiveram próximas à 75 e $100 \mathrm{mg} \cdot \mathrm{L}^{-1}$, respectivamente.

Os sólidos suspensos inorgânicos (SSI) representaram pequena porcentagem (entre 2 e 13\%) em relação ao SST. Na lagoa facultativa de Pariquera-Açu, as maiores concentrações de SSI ocorreram em abril, às $13 \mathrm{~h}$ (23 mg. $\mathrm{L}^{-1}$, interface água-sedimento) e as menores, em setembro, entre 0,5 (7 e 16, interface água-sedimento; 13h, subsuperfície e meio) e $3,5 \mathrm{mg} \cdot \mathrm{L}^{-1}$ (7h, meio).

Foram observadas variações sazonais, horárias e verticais, exceto em setembro. A maior variação horária e vertical ocorreu em abril, às $13 \mathrm{~h}$, quando as concentrações 
obtidas variaram entre 10 e $23 \mathrm{mg} \cdot \mathrm{L}^{-1}$, na sub-superfície e na interface água-sedimento, respectivamente.

Também foram observadas variações sazonal, horária e vertical em todo o período amostrado, na lagoa facultativa de Jacupiranga. As menores concentrações de SSI foram obtidas no mês de abril e variaram de 0,5 (10h, sub-superfície e 13h, interface água-sedimento) a $4 \mathrm{mg} \cdot \mathrm{L}^{-1}$ (7h, sub-superfície e meio). Enquanto que as maiores ocorreram em setembro e variaram de 10 (10h, meio e 13h, interface água-sedimento) a $14,5 \mathrm{mg} \cdot \mathrm{L}^{-1}$ (13h, sub-superfície). 

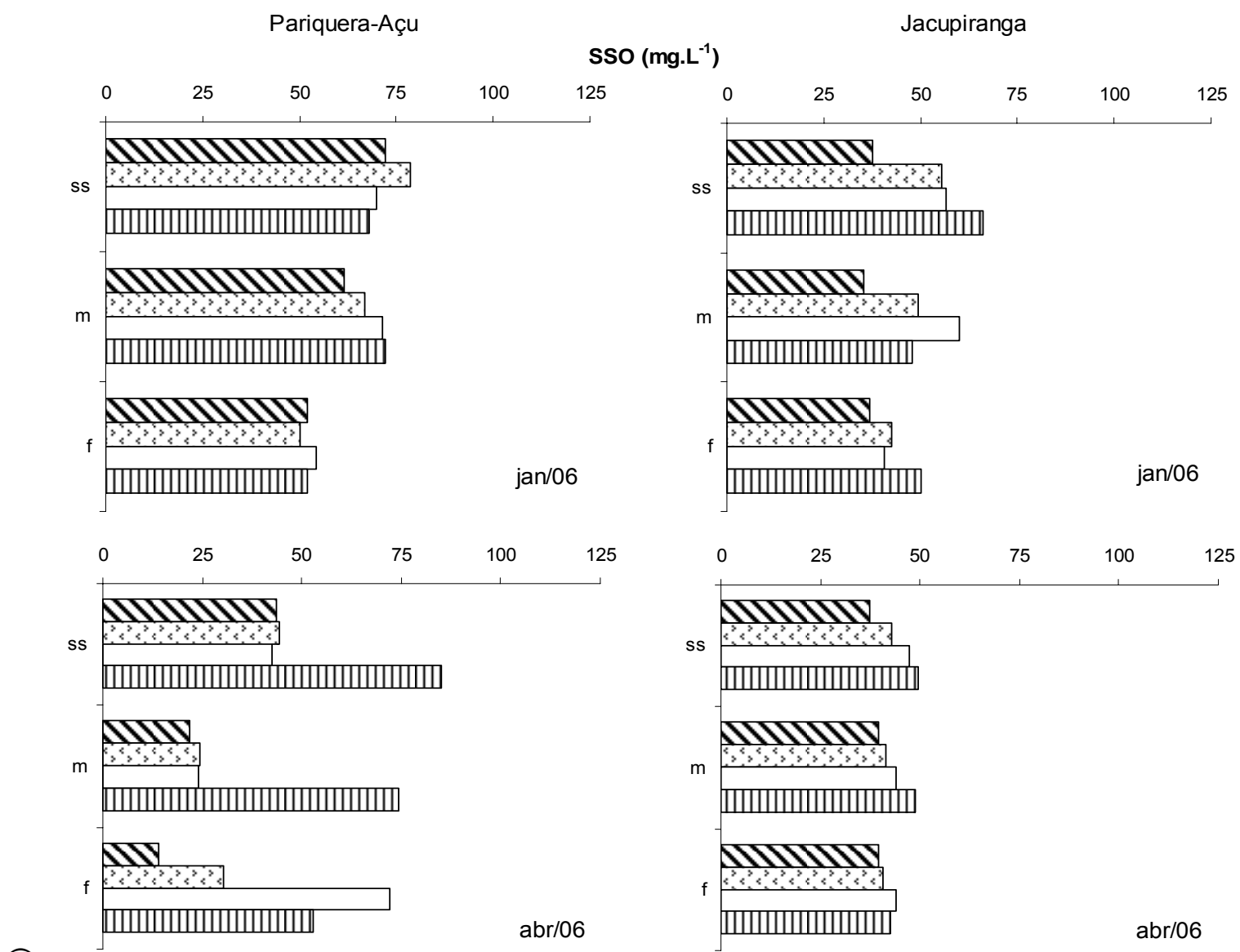

$\begin{array}{llllll}0 & 25 & 50 & 75 & 100 & 125\end{array}$

ss

सापालाए

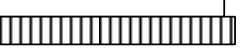

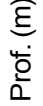

\begin{tabular}{cccccc}
0 & 25 & 50 & 75 & 100 & 125 \\
\hline
\end{tabular}

ss

MIIIIIIIIIIIIIV

s

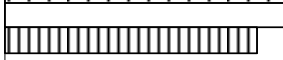

MIIIIIIIIIV

$\mathrm{m}$

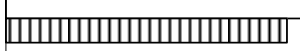

MINININININ

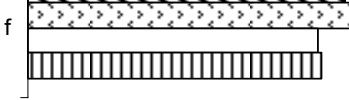

jul/06

(3)

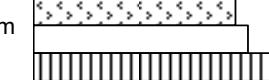

mann-m

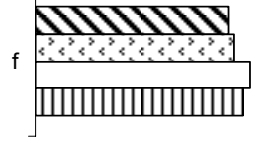

$\mathrm{abr} / 06$

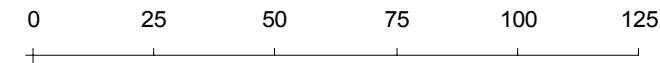

ss

\section{S1111IIIIIII}

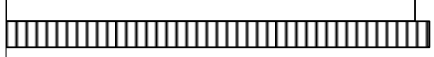

MIIIIIIIIIIII

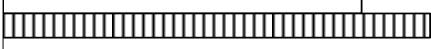

MIIIIIIIIIIIII

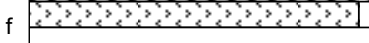

ரाएा

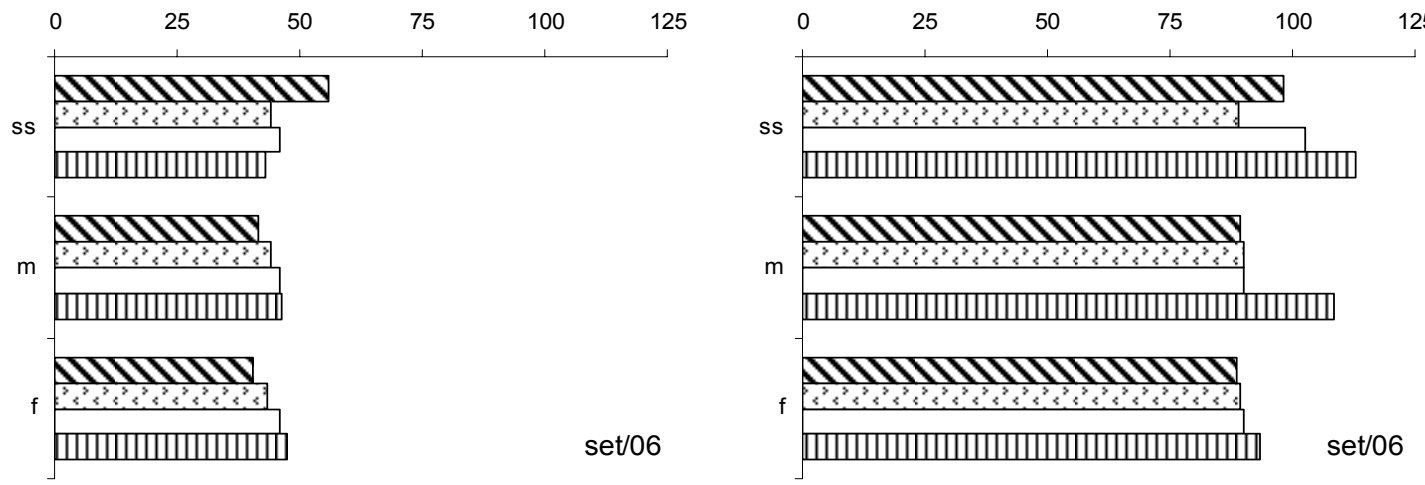

N7h $\quad \square$ 10h

Figura 23: Concentrações de Sólidos Suspensos Orgânicos - SSO (mg. $\left.\mathrm{L}^{-1}\right)$, nas lagoas facultativas das ETEs de Pariquera-Açu e Jacupiranga (ss: sub-superfície, m: meio e f: interface água-sedimento), em diferentes épocas do ano. 


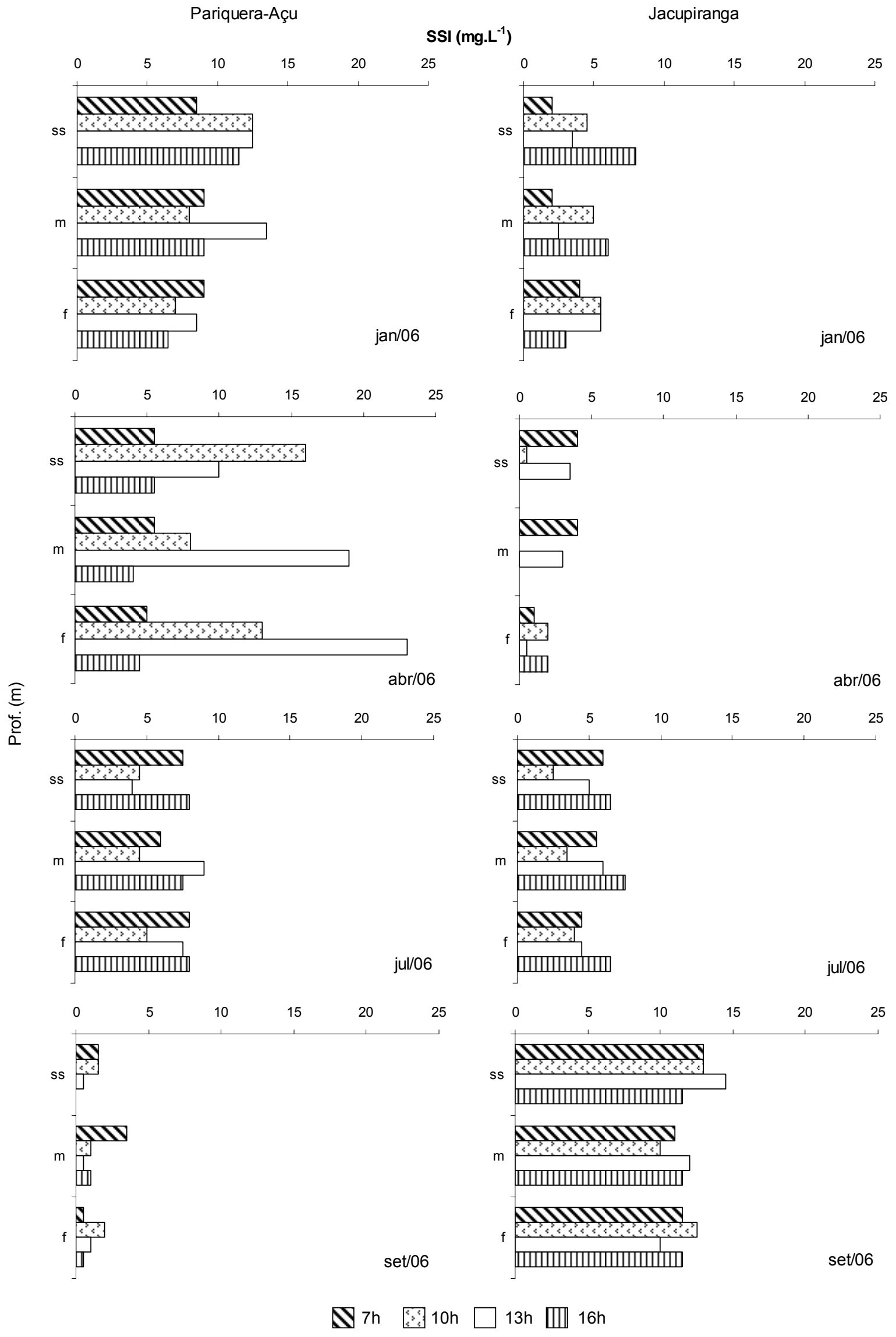

Figura 24: Concentrações de Sólidos Suspensos Inorgânicos - SSI (mg. $\left.\mathrm{L}^{-1}\right)$, nas lagoas facultativas das ETEs de Pariquera-Açu e Jacupiranga (ss: sub-superfície, m: meio e f: interface água-sedimento), em diferentes épocas do ano. 


\subsection{Variáveis Bióticas}

\subsubsection{Determinação da biomassa fitoplanctônica por contagem direta}

Na lagoa facultativa da estação de tratamento de esgoto de Pariquera-Açu, foram identificados 72 taxa em todo o período amostrado, sendo que destes, 14 pertenceram ao grupo das cianobactérias, 44 ao das clorofíceas, 3 ao das euglenofíceas, 6 ao das criptofíceas e 4 ao das bacilariofíceas. Na lagoa de Jacupiranga, foram identificados 73 taxa, dos quais 17 pertenceram ao grupo das cianobactérias, 39 ao das clorofícea, 4 ao das euglenofíceas, 8 ao das criptofíceas e 5 ao das bacilariofíceas. As espécies e gêneros identificados de cianobactéria estão presentes na Tabela 9, enquanto os de euglenofícea, bacilariofícea e criptofícea são apresentados na Tabela 10 e clorofícea na Tabela 11.

Tabela 9: Gêneros e espécies de Cianobactérias presentes nas lagoas facultativas das ETEs de Pariquera-Açu (PA) e Jacupiranga (JA).

\begin{tabular}{lll|lcc}
\hline Cianobactéria & PA & JA & Cianobactéria & PA & JA \\
\hline Aphanocapsa minutíssima & ++ & - & Merismopedia punctata & ++ & ++ \\
\hline Aphanocapsa sp & ++ & ++ & Nostoc kihlmani & - & ++ \\
\hline Aphanotece castagnei & ++ & ++ & Phormidium sp & ++ & ++ \\
\hline Aphanotece comassi & ++ & ++ & Pseudoanabaena moliniformis & ++ & ++ \\
\hline Células livres de Microsystis & ++ & ++ & Romeria gracilis & ++ & ++ \\
\hline Chroccocus turgidus & - & ++ & Spirulina meneghiniana & - & ++ \\
\hline Cianobactéria não identificada 1 & ++ & ++ & Synechococus leopoliensis & - & ++ \\
\hline Lyngbia sp & ++ & ++ & Synechococus SP & ++ & ++ \\
\hline Merismopedia glauca & ++ & ++ & Synechocystis aquatilis & ++ & ++ \\
\hline
\end{tabular}

(++) gênero ou espécie presente, (-) gênero ou espécie ausente.

Tabela 10: Gêneros e espécies de Euglenofíceas, Bacilariofíceas e Criptofíceas presentes nas lagoas facultativas das ETEs de Pariquera-Açu (PA) e Jacupiranga (JA).

\begin{tabular}{lcc|lcc}
\hline Euglenofícea & PA & JA & Criptofícea & PA & JA \\
\hline Euglena acus & - & ++ & Chilomonas oblonga & ++ & - \\
\hline Euglena spirogyra & - & ++ & Chilomonas paramecium & ++ & ++ \\
\hline Phacus curvicauda & ++ & ++ & Cryptomonas brasiliensis & ++ & ++ \\
\hline Phacus longicauda & ++ & - & Cryptomonas erosa & - & ++ \\
\hline Trachelomonas oblonga & ++ & ++ & Cryptomonas ovata & - & ++ \\
\hline Bacilariofícea & & & Cryptomonas sp & - & ++ \\
\hline Amphora ovalis & ++ & ++ & Cryptomonas tenuis & ++ & ++ \\
\hline Bacillariofícea não identificada & ++ & ++ & Cyanomonas americana & - & ++ \\
\hline Cyclotella sp & ++ & ++ & Cyathomonas truncata & ++ & - \\
\hline Navícula sp & ++ & ++ & Phanonephos dispar & - & ++ \\
\hline Nitszhia sp & - & ++ & Rhodomonas lacustris & ++ & - \\
\hline Penalles sp & - & ++ & & & +
\end{tabular}

$(++)$ gênero ou espécie presente, (-) gênero ou espécie ausente. 
Tabela 11: Gêneros e espécies de Clorofíceas presentes nas lagoas facultativas das ETEs de Pariquera-Açu (PA) e Jacupiranga (JA).

\begin{tabular}{|c|c|c|c|c|c|}
\hline Clorofícea & PA & JA & Clorofícea & PA & JÁ \\
\hline Actinastrum hantzschii & - & ++ & Gloeotece rupestris & ++ & ++ \\
\hline Ankira ocellata & ++ & - & Golenkinia radiata & ++ & ++ \\
\hline Ankistrodesmus sp & ++ & - & Granulochloris sp & - & ++ \\
\hline Ankistrodesmus spiralis & - & ++ & Hyaloraphidium contortum & ++ & ++ \\
\hline Carteria globulosa & ++ & - & Kirchneriella lunaris & ++ & ++ \\
\hline Chlamydomonas gracilis & ++ & - & Micractinium pusillum & ++ & ++ \\
\hline Chlamydomonas não identificada 1 & ++ & - & Micractinium quadrisetum & - & ++ \\
\hline Chlamydomonas sp & ++ & ++ & Monoraphidium circinale & ++ & ++ \\
\hline Chlorella kessleri & ++ & ++ & Monoraphidium contortum & ++ & ++ \\
\hline Chlorodonium fusiforme & ++ & ++ & Monoraphidium fontinale & - & ++ \\
\hline Clorofícea não identificada 1 & ++ & ++ & Monoraphidium griffithii & ++ & ++ \\
\hline Clorofícea não identificada 2 & ++ & - & Monoraphidium indicum & ++ & - \\
\hline Clorofícea não identificada 3 & ++ & ++ & Monoraphidium irregulare & ++ & ++ \\
\hline Clorofícea não identificada 4 & ++ & ++ & Monoraphidium minutum & ++ & - \\
\hline Clorofícea não identificada 5 & ++ & - & Monoraphidium sp & ++ & ++ \\
\hline Clorofícea não identificada 6 & ++ & - & Neodesmus danubialis & ++ & ++ \\
\hline Closterium acutum & ++ & ++ & Nostoc Kihlmani & ++ & - \\
\hline Closterium calosporum & - & ++ & Pyrobotrys cassionisis & ++ & - \\
\hline Coelastrum microporum & ++ & ++ & Radiococcus planktonicus & ++ & ++ \\
\hline Coelosphaerium anomalum & ++ & ++ & Scenedesmus acuminatus & - & ++ \\
\hline Coelosphaerium sp & ++ & - & Scenedesmus bicaudatus & - & ++ \\
\hline Diacanthos belenophorus & ++ & ++ & Scenedesmus opoliensis & - & ++ \\
\hline Dicloster acuatus & - & ++ & Tetrastrum hemisphaericum & ++ & ++ \\
\hline Dictyosphaerium pulchellum & ++ & ++ & Tetrastrum heteracanthum & ++ & ++ \\
\hline Eutetramorus globosus & ++ & ++ & Tetrastrum triangulare & - & ++ \\
\hline Eutetramorus planctonicus & ++ & ++ & Volvocales não identificada 1 & ++ & - \\
\hline Gloeocystis baneergattensis & ++ & ++ & Volvocales não identificada 2 & ++ & - \\
\hline
\end{tabular}

$(++)$ gênero ou espécie presente, (-) gênero ou espécie ausente.

Dentre as clorofíceas, os gêneros e espécies comuns entre as lagoas foram: Chlamydomonas sp, Chlorella kessleri, Chlorodonium fusiforme, Closterium acutum, Coelastrum microporum, Coelosphaerium anomalum, Diacanthos belenophorus, Dictyosphaerium pulchellum, Eutetramorus globosus, Eutetramorus planctonicus, Gloeocystis baneergattensis, Gloeotece rupestris, Golenkinia radiata, Hyaloraphidium contortum, Kirchneriella lunaris, Micractinium pusillum, Monoraphidium circinale, Monoraphidium contortum, Monoraphidium griffithii, Monoraphidium irregulare, Monoraphidium sp, Neodesmus danubialis, Radiococcus planktonicus, Tetrastrum hemisphaericume Tetrastrum heteracanthum.

Entre as cianobactérias foram: Aphanocapsa sp, Aphanotece castagnei, Aphanotece comassi, Células livres de Microsystis, Lyngbia sp, Merismopedia glauca, 
Merismopedia punctata, Phormidium sp, Pseudoanabaena moliniformis, Romeria gracilis, Synechococus sp e Synechocystis aquatilis.

$\mathrm{Na}$ Tabela 12 estão apresentadas as densidades fitoplanctônicas totais obtidas durante nos períodos e lagoas estudadas. Na lagoa de Pariquera-Açu, pôde-se observar variação sazonal, sendo que em julho foram obtidas as maiores densidades (entre 5 e 15 x $10^{5}$ indivíduos. $\mathrm{mL}^{-1}$ ). Em janeiro, a densidade variou entre 2 e $11 \times 10^{5}$ indivíduos. $\mathrm{mL}^{-1}$. Já em abril e setembro, foram observadas as menores densidades, que variaram entre 0,6 e 1,1 × $10^{5}$ indivíduos. $\mathrm{mL}^{-1}$, em abril; e entre 0,7 e 16,6 × $10^{5}$ indivíduos. $\mathrm{mL}^{-1}$, em setembro. Nesta lagoa, não foram observadas variações horárias e verticais, exceto às $7 \mathrm{~h}$, em janeiro, e às 10 e $16 \mathrm{~h}$, em julho.

$\mathrm{Na}$ lagoa de Jacupiranga, as maiores densidades foram obtidas em setembro, variando entre 14 e $38 \times 10^{5}$ indivíduos. $\mathrm{mL}^{-1}$. Em julho, a densidade variou entre 3,7 e 14 $\times 10^{5}$ indivíduos. $\mathrm{mL}^{-1}$. Já em janeiro e abril foram observadas as menores densidades,

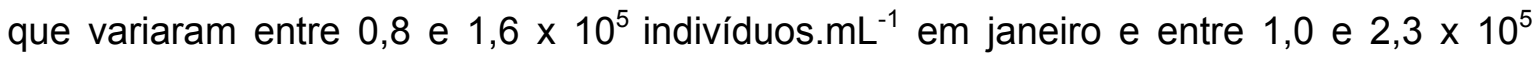
indivíduos. $\mathrm{mL}^{-1}$ em abril. Nesta lagoa não foram observadas variações horárias e verticais, exceto em setembro, quando se verificou aumento da densidade em direção à interface água-sedimento, às $7 \mathrm{~h}$.

Tabela 12: Densidade fitoplanctônica $\left(10^{5}\right.$ indivíduos. $\left.\mathrm{mL}^{-1}\right)$, nas lagoas facultativas das ETEs de PariqueraAçu e Jacupiranga (ss: sub-superfície, m: meio e f: interface água-sedimento), em diferentes épocas do ano.

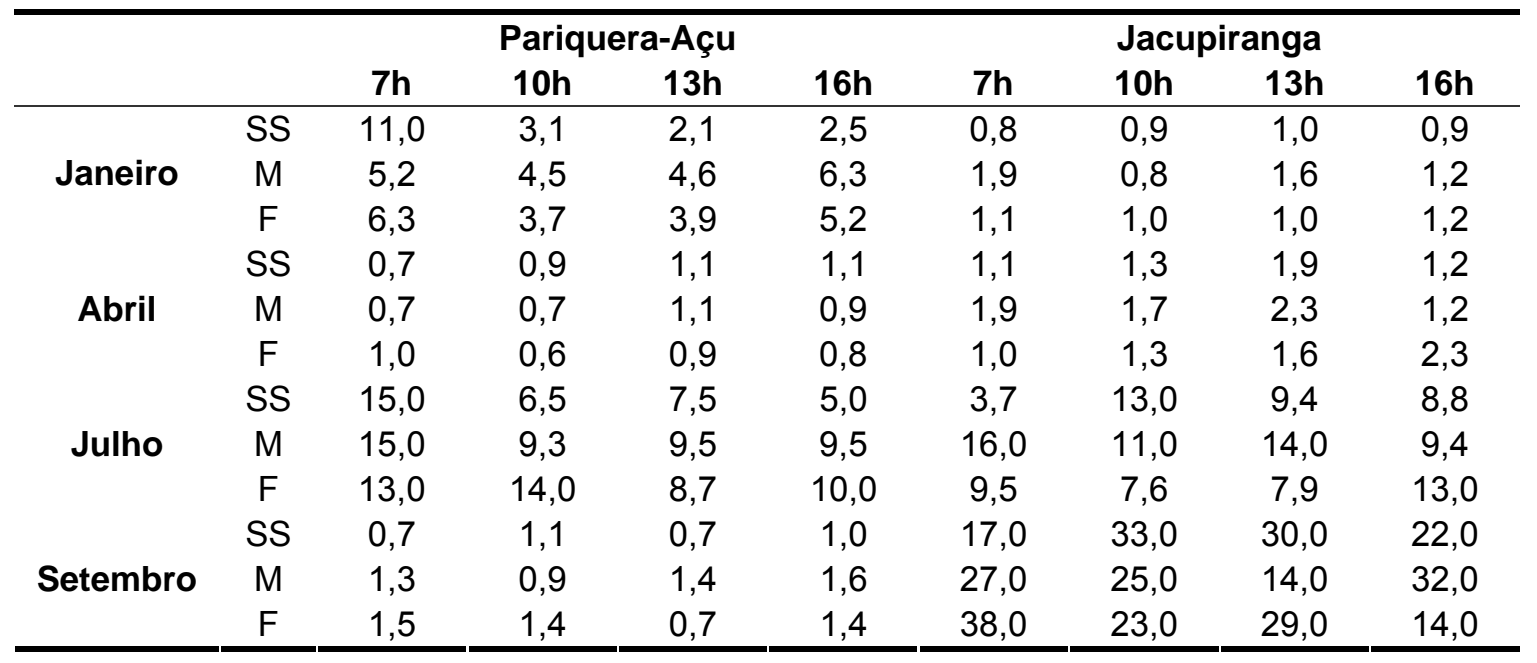

Nas Tabelas 13 a 16 estão representadas as porcentagens de contribuições dos principais grupos fitoplanctônicos, nos períodos e nas lagoas estudadas.

De acordo com a classificação proposta, em janeiro (Tabela 13), nas duas lagoas, as cianobactérias e as clorofíceas foram abundantes na sub-superfície e no meio da coluna de água. As cianobactérias foram predominantes, às $13 \mathrm{~h}$, na interface água- 
sedimento em Pariquera-Açu (63,3\%) e em Jacupiranga (60,6 \%). As clorofíceas predominaram apenas às 10h, na interface água-sedimento, em Jacupiranga (67,3\%). As euglenofíceas e criptofíceas foram ocasionais ou raras e as bacilariofíceas estiveram ausentes durante toda a amostragem de janeiro nesta lagoa.

Tabela 13: Contribuição dos grupos fitoplanctônicos (\%) nas lagoas facultativas das ETEs de Pariquera-Açu e Jacupiranga, em janeiro de 2006.

\begin{tabular}{|c|c|c|c|c|c|c|c|c|}
\hline & \multicolumn{4}{|c|}{ Pariquera-Açu } & \multicolumn{4}{|c|}{ Jacupiranga } \\
\hline & 7h & $10 \mathrm{~h}$ & $13 \mathrm{~h}$ & $16 \mathrm{~h}$ & $7 \mathrm{~h}$ & $10 \mathrm{~h}$ & $13 \mathrm{~h}$ & $16 \mathrm{~h}$ \\
\hline \multicolumn{9}{|l|}{ Sub-superfície } \\
\hline Cianobactéria & 45,4 & 39,1 & 41,3 & 52,7 & 40,0 & 40,3 & 42,8 & 52,1 \\
\hline Clorofícea & 54,4 & 58,7 & 58,6 & 46,8 & 55,9 & 55,6 & 51,8 & 46,0 \\
\hline Euglenofícea & - & 2,2 & - & 0,5 & 2,9 & 2,9 & 2,3 & 1,6 \\
\hline Criptofícea & 0,2 & & 0,1 & 14,2 & 1,2 & 1,2 & 3,1 & 1,2 \\
\hline Bacilariofícea & - & - & - & - & - & - & - & - \\
\hline \multicolumn{9}{|l|}{ Meio } \\
\hline Cianobactéria & 58,6 & 46,2 & 45,7 & 56,8 & 46,5 & 50,4 & 46,8 & 47,1 \\
\hline Clorofícea & 41,1 & 53,6 & 53,8 & 43,2 & 42,9 & 44,5 & 45,5 & 39,4 \\
\hline Euglenofícea & 0,3 & - & - & - & 1,6 & 1,3 & 1,4 & 1,8 \\
\hline Criptofícea & - & 0,2 & 0,5 & - & 9,0 & 3,8 & 6,3 & 11,7 \\
\hline Bacilariofícea & - & - & - & - & & & & \\
\hline \multicolumn{9}{|l|}{$\begin{array}{l}\text { Interface água- } \\
\text { sedimento }\end{array}$} \\
\hline Cianobactéria & 44,9 & 52,7 & 63,3 & 57,3 & 47,0 & 28,8 & 60,6 & 50,8 \\
\hline Clorofícea & 53,0 & 47,3 & 36,7 & 42,7 & 50,0 & 67,3 & 34,6 & 42,9 \\
\hline Euglenofícea & 0,4 & - & - & - & 0,9 & 0,9 & 1,3 & 1,6 \\
\hline Criptofícea & 1,7 & - & - & - & 2,1 & 3,0 & 3,5 & 4,7 \\
\hline Bacilariofícea & - & - & - & - & - & - & - & - \\
\hline
\end{tabular}

$\mathrm{Na}$ lagoa de Pariquera-Açu, em abril (Tabela 14), as cianobactérias foram predominantes na sub-superfície, às $16 \mathrm{~h}(71,8 \%)$, no meio, às $7 \mathrm{~h}(63,5 \%)$ e na interface água-sedimento, às $10 \mathrm{~h}(66,9 \%)$. Enquanto as clorofíceas foram abundantes (49,0 e $51,8 \%)$, exceto às $7 \mathrm{~h}$ na sub-superfície, onde estas foram predominantes $(68,4 \%)$ e às $16 \mathrm{~h}$, quando se apresentaram como comum (27,5 \%). Na lagoa facultativa de Jacupiranga, as cianobactérias foram predominantes às $7 \mathrm{~h}$, com $68,4 \%$ e comuns às 13h (29,9\%), ambas na sub-superfície, enquanto as clorofíceas foram predominantes somente às 13 e $16 \mathrm{~h}$ (65,4 e 61,6 \%, respectivamente), também na sub-superfície; nos demais horários e profundidades este grupo foi abundante. Os demais grupos (euglenofíceas, criptofíceas e bacilariofíceas) foram ocasionais, raros ou ausentes. 
Tabela 14: Contribuição dos grupos fitoplanctônicos (\%), nas lagoas facultativas das ETEs de PariqueraAçu e Jacupiranga, em abril de 2006.

\begin{tabular}{lcccccccc}
\hline & \multicolumn{3}{c}{ Pariquera-Açu } & \multicolumn{5}{c}{ Jacupiranga } \\
\hline Sub-superfície & $\mathbf{7 h}$ & $\mathbf{1 0 h}$ & $\mathbf{1 3 h}$ & $\mathbf{1 6 h}$ & $\mathbf{7 h}$ & $\mathbf{1 0 h}$ & $\mathbf{1 3 h}$ & $\mathbf{1 6 h}$ \\
\hline Cianobactéria & 28,9 & 52,4 & 50,9 & $\mathbf{7 1 , 8}$ & 68,4 & 33,2 & 29,9 & 35,4 \\
\hline Clorofícea & 68,4 & 44,6 & 46,9 & 27,5 & 30,8 & 47,6 & 65,4 & 61,6 \\
\hline Euglenofícea & - & 0,4 & 0,7 & 0,7 & 0,4 & 1,5 & 0,9 & 1,5 \\
\hline Criptofícea & 0,9 & 2,63 & 1,5 & - & - & 17,2 & 3,8 & 0,9 \\
\hline Bacilariofícea & 1,8 & - & - & - & 0,4 & 0,5 & - & 0,6 \\
\hline Meio & & & & & & & & \\
\hline Cianobactéria & 63,5 & 46,6 & 51,0 & 55,7 & 47,0 & 44,1 & 47,0 & 45,7 \\
\hline Clorofícea & 35,3 & 51,8 & 49,0 & 43,4 & 42,1 & 48,8 & 49,5 & 53,9 \\
\hline Euglenofícea & 0,6 & 0,4 & - & - & 1,6 & 0,3 & 2,2 & - \\
\hline Criptofícea & 0,6 & 0,8 & - & 0,9 & 9,3 & 6,8 & 1,3 & - \\
\hline Bacilariofícea & - & 0,4 & - & - & - & - & - & 0,4 \\
\hline Interface água- & & & & & & & & \\
sedimento & & & & & & & & \\
\hline Cianobactéria & 51,3 & 66,9 & 59,2 & 54,3 & 42,1 & 52,3 & 56,4 & 53,2 \\
\hline Clorofícea & 48,7 & 32,2 & 39,9 & 45,3 & 51,6 & 45,3 & 38,6 & 43,2 \\
\hline Euglenofícea & - & 0,9 & 0,3 & 0,4 & 0,9 & 1,8 & 1,1 & 0,4 \\
\hline Criptofícea & - & - & 0,6 & - & 4,7 & 0,7 & 3,9 & 3,2 \\
\hline Bacilariofícea & - & - & - & - & 0,6 & - & - & - \\
\hline
\end{tabular}

No mês de julho (Tabela 15), nas duas lagoas, as clorofíceas foram predominantes, exceto no meio (10h) e na interface água-sedimento (todos os horários), na lagoa de Jacupiranga, quando estas foram abundantes. Na lagoa facultativa de Pariquera-Açu, as espécies de cianobactéria foram comuns em quase todas as amostragens, exceto às $16 \mathrm{~h}$, na sub-superfície, quando foi abundante $(36,2 \%)$ e às $10 \mathrm{~h}$ na interface água-sedimento, quando foi ocasional (8,3\%). Já em Jacupiranga, estas espécies foram abundantes em todo o período de amostragem, exceto às $13 \mathrm{~h}$, na interface água-sedimento, onde esta foi comum $(27,7 \%)$. Os demais grupos foram ocasionais, raros ou ausentes.

O mês de setembro (Tabela 16) foi semelhante ao de julho, sendo as clorofíceas predominantes em quase todo o período amostrado, acima de $60 \%$ de contribuição, exceto às $10 \mathrm{~h}$ (meio e interface água-sedimento) e às $16 \mathrm{~h}$ (interface água-sedimento), em que foram abundantes. Na lagoa de Pariquera-Açu, as cianobactérias foram abundantes e comuns. Em Jacupiranga, as clorofíceas dominaram todo o período, e as porcentagens de contribuição estiveram entre 94,4 e $100 \%$ (13h, sub-superfície e 10h, interface água-sedimento, respectivamente). 
Tabela 15: Contribuição dos grupos fitoplanctônicos (\%), nas lagoas facultativas das ETEs de Pariquera-Açu e Jacupiranga, em julho de 2006.

\begin{tabular}{lcccccccc}
\hline & \multicolumn{3}{c}{ Pariquera-Açu } & \multicolumn{5}{c}{ Jacupiranga } \\
\hline Sub-superfície & $\mathbf{7 h}$ & $\mathbf{1 0 h}$ & $\mathbf{1 3 h}$ & $\mathbf{1 6 h}$ & $\mathbf{7 h}$ & $\mathbf{1 0 h}$ & $\mathbf{1 3 h}$ & $\mathbf{1 6 h}$ \\
\hline Cianobactéria & 19,3 & 22,7 & 24,6 & 36,2 & 33,3 & 35,5 & 33,6 & 31,8 \\
\hline Clorofícea & 80,1 & 73,9 & 72,7 & 62,1 & 64,8 & 60,6 & 65,5 & 67,2 \\
\hline Euglenofícea & 0,6 & 0,5 & 0,7 & 1,7 & 0,2 & 0,6 & - & 0,3 \\
\hline Criptofícea & - & 0,5 & 0,3 & - & 1,3 & 1,2 & 0,6 & \\
\hline Bacilariofícea & - & 2,4 & 1,7 & - & 0,4 & 2,1 & 0,3 & 0,7 \\
\hline Meio & & & & & & & & \\
\hline Cianobactéria & 26,9 & 28,4 & 19,6 & 25,6 & 36,8 & 59,6 & 27,7 & 30,4 \\
\hline Clorofícea & 72,1 & 70,6 & 79,0 & 74,4 & 62,6 & 39,8 & 71,1 & 68,5 \\
\hline Euglenofícea & - & - & 1,4 & - & 0,3 & - & - & \\
\hline Criptofícea & 0,5 & - & - & - & - & 0,3 & 1,2 & 1,1 \\
\hline Bacilariofícea & 0,5 & 1,0 & - & - & 0,3 & 0,3 & - & - \\
\hline Interface água- & & & & & & & & \\
sedimento & & & & & & & & \\
\hline Cianobactéria & 22,3 & 8,3 & 21,3 & 15,5 & 49,6 & 53,6 & 44,6 & 40,4 \\
\hline Clorofícea & 76,5 & 91,7 & 75,1 & 83,3 & 50,4 & 45,5 & 54,6 & 59,6 \\
\hline Euglenofícea & 0,6 & - & 0,6 & 0,6 & - & - & 0,4 & - \\
\hline Criptofícea & - & - & 2,4 & - & - & 0,9 & 0,4 & - \\
\hline Bacilariofícea & 0,6 & - & 0,6 & 0,6 & - & - & - & - \\
\hline
\end{tabular}

Tabela 16: Contribuição dos grupos fitoplanctônicos (\%), nas lagoas facultativas das ETEs de Pariquera-Açu e Jacupiranga, em setembro de 2006.

\begin{tabular}{|c|c|c|c|c|c|c|c|c|}
\hline & \multicolumn{4}{|c|}{ Pariquera-Açu } & \multicolumn{4}{|c|}{ Jacupiranga } \\
\hline & $7 \mathrm{~h}$ & $10 \mathrm{~h}$ & $13 \mathrm{~h}$ & $16 \mathrm{~h}$ & $7 \mathrm{~h}$ & $10 \mathrm{~h}$ & $13 \mathrm{~h}$ & $16 h$ \\
\hline \multicolumn{9}{|l|}{ Sub-superfície } \\
\hline Cianobactéria & 28,9 & 39,8 & 35,9 & 26,9 & 4,1 & 3,2 & 5,6 & 3,1 \\
\hline Clorofícea & 68,4 & 59,0 & 61,4 & 73,1 & 95,9 & 96,8 & 94,4 & 96,9 \\
\hline Euglenofícea & - & 0,8 & 2,1 & - & - & - & - & - \\
\hline Criptofícea & 0,9 & - & - & - & - & - & - & - \\
\hline Bacilariofícea & 1,8 & 0,4 & 0,6 & - & - & - & - & - \\
\hline \multicolumn{9}{|l|}{ Meio } \\
\hline Cianobactéria & 30,1 & 35,2 & 32,3 & 28,0 & 0,8 & 0,9 & 2,5 & 3,7 \\
\hline Clorofícea & 69,0 & 64,4 & 67,3 & 72,0 & 98,8 & 98,6 & 96,5 & 96,3 \\
\hline Euglenofícea & - & 0,4 & 0,5 & - & - & - & - & - \\
\hline Criptofícea & 0,5 & - & - & - & 0,4 & 0,5 & 1,0 & - \\
\hline Bacilariofícea & 0,4 & - & - & - & - & - & - & - \\
\hline \multicolumn{9}{|l|}{$\begin{array}{l}\text { Interface água- } \\
\text { sedimento }\end{array}$} \\
\hline Cianobactéria & 38,3 & 43,5 & 21,3 & 43,3 & 0,9 & & 3,0 & 0,6 \\
\hline Clorofícea & 61,4 & 55,4 & 75,1 & 55,6 & 99,1 & 100,0 & 97,0 & 98,8 \\
\hline Euglenofícea & 0,3 & 1,1 & 0,6 & 1,1 & - & - & - & - \\
\hline Criptofícea & - & - & 2,4 & - & - & - & - & 0,6 \\
\hline Bacilariofícea & - & - & 0,6 & - & - & - & - & - \\
\hline
\end{tabular}


No anexo 1 (Tabelas 36 a 39) estão apresentadas as abundâncias relativas dos gêneros e espécies fitoplanctônicas encontrados nas lagoas facultativas de Pariquera-Açu e de Jacupiranga, respectivamente. Na lagoa de Pariquera-Açu, em abril, Phormidium sp (cianobactéria) foi abundante em todas as profundidades e horários, exceto na subsuperfície às $16 \mathrm{~h}$, onde foi predominante e às $7 \mathrm{~h}$ (ausente). Em setembro foram abundantes: Synecocystis aquatilis (cianobactéria) às 7h (interface água-sedimento), as 10h (sub-superfície, meio e interface água-sedimento) e às 16h (interface águasedimento) e Kirchneriella lunaris (clorofícea) às 7, 10 e 16h (sub-superfície, meio e interface água-sedimento) e às $13 \mathrm{~h}$ (sub-superfície e meio) e predominantes às $13 \mathrm{~h}$ (interface água-sedimento). Kirchneriella lunaris também foi abundante em abril (7h, subsuperfície), em julho, às 7, 10 e 16h (sub-superfície e meio), às 13h (sub-superfície) e predominantes em julho, às 7, 10 e 16h (interface água-sedimento) e 13h (meio e interface água-sedimento).

$\mathrm{Na}$ lagoa de Jacupiranga, a cianobactéria Synecocystis aquatilis foi abundante na interface água-sedimento em todos os horários de amostragem dos meses de janeiro (exceto às 10h), abril e julho e no meio, às 13, 16h (janeiro) e 10h (abril). Em setembro, às $7 \mathrm{~h}$ (sub-superfície), 10h (todas as profundidades), $13 \mathrm{e} 16 \mathrm{~h}$ (interface águasedimento), a clorofícea Chlorella kessleri foi predominante e nos outros horários e profundidades foi abundante. Neste mesmo período a Kirchneriella lunaris foi abundante somente às 7 e 10h, no meio e na interface água-sedimento; às 13 e 16h, na subsuperfície e meio; ausente às $7 \mathrm{~h}$ e comum às $10 \mathrm{~h}$, na sub-superfície; 13 e 16h, na interface água-sedimento.

Chlorella kessleri foi abundante em janeiro (13h, meio), abril (7h e 10h, interface água-sedimento; 13h, sub-superfície e 16h, sub-superfície e meio) e julho (7h, meio; 10h, sub-superfície; 13 e 16h, todas as profundidades).

Os índices de riqueza, diversidade, dominância e equidade estão apresentados na Tabela 17 (lagoa de Pariquera-Açu) e na Tabela 18, (lagoa de Jacupiranga). Comparando-se os diferentes horários de coleta, a riqueza de espécies (d), na lagoa de Pariquera-Açu, foi mais alta às $13 \mathrm{~h}$, na sub-superfície, em todos os meses amostrados (entre 20,88 e 24,88, respectivamente, em julho e abril). Entre os diferentes períodos de coleta, em janeiro, a riqueza foi maior que nos outros meses (abril, julho e setembro). Os maiores valores deste índice ocorreram às $13 \mathrm{~h}$, na sub-superfície $(24,88 ; 20,88$; e 22,88; em abril, julho e setembro, respectivamente). O índice menor ocorreu em abril e foi de 12,87 (7h, sub-superfície), em julho foi de 7,86 (10h, interface água-sedimento) e setembro, foi de 8,87 (16h, sub-superfície).

Como era esperado, a diversidade de espécies $\left(\mathrm{H}^{\prime}\right)$ seguiu o mesmo padrão observado da riqueza, ou seja, em janeiro, a diversidade foi maior que em abril, julho e 
setembro. Os valores deste índice não variaram muito; em janeiro, foram obtidos os maiores, entre 3,02 a 3,82 e nos outros períodos amostrados estes variaram de 1,41 a 3,29 .

A dominância (c) foi menor em janeiro variando entre 0,10 (7h, meio e $10 \mathrm{~h}$, subsuperfície) e 0,16 (10h, interface água-sedimento) e em setembro, entre 0,20 e 0,42 (13h na sub-superfície e interface água-sedimento, respectivamente). Enquanto que nas amostragens de abril e julho ocorreram as maiores variações entre 0,15 e 0,46 (7h na interface água-sedimento e 16h na sub-superfície, respectivamente), em abril e 0,18 e 0,49 (13h, sub-superfície e 16h, interface água-sedimento, respectivamente), em julho.

O índice de equidade de espécie foi maior em janeiro, porém não houve variação entre os horários e as profundidades. Os valores estiveram entre 0,76 (7 e 13h, interface água-sedimento) e 0,82 (7h, sub-superfície). Em abril e julho, os valores estiveram próximos e variaram entre 0,47 (16h, sub-superfície); 0,46 (13h, meio) e 0,75 (7h, interface água-sedimento e $13 \mathrm{~h}$, sub-superfície), respectivamente. Em setembro, os menores valores foram observados e estiveram entre 0,52 (13h, interface águasedimento) e 0,66 (13 e 16h, sub-superfície).

Tabela 17: Índices de riqueza (d), diversidade $\left(\mathrm{H}^{\prime}\right)$, dominância (c) e eqüidade (e), na lagoa facultativa da ETE de Pariquera-Açu (ss: sub-superfície, m: meio e f: interface água-sedimento), em diferentes épocas do ano.

\begin{tabular}{|c|c|c|c|c|c|c|c|c|c|c|c|c|}
\hline & \multicolumn{3}{|c|}{ Janeiro } & \multicolumn{3}{|c|}{ Abril } & \multicolumn{3}{|c|}{ Julho } & \multicolumn{3}{|c|}{ Setembro } \\
\hline & ss & $\mathrm{m}$ & f & ss & $\mathrm{m}$ & $\mathrm{f}$ & ss & $\mathrm{m}$ & f & ss & $\mathrm{m}$ & f \\
\hline \multicolumn{13}{|l|}{$d$} \\
\hline $7 \mathrm{~h}$ & 19,89 & 29,89 & 22,88 & 12,87 & 16,87 & 17,89 & 13,87 & 15,87 & 14,87 & 12,87 & 15,87 & 13,88 \\
\hline $10 \mathrm{~h}$ & 20,88 & 21,89 & 14,88 & 15,87 & 20,87 & 15,87 & 17,87 & 10,87 & 7,86 & 13,88 & 15,88 & 13,88 \\
\hline $13 \mathrm{~h}$ & 23,89 & 22,89 & 18,88 & 24,88 & 13,87 & 18,88 & 20,88 & 9,86 & 14,86 & 22,88 & 16,87 & 14,86 \\
\hline $16 \mathrm{~h}$ & 17,89 & 17,89 & 21,88 & 18,86 & 16,87 & 15,87 & 18,87 & 8,87 & 10,86 & 8,87 & 9,87 & 14,88 \\
\hline \multicolumn{13}{|l|}{$H^{\prime}$} \\
\hline $7 \mathrm{~h}$ & 3,53 & 3,82 & 3,44 & 2,14 & 2,32 & 3,14 & 2,40 & 2,76 & 2,13 & 2,14 & 2,87 & 2,18 \\
\hline $10 \mathrm{~h}$ & 3,53 & 3,47 & 3,02 & 2,69 & 2,87 & 2,72 & 2,42 & 2,02 & 1,41 & 2,10 & 2,56 & 2,22 \\
\hline $13 \mathrm{~h}$ & 3,63 & 3,47 & 3,21 & 3,19 & 2,68 & 3,00 & 3,29 & 1,52 & 2,02 & 2,98 & 2,33 & 2,02 \\
\hline $16 \mathrm{~h}$ & 3,36 & 3,39 & 3,43 & 2,01 & 2,78 & 2,53 & 2,99 & 2,04 & 1,70 & 2,08 & 1,97 & 2,25 \\
\hline \multicolumn{13}{|l|}{$C$} \\
\hline $7 \mathrm{~h}$ & 0,11 & 0,10 & 0,13 & 0,31 & 0,37 & 0,15 & 0,35 & 0,25 & 0,39 & 0,31 & 0,23 & 0,30 \\
\hline $10 \mathrm{~h}$ & 0,13 & 0,12 & 0,16 & 0,25 & 0,23 & 0,27 & 0,32 & 0,37 & 0,57 & 0,32 & 0,24 & 0,29 \\
\hline $13 \mathrm{~h}$ & 0,10 & 0,13 & 0,15 & 0,20 & 0,25 & 0,18 & 0,18 & 0,54 & 0,42 & 0,20 & 0,29 & 0,42 \\
\hline $16 \mathrm{~h}$ & 0,11 & 0,12 & 0,13 & 0,46 & 0,25 & 0,28 & 0,21 & 0,36 & 0,49 & 0,32 & 0,35 & 0,29 \\
\hline \multicolumn{13}{|l|}{$e$} \\
\hline $7 \mathrm{~h}$ & 0,82 & 0,78 & 0,76 & 0,58 & 0,57 & 0,75 & 0,63 & 0,69 & 0,54 & 0,58 & 0,72 & 0,57 \\
\hline $10 \mathrm{~h}$ & 0,80 & 0,78 & 0,77 & 0,67 & 0,65 & 0,68 & 0,58 & 0,59 & 0,47 & 0,55 & 0,64 & 0,58 \\
\hline $13 \mathrm{~h}$ & 0,79 & 0,77 & 0,76 & 0,69 & 0,70 & 0,71 & 0,75 & 0,46 & 0,52 & 0,66 & 0,57 & 0,52 \\
\hline $16 \mathrm{~h}$ & 0,81 & 0,81 & 0,77 & 0,47 & 0,68 & 0,63 & 0,70 & 0,64 & 0,49 & 0,66 & 0,59 & 0,57 \\
\hline
\end{tabular}

$\mathrm{Na}$ lagoa facultativa do sistema de Jacupiranga (Tabela 18), a riqueza e a diversidade de espécies atingiram os maiores valores em janeiro, abril e julho. Em janeiro, estes índices variaram entre 18,88 (16h, interface água-sedimento) e 30,88 (10h, sub-superfície) para a riqueza; entre 2,44 e 3,66 (10h, interface água-sedimento e sub- 
superfície, respectivamente) para a diversidade. Em abril e julho, a riqueza e a diversidade de espécies variaram entre 22,88 e 34,88 (16h, meio e sub-superfície, respectivamente) e entre 3,14 (13h, interface água-sedimento) e 3,87 (16h, subsuperfície), respectivamente, em abril; em julho, entre 14,88 e 30,89 (7h, interface águasedimento e sub-superfície, respectivamente) e entre 2,58 e 3,89 (7h, interface águasedimento e sub-superfície, respectivamente).

Em setembro foi observada diminuição da riqueza e da diversidade de espécies em relação aos outros resultados obtidos nos períodos amostrados. Estes índices variaram, respectivamente, entre 4,86 (7 e 13h, sub-superfície) e 9,87 (13 e 16h, meio) e entre 1,12 (10h, meio) e 1,48 (13h, sub-superfície).

A dominância de espécie foi maior em setembro, variando entre 0,44 (10h, subsuperfície e meio) e 0,57 (7h, sub-superfície), enquanto que em abril as variações estiveram entre 0,11 e 0,22 (13h na sub-superfície e 16h na interface água-sedimento, respectivamente),e em julho entre 0,10 e 0,26 (7h, sub-superfície e interface águasedimento, respectivamente).

A equidade foi semelhante em todos os meses amostrados. Em janeiro houve variação entre 0,56 e 0,74 (10h, sub-superfície e interface água-sedimento, respectivamente), enquanto que em abril variou entre 0,67 e 0,77 ( $13 \mathrm{~h}$, meio e subsuperfície, respectivamente); em julho e setembro, respectivamente, as variações estiveram entre 0,60 (16h, interface água-sedimento) e 0,79 (7h, sub-superfície) e entre 0,39 e 0,51(10h, sub-superfície e interface água-sedimento, respectivamente).

Tabela 18: Índices de riqueza (d), diversidade $\left(\mathrm{H}^{\prime}\right)$, dominância (c) e eqüidade (e), na lagoa facultativa da ETE de Jacupiranga (ss: sub-superfície, m: meio e f: interface água-sedimento), em diferentes épocas do ano.

\begin{tabular}{|c|c|c|c|c|c|c|c|c|c|c|c|c|}
\hline & \multicolumn{3}{|c|}{ Janeiro } & \multicolumn{3}{|c|}{ Abril } & \multicolumn{3}{|c|}{ Julho } & \multicolumn{3}{|c|}{ Setembro } \\
\hline & Ss & m & $f$ & ss & $\mathrm{m}$ & $f$ & ss & $\mathrm{m}$ & $f$ & Ss & $\mathrm{m}$ & $f$ \\
\hline \multicolumn{13}{|l|}{$d$} \\
\hline $7 \mathrm{~h}$ & 29,88 & 28,88 & 26,88 & 26,89 & 28,88 & 23,88 & 30,89 & 21,88 & 14,88 & 4,86 & 7,87 & 7,87 \\
\hline $10 \mathrm{~h}$ & 30,88 & 19,88 & 19,88 & 28,89 & 32,89 & 25,87 & 27,88 & 18,88 & 25,87 & 8,87 & 5,87 & 4,86 \\
\hline $13 \mathrm{~h}$ & 26,88 & 24,88 & 23,88 & 27,89 & 25,88 & 23,87 & 24,88 & 16,87 & 19,88 & 8,87 & 9,87 & 9,86 \\
\hline $16 \mathrm{~h}$ & 27,88 & 22,88 & 18,88 & 34,88 & 22,88 & 26,88 & 24,88 & 22,88 & 19,88 & 7,87 & 9,87 & 6,86 \\
\hline \multicolumn{13}{|l|}{$\mathrm{H}^{\prime}$} \\
\hline $7 \mathrm{~h}$ & 3,44 & 3,49 & 3,25 & 3,59 & 3,49 & 3,43 & 3,89 & 2,84 & 2,58 & 1,14 & 1,37 & 1,30 \\
\hline $10 \mathrm{~h}$ & 3,66 & 3,00 & 2,44 & 3,59 & 3,71 & 4,21 & 3,46 & 2,80 & 3,70 & 1,25 & 1,12 & 1,18 \\
\hline $13 \mathrm{~h}$ & 3,42 & 3,42 & 3,19 & 3,70 & 3,15 & 3,14 & 3,22 & 2,92 & 2,68 & 1,48 & 1,47 & 1,40 \\
\hline $16 \mathrm{~h}$ & 3,34 & 3,31 & 2,94 & 3,87 & 3,35 & 3,39 & 3,06 & 3,31 & 2,61 & 1,38 & 1,41 & 1,16 \\
\hline \multicolumn{13}{|l|}{$c$} \\
\hline $7 \mathrm{~h}$ & 0,16 & 0,14 & 0,19 & 0,13 & 0,14 & 0,15 & 0,10 & 0,23 & 0,26 & 0,57 & 0,45 & 0,47 \\
\hline $10 \mathrm{~h}$ & 0,13 & 0,20 & 0,29 & 0,13 & 0,12 & 0,17 & 0,16 & 0,20 & 0,11 & 0,53 & 0,51 & 0,50 \\
\hline $13 \mathrm{~h}$ & 0,15 & 0,14 & 0,19 & 0,11 & 0,19 & 0,22 & 0,18 & 0,21 & 0,25 & 0,44 & 0,44 & 0,51 \\
\hline $16 \mathrm{~h}$ & 0,16 & 0,17 & 0,21 & 0,12 & 0,17 & 0,16 & 0,21 & 0,17 & 0,23 & 0,45 & 0,45 & 0,54 \\
\hline \multicolumn{13}{|l|}{$\boldsymbol{e}$} \\
\hline $7 \mathrm{~h}$ & 0,70 & 0,72 & 0,68 & 0,76 & 0,72 & 0,75 & 0,79 & 0,64 & 0,66 & 0,49 & 0,46 & 0,43 \\
\hline $10 \mathrm{~h}$ & 0,74 & 0,69 & 0,56 & 0,74 & 0,74 & 0,89 & 0,72 & 0,66 & 0,79 & 0,39 & 0,43 & 0,51 \\
\hline $13 \mathrm{~h}$ & 0,72 & 0,74 & 0,70 & 0,77 & 0,67 & 0,68 & 0,69 & 0,71 & 0,62 & 0,47 & 0,44 & 0,42 \\
\hline $16 \mathrm{~h}$ & 0,70 & 0,73 & 0,69 & 0,76 & 0,74 & 0,71 & 0,66 & 0,73 & 0,60 & 0,46 & 0,42 & 0,41 \\
\hline
\end{tabular}




\subsubsection{Determinação da biomassa fitoplanctônica - biovolume}

Para o cálculo do biovolume foram escolhidos os organismos mais freqüentes, ou seja, os gêneros ou espécies que estiveram presentes em todos os horários e profundidades de cada período de amostragem, nas duas lagoas estudadas (Tabelas 19 a 22, para a lagoa de Pariquera-Açu; e Tabelas 23 a 26, para a lagoa de Jacupiranga).

$\mathrm{Na}$ lagoa de Pariquera-Açu, dois grupos fitoplanctônicos contribuíram significativamente para a biomassa, tanto em densidade quanto em biovolume: as cianobactérias e as clorofíceas. Porém, os gêneros e espécies variaram entre os períodos amostrados.

Em janeiro (Tabela 19), as cianobactérias mais representativas foram Aphanocapsa sp, Lyngbia sp, Phormidium sp e Synecocystis aquatilis; e as clorofíceas foram Chlamydomonas sp, Golenkinia radiata, Kirchneriella lunaris e Monoraphidium contortum. Em abril (Tabela 20), apenas Phormidium sp e Golenkinia radiata continuaram presentes e duas novas espécies de clorofíceas apareceram, Closterium acutum e Radiococcus planktonicus.

Synecocystis aquatilis e Monoraphidium contortum voltaram a aparecer nos meses de julho (Tabela 21) e setembro (Tabela 22), junto com Chlorella Kessleri, Kirchneriella lunaris e Monoraphidium sp, este último presente apenas em setembro.

Comparando a contribuição da biomassa em biovolume e densidade, diferenças foram observadas para os períodos de janeiro e setembro, enquanto que em abril e julho, isto não ocorreu.

A maior contribuição para o biovolume, em janeiro, foi de Phormidium sp, em todos os horários e profundidades. A contribuição da densidade, no entanto, foi de Kirchneriella lunaris (7h, sub-superfície e meio; 10 e 16h, meio e interface águasedimento; 13, meio), Synecocystis aquatilis (7 e 13h, interface água-sedimento), Phormidium sp (13 e 16h, sub-superfície) e Chlamydomonas sp (7 e 10h, sub-superfície).

Em abril, a contribuição maior foi de Phormidium sp, exceto na sub-superfície, às $7 \mathrm{~h}$, onde houve contribuição de Closterium acutum e Golenkinia radiata, também tanto em biovolume quanto em densidade.

Em julho, Chlorella kessleri e Kirchneriella lunaris apresentaram maior contribuição na maioria dos horários e profundidades amostradas, exceto na interface águasedimento, às $16 \mathrm{~h}$, onde Monoraphidium contortum apresentou maior biovolume que Chlorella kessleri (680 e $1499 \times 10^{3} \mu^{3} . \mathrm{mL}^{-1}$, respectivamente).

A contribuição para a densidade fitoplanctônica, em setembro, foi de Kirchneriella lunaris, em todos os horários e profundidades. No entanto, a maior contribuição em biovolume foi de Monoraphidium sp, exceto às 7 e 13h (meio e interface água-sedimento, 
respectivamente) onde $C$. kessleri foi a que mais contribuiu; e às 7 e $16 \mathrm{~h}$ (interface águasedimento e meio, respectivamente), quando a maior contribuição foi Monoraphidium contortum.

Tabela 19: Densidade fitoplanctônica $\left(10^{3}\right.$ ind. $\left.\mathrm{mL}^{-1}\right)$ e biovolume $\left(10^{3} \mu \mathrm{m}^{3} \cdot \mathrm{mL}^{-1}\right)$ dos gêneros e espécies mais freqüentes, na lagoa facultativa da ETE de Pariquera-Açu, em janeiro de 2006 (ss: sub-superfície, m: meio e f: interface água-sedimento).

\begin{tabular}{|c|c|c|c|c|c|c|c|c|c|c|c|c|c|}
\hline & \multicolumn{3}{|c|}{$7 \mathrm{~h}$} & \multicolumn{3}{|c|}{$10 \mathrm{~h}$} & \multicolumn{3}{|c|}{$13 \mathrm{~h}$} & \multicolumn{3}{|c|}{16} \\
\hline & & SS & M & $\mathrm{F}$ & SS & $\mathrm{M}$ & $\mathrm{F}$ & SS & $\mathrm{M}$ & $\mathrm{F}$ & SS & $\mathrm{M}$ & $\mathrm{F}$ \\
\hline \multirow{2}{*}{ Aphanocapsa sp } & Dens & 22 & 36 & 41 & 17 & 22 & 14 & 4 & 14 & 7 & 3 & 34 & 7 \\
\hline & Biov & 7229 & 14388 & 12607 & 4629 & 8112 & 4927 & 1169 & 4286 & 2836 & 741 & 10614 & 2636 \\
\hline \multirow{2}{*}{ Lyngbia sp } & Dens & 111 & 50 & 39 & 29 & 39 & 31 & 12 & 20 & 12 & 24 & 39 & 37 \\
\hline & Biov & 4166 & 1971 & 1636 & 1281 & 1517 & 1093 & 496 & 769 & 491 & 1099 & 1642 & 1703 \\
\hline \multirow{2}{*}{ Phormidium sp } & Dens & 144 & 42 & 33 & 38 & 26 & 27 & 30 & 12 & 12 & 38 & 39 & 32 \\
\hline & Biov & 798792 & 140495 & 108483 & 129515 & 104696 & 90389 & 95276 & 33370 & 33089 & 102637 & 114902 & 84899 \\
\hline \multirow{2}{*}{ S. aquatilis } & Dens & 107 & 22 & 163 & 16 & 20 & 38 & 12 & 62 & 109 & 27 & 140 & 4 \\
\hline & Biov & 669 & 139 & 1021 & 98 & 126 & 239 & 77 & 387 & 681 & 169 & 876 & 26 \\
\hline \multirow{2}{*}{ Chlamydomonas sp } & Dens & 205 & 52 & 28 & 89 & 50 & - & 24 & 29 & 21 & 34 & 55 & - \\
\hline & Biov & 31033 & 13503 & 4232 & 14790 & 12439 & - & 4649 & 5201 & 2247 & 4496 & 7406 & - \\
\hline \multirow{2}{*}{ G. radiata } & Dens & 83 & 40 & 37 & 26 & 33 & 14 & 23 & 11 & 9 & 24 & 33 & 43 \\
\hline & Biov & 6460 & 2929 & 2097 & 2057 & 3066 & 1114 & 2830 & 782 & 698 & 1460 & 2729 & 3937 \\
\hline \multirow{2}{*}{ K. lunaris } & Dens & 144 & 113 & 114 & 10 & 99 & 104 & 28 & 106 & 43 & 24 & 104 & 76 \\
\hline & Biov & 151 & 118 & 119 & 11 & 104 & 109 & 29 & 111 & 45 & 25 & 109 & 80 \\
\hline \multirow{2}{*}{ M. contortun } & Dens & 38 & 2 & 31 & 5 & 21 & 26 & 10 & 19 & 49 & 10 & 25 & 17 \\
\hline & Biov & 777 & 41 & 582 & 91 & 472 & 614 & 231 & 401 & 977 & 202 & 506 & 352 \\
\hline
\end{tabular}

(-) espécie ausente nos campos de contagem

Tabela 20: Densidade fitoplanctônica $\left(10^{3}\right.$ ind. $\left.\mathrm{mL}^{-1}\right)$ e biovolume $\left(10^{3} \mu \mathrm{m}^{3} \cdot \mathrm{mL}^{-1}\right)$ dos gêneros e espécies mais freqüentes, na lagoa facultativa da ETE de Pariquera-Açu, em abril de 2006 (ss: sub-superfície, m: meio e f: interface água-sedimento).

\begin{tabular}{|c|c|c|c|c|c|c|c|c|c|c|c|c|c|}
\hline & \multicolumn{3}{|c|}{$7 \mathrm{~h}$} & \multicolumn{3}{|c|}{$10 \mathrm{~h}$} & \multicolumn{3}{|c|}{$13 \mathrm{~h}$} & \multicolumn{3}{|c|}{16} \\
\hline & & SS & $M$ & $F$ & SS & $M$ & $F$ & SS & $M$ & $\mathrm{~F}$ & SS & $M$ & $F$ \\
\hline \multirow{2}{*}{ Phormidium sp } & Dens & - & 39 & 26 & 40 & 28 & 30 & 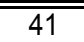 & 477 & 26 & 70 & 443 & 36 \\
\hline & Biov & - & 92637 & 67435 & 103781 & 63829 & 72364 & 81318 & 109156 & 60171 & 157308 & 102990 & 84661 \\
\hline \multirow{2}{*}{ C. acutum } & Dens & 1 & 8 & 19 & 20 & 15 & 6 & 2 & 22 & 13 & 15 & 14 & 18 \\
\hline & Biov & 14 & 373 & 852 & 1041 & 745 & 312 & 75 & 1038 & 738 & 716 & 671 & 833 \\
\hline \multirow{2}{*}{ G. radiata } & Dens & 1 & 2 & 4 & 3 & 4 & 1 & 9 & 3 & 1 & 2 & 3 & 3 \\
\hline & Biov & 16 & 121 & 153 & 275 & 249 & 79 & 791 & 158 & 77 & 120 & 163 & 136 \\
\hline \multirow{2}{*}{ R. planktonicus } & Dens & - & 5 & 11 & 7 & 6 & 3 & 8 & 6 & 6 & 4 & 11 & 5 \\
\hline & Biov & - & 1145 & 2496 & 1551 & 1306 & 786 & 1637 & 1112 & 1146 & 1061 & 2084 & 1059 \\
\hline
\end{tabular}

(-) espécie ausente nos campos de contagem 
Tabela 21: Densidade fitoplanctônica $\left(10^{3}\right.$ ind. $\left.\mathrm{mL}^{-1}\right)$ e biovolume $\left(10^{3} \mu \mathrm{m}^{3} . \mathrm{mL}^{-1}\right)$ dos gêneros e espécies mais freqüentes, na lagoa facultativa da ETE de Pariquera-Açu, em julho de 2006 (ss: sub-superfície, m: meio e f: interface água-sedimento).

\begin{tabular}{|c|c|c|c|c|c|c|c|c|c|c|c|c|c|}
\hline & \multicolumn{3}{|c|}{$7 \mathrm{~h}$} & \multicolumn{3}{|c|}{$10 \mathrm{~h}$} & \multicolumn{3}{|c|}{$13 \mathrm{~h}$} & \multicolumn{3}{|c|}{16} \\
\hline & & SS & $\mathrm{M}$ & $F$ & SS & $\mathrm{M}$ & $F$ & SS & $\mathrm{M}$ & $F$ & SS & $\mathrm{M}$ & $F$ \\
\hline \multirow{2}{*}{ S. aquatilis } & Dens & 121 & 180 & 215 & 126 & 217 & 89 & 83 & 117 & 154 & 62 & 157 & 157 \\
\hline & Biov & 759 & 1128 & 1350 & 791 & 1360 & 558 & 521 & 738 & 968 & 387 & 984 & 986 \\
\hline \multirow{2}{*}{ C. kessleri } & Dens & 130 & 90 & 61 & 43 & 41 & 79 & 68 & 35 & 48 & 9 & 46 & 19 \\
\hline & Biov & 5391 & 3240 & 2381 & 1667 & 1725 & 3520 & 3024 & 1438 & 1990 & 330 & 2054 & 680 \\
\hline \multirow{2}{*}{ K. lunaris } & Dens & 864 & 705 & 806 & 341 & 516 & 1066 & 279 & 691 & 537 & 219 & 539 & 685 \\
\hline & Biov & 904 & 738 & 844 & 357 & 540 & 1116 & 292 & 723 & 562 & 229 & 564 & 717 \\
\hline \multirow{2}{*}{ M. contortum } & Dens & 69 & 104 & 84 & 25 & 46 & 128 & 13 & - & 11 & 9 & - & 57 \\
\hline & Biov & 1779 & 2582 & 2033 & 573 & 1104 & 3277 & 339 & - & 240 & 236 & - & 1499 \\
\hline
\end{tabular}

(-) espécie ausente nos campos de contagem

Tabela 22: Densidade fitoplanctônica $\left(10^{3}\right.$ ind. $\left.\mathrm{mL}^{-1}\right)$ e biovolume $\left(10^{3} \mu \mathrm{m}^{3} \cdot \mathrm{mL}^{-1}\right)$ dos gêneros e espécies mais freqüentes, na lagoa facultativa da ETE de Pariquera-Açu, em setembro de 2006 (ss: sub-superfície, m: meio e f: interface água-sedimento).

\begin{tabular}{|c|c|c|c|c|c|c|c|c|c|c|c|c|c|}
\hline & \multicolumn{3}{|c|}{$7 \mathrm{~h}$} & \multicolumn{3}{|c|}{$10 \mathrm{~h}$} & \multicolumn{3}{|c|}{$13 \mathrm{~h}$} & \multicolumn{3}{|c|}{16} \\
\hline & & SS & $M$ & $F$ & SS & $M$ & $\mathrm{~F}$ & SS & $M$ & $\mathrm{~F}$ & SS & $M$ & $\mathrm{~F}$ \\
\hline \multirow{2}{*}{ S. aquatilis } & Dens & 20 & 14 & 54 & 43 & 29 & $\bar{~} \overline{44}$ & $\overline{19}$ & $\overline{39}$ & $\overline{112}$ & 27 & $\overline{42}$ & $\overline{444}$ \\
\hline & Biov & 123 & 90 & 338 & 270 & 181 & 278 & 121 & 243 & 77 & 167 & 263 & 278 \\
\hline \multirow{2}{*}{ C. kessleri } & Dens & 2 & 7 & 5 & 4 & 5 & 1 & 2 & 7 & 4 & 7 & 3 & 1 \\
\hline & Biov & 73 & 279 & 240 & 195 & 177 & 17 & 101 & 257 & 138 & 293 & 106 & 21 \\
\hline \multirow{2}{*}{ K. lunaris } & Dens & 33 & 56 & 54 & 45 & 31 & 55 & 20 & 62 & 43 & 51 & 81 & 55 \\
\hline & Biov & 34 & 59 & 57 & 47 & 32 & 58 & 21 & 65 & 45 & 53 & 84 & 58 \\
\hline \multirow{2}{*}{ M. contortum } & Dens & 7 & 8 & 20 & 4 & 10 & 11 & 6 & 15 & 1 & 9 & 18 & 11 \\
\hline & Biov & 261 & 260 & 621 & 118 & 317 & 298 & 137 & 547 & 33 & 206 & 715 & 252 \\
\hline \multirow[t]{2}{*}{ Monoraphidium sp } & Dens & 5 & 2 & 5 & 9 & 8 & 5 & 8 & 6 & 1 & 8 & 8 & 5 \\
\hline & Biov & 542 & 92 & 524 & 1292 & 563 & 734 & 548 & 662 & 78 & 901 & 705 & 365 \\
\hline
\end{tabular}

$\mathrm{Na}$ lagoa facultativa de Jacupiranga, em janeiro (Tabela 23), as cianobactérias mais representativas foram Lyngbia sp, Phormidium sp, S. aquatilis; a euglenofícea Trachelomonas oblonga; e as clorofíceas Micractinium pusillum, Monoraphidium contortum e Monoraphidium sp Em abril (Tabela 24) as espécies de cianobactéria, de euglenofícea e Monoraphidium contortum continuaram presentes e duas novas espécies de clorofíceas apareceram Chlorella Kessleri e Eutetramorus planctonicus.

Em julho (Tabela 25), Lyngbia sp, Synecocystis aquatilis, Chlorella kessleri, Eutetramorus planctonicus e Monoraphidium contortum voltaram a aparecer junto com a clorofícea Kirchneriella lunaris. A amostra do mês de setembro (Tabela 26) foi a única em que houve predominância de Chlorella Kessleri e Kirchneriella lunaris.

As maiores contribuições de biovolume, em janeiro, foram de Phormidium sp e Micractinium pusillum. Quanto à densidade fitoplanctônica, a espécie mais representativa foi Synecocystis aquatilis, exceto às 7 e 10h (na sub-superfície), onde Monoraphidium sp 
foi a mais representativa e às $10 \mathrm{~h}$ (interface água-sedimento), quando Micractinium pusillum.

Em abril, a contribuição de biovolume foi maior por parte de Phormidium $\mathrm{sp}$ e de densidade, Synecocystis aquatilis (7h, sub-superfície e meio; 10h, interface águasedimento; $13 \mathrm{~h}$, meio e interface água-sedimento; 16h, interface água-sedimento) e $C$. kessleri $(7 \mathrm{~h}$, interface água-sedimento; $10 \mathrm{~h}$, sub-superfície e meio; $13 \mathrm{~h}$, sub-superfície; 16h, sub-superfície e meio).

Em julho, as maiores contribuições de densidade também foram de Synecocystis aquatilis (7h, interface água-sedimento; 10h, meio e interface água-sedimento; 13h, interface água-sedimento) e Chlorella kessleri (7h, meio e interface água-sedimento; 10h, sub-superfície; 13h sub-superfície e meio; 16h, sub-superfície, meio e interface águasedimento). Porém, a maior contribuição em biovolume foi de Eutetramorus planctonicus, exceto às $10 \mathrm{~h}$ (interface água-sedimento), quando Chlorella kessleri foi maior. Em setembro, Chlorella kessleri apresentou a maior contribuição em biovolume e Kirchneriella lunaris, a maior densidade.

Tabela 23: Densidade fitoplanctônica $\left(10^{3}\right.$ ind. $\left.\mathrm{mL}^{-1}\right)$ e biovolume $\left(10^{3} \mu \mathrm{m}^{3} \cdot \mathrm{mL}^{-1}\right)$ dos gêneros e espécies mais freqüentes, na lagoa facultativa da ETE de Jacupiranga, em janeiro de 2006 (ss: sub-superfície, m: meio e f: interface água-sedimento).

\begin{tabular}{|c|c|c|c|c|c|c|c|c|c|c|c|c|c|}
\hline & \multicolumn{3}{|c|}{$7 \mathrm{~h}$} & \multicolumn{3}{|c|}{$10 \mathrm{~h}$} & \multicolumn{3}{|c|}{$13 \mathrm{~h}$} & \multicolumn{3}{|c|}{16} \\
\hline & & SS & $\mathrm{M}$ & $\mathrm{F}$ & SS & $\mathrm{M}$ & $\mathrm{F}$ & SS & $\mathrm{M}$ & $\mathrm{F}$ & SS & $\mathrm{M}$ & $\mathrm{F}$ \\
\hline \multirow{2}{*}{ Lyngbia sp } & Dens & 9 & $\overline{77}$ & $\overline{7}$ & 9 & $\overline{5}$ & 8 & 8 & 2 & $\overline{5}$ & 8 & $\bar{~} 6$ & $\overline{76}$ \\
\hline & Biov & 2515 & 2004 & 558 & 2420 & 1354 & 660 & 1487 & 194 & 407 & 2308 & 507 & 439 \\
\hline \multirow{2}{*}{ Phormidium sp } & Dens & 5 & 17 & 4 & 3 & 1 & 8 & 10 & 12 & 4 & 5 & 4 & 8 \\
\hline & Biov & 30234 & 62027 & 11536 & 11708 & 3527 & 24954 & 34933 & 42218 & 12518 & 5072 & 12891 & 28628 \\
\hline \multirow{2}{*}{ S. aquatilis } & Dens & 15 & 51 & 35 & 17 & 19 & - & 20 & 48 & 43 & 26 & 43 & 38 \\
\hline & Biov & 94 & 322 & 221 & 111 & 119 & - & 140 & 304 & 267 & 688 & 267 & 236 \\
\hline \multirow{2}{*}{ Trachelomonas } & Dens & 2 & 3 & 1 & 2 & 1 & 1 & 2 & 2 & 1 & 2 & 2 & 1 \\
\hline & Biov & 2335 & 2842 & 1284 & 3413 & 1120 & 1357 & 2965 & 2648 & 2368 & 1835 & 1997 & 987 \\
\hline \multirow{2}{*}{ M. pusillum } & Dens & 11 & 1 & 10 & 11 & 8 & 19 & 13 & 1 & 5 & 8 & 13 & 18 \\
\hline & Biov & 10010 & 595 & 9500 & 14794 & 8793 & 19244 & 25238 & 518 & 4781 & 14777 & 18735 & 29778 \\
\hline \multirow{2}{*}{ M. contortun } & Dens & 3 & 9 & 4 & 3 & 3 & 3 & 4 & 6 & 1 & 6 & 6 & 3 \\
\hline & Biov & 69 & 246 & 153 & 119 & 103 & 145 & 150 & 267 & 41 & 680 & 187 & 90 \\
\hline \multirow[t]{2}{*}{ Monoraphidium sp } & Dens & 21 & 2 & 11 & 21 & 7 & 15 & 16 & 2 & 11 & 8 & 11 & 9 \\
\hline & Biov & 1617 & 367 & 1073 & 2742 & 742 & 2457 & 2417 & 398 & 2125 & 2545 & 1318 & 1260 \\
\hline
\end{tabular}

(-) espécie ausente nos campos de contagem 
Tabela 24: Densidade fitoplanctônica $\left(10^{3}\right.$ ind. $\left.\mathrm{mL}^{-1}\right)$ e biovolume $\left(10^{3} \mu \mathrm{m}^{3} \cdot \mathrm{mL}^{-1}\right)$ dos gêneros e espécies mais freqüentes, na lagoa facultativa da ETE de Jacupiranga, em abril de 2006 (ss: sub-superfície, m: meio e f: interface água-sedimento).

\begin{tabular}{|c|c|c|c|c|c|c|c|c|c|c|c|c|c|}
\hline & \multicolumn{3}{|c|}{$7 \mathrm{~h}$} & \multicolumn{3}{|c|}{$10 \mathrm{~h}$} & \multicolumn{3}{|c|}{$13 \mathrm{~h}$} & \multicolumn{3}{|c|}{16} \\
\hline & & SS & $\mathrm{M}$ & $\mathrm{F}$ & SS & $\mathrm{M}$ & $\mathrm{F}$ & SS & $\mathrm{M}$ & $\mathrm{F}$ & SS & $\mathrm{M}$ & $\mathrm{F}$ \\
\hline \multirow{2}{*}{ Lyngbia sp } & Dens & 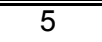 & 7 & 2 & 4 & $\overline{5}$ & 2 & 3 & 17 & 17 & 4 & 2 & $\overline{5}$ \\
\hline & Biov & 219 & 552 & 148 & 205 & 353 & 114 & 182 & 1110 & 1006 & 213 & 106 & 315 \\
\hline \multirow{2}{*}{ Phormidium sp } & Dens & 28 & 17 & 5 & 10 & 12 & 6 & 23 & 14 & 5 & 15 & 12 & 15 \\
\hline & Biov & 84980 & 53189 & 15866 & 28890 & 36022 & 17675 & 80248 & 47554 & 16646 & 53401 & 38611 & 45340 \\
\hline \multirow{2}{*}{ S. aquatilis } & Dens & 31 & 51 & 29 & 19 & 52 & 49 & 21 & 68 & 59 & 6 & 35 & 80 \\
\hline & Biov & 198 & 322 & 180 & 118 & 325 & 310 & 132 & 424 & 371 & 35 & 219 & 501 \\
\hline \multirow{2}{*}{ T. oblonga } & Dens & 1 & 3 & 1 & 2 & 1 & 2 & 2 & 5 & 2 & 2 & - & 1 \\
\hline & Biov & 802 & 5325 & 767 & 2802 & 651 & 3077 & 2035 & 6633 & 2381 & 2286 & - & 950 \\
\hline \multirow{2}{*}{ C. kessleri } & Dens & - & 44 & 33 & 35 & 50 & 46 & 61 & 27 & 16 & 39 & 44 & 56 \\
\hline & Biov & - & 5787 & 3786 & 3372 & 4988 & 4902 & 6873 & 3210 & 1999 & 5112 & 6067 & 6660 \\
\hline \multirow{2}{*}{ E. planctonicus } & Dens & 1 & 9 & 2 & 2 & 7 & 1 & 10 & - & 1 & 3 & 2 & 5 \\
\hline & Biov & 445 & 5572 & 1290 & 1024 & 4733 & 882 & 8766 & - & 706 & 2979 & 1480 & 3188 \\
\hline \multirow[t]{2}{*}{ M. contortum } & Dens & 3 & 9 & 3 & 5 & 10 & 2 & 5 & 12 & 6 & 6 & 4 & 11 \\
\hline & Biov & 118 & 265 & 65 & 150 & 135 & 29 & 177 & 190 & 89 & 534 & 88 & 259 \\
\hline
\end{tabular}

(-) espécie ausente nos campos de contagem

Tabela 25: Densidade fitoplanctônica $\left(10^{3}\right.$ ind. $\left.\mathrm{mL}^{-1}\right)$ e biovolume $\left(10^{3} \mu \mathrm{m}^{3} \cdot \mathrm{mL}^{-1}\right)$ dos gêneros e espécies mais freqüentes, na lagoa facultativa da ETE de Jacupiranga, em julho de 2006 (ss: sub-superfície, m: meio e f: interface água-sedimento).

\begin{tabular}{|c|c|c|c|c|c|c|c|c|c|c|c|c|c|}
\hline & \multicolumn{3}{|c|}{$7 \mathrm{~h}$} & \multicolumn{3}{|c|}{$10 \mathrm{~h}$} & \multicolumn{3}{|c|}{$13 \mathrm{~h}$} & \multicolumn{3}{|c|}{16} \\
\hline & & SS & $\mathrm{M}$ & $F$ & SS & $\mathrm{M}$ & $\mathrm{F}$ & SS & $\mathrm{M}$ & $\mathrm{F}$ & SS & $M$ & $\mathrm{~F}$ \\
\hline \multirow{2}{*}{ Lyngbia sp } & Dens & 59 & 177 & 69 & 162 & 329 & 31 & 444 & 999 & 253 & 28 & 35 & $\overline{79}$ \\
\hline & Biov & 2979 & 10123 & 3775 & 8921 & 19217 & 1865 & 2558 & 5733 & 2927 & 1729 & 2064 & 4699 \\
\hline \multirow{2}{*}{ S. aquatilis } & Dens & 29 & 359 & 380 & 190 & 292 & 352 & 210 & 199 & 276 & 212 & 207 & 399 \\
\hline & Biov & 182 & 2256 & 2387 & 1190 & 1832 & 2213 & 1319 & 1250 & 1736 & 1331 & 4166 & 2504 \\
\hline \multirow{2}{*}{ C. kessleri } & Dens & 29 & 652 & 276 & 430 & 227 & 207 & 321 & 575 & 265 & 335 & 373 & 407 \\
\hline & Biov & 1477 & 33226 & 13180 & 21923 & 13152 & 9241 & 16331 & 29284 & 16336 & 15963 & 16634 & 25039 \\
\hline \multirow{2}{*}{ E. planctonicus } & Dens & 32 & 88 & 35 & 91 & 55 & - & 58 & 55 & 47 & 40 & 41 & 71 \\
\hline & Biov & 29989 & 55472 & 29850 & 61099 & 38484 & - & 53546 & 50996 & 30824 & 37627 & 41608 & 48644 \\
\hline \multirow{2}{*}{ K. lunaris } & Dens & 4 & 50 & 45 & - & 46 & 59 & 28 & 144 & 11 & 46 & 69 & 150 \\
\hline & Biov & 4 & 52 & 47 & - & 48 & 61 & 29 & 150 & 12 & 48 & 72 & 157 \\
\hline \multirow[t]{2}{*}{ M. contortum } & Dens & 13 & 33 & 24 & 47 & 31 & 17 & 36 & 72 & 6 & 28 & 38 & 12 \\
\hline & Biov & 300 & 778 & 329 & 1091 & 604 & 347 & 1238 & 6778 & 280 & 583 & 1074 & 233 \\
\hline
\end{tabular}

(-) espécie ausente nos campos de contagem

Tabela 26: Densidade fitoplanctônica $\left(10^{3}\right.$ ind. $\left.\mathrm{mL}^{-1}\right)$ e biovolume $\left(10^{3} \mu \mathrm{m}^{3} \cdot \mathrm{mL}^{-1}\right)$ dos gêneros e espécies mais freqüentes, na lagoa facultativa da ETE de Jacupiranga, em setembro de 2006 (ss: sub-superfície, m: meio e f: interface água-sedimento).

\begin{tabular}{|c|c|c|c|c|c|c|c|c|c|c|c|c|c|}
\hline & \multicolumn{3}{|c|}{$7 \mathrm{~h}$} & \multicolumn{3}{|c|}{$10 \mathrm{~h}$} & \multicolumn{3}{|c|}{$13 \mathrm{~h}$} & \multicolumn{3}{|c|}{16} \\
\hline & & SS & M & $\mathrm{F}$ & SS & $\mathrm{M}$ & $\mathrm{F}$ & SS & $\mathrm{M}$ & $\mathrm{F}$ & SS & M & $\mathrm{F}$ \\
\hline \multirow{2}{*}{ C. kessleri } & Dens & 369 & 1163 & 2021 & 881 & 875 & 829 & 1175 & 601 & 743 & 1186 & 1313 & 415 \\
\hline & Biov & 16428 & 48396 & 84094 & 39274 & 33935 & 34500 & 81544 & 30621 & 37837 & 64449 & 66875 & 23994 \\
\hline \multirow[t]{2}{*}{ K. Iunaris } & Dens & 1209 & 1405 & 1589 & 2211 & 1555 & 1410 & 1575 & 691 & 1917 & 887 & 1745 & 950 \\
\hline & Biov & 7594 & 8823 & 9980 & 13886 & 9763 & 8852 & 9893 & 4339 & 12041 & 5569 & 10957 & 5966 \\
\hline
\end{tabular}




\subsubsection{Determinação da biomassa fitoplanctônica - concentração de clorofila a e feofitina}

Nas lagoas facultativas estudadas, as concentrações de clorofila a e de feofitina foram muito altas, por isso houve a necessidade de transformar as unidades de $\mu \mathrm{g} . \mathrm{L}^{-1}$ para $\mathrm{mg} \cdot \mathrm{L}^{-1}$.

Foi observada variabilidade sazonal na concentração de clorofila a na lagoa facultativa de Pariquera-Açu (Figura 25). As maiores concentrações desta variável ocorreram em janeiro (1,56 mg. $\mathrm{L}^{-1}$, às $13 \mathrm{~h}$, meio) e a menor, em julho $\left(0,21 \mathrm{mg} \cdot \mathrm{L}^{-1}\right.$, às 13h, interface água-sedimento). Nas amostragens de janeiro e abril houve variações vertical e horária. Em abril, a concentração de clorofila a diminuiu com a profundidade, principalmente às $16 \mathrm{~h}$, quando na sub-superfície a concentração foi de $1,18 \mathrm{mg} \cdot \mathrm{L}^{-1} ; 0,89$ $\mathrm{mg} \cdot \mathrm{L}^{-1}$ no meio e chegando a $0,65 \mathrm{mg} \cdot \mathrm{L}^{-1}$ na interface água-sedimento. Em janeiro, neste mesmo horário, a concentração aumentou com a profundidade variando de $0,95 \mathrm{mg} \cdot \mathrm{L}^{-1}$ (sub-superfície) a 1,21 mg. $\mathrm{L}^{-1}$ (interface água-sedimento). Nos demais períodos, as concentração obtidas para esta variável foram maiores na sub-superfície e menores na interface água-sedimento.

$\mathrm{Na}$ lagoa de Jacupiranga também foi observada variação sazonal, sendo que as menores concentrações ocorreram em abril (entre 0,38; interface água-sedimento, às $13 \mathrm{~h}$; e $0,52 \mathrm{mg} . \mathrm{L}^{-1}$; sub-superfície, às $16 \mathrm{~h}$ ) e as maiores, em setembro (entre 0,93; meio, às $10 \mathrm{~h}$; e $1,75 \mathrm{mg} \cdot \mathrm{L}^{-1}$; sub-superfície, às $16 \mathrm{~h}$ ). Nesta mesma lagoa houve variação horária nas amostragens de janeiro e setembro, quando as concentrações de clorofila a aumentaram principalmente na sub-superfície, entre as $7\left(0,48\right.$ e 1,06 mg.L $\left.{ }^{-1}\right)$ e $16 \mathrm{~h}(0,88$ e $\left.1,75 \mathrm{mg} \cdot \mathrm{L}^{-1}\right)$.

As concentrações de feofitina estão apresentadas na Figura 26. Na lagoa de Pariquera-Açu, em janeiro, foi observado pico $\left(0,63 \mathrm{mg} \cdot \mathrm{L}^{-1}\right)$ às $10 \mathrm{~h}$ (meio), enquanto nos outros horários, também na interface água-sedimento, as concentrações permaneceram entre 0,08 e $0,16 \mathrm{mg} \cdot \mathrm{L}^{-1}$ (7 e $13 \mathrm{~h}$, respectivamente). Nos outros períodos não foram observadas variações sazonais, horárias e verticais e as concentrações variaram entre $0,08 \mathrm{mg} \cdot \mathrm{L}^{-1}$ (10h, interface água-sedimento) em setembro e $0,20 \mathrm{mg} \cdot \mathrm{L}^{-1}$ (13h, meio), em julho.

Na lagoa de Jacupiranga não ocorreram variações horárias e verticais, porém foi observada variação sazonal, sendo as maiores concentrações verificadas em julho e setembro (30 mg. $\mathrm{L}^{-1}$, às $16 \mathrm{~h}$; interface água-sedimento e sub-superfície) e as menores, em janeiro (entre 0,09 e $0,20 \mathrm{mg}^{-1} \mathrm{~L}^{-1}$; $10 \mathrm{~h}$, interface água-sedimento; e $16 \mathrm{~h}$, subsuperfície, respectivamente). 


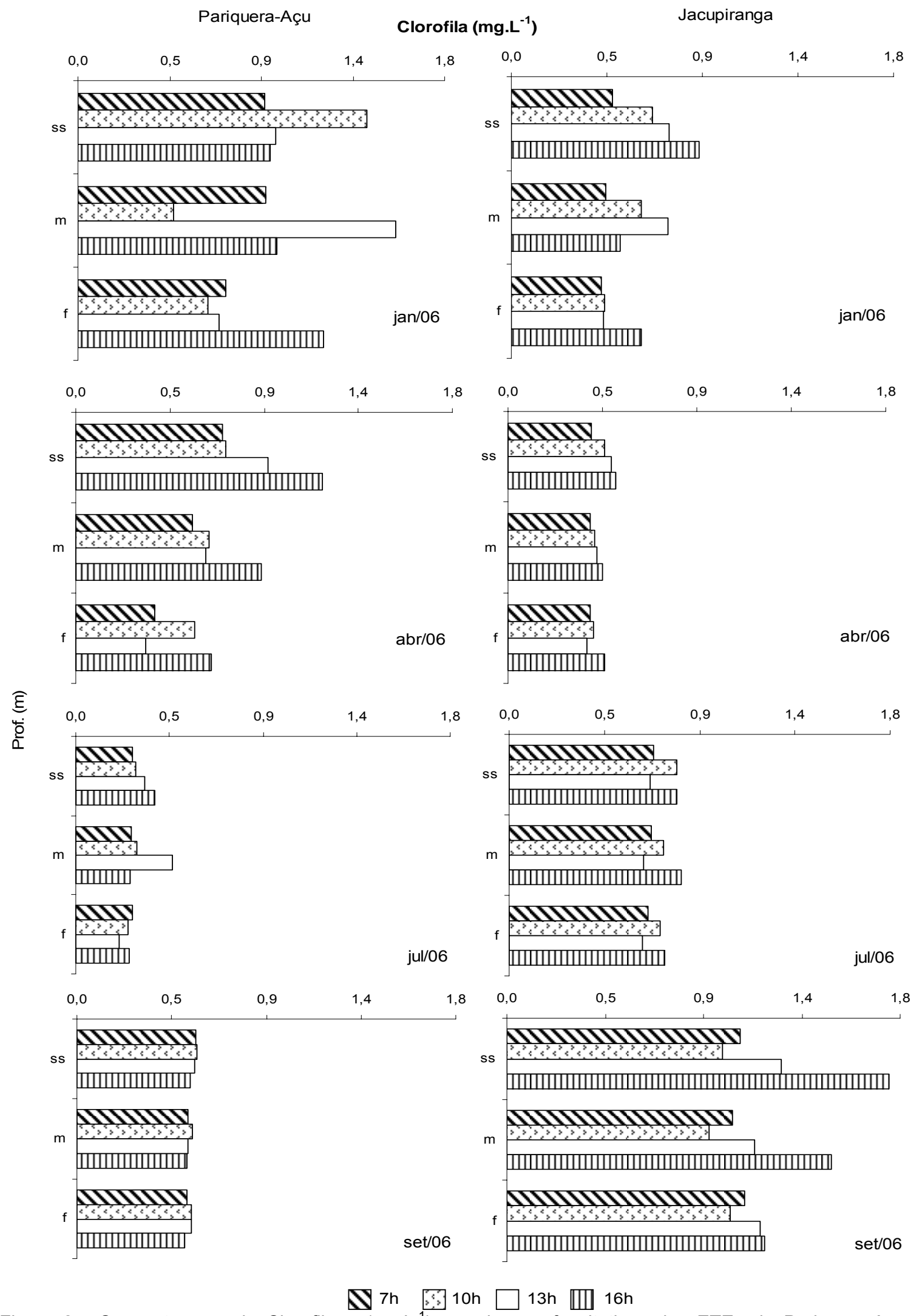

Figura 25: Concentrações de Clorofila a $\left(\mathrm{mg}^{-\mathrm{L}^{-1}}\right)$, nas lagoas facultativas das ETEs de Pariquera-Açu e Jacupiranga (ss: sub-superfície, m: meio e f: interface água-sedimento), em diferentes épocas do ano. 

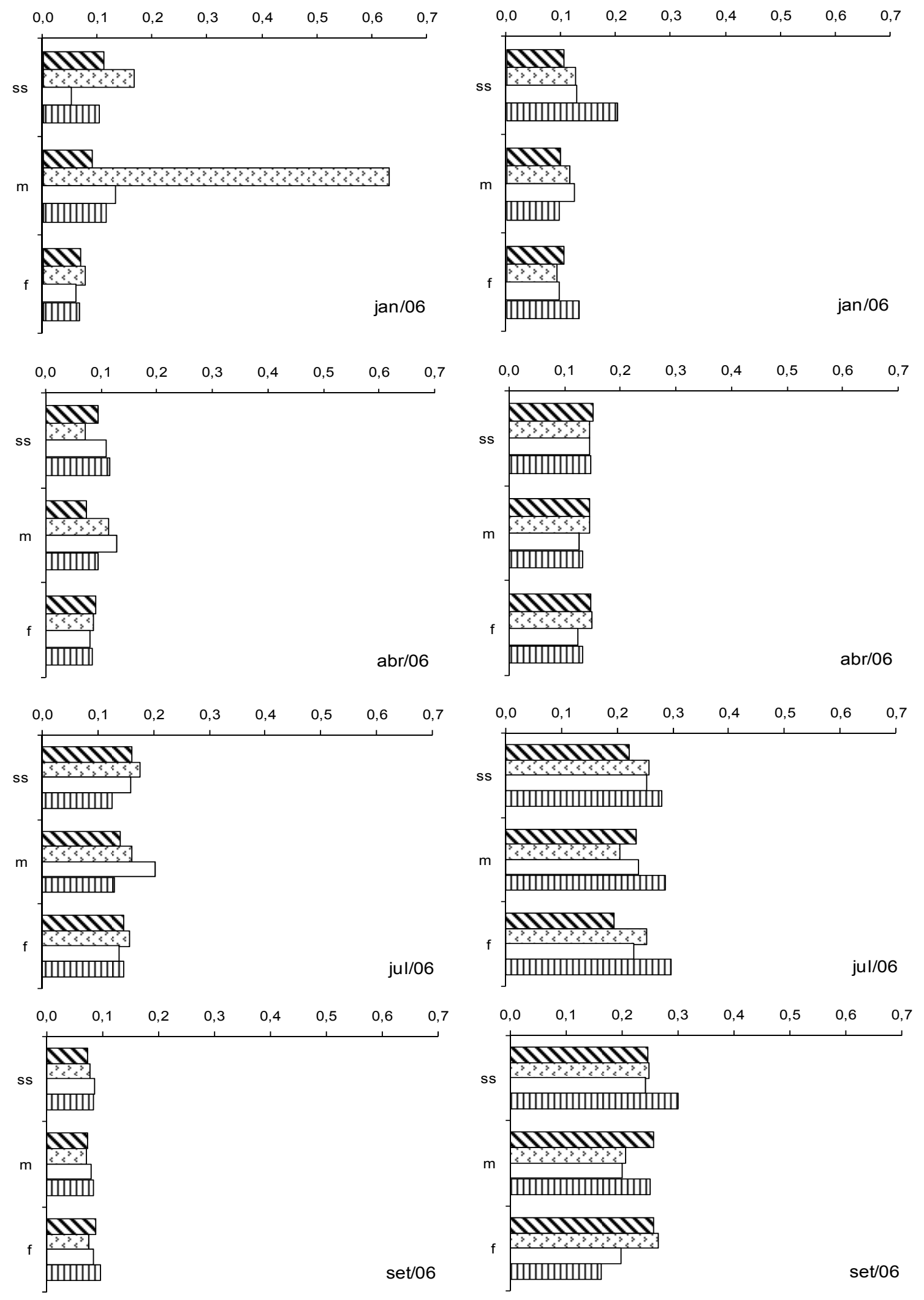

$\mathbf{N} 7 \mathrm{~h} \quad$ 10h $\square$ 13h

Figura 26: Concentrações de Feofitina (mg. $\mathrm{L}^{-1}$ ), nas lagoas facultativas das ETEs de Pariquera-Açu e Jacupiranga (ss: sub-superfície, m: meio e f: interface água-sedimento), em diferentes épocas do ano. 


\subsubsection{Produção primária fitoplanctônica}

Nas tabelas 27 e 28 estão apresentados os valores de produção primária líquida (PPL) e produção primária bruta (PPB), respectivamente, obtidos nas duas lagoas facultativas estudadas.

Observaram-se maiores valores PPL e PPB na sub-superfície da lagoa facultativa de Pariquera-Açu, em janeiro, e na interface água-sedimento, em setembro. Os maiores valores de PPL foram observados em janeiro quando estiveram entre 13660 e 15520 $\mathrm{mgO}_{2} \cdot \mathrm{m}^{-3} \cdot \mathrm{h}^{-1}(10 \mathrm{~h})$ e os de PPB, em setembro, entre 15520 e $15891 \mathrm{mgO}_{2} \cdot \mathrm{m}^{-3} \cdot \mathrm{h}^{-1}$, às $7 \mathrm{~h}$.

$\mathrm{Na}$ lagoa facultativa de Jacupiranga, os maiores valores de PPL ocorreram em julho, apenas na sub-superfície, às 10 e $13 \mathrm{~h}\left(11931\right.$ e $\left.10069 \mathrm{mgO}_{2} \cdot \mathrm{m}^{-3} \cdot \mathrm{h}^{-1}\right)$ e o maior de PPB em janeiro, às $13 \mathrm{~h}\left(20600 \mathrm{mgO} \mathrm{O}_{2} \cdot \mathrm{m}^{-3} \cdot \mathrm{h}^{-1}\right.$, na sub-superfície).

Elevados valores de respiração da comunidade $(\mathrm{Rc})$ foram observados nas duas lagoas estudadas (Tabela 29). Na lagoa de Pariquera-Açu, os maiores valores de Rc ocorreram na sub-superfície, sendo que o maior foi de $7000 \mathrm{mgO} \cdot \mathrm{m}^{-3} \cdot \mathrm{h}^{-1}$, em janeiro (16h) e $6968 \mathrm{mgO}_{2} \cdot \mathrm{m}^{-3} \cdot \mathrm{h}^{-1}$, em setembro (10h).

Os maiores valores obtidos de Rc, na lagoa de Jacupiranga, foram de 17040 (na sub-superfície) e $34579 \mathrm{mgO} \cdot \mathrm{m}^{-3} \cdot \mathrm{h}^{-1}$ (no meio), em janeiro e setembro, respectivamente, às $13 \mathrm{~h}$.

Tabela 27: Produção Primária Líquida fitoplanctônica - PPL $\left(\mathrm{mgO}_{2} \cdot \mathrm{m}^{-3} \cdot \mathrm{h}^{-1}\right)$, nas lagoas facultativas das ETEs de Pariquera-Açu e Jacupiranga (ss: sub-superfície, m: meio e f: interface água-sedimento), em diferentes épocas do ano.

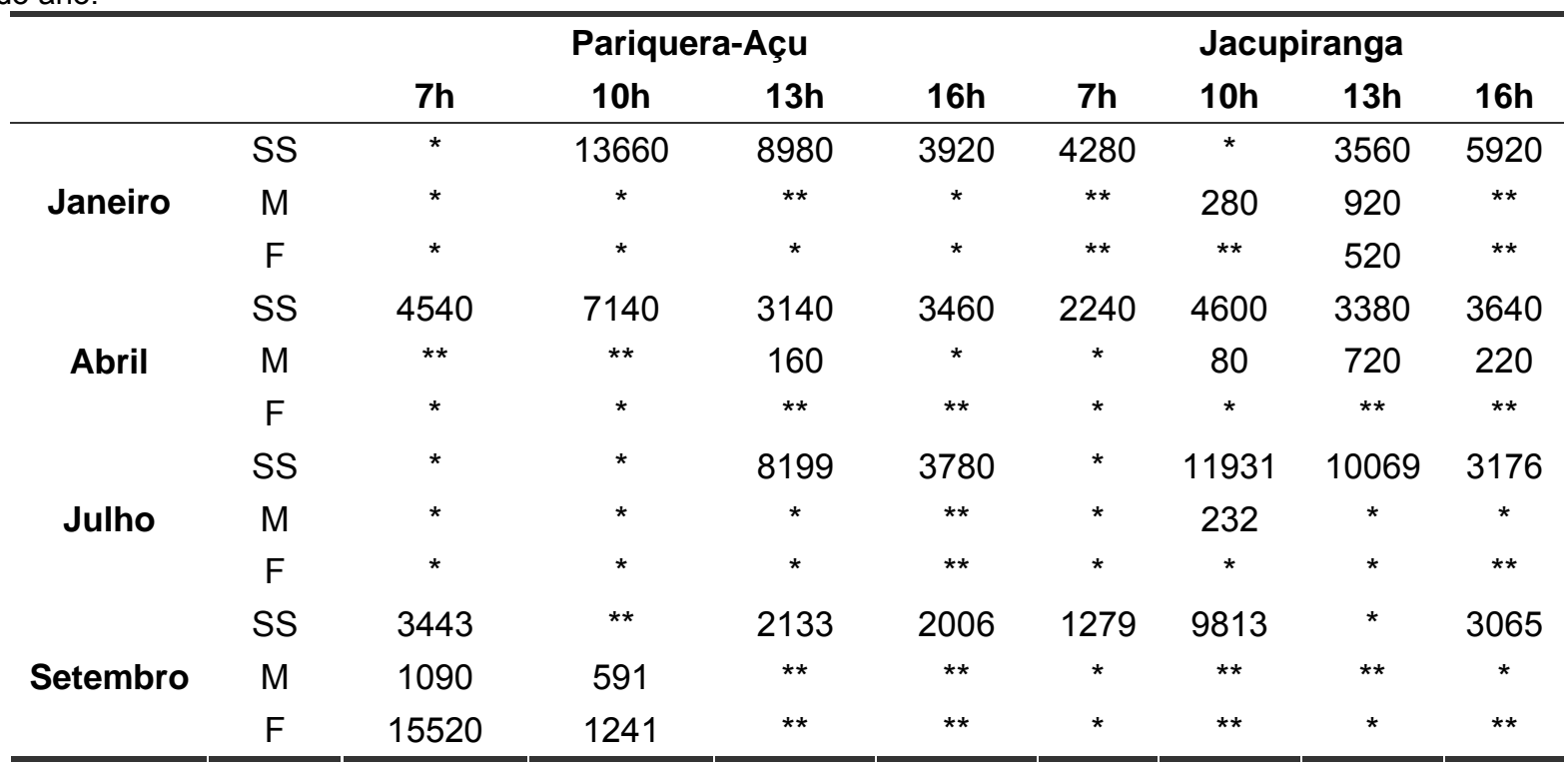

$\left.{ }^{*}\right)$ : concentração de OD abaixo do limite do método $\left(0,06 \mathrm{mg} \cdot \mathrm{L}^{-1}\right)$, segundo APHA (1999); $\left(^{* \star}\right)$ Rc >PPB. 
Tabela 28: Produção Primária Bruta fitoplanctônica - PPB $\left(\mathrm{mgO}_{2} \cdot \mathrm{m}^{-3} \cdot \mathrm{h}^{-1}\right)$, nas lagoas facultativas das ETEs de Pariquera-Açu e Jacupiranga (ss: sub-superfície, m: meio e f: interface água-sedimento), em diferentes épocas do ano.

\begin{tabular}{|c|c|c|c|c|c|c|c|c|c|}
\hline & & \multicolumn{4}{|c|}{ Pariquera-Açu } & \multicolumn{4}{|c|}{ Jacupiranga } \\
\hline & & $7 \mathrm{~h}$ & $10 \mathrm{~h}$ & $13 \mathrm{~h}$ & $16 \mathrm{~h}$ & $7 \mathrm{~h}$ & $10 \mathrm{~h}$ & $13 \mathrm{~h}$ & $16 \mathrm{~h}$ \\
\hline & SS & * & 15520 & 12320 & 10920 & 5560 & * & 20600 & 6940 \\
\hline \multirow[t]{3}{*}{ Janeiro } & M & * & * & * & * & 320 & 920 & 1900 & 1440 \\
\hline & $\mathrm{F}$ & * & * & * & * & 540 & 1640 & 5700 & 1100 \\
\hline & SS & 5480 & 12140 & 8080 & 3460 & 2240 & 7380 & 6980 & 4700 \\
\hline \multirow[t]{3}{*}{ Abril } & $M$ & 340 & 1720 & 1200 & 540 & * & 2000 & 2380 & 720 \\
\hline & $\mathrm{F}$ & $*$ & * & * & $*$ & * & $*$ & 1680 & 860 \\
\hline & SS & * & * & 13626 & 4673 & * & 11931 & 14348 & 8534 \\
\hline \multirow[t]{3}{*}{ Julho } & $M$ & * & * & * & 1461 & * & 232 & * & * \\
\hline & $\mathrm{F}$ & * & * & * & * & * & * & * & * \\
\hline & SS & 4150 & 1020 & 4035 & 2957 & 1279 & 12934 & * & 15162 \\
\hline \multirow[t]{2}{*}{ Setembro } & M & 1785 & 2203 & 856 & 255 & * & 573 & 3087 & * \\
\hline & $\mathrm{F}$ & 15891 & 2052 & 719 & 209 & * & 2117 & $*$ & * \\
\hline
\end{tabular}

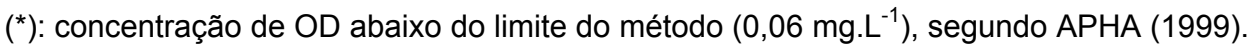

Tabela 29: Respiração da comunidade - $\mathrm{Rc}\left(\mathrm{mgO}_{2} \cdot \mathrm{m}^{-3} \cdot \mathrm{h}^{-1}\right)$, nas lagoas facultativas das ETEs de PariqueraAçu e Jacupiranga (ss: sub-superfície, m: meio e f: interface água-sedimento), em diferentes épocas do ano.

\begin{tabular}{|c|c|c|c|c|c|c|c|c|c|}
\hline & & \multicolumn{4}{|c|}{ Pariquera-Açu } & \multicolumn{4}{|c|}{ Jacupiranga } \\
\hline & & $7 \mathrm{~h}$ & $10 \mathrm{~h}$ & $13 \mathrm{~h}$ & $16 \mathrm{~h}$ & $7 \mathrm{~h}$ & $10 \mathrm{~h}$ & $13 \mathrm{~h}$ & $16 \mathrm{~h}$ \\
\hline \multirow{3}{*}{ Janeiro } & SS & * & 1860 & 3340 & 7000 & 1280 & * & 17040 & 1020 \\
\hline & $M$ & * & $*$ & 1980 & * & 1160 & 640 & 980 & 2460 \\
\hline & $F$ & * & * & * & * & 700 & 2540 & 5180 & 1560 \\
\hline \multirow{3}{*}{ Abril } & SS & 940 & 5000 & 4940 & * & * & 2780 & 3600 & 1060 \\
\hline & $M$ & 720 & 2060 & 1040 & 1200 & * & 1920 & 1660 & 500 \\
\hline & $\mathrm{F}$ & * & * & 800 & 1160 & * & * & 2680 & 1000 \\
\hline \multirow{3}{*}{ Julho } & SS & * & * & 5427 & 893 & * & * & 4279 & 5359 \\
\hline & $M$ & * & * & * & 2017 & * & * & * & * \\
\hline & $\mathrm{F}$ & * & * & * & 3849 & * & * & * & 937 \\
\hline \multirow{3}{*}{ Setembro } & SS & 707 & 6968 & 1901 & 951 & * & 3120 & * & 12096 \\
\hline & $M$ & 696 & 1612 & 1785 & 1206 & * & 2238 & 34579 & * \\
\hline & $\mathrm{F}$ & 371 & 812 & 2063 & 1183 & * & 3120 & * & 706 \\
\hline
\end{tabular}

$\left(^{*}\right)$ : concentração de OD abaixo do limite do método $\left(0,06 \mathrm{mg} \cdot \mathrm{L}^{-1}\right)$, segundo APHA (1999).

Entre as lagoas estudadas, pôde-se observar padrão diferenciado de PPL para os valores integrados da coluna de água (Tabela 30). Na lagoa facultativa de Pariquera-Açu, os picos de PPL ocorreram em janeiro e julho, às 10 e $13 \mathrm{~h}$ (3415 e $2870 \mathrm{mg} \cdot \mathrm{O}_{2} \cdot \mathrm{m}^{-2} \cdot \mathrm{h}^{-1}$, respectivamente). Abril foi o único período em que houve produção em todos os horários, porém não foi observada variação horária sendo que os valores obtidos estiveram entre 1033 e $1768 \mathrm{mg} \cdot \mathrm{O}_{2} \cdot \mathrm{m}^{-2} \cdot \mathrm{h}^{-1}$ (13 e $10 \mathrm{~h}$, respectivamente). 
Na lagoa de Jacupiranga, os maiores valores de PPL foram observados em julho (tabela 30 ), às 10 e $13 \mathrm{~h}$ (3579 e $3021 \mathrm{mg} \cdot \mathrm{O}_{2} \cdot \mathrm{m}^{-2} \cdot \mathrm{h}^{-1}$, respectivamente) e em setembro, às 10h (3245 mg. $\left.\mathrm{O}_{2} \cdot \mathrm{m}^{-2} \cdot \mathrm{h}^{-1}\right)$. Em abril, nesta lagoa, também foram observados valores de PPL em todos os horários, porém foi observada variação horária. Os valores obtidos em Jacupiranga estiveram entre 560 e $1181 \mathrm{mg} \cdot \mathrm{O}_{2} \cdot \mathrm{m}^{-2} \cdot \mathrm{h}^{-1}$ (7 e 13h, respectivamente).

No entanto na lagoa de Pariquera-Açu, neste mesmo período, também foram observados valores de PPL em todos os horários mas não foi observada variação horária, os valores obtidos estiveram entre 1033 e 1768 mg. $\mathrm{O}_{2} \cdot \mathrm{m}^{-2} \cdot \mathrm{h}^{-1}$ (13 e 10h, respectivamente). A a PPB seguiu o mesmo padrão da PPL, ou seja, os maiores valores foram verificados em janeiro e julho, às 10 e $13 \mathrm{~h}$ (3880 e $4769 \mathrm{mg} \cdot \mathrm{O}_{2} \cdot \mathrm{m}^{-2} \cdot \mathrm{h}^{-1}$, respectivamente). Para Rc, nesta lagoa, foram verificados valores entre 118 e 2155 $\mathrm{mg} \cdot \mathrm{O}_{2} \cdot \mathrm{m}^{-2} \cdot \mathrm{h}^{-1}$, em setembro (7 e $10 \mathrm{~h}$, respectivamente).

$\mathrm{Na}$ lagoa de Jacupiranga, o maior valor de PPB foi obtido em janeiro, às $13 \mathrm{~h}$ (7905 mg. $\left.\mathrm{O}_{2} \cdot \mathrm{m}^{-2} \cdot \mathrm{h}^{-1}\right)$, no entanto, coincidiu com a maior Rc $\left(6353 \mathrm{mg} \cdot \mathrm{O}_{2} \cdot \mathrm{m}^{-2} \cdot \mathrm{h}^{-1}\right)$, o que resultou em baixa PPL (1552 $\left.\mathrm{mg} \cdot \mathrm{O}_{2} \cdot \mathrm{m}^{-2} \cdot \mathrm{h}^{-1}\right)$. Em julho e setembro, foram observados valores próximos de PPB entre os horários amostrados (entre 2560 e $4305 \mathrm{mg} \cdot \mathrm{O}_{2} \cdot \mathrm{m}^{-2} \cdot \mathrm{h}^{-1}$, em julho, às 16 e $13 \mathrm{~h}$, respectivamente; e 843 e $4548 \mathrm{mg} \cdot \mathrm{O}_{2} \cdot \mathrm{m}^{-2} \cdot \mathrm{h}^{-1}$, em setembro, às 7 e $16 \mathrm{~h}$, respectivamente).

Tabela 30: Produção Primária Líquida fitoplanctônica (PPL), Produção Primária Bruta fitoplanctônica (PPB) e Respiração da Comunidade (Rc), por área $\left(\mathrm{mgO}_{2} \cdot \mathrm{m}^{-2} \cdot \mathrm{h}^{-1}\right)$ nas lagoas facultativas das ETEs de Pariquera-Açu e Jacupiranga, em diferentes épocas do ano.

\begin{tabular}{clcccccccc}
\hline & & \multicolumn{4}{c}{ Pariquera-Açu } & \multicolumn{4}{c}{ Jacupiranga } \\
& & $\mathbf{7 h}$ & $\mathbf{1 0 h}$ & $\mathbf{1 3 h}$ & $\mathbf{1 6 h}$ & $\mathbf{7 h}$ & $\mathbf{1 0 h}$ & $\mathbf{1 3 h}$ & $\mathbf{1 6 h}$ \\
\hline \multirow{3}{*}{ PPL } & Janeiro & $*$ & 3415 & 2146 & 980 & 560 & $* *$ & 1552 & 781 \\
& Abril & 1116 & 1768 & 1033 & 1180 & 560 & 1154 & 1181 & 953 \\
& Julho & $*$ & $*$ & 2870 & 1668 & $*$ & 3579 & 3021 & 1234 \\
& Setembro & $* *$ & $* *$ & 276 & 962 & 384 & 3245 & $*$ & 1131 \\
\hline \multirow{2}{*}{ PPB } & Janeiro & $*$ & 3880 & 3080 & 2730 & 1728 & 998 & 7905 & 2857 \\
& Abril & 1387 & 3121 & 2080 & 892 & 560 & 1945 & 1360 & 953 \\
& Julho & $*$ & $*$ & 4769 & 1668 & $*$ & 3579 & 4305 & 2560 \\
& Setembro & $*$ & $*$ & 276 & 962 & 843 & 3245 & $*$ & 4548 \\
\hline \multirow{2}{*}{ Rc } & Janeiro & $*$ & 465 & 934 & 1750 & 1168 & 1114 & 6353 & 2076 \\
& Abril & 271 & 1353 & 1047 & $*$ & $*$ & 791 & 179 & $*$ \\
& Julho & $*$ & $*$ & 1900 & $*$ & $*$ & $*$ & 1284 & 1326 \\
& Setembro & 118 & 2155 & $*$ & $*$ & 460 & $*$ & $*$ & 3417 \\
\hline
\end{tabular}

$\left.{ }^{*}\right)$ : concentração de OD abaixo do limite do método $\left(0,06 \mathrm{mg} \cdot \mathrm{L}^{-1}\right)$, segundo APHA (1999); $\left.{ }^{* *}\right)$ Rc >PPB. 


\subsection{Análise Estatística}

Na tabela 31 está apresentada a análise de variância fatorial das variáveis abióticas e bióticas (densidade, clorofila e feofitina) entre as duas lagoas estudadas (ETE), entre os meses (sazonal), horários (diária) e profundidades (vertical) amostradas.

Foram observadas variações significativas entre as lagoas facultativas de Pariquera-Açu e Jacupiranga ( $\alpha<5 \%$ ) para a maioria das variáveis analisadas, exceto para SSI $(0,1731), \operatorname{COD}(0,5436), \mathrm{CO}_{2}$ livre $(0,7111)$, carbonato $(0,3009), \mathrm{pH}(0,4339)$, temperatura $(0,2807)$ e CE $(0,0907)$.

Não foi observada variação sazonal entre os períodos amostrados para a maioria das variáveis analisadas, exceto para SSI $(0,2828)$, carbonato $(0,2780)$ e pH $(0,1949)$; e entre os horários, exceto para feofitina $(0,3276)$, Namoniacal $(0,9342)$, SSI $(0,3440)$, COD $(0,3459)$, carbonato $(0,1899)$, temperatura $(0,4488)$, CE $(0,6654)$ e densidade $(0,4463)$. Porém pôde-se observar variação vertical para clorofila $(0,0015)$, ortofosfato $(0,0014)$, SST (0,0048), SSO (0,0098), bicarbonato, $\mathrm{CO}_{2}$ total, Cinorgânico $(<, 0001), \mathrm{CO}_{2}$ livre $(0,0004)$, alcalinidade $(0,0398), \mathrm{pH}(0,0247)$ e CE $(0,0001)$.

Tabela 31: Análise de variância fatorial $(\alpha=5 \%)$ nas lagoas facultativas das ETEs de Pariquera-Açu e Jacupiranga, em diferentes épocas do ano, horários e profundidades.

\begin{tabular}{|c|c|c|c|c|c|}
\hline & ETE & Sazonal & Diária & Vertical & $r^{2}$ \\
\hline Clorofila & 0,0021 & $<, 0001$ & 0,0008 & 0,0015 & 0,8473 \\
\hline Feofitina & $<, 0001$ & $<, 0001$ & 0,3276 & 0,1956 & 0,6839 \\
\hline Ortofosfato & 0,0010 & $<, 0001$ & 0,0051 & 0,0014 & 0,8447 \\
\hline Nitrato & $<, 0001$ & $<, 0001$ & 0,0044 & 0,9121 & 0,9980 \\
\hline Nitrito & $<, 0001$ & $<, 0001$ & 0,0304 & 0,3239 & 0,8945 \\
\hline NTK & $<, 0001$ & $<, 0001$ & 0,0555 & 0,2062 & 0,9557 \\
\hline Namoniacal & 0,0003 & $<, 0001$ & 0,9342 & 0,6977 & 0,8449 \\
\hline SST & $<, 0001$ & 0,0267 & $<, 0001$ & 0,0048 & 0,8267 \\
\hline SSO & $<, 0001$ & $<, 0001$ & 0,0009 & 0,0098 & 0,8543 \\
\hline SSI & 0,1731 & 0,2828 & 0,3440 & 0,3606 & 0,4265 \\
\hline Bicarbonato & $<, 0001$ & $<, 0001$ & $<, 0001$ & $<, 0001$ & 0,9695 \\
\hline $\mathrm{CO}_{2}$ total & 0,0022 & $<, 0001$ & 0,0004 & $<, 0001$ & 0,8645 \\
\hline Cinorgânico & 0,0006 & $<, 0001$ & $<, 0001$ & $<, 0001$ & 0,9179 \\
\hline COD & 0,5436 & $<, 0001$ & 0,3459 & 0,4013 & 0,5687 \\
\hline $\mathrm{CO}_{2}$ livre & 0,7111 & 0,0017 & 0,0108 & 0,0004 & 0,6142 \\
\hline Carbonato & 0,3009 & 0,2780 & 0,1899 & 0,2503 & 0,4762 \\
\hline Alcalinidade & 0,0013 & $<, 0001$ & 0,0375 & 0,0398 & 0,8023 \\
\hline $\mathrm{pH}$ & 0,4390 & 0,1949 & 0,0301 & 0,0247 & 0,5568 \\
\hline Temperatura & 0,2807 & 0,3206 & 0,4488 & 0,2776 & 0,4450 \\
\hline CE & 0,0907 & $<, 0001$ & 0,6654 & 0,0001 & 0,7960 \\
\hline Densidade & $<, 0001$ & $<, 0001$ & 0,4463 & 0,6322 & 0,8885 \\
\hline
\end{tabular}

(valores em negrito) Variação significativa, $\alpha<5 \%$. 
Para as variáveis que apresentaram diferenças significativas $(\alpha<5 \%)$ na análise fatorial foi realizado o teste Turkey, com nível de significância de 5\%. Na tabela 32, estão apresentados os valores médios obtidos no teste Turkey para clorofila, feofitina, ortofosfato, nitrato, nitrito, NTK, Namoniacal, SST, SSO, bicarbonato, $\mathrm{CO}_{2}$ total, Cinorgânico, alcalinidade e densidade entre as lagoas facultativas estudadas. As letras diferentes ao lado das médias significam a diferença observada.

Para as variáveis $\mathrm{SSI}, \mathrm{COD}, \mathrm{CO}_{2}$ livre, carbonato, $\mathrm{pH}$, temperatura e $\mathrm{CE}$ não foi necessára a realização do teste Turkey pois elas não apresentaram variação significativa ao nível de $5 \%$.

\begin{tabular}{|c|c|c|}
\hline ETE & Pariquera-Açu & Jacupiranga \\
\hline Clorofila & $0,62 \mathrm{~B}$ & $0,72 \mathrm{~A}$ \\
\hline Feofitina & $0,12 \mathrm{~B}$ & $0,18 \mathrm{~A}$ \\
\hline Ortofosfato & $0,57 \mathrm{~B}$ & $0,68 \mathrm{~A}$ \\
\hline Nitrato & $1,04 \mathrm{~B}$ & $1,32 \mathrm{~A}$ \\
\hline Nitrito & $4,64 \mathrm{~B}$ & $9,58 \mathrm{~A}$ \\
\hline NTK & $1,77 \mathrm{~B}$ & $21,51 \mathrm{~A}$ \\
\hline Namoniacal & $13,52 \mathrm{~B}$ & $15,55 \mathrm{~A}$ \\
\hline SST & $65,75 \mathrm{~B}$ & $71,46 \mathrm{~A}$ \\
\hline SSO & $55,27 \mathrm{~B}$ & $65,71 \mathrm{~A}$ \\
\hline SSI & * & * \\
\hline Bicarbonato & 128,48 B & $136,08 \mathrm{~A}$ \\
\hline $\mathrm{CO}_{2}$ total & $99,79 \mathrm{~B}$ & $106,15 \mathrm{~A}$ \\
\hline Cinorgânico & $27,44 \mathrm{~B}$ & $28,87 \mathrm{~A}$ \\
\hline COD & * & * \\
\hline $\mathrm{CO}_{2}$ livre & * & * \\
\hline Carbonato & * & * \\
\hline Alcalinidade & $114,37 \mathrm{~B}$ & $123,69 \mathrm{~A}$ \\
\hline $\mathrm{pH}$ & * & * \\
\hline Temperatura & * & * \\
\hline CE & * & * \\
\hline Densidade & $4,28 \mathrm{~B}$ & $9,57 \mathrm{~A}$ \\
\hline
\end{tabular}

Na tabela 33 estão apresentados os valores médios obtidos no teste Turkey para clorofila, feofitina, ortofosfato, nitrato, nitrito, NTK, Namoniacal, SST, SSO, bicarbonato, $\mathrm{CO}_{2}$ total, $\mathrm{COD}, \mathrm{CO}_{2}$ livre, Cinorgânico, alcalinidade, $\mathrm{CE}$ e densidade entre os meses de 
amostragem (janeiro, abril, julho e setembro). As letras diferentes ao lado das médias significam a diferença observada.

Para as variáveis SSI, carbonato, $\mathrm{pH}$ e temperatura não foram necessários à realização do teste Turkey, pois não apresentaram variação significativa ao nível de $5 \%$.

Tabela 33: Teste Turkey entre os meses de amostragem (variação sazonal).

As letras presentes indicam as diferenças ao nível de $5 \%$.

\begin{tabular}{|c|c|c|c|c|}
\hline & Janeiro & Abril & Julho & Setembro \\
\hline Clorofila & $0,76 \mathrm{~A}$ & $0,55 \mathrm{~B}$ & $0,55 \mathrm{~B}$ & $0,85 \mathrm{~A}$ \\
\hline Feofitina & $0,12 \mathrm{~B}$ & $0,11 \mathrm{~B}$ & $0,19 \mathrm{~A}$ & $0,15 \mathrm{AB}$ \\
\hline Ortofosfato & $0,52 \mathrm{~B}$ & $0,47 \mathrm{~B}$ & $0,80 \mathrm{~A}$ & $0,72 \mathrm{~A}$ \\
\hline Nitrato & $0,71 \mathrm{C}$ & $0,57 \mathrm{D}$ & $0,79 \mathrm{~B}$ & $2,71 \mathrm{~A}$ \\
\hline Nitrito & $6,51 \mathrm{~B}$ & $7,71 \mathrm{~B}$ & $9,19 \mathrm{~A}$ & $5,00 \mathrm{C}$ \\
\hline NTK & $15,14 \mathrm{D}$ & $16,39 \mathrm{C}$ & $23,55 B$ & $25,60 \mathrm{~A}$ \\
\hline Namoniacal & $10,26 \mathrm{~B}$ & $10,68 \mathrm{~B}$ & $18,71 \mathrm{~A}$ & $18,65 \mathrm{~A}$ \\
\hline SST & $57,81 \mathrm{~B}$ & $56,12 \mathrm{C}$ & $76,08 \mathrm{~A}$ & $83,66 \mathrm{~A}$ \\
\hline SSO & $56,14 \mathrm{~B}$ & $43,66 \mathrm{C}$ & $71,54 \mathrm{~A}$ & $70,27 \mathrm{~A}$ \\
\hline SSI & * & * & * & * \\
\hline Bicarbonato & $120,35 \mathrm{~B}$ & $212,95 \mathrm{~B}$ & $120,25 B$ & $169,93 \mathrm{~A}$ \\
\hline $\mathrm{CO}_{2}$ total & $96,00 \mathrm{~B}$ & $93,86 \mathrm{~B}$ & $93,52 \mathrm{~B}$ & $133,52 \mathrm{~A}$ \\
\hline Cinorgânico & $26,18 \mathrm{~B}$ & $25,61 \mathrm{~B}$ & $25,52 \mathrm{~B}$ & $36,40 \mathrm{~A}$ \\
\hline COD & $17,99 \mathrm{~B}$ & $24,72 \mathrm{~B}$ & $15,53 \mathrm{~B}$ & $53,71 \mathrm{~A}$ \\
\hline $\mathrm{CO}_{2}$ livre & $8,98 \mathrm{AB}$ & $5,34 \mathrm{C}$ & $6,49 \mathrm{BC}$ & $10,50 \mathrm{~A}$ \\
\hline Carbonato & * & * & * & * \\
\hline Alcalinidade & 109,02 B & $111,29 \mathrm{~B}$ & $108,97 \mathrm{~B}$ & $154,48 \mathrm{~A}$ \\
\hline $\mathrm{pH}$ & * & * & * & * \\
\hline Temperatura & * & * & * & * \\
\hline CE & $460,91 \mathrm{~B}$ & $369,95 \mathrm{C}$ & $554,95 \mathrm{~A}$ & $556,16 \mathrm{~A}$ \\
\hline Densidade & $2,99 \mathrm{C}$ & $1,21 \mathrm{C}$ & $10,26 \mathrm{~B}$ & $13,24 \mathrm{~A}$ \\
\hline
\end{tabular}

$\left.{ }^{*}\right)$ Não houve variação significativa $(\alpha>5 \%)$

$\mathrm{Na}$ tabela 34 estão apresentados os valores médios obtidos no teste Turkey para clorofila, ortofosfato, nitrato, nitrito, NTK, SST, SSO, bicarbonato, $\mathrm{CO}_{2}$ total, $\mathrm{CO}_{2}$ livre, Cinorgânico, alcalinidade, entre os horários de amostragem (7, 10, 13 e 16h). As letras diferentes ao lado das médias significam a diferença observada.

Para as variáveis SSI, feofitina, Namoniacal, COD, carbonato, $\mathrm{pH}$, temperatura, CE e densidade não foram necessários à realização do teste Turkey, pois não apresentaram variação significativa ao nível de $5 \%$. 
Tabela 34: Teste Turkey entre os horários de amostragem (variação diária). As letras presentes indicam as diferenças ao nível de $5 \%$.

\begin{tabular}{|c|c|c|c|c|}
\hline & $7 \mathrm{~h}$ & $10 \mathrm{~h}$ & $13 \mathrm{~h}$ & $16 \mathrm{~h}$ \\
\hline Clorofila & $0,59 \mathrm{~B}$ & $0,63 \mathrm{~B}$ & $0,68 \mathrm{AB}$ & $0,77 \mathrm{~A}$ \\
\hline Feofitina & * & * & * & * \\
\hline Ortofosfato & $0,56 \mathrm{~B}$ & $0,59 \mathrm{~B}$ & $0,64 \mathrm{AB}$ & $0,72 \mathrm{~A}$ \\
\hline Nitrato & $1,17 \mathrm{AB}$ & $1,19 \mathrm{AB}$ & $1,20 \mathrm{~B}$ & $1,22 \mathrm{~A}$ \\
\hline Nitrito & $7,98 \mathrm{~A}$ & $6,84 \mathrm{AB}$ & $6,62 \mathrm{~B}$ & $6,97 \mathrm{AB}$ \\
\hline NTK & $20,28 \mathrm{AB}$ & $19,53 \mathrm{~B}$ & $20,59 \mathrm{~A}$ & $20,28 \mathrm{AB}$ \\
\hline Namoniacal & * & * & * & * \\
\hline SST & $69,52 \mathrm{AB}$ & $61,06 \mathrm{~B}$ & $70,87 \mathrm{~A}$ & $72,22 \mathrm{~A}$ \\
\hline SSO & $55,33 \mathrm{~B}$ & $57,85 \mathrm{~B}$ & $62,04 \mathrm{AB}$ & $66,39 \mathrm{~A}$ \\
\hline SSI & * & * & * & * \\
\hline Bicarbonato & $136,68 \mathrm{~A}$ & $134,29 \mathrm{AB}$ & $131,57 \mathrm{~B}$ & $129,95 \mathrm{C}$ \\
\hline CO2total & $108,97 \mathrm{~A}$ & $105,26 \mathrm{~A}$ & $101,91 \mathrm{AB}$ & $100,76 \mathrm{~B}$ \\
\hline Cinorgânico & $29,75 \mathrm{~A}$ & $28,71 \mathrm{AB}$ & $27,79 \mathrm{BC}$ & $27,46 \mathrm{C}$ \\
\hline COD & * & * & * & * \\
\hline CO2livre & $10,29 A$ & $8,23 \mathrm{AB}$ & $6,61 \mathrm{~B}$ & $6,18 \mathrm{~B}$ \\
\hline Carbonato & * & * & * & * \\
\hline Alcalinidade & $123,50 \mathrm{~A}$ & $121,57 \mathrm{~A}$ & $119,51 \mathrm{~A}$ & $119,19 \mathrm{~B}$ \\
\hline $\mathrm{pH}$ & $7,31 \mathrm{~B}$ & $7,47 \mathrm{~A}$ & $7,59 \mathrm{~A}$ & $7,72 \mathrm{~A}$ \\
\hline Temperatura & * & * & * & $*$ \\
\hline CE & * & * & * & * \\
\hline Densidade & * & * & * & * \\
\hline
\end{tabular}

$\left(^{*}\right)$ Não houve variação significativa $(\alpha>5 \%)$

$\mathrm{Na}$ tabela 35 estão apresentados os valores médios obtidos no teste Turkey para clorofila, ortofosfato, SST, SSO, bicarbonato, $\mathrm{CO}_{2}$ total, $\mathrm{CO}_{2}$ livre, Cinorgânico, alcalinidade, $\mathrm{pH}$ e CE entre as profundidades (ss, $\mathrm{m}$ e f). As letras diferentes ao lado das médias significam a diferença observada.

Para as variáveis SSI, feofitina, nitrato, nitrito, NTK, Namoniacal, COD, carbonato, temperatura e densidade não foram necessários à realização do teste Turkey, pois não apresentaram variação significativa ao nível de $5 \%$. 
Tabela 35: Teste Turkey entre as profundidades amostradas (variação vertical); ss: sub-superfície, m: meio e f: interface água-sedimento. As letras presentes indicam as diferenças ao nível de $5 \%$.

\begin{tabular}{lccc}
\hline & Ss & m & f \\
\hline \hline Clorofila & $0,74 \mathrm{~A}$ & $0,67 \mathrm{AB}$ & $0,59 \mathrm{~B}$ \\
\hline Feofitina & ${ }^{*}$ & ${ }^{*}$ & ${ }^{*}$ \\
\hline Ortofosfato & $0,70 \mathrm{~A}$ & $0,63 \mathrm{AB}$ & $0,56 \mathrm{~B}$ \\
\hline Nitrato & ${ }^{*}$ & ${ }^{*}$ & ${ }^{*}$ \\
\hline Nitrito & ${ }^{*}$ & ${ }^{*}$ & ${ }^{*}$ \\
\hline NTK & ${ }^{*}$ & ${ }^{*}$ & ${ }^{*}$ \\
\hline Namoniacal & ${ }^{*}$ & ${ }^{*}$ & ${ }^{*}$ \\
\hline SST & $73,07 \mathrm{~A}$ & $68,65 \mathrm{AB}$ & $63,53 \mathrm{~B}$ \\
\hline SSO & $64,50 \mathrm{~A}$ & $60,28 \mathrm{AB}$ & $56,43 \mathrm{~B}$ \\
\hline SSI & ${ }^{*}$ & ${ }^{*}$ & ${ }^{*}$ \\
\hline Bicarbonato & $129,97 \mathrm{C}$ & $133,41 \mathrm{~B}$ & $135,97 \mathrm{~B}$ \\
\hline CO total & $100,30 \mathrm{~B}$ & $103,65 \mathrm{AB}$ & $108,72 \mathrm{~A}$ \\
\hline Cinorgânico & $27,39 \mathrm{C}$ & $28,30 \mathrm{~B}$ & $29,60 \mathrm{~A}$ \\
\hline COD & ${ }^{*}$ & ${ }^{*}$ & ${ }^{*}$ \\
\hline CO2livre & $5,81 \mathrm{~B}$ & $7,21 \mathrm{AB}$ & $10,47 \mathrm{~A}$ \\
\hline Carbonato & ${ }^{*}$ & ${ }^{*}$ & ${ }^{*}$ \\
\hline Alcalinidade & $119,06 \mathrm{~B}$ & $120,79 \mathrm{AB}$ & $122,98 \mathrm{~A}$ \\
\hline pH & $7,74 \mathrm{~A}$ & $7,48 \mathrm{AB}$ & $7,35 \mathrm{~B}$ \\
\hline Temperatura & ${ }^{*}$ & ${ }^{*}$ & ${ }^{*}$ \\
\hline CE & $470,53 \mathrm{~B}$ & $468,40 \mathrm{~B}$ & $517,56 \mathrm{~A}$ \\
\hline Densidade & ${ }^{*}$ & ${ }^{*}$ & ${ }^{*}$ \\
\hline$\left.{ }^{*}\right)$ Não houve variação significativa $(\alpha>5 \%)$ &
\end{tabular}

Pela análise estatística de Correlação de Pearson $(r>5 \%)$ foi observada correlação da densidade fitoplanctônica com: SSI $(r=0,97)$, bicarbonato e carbonato $(r=$ $0,99), \mathrm{pH}(r=0,96)$ e temperatura $(r=0,99)$.

O gênero Phormidium sp apresentou correlação com: clorofila $(r=0,56)$, NTK $(r=-0,63)$, nitrogênio amoniacal $(r=-0,62)$, nitrato $(r=0,66)$ e SST $(r=0,67)$. Enquanto que Chlorella Kessleri apresentou correlação com: clorofila $(r=0,56)$, NTK $(r=0,56)$, nitrato $(r=0,66)$, SSO $(r=0,68)$, SST $(r=0,67)$, bicarbonato $(r=0,58), \mathrm{CO}_{2}$ livre $(r=$ $0,55)$, alcalinidade $(r=0,54)$ e com Cinorgânico $(r=0,56)$.

A espécie Kirchneriella lunaris apresentou correlação com: NTK ( $r=0,61)$ nitrogênio amoniacal $(r=0,51)$, nitrato $(r=0,68)$, SSO e SSI $(r=0,63)$, SST $(r=0,61)$, bicarbonato $(r=0,62), \mathrm{CO}_{2}$ livre $(r=0,58)$, alcalinidade $(r=0,57)$ e com Cinorgânico $\quad(r=$ $0,56)$. E as espécies Synechocystis aquatilis com ortofosfato $(r=0,51)$ e Eutetramorus planctonicus com ortofosfato $(r=0,58)$, nitrito $(r=0,66)$ e condutividade elétrica $(r=-$ $0,60)$. 
Foram observadas, também correlações entre algumas espécies: Phormidium sp com Aphanocapsa sp $(r=0,56)$, Golenkinia radiata $(r=0,72)$ e Chlamydomonas sp $(r=$ $0,87$ ); Chlorella Kessleri com Kirchneriella lunaris ( $r=0,72)$; Radiococcus planktonicus com Closterium acutum ( $r=0,82)$; Lyngbia sp com Synechocystis aquatilis $(r=0,69)$ e Aphanocapsa sp ( $r=0,58)$; Aphanocapsa sp com Gloenkinia radiata $(r=0,65)$ e Chlamydomonas sp $(r=0,66)$; Monoraphidium contortum com Monoraphidium sp $(r=$ $0,66)$ e Trachelomonas oblonga $(r=0,81)$. 


\section{Discussão}

As lagoas facultativas que compõem sistemas de tratamento biológico de esgotos podem ser consideradas ambientes lênticos, rasos e hipereutróficos. Estes ambientes são altamente influenciados pela chuva, vento e aquecimento solar, os quais podem aumentar ou diminuir o TDH e a mistura da coluna de água e, assim, contribuir para a heterogeneidade espacial e a variabilidade temporal dos fatores abióticos e bióticos, inclusive as da comunidade fitoplanctônica.

Apesar das lagoas facultativas serem consideradas ambientes hipereutróficos, devido à alta carga de matéria orgânica e nutrientes que recebem, os dois sistemas estudados nesta pesquisa receberam esgoto bruto que pôde ser classificado, durante a amostragem, como fraco ou médio (HOEPPNER, 2007), quanto a DQO (128 mg. $\mathrm{L}^{-1}$, em Pariquera-Açu e 126 mg. $\mathrm{L}^{-1}$, em Jacupiranga).

Porém, quanto às concentrações médias obtidas nas lagoas facultativas de Pariquera-Açu e de Jacupiranga, para nitrogênio total (33 e $35 \mathrm{mg} \cdot \mathrm{L}^{-1}$, respectivamente), fósforo total $\left(4,0\right.$ e 4,5 mg. $\mathrm{L}^{-1}$, respectivamente) e clorofila a $\left(0,6\right.$ e $0,7 \mathrm{mg} \cdot \mathrm{L}^{-1}$, respectivamente), estas foram maiores do que se espera encontrar, segundo Wetzel (1983), em ambientes eutróficos (fósforo total entre 0,03 e $0,1 \mathrm{mg} \cdot \mathrm{L}^{-1}$; nitrogênio total entre 0,5 e $15 \mathrm{mg} \cdot \mathrm{L}^{-1}$; e clorofila entre 0,01 e $0,1 \mathrm{mg} \cdot \mathrm{L}^{-1}$ ).

As densidades fitoplanctônicas encontradas nas lagoas estudadas não acompanharam a diluição do afluente pois a média da densidade foi maior que a observada por Falco (2005), na lagoa facultativa da ETE de Novo Horizonte, onde os valores de densidade variaram entre 0,25 a $9,0 \times 10^{5}$ ind. $\mathrm{mL}^{-1}$ e por Vasconcelos e Pereira (2001), em um sistema de lagoas de estabilização em Portugal, onde as densidades máximas foram próximas de $1,0 \times 10^{3}$ ind. $\mathrm{mL}^{-1}$.

Como o afluente destes sistemas permaneceu diluído com relação à carga orgânica, no período estudado, esperava-se encontrar altos limites de zona eufótica (Zeuf), pois a concentração de matéria orgânica e de sólidos suspensos seriam menores. Porém, houve predomínio de organismos fitoplanctônicos que tornaram a coluna de água menos transparente. Portanto, pôde ser observada pequena profundidade da zona eufótica nas lagoas facultativas da ETE de Pariquera-Açu e de Jacupiranga, com os limites inferiores a $0,65 \mathrm{~m}$ e $1,05 \mathrm{~m}$, respectivamente, sendo que a profundidade máxima destas é de 1,5 $\mathrm{m}$.

Segundo von Sperling (1996), a maior densidade fitoplanctônica pode ser encontrada nos primeiros $0,50 \mathrm{~m}$ da coluna de água, nas lagoas facultativas. Na lagoa de Pariquera-Açu este fato foi observado apenas em janeiro, às $7 \mathrm{~h}$, pois a Zeuf neste horário 
foi reduzida $(0,25 \mathrm{~m})$. Neste mesmo período, às 13 e $16 \mathrm{~h}$ e em julho, às 10 e $16 \mathrm{~h}$, a densidade fitoplanctônica foi maior na interface água-sedimento, contrariamente ao exposto pelo autor. Isto pode ter ocorrido devido ao fato de que nestes horários de amostragem foram observadas estratificações térmicas, que podem ter impedido que os organismos fitoplanctônicos não flagelados, comuns nestas lagoas, atingissem a subsuperfície da coluna de água. Este fato também foi observado por Falco (2005) e Miwa (2007), que encontraram maior densidade fitoplanctônica na interface água-sedimento das lagoas facultativas de Novo Horizonte e de Cajati (SP), respectivamente.

Em abril e setembro, na lagoa de Pariquera-Açu, a densidade fitoplanctônica permaneceu praticamente homogênea em toda a coluna de água e não foi observada estratificação térmica, o que também favoreceu a distribuição homogênea dos organismos fitoplanctônicos na coluna de água. Na lagoa facultativa da ETE de Jacupiranga, a densidade fitoplanctônica também permaneceu homogênea em toda a coluna de água em todas as amostragens, mesmo sendo observadas estratificações térmicas, principalmente às 13 e 16h, horários em que foram obtidos os maiores valores de RSFA.

De acordo com Pearson et al. (1987) a diferença de concentração do fitoplâncton na coluna de água também pode interferir na atenuação da RSFA e na redução dos organismos patogênicos. Curtis et al. (1994) também observaram que, em estudos sobre a penetração de radiação solar em lagoas de estabilização, diferenças nos coeficientes de atenuação da radiação, em diferentes sistemas, estão diretamente relacionados com a concentração de sólidos suspensos, principalmente representada por matéria orgânica (biomassa fitoplanctônica).

Nas duas lagoas estudadas foi observado relação direta entre a matéria orgânica e a densidade fitoplanctônica, pois nas amostragens de janeiro e julho, na lagoa de Pariquera-Açu, foram observadas as maiores concentrações médias de sólidos suspensos $\left(84,1\right.$ e 66,8 mg. $\left.\mathrm{L}^{-1}\right)$ e média de densidade fitoplanctônica $(4,87$ e 10,25 ×10 indivíduos. $\mathrm{mL}^{-1}$, respectivamente). Estas concentrações interferiram na atenuação da RSFA, que foi menor nestes períodos (67 e $50 \%$ ) do que nos outros amostrados (68, abril e $79 \%$, setembro).

Na lagoa de Jacupiranga, pôde-se observar atenuação da radiação solar incidente de mais de $90 \%$, em setembro, quando ocorreram as maiores densidades fitoplanctônicas e concentração de sólidos suspensos $\left(25,33 \times 10^{5}\right.$ ind. $\mathrm{mL}^{-1}$ e 95,2 mg.L' ${ }^{1}$ ), corroborando o descrito por Curtis et al. (1994).

Nas lagoas de estabilização de Pariquera-Açu e Jacupiranga, as diversidades de espécies fitoplanctônicas foram semelhantes e não houve variação temporal e vertical na estrutura da comunidade. Nestas lagoas houve predomínio de clorofíceas e 
cianobactérias, alternadamente. Uma única exceção foi verificada na lagoa de Jacupiranga, em setembro, onde a diversidade foi mais baixa $(1,14$ a 1,48$)$ em relação aos outros períodos estudados (2,44 a 3,66 e 3,14 a 4,21; em janeiro e abril, respectivamente), devido à dominância de clorofíceas.

Miwa (2007) também não encontrou variações temporal e vertical na estrutura da comunidade fitoplanctônica da lagoa facultativa de Cajati (SP) e o grupo predominante neste sistema, em todo o período amostrado, foi o das cianobactérias.

Já Granado (2004), na lagoa facultativa da ETE de Novo Horizonte (SP), encontrou maiores densidades de organismos pertencentes ao grupo das clorofíceas e o índice de diversidade foi sempre menor do que 1 devido à predominância da espécie Chlorella vulgaris. A autora não observou variação vertical da comunidade fitoplanctônica neste sistema.

A baixa variabilidade temporal observada nas lagoas corrobora a afirmação de Hutchinson (1967), de que as mudanças sazonais na comunidade fitoplanctônica são menos freqüentes em ambientes tropicais naturais, se comparadas às que ocorrem em ambientes temperados de alta latitude. De acordo com o autor, alterações diárias são mais comuns em ambientes tropicais. No entanto os valores obtidos nas lagoas facultativas estudadas não corroboram com o autor, pois não foram observadas variações diárias, mas as sazonais foram evidentes.

De acordo com a análise estatística de variância fatorial não foram observadas variações diária $(0,4463)$ e vertical $(0,6322)$ da densidade fitoplanctônica, nas lagoas estudadas. No entanto, variações sazonais e entre as duas lagoas $(<0,0001)$ foram evidentes. Na lagoa de Pariquera-Açu, as maiores densidades ocorreram em julho (5,0 e $15,0 \times 10^{5}$ ind. $\left.\mathrm{mL}^{-1}\right)$ e janeiro $\left(2,1\right.$ e $\left.11,0 \times 10^{5} \mathrm{ind} \cdot \mathrm{mL}^{-1}\right)$ e que em Jacupiranga, em setembro $\left(14,0\right.$ e $38,0 \times 10^{5}$ ind. $\left.\mathrm{mL}^{-1}\right)$ e em julho $\left(3,7\right.$ e $16,0 \times 10^{5}$ ind. $\left.\mathrm{mL}^{-1}\right)$.

Assim como a densidade, os índices de riqueza, diversidade e equidade não apresentaram diferenças significativas entre os períodos e profundidades estudados na lagoa facultativa de Pariquera-Açu. A riqueza de espécie variou entre 8,87 (meio, em julho e sub-superfície, em setembro) e 24,88 (sub-superfície, em abril), enquanto que a diversidade variou entre 1,41 (interface água-sedimento, em julho) e 3,82 (meio, em janeiro). A equidade foi alta (próximos a 1,0), principalmente em janeiro; como esperado, a dominância de espécie foi baixa (entre 0,10 e 0,16).

$\mathrm{Na}$ lagoa de Jacupiranga, os índices de riqueza e diversidade de espécie foram semelhantes nas amostragens de janeiro, abril e julho (18,88 e 30,89; 2,44 e 4,21, respectivamente). Em setembro foram observados os menores valores dos índices de riqueza e diversidade (variando entre 4,86 e 9,87; 1,12 e 1,48, respectivamente). Neste período, o índice de dominância esteve próximo de 0,50 , pois apenas as espécies 
Chlorella kessleri e Kirchneriella lunaris estiveram presentes na lagoa e foram responsáveis por estes baixos valores.

A biomassa fitoplanctônica pode ser estimada através do biovolume, densidade e concentrações de clorofila. Cerqueira (1995), estudando lagoas de estabilização em São Carlos (SP), estimou a biomassa utilizando a concentração de clorofila a e observou que esta variou entre 0,62 a 2,62 mg. $\mathrm{L}^{-1}$, na lagoa facultativa. A autora encontrou concentrações maiores do que as obtidas nesta pesquisa, onde estas concentrações estiveram entre 0,21 e $1,56 \mathrm{mg} \cdot \mathrm{L}^{-1}$ em Pariquera-Açu e entre 0,38 e 1,75 mg. $\mathrm{L}^{-1} \mathrm{em}$ Jacupiranga. Miwa (2007) obteve concentrações de clorofila maiores, entre 0,30 a 4,15 mg. $L^{-1}$, em Cajati.

A determinação da clorofila a através de espectrofometria, como foi realizado nesta pesquisa, é muito utilizada em programas de monitoramento, pois se trata de um método de fácil aplicação em relação ao de cromatografia (HPLC) (DOS SANTOS et al., 2003), porém não apresenta a mesma eficácia. De acordo com Carson e Simpson (1996), o método de espectrofometria apresenta muitos interferentes, tais como outros tipos de clorofila (b e c) e seus produtos de degradação, que podem superestimar as concentrações de clorofila a. No entanto, dos Santos et al. (op cit) sugeriram que este método é eficiente em ambientes com dominância de cianobactérias (como é o caso do reservatório de Salto Grande) ou quando se compara dois sistemas, pois o erro inerente pode ser desprezado, já que ocorre nos dois ambientes.

De acordo com os autores, o método de cromatografia é considerado o melhor para determinar a clorofila, pois pode-se obter as concentrações dos diferentes tipos de clorofila separadamente e valores mais próximos do real. Contudo, o custo do equipamento e o tempo que esta metodologia exige dificultam a rotina das análises.

As maiores precipitações ocorreram em janeiro, nos dois municípios (Figuras 11 e 12); as chuvas que antecederam as coletas afetaram a concentração dos nutrientes e na biomassa fitoplanctônica, principalmente na lagoa de Jacupiranga. A precipitação acumulada dos 5 dias que antecederam a coleta, nesta lagoa, foi de 125,7 mm em janeiro, quando foi observada a menor média de densidade fitoplanctônica $\left(1,2 \times 10^{5}\right.$ ind. $\mathrm{mL}^{-1}$ ), enquanto que em julho não houve precipitação acumulada e a densidade foi de $10,28 \times 10^{5}$ ind. $\mathrm{mL}^{-1}$.

Nos períodos de maior precipitação é esperada a redução da densidade fitoplanctônica e a concentrações de nutrientes, pois há um aumento na vazão e, consequentemente, diminuição no tempo de detenção hidráulico (MENDONÇA, 2000; GURUNG, DHAKAL e BISTA, 2006).

Esta diluição também pôde ser observada na lagoa facultativa de Pariquera-Açu, pois nos meses em que ocorreu precipitação próxima ao dia de amostragem (janeiro, 
abril e setembro), a densidade (biomassa) esteve mais baixa (4,9;0,87 e 1,13 x $10^{5}$ ind. $\mathrm{mL}^{-1}$, respectivamente) e em julho, quando não ocorreu precipitação nos 5 dias que antecederam a coleta, foram observadas as maiores densidades $10,25 \times 10^{5}$ ind. $\mathrm{mL}^{-1}$ ).

O teste de variância fatorial realizado com as variáveis abióticas revelou que os resultados obtidos nos diferentes meses de amostragem foram estatisticamente diferentes para as concentrações de nutrientes $(p>0,05)$. Conforme observado para a densidade, as maiores concentrações médias de ortofosfato, nitrato, nitrito, nitrogênio amoniacal e total foram obtidas em julho, enquanto que em janeiro ocorreram as menores (tabela 33).

No período de janeiro e abril, principalmente, a condutividade elétrica manteve-se constante em quase toda a coluna de água, exceto na interface água-sedimento, onde houve aumento de aproximadamente $20 \mu \mathrm{S} . \mathrm{cm}^{-1}$, em todos os horários. Este aumento esteve aparentemente relacionado com a ressuspensão do material que estava sedimentado, através do movimento da sonda, isto porque a condutividade elétrica está relacionada com a quantidade de íons presentes na água.

$\mathrm{Na}$ lagoa da ETE de Jacupiranga, em abril, foi observada a menor concentração de sólidos suspensos $\left(44,9 \mathrm{mg} \cdot \mathrm{L}^{-1}\right)$ e, conseqüentemente, os menores valores de condutividade elétrica (374 e $\left.396 \mu \mathrm{S} . \mathrm{cm}^{-1}\right)$. A maior concentração de sólidos suspensos (107 mg. L ${ }^{-1}$ ) e as maiores condutividades elétricas (488 e $552 \mu \mathrm{S} . \mathrm{cm}^{-1}$ ), ocorreram em setembro.

A incidência da radiação solar aquece a camada superficial da coluna de água, causando diferença na densidade desta e, conseqüentemente, a estratificação térmica da coluna de água que, por sua vez pode alterar a estrutura da comunidade fitoplanctônica. De acordo com Kellner e Pires (2002), a coluna de água das lagoas de estabilização, em climas tropicais, é considerada estratificada quando se observa gradiente de $0,6{ }^{\circ} \mathrm{C}$ por metro.

$\mathrm{Na}$ presente pesquisa, segundo o critério descrito pelos autores, foi observada estratificação nas lagoas facultativas de Pariquera-Açu (janeiro e abril) e de Jacupiranga (em todos os meses amostrados), principalmente nas amostragens das 13 e 16h, coincidindo com os maiores valores de RSFA. Nas amostragens das 7 e 10h, a temperatura na coluna de água permaneceu constante em todos os meses, nas duas lagoas.

A velocidade do vento também influencia os períodos de estratificação e mistura. Na lagoa de Pariquera-Açu, no mês de setembro, obteve-se a maior velocidade do vento, o que pode ter favorecido a homogeneidade da coluna de água. Em Jacupiranga, a velocidade do vento foi praticamente constante durante todo o período estudado não interferindo no padrão de estratificação desta lagoa. 
De acordo com Arauzo et al. (2000), comparando os períodos de estratificação e mistura, são esperados altos valores de biomassa nos períodos de estratificação, pois as espécies oportunistas costumam dominar nestes períodos. Segundo os autores, em sistemas de lagoas de estabilização profundas, as espécies que espera-se encontrar são da ordem Chlorococcales e Volvocales, durante o período de estratificação, com as euglenofíceas dominando em períodos de mistura, sendo esta uma característica que distingue os sistemas de tratamento fundos dos rasos. As euglenofíceas são organismos heterotróficos facultativos, e podem produzir oxigênio através da fotossíntese, na zona eufótica, ou mineralizar a matéria orgânica, na zona afótica. Os resultados obtidos no presente estudo não corroboram os obtidos pelos autores, pois tanto no período de estratificação como no de mistura as densidades fitoplanctônicas foram semelhantes, comparando-se os quatro períodos estudados, para as duas lagoas estudadas, visto que estas são ambientes rasos (1,5 m). Por este motivo, as euglenofíceas foram ocasionais, raras ou ausentes, enquanto as Chlorococcales estiveram presentes em todos os períodos, independentemente da condição térmica da coluna de água. Estes organismos são considerados oportunistas por apresentarem pequeno tamanho e crescimento rápido, o que os tornam eficientes, favorecendo sua presença em qualquer época do ano (HAPPEY-WOOD, 1988).

A comunidade fitoplanctônica encontrada nas lagoas facultativas de PariqueraAçu e Jacupiranga foram semelhantes em relação diversidade e espécies. Foram encontrados 72 taxa em Pariquera-Açu e 74 em Jacupiranga, enquanto Granado (2004), em Novo Horizonte, encontrou 33 taxa e Miwa (2007), em Cajati, 31taxa. Nos sistemas de Jacupiranga e Pariquera-Açu pode-se observar maior diversidade de espécies do que nas lagoas citadas, mesmo estando todas localizadas na mesma região e tendo configurações de projeto diferentes.

Nas lagoas facultativas de Pariquera-Açu e Jacupiranga foram encontrados os seguintes grupos fitoplanctônicos: cianobactérias, clorofíceas, euglenofíceas, criptofíceas e bacilariofíceas, como já foi observado por diversos autores (GLOYNA, 1973; KÖNIG, 1984; KELLNER e PIRES, 1998; ARAÚZO et al., 2000; GRANADO, 2004; MIWA, 2007. No entanto, apenas as cianobactérias e as clorofíceas foram predominantes, embora em períodos alternados.

A maior contribuição das clorofíceas Chlamydomonas sp, Kirchneriella lunaris, Chlorella Kessleri, Monoraphidium contortum, Monoraphidium sp, Micractinium pusillum e Eutetramorus planctonicus se deve ao fato de serem classificadas, segundo Reynolds (1988), como C-estrategistas, ou seja, que apresentam crescimento rápido em ambientes onde há disponibilidade de nutrientes (eutróficos) e de RSFA, principalmente nas camadas superficiais da coluna de água, e podem ocorrer em períodos de estratificação 
ou mistura. De acordo com Bicudo et al. (1999), estes organismos são beneficiados pela mistura da coluna de água, sendo as Chlorococcales as mais beneficiadas.

Reynolds et al. (2002) aplicou o conceito de "grupos funcionais", criado por Hutchinson (1967), para entender as mudanças espacial e temporal na estrutura da comunidade fitoplanctônica. Segundo o autor, o gênero Chlorella $\mathrm{sp}$ faz parte do grupo funcional X1, onde estão agrupados os organismos que ocupam ambientes rasos, transparentes, misturados e meso-eutróficos, sendo sensíveis à deficiência de nutrientes.

Oliveira (1988) descreve uma característica importante das clorofíceas, o metabolismo mixotrófico, ou seja, a capacidade de crescer no escuro através da assimilação oxidativa de $\mathrm{CO}_{2}$ e na presença de RSFA, pela assimilação fotossintética, resultando em alta eficiência energética. Segundo Reynolds et al. (2006), este grupo também é conhecido por fazer a osmotrofia, ou seja, a capacidade de absorver mas moléculas orgânicas para uso metabólico, como fazem as bactérias. Huisman et al. (1999), em estudo sobre a competição de espécies, demonstraram que Chlorella sp apresenta vantagens na competição com cianobactérias sob baixa RSFA, mas isto é somente um dos fatores que levam o predomínio destes grupos fitoplanctônicos no ambiente, pois são fatores complementares à competição por nutrientes.

Chlorella, que esteve presente em abundância na lagoa facultativa de Jacupiranga, possui metabolismo mixotrófico e apresenta vantagem de sobreviver em lagoas de estabilização em que a zona eufótica é reduzida, já que assimilam carbono orgânico no escuro (KÖNIG et al., 1994). Reynolds (1996) classificou este organismo como nanoplâncton (2 a $20 \mu \mathrm{m}$ de diâmetro) eutrófico, de crescimento rápido em águas ricas em fósforo e carbono inorgânico, como é o caso das lagoas estudadas.

De acordo com Happey-Wood (1988), em ambientes eutróficos, estes organismos são eficientes na assimilação de nutrientes ou de substâncias liberadas pelas células senescentes dos organismos maiores, devido ao seu pequeno tamanho, apresentando crescimento oportunista o que favorece sua dominância em qualquer época do ano. Esta estratégia de sobrevivência pôde ser observada principalmente na lagoa da ETE de Jacupiranga, nas amostragens de julho e setembro, quando as clorofíceas foram dominantes e foram observadas as maiores densidades $\left(3,7\right.$ e 38,0 $\times 10^{5}$ ind. $\left.\mathrm{mL}^{-1}\right)$.

Segundo a classificação de Reynolds et al. (2006), tanto Chlorella kessleri quanto Synecocystis aquatilis, consideradas como picoplâncton, podem ser incluídas no grupo funcional Z, cujas principais características seriam: ocupar ambientes transparentes, oligo ou ultraoligotrófico. Estes organismos, por serem unicelulares e pequenos, apresentam características semelhantes, que os tornam organismos muito comuns, principalmente em função da sua grande adequação a alta disponibilidade de RSFA e nutriente, a temperatura e pH constantes, não sedimentarem com facilidade e serem sensíveis à 
predação (HAl et al., 2000). Nas lagoas facultativas de Novo Horizonte (GRANADO, 2004) e Cajati (MIWA, 2007), os organismos que se apresentaram com maiores densidades foram, respectivamente, a Chlorella vulgaris (clorofícea) e a Synechocystis sp (cianobactéria), em todos os períodos amostrados, visto que estes são mais resistentes as alterações ambientais.

No entanto, em regiões tropicais, HUSZAR et al. (2000) observou a presença de S. aquatilis e C. minutíssima em ambientes eu-hipereutróficos (X1), que estiveram associados a níveis elevados de nutrientes e carbono, como o observado nas lagoas facultativas.

Synechocystis aquatilis foi representativa nas amostragens, principalmente em densidade, em todo o período de aestudo, exceto em abril (Pariquera-Açu) e em setembro (Jacupiranga). De acordo com Blomqvist, Pettersson e Hyenstrand (1994), pequenas cianobactérias sem heterocistos como Synechocystis sp e Merismopedia sp respondem melhor ao enriquecimento por nitrogênio amoniacal do que por nitrato. Nas lagoas estudadas, as concentrações de nitrogênio amoniacal estiveram entre 6,13 a 20,72 mg. $\mathrm{L}^{-1}$ em Pariquera-Açu e 7,06 a 36,12 mg. $\mathrm{L}^{-1}$ em Jacupiranga; e as concentrações de nitrato entre 0,41 a 2,64 e 70,57 a 3,04 mg. $\mathrm{L}^{-1}$ (Pariquera-Açu e Jacupiranga, respectivamente).

Para Shapiro (1990) e Dokulil e Teubner (2000) as cianobactérias podem dominar em ambientes hipereutróficos devido, principalmente, à baixa necessidade de luz pela presença de ficobilinas (que absorvem diferentes comprimentos de luz); à temperatura ótima mais elevada, comum em ambientes tropicais; a capacidade de acumular de fósforo; e a capacidade de algumas espécies de migrar para a superfície pela presença de aerótopos, que otimizam sua atividade fotossintética. Assim, as cianobactérias são mais eficientes em períodos com menor disponibilidade de gás carbônico do que as clorofíceas.

Em abril, nas duas lagoas facultativas estudadas, as cianobactérias foram predominantes em alguns horários. Neste período foram observados valores baixos de RSFA (93,7 e 901,4 $\mu \mathrm{E} \cdot \mathrm{m}^{-2} \cdot \mathrm{s}^{-1}$; em Pariquera-Açu e 119,4 e 1317,0 $\mu \mathrm{E} \cdot \mathrm{m}^{-2} . \mathrm{s}^{-1}$; em Jacupiranga), se comparado aos outros períodos amostrados, reduzida Zeuf $(0,05$ e 0,40 m; em Pariquera-Açu e 0,05 e 0,70 m; em Jacupiranga) e baixas concentrações de $\mathrm{CO}_{2}$ total (68 e $96 \mathrm{mg} \cdot \mathrm{L}^{-1}$; em Pariquera-Açu e 89 e $110 \mathrm{mg} \cdot \mathrm{L}^{-1}$; em Jacupiranga), nitrato $\left(0,46\right.$ e $0,58 \mathrm{mg} \cdot \mathrm{L}^{-1}$; em Pariquera-Açu e 0,57 e $0,62 \mathrm{mg} \cdot \mathrm{L}^{-1}$; em Jacupiranga) e ortofosfato $\left(0,20\right.$ e 0,44 mg. $\mathrm{L}^{-1}$; em Pariquera-Açu e 0,60 e 0,78 mg. $\mathrm{L}^{-1}$; em Jacupiranga), em relação aos outros períodos estudados.

Na lagoa facultativa de Pariquera-Açu, na amostragem de abril, Phormidium sp foi predominante às $16 \mathrm{~h}$ (sub-superfície) e abundante nos outros períodos, exceto às $7 \mathrm{~h}$ na 
sub-superfície (ausente) e na interface água-sedimento (comum). Vasconcelos e Pereira (2000) encontraram que esta cianobactéria é comum em sistemas de tratamentos de esgoto devido à grande quantidade de nutrientes, à alta temperatura e à radiação solar. Cañizares-Villanueva et al. (1994) usaram Phormidium sp para tratar água residuária de suinocultura, pois estes organismos são tolerantes a altas concentrações de amônia e à baixa RSFA. Neste estudo, em abril foram observados baixos valores de RSFA incidente, principalmente às 13 e $16 \mathrm{~h}\left(576,9\right.$ e $93,7 \mu \mathrm{E} \cdot \mathrm{m}^{-2} \cdot \mathrm{s}^{-1}$, respectivamente) e baixos limites de Zeuf (entre 0,05 e 0,40m), o que pode ter favorecido a presença de Phormidium sp

Gibson e Smith (1982) observaram que este gênero é mais competitivo com relação a outras espécies quando os valores de pH são elevados (entre 8,5 e 10) e que utiliza taxas maiores de $\mathrm{CO}_{2}$ que as clorofíceas. Nesta pesquisa, o período de predominância de Phormidium sp na lagoa de Pariquera-Açu coincidiu com os maiores valores de pH (entre 7,03 e 9,61) e obteve correlação positiva com o dióxido de carbono livre $(0,52)$.

Aparentemente, as diferenças observadas na estrutura da comunidade nas duas lagoas facultativas estudadas não estiveram relacionadas à diferença no projeto das estações de tratamento de esgoto. A maior biomassa na lagoa da ETE de Jacupiranga pôde ser relacionada à operação da lagoa, porém os fatores que mais influenciaram a comunidade foram os ambientais, como a precipitação e a profundidade da zona eufótica.

Além do estudo sobre a composição de espécies é necessário entender os processos dos quais estes organismos participam, como a produção primária. Segundo Venrick, Beers e Heinbokel (1977), experimentos realizados com a técnica de Winkler, com incubações in situ, devem durar pelo menos duas horas para que ocorra mudança significativa nas concentrações de oxigênio dissolvido nos frascos.

De acordo com Falco (2005), que comparou tempos de incubação de 60 e 30 minutos, foram observadas mudanças significativas nas concentrações OD após apenas 30 minutos e valores mais altos de produção primária. Para Calijuri e Dos Santos (2004), a técnica de incubações in situ é a que mais se aproxima do ambiente real, porém os resultados devem ser analisados com cuidado, pois a comunidade fica isolada da variabilidade ambiental durante o período de incubação.

Altas temperaturas podem acelerar a degradação de compostos orgânicos, devido ao aumento da atividade metabólica dos microrganismos. Por outro lado, podem diminuir a solubilidade do oxigênio dissolvido na água. Kayombo et al. (2002) e Tadesse, Green e Puhakka (2004) estudaram as variações diurna da temperatura, pH e OD e encontraram relação direta entre estas variáveis.

Estes autores encontraram que os maiores valores de $\mathrm{pH}$ e de concentrações de OD ocorreram no horário de maior temperatura, corroborando os valores encontrados 
nesta pesquisa, principalmente nas amostragens das 10,13 e 16h, quando ocorreram as maiores temperaturas, porcentagem de saturação de OD, valores de $\mathrm{pH}$ e, conseqüentemente, os picos de produção primária.

Em janeiro, na lagoa de Pariquera-Açu, às $10 \mathrm{~h}$, foi obtida a produção primária bruta de $15520 \mathrm{mgO} \cdot \mathrm{m}^{-3} \cdot \mathrm{h}^{-1}$ e os valores de temperatura da água, concentração de oxigênio dissolvido e $\mathrm{pH}$ foram, respectivamente de $27,98{ }^{\circ} \mathrm{C} ; 5,19 \mathrm{mg} \cdot \mathrm{L}^{-1}$ e 7,65. $\mathrm{Na}$ lagoa de Jacupiranga, às $16 \mathrm{~h}$, em julho, a temperatura foi de $26,24{ }^{\circ} \mathrm{C}$; OD de $8,64 \mathrm{mg} \cdot \mathrm{L}^{-}$ 1; o pH de 8,06; e a PPB de $8534 \mathrm{mgO}_{2} \cdot \mathrm{m}^{-3} \cdot \mathrm{h}^{-1}$.

Para Kayombo et al. (2002), em lagoas de estabilização, as concentrações de $\mathrm{CO}_{2}$ podem ser limitantes para o fitoplâncton e, conseqüentemente, para a produção primária, pois para oxidar a matéria orgânica estes organismos assimilam mais $\mathrm{CO}_{2}$. Este fenômeno, segundo os autores, geralmente ocorre em pH maior que 8.

$\mathrm{Na}$ lagoa facultativa de Pariquera-Açu foram encontradas as maiores concentrações de $\mathrm{CO}_{2}$ e os maiores valores de PPL (5,52 e 18,94 mg..-1; 3920 e 13660 $\mathrm{mgO}_{2} \cdot \mathrm{m}^{-3} \cdot \mathrm{h}^{-1}$; em janeiro), porém em abril, quando ocorreram as menores concentrações deste gás $\left(0,08\right.$ e 9,13 mg. $\left.\mathrm{L}^{-1}\right)$, também houve produção em todos os horários (4540 ; $7140 ; 3140$ e $3460 \mathrm{mgO}_{2} \cdot \mathrm{m}^{-3} \cdot \mathrm{h}^{-1}$; respectivamente, às $7 ; 10 ; 13$ e 16h). Na lagoa de Jacupiranga, na amostragem de julho, foram obtidos os maiores valores de PPL (232 e $\left.11931 \mathrm{mgO}_{2} \cdot \mathrm{m}^{-3} \cdot \mathrm{h}^{-1}\right)$ e as menores concentrações de $\mathrm{CO}_{2}\left(2,50\right.$ e 8,93 $\left.\mathrm{mg} \cdot \mathrm{L}^{-1}\right)$.

Conforme os autores acima, o $\mathrm{pH}$ pode ser utilizado como indicador da atividade fotossintética, pois valores acima de 8 indicam maior consumo de $\mathrm{CO}_{2}$ do que reposição deste através da respiração e decomposição. Valores de pH abaixo de 8 indicam maior concentração de $\mathrm{CO}_{2} \mathrm{e}$, portanto, menor atividade fotossintética, como ocorreu na maioria dos períodos estudados, nas duas lagoas, principalmente nas amostragens das 7 e $10 \mathrm{~h}$

$\mathrm{O} \mathrm{CO}_{2}$ pode se tornar limitante para o metabolismo fitoplanctônico em ambientes com $\mathrm{pH}$ acima de 8. Este valor ocorreu apenas em alguns períodos na sub-superfície das duas lagoas estudadas, principalmente às 13 e 16h. No entanto, o carbono não foi limitante durante o período de amostragem, pois através do balanço de C:N:P (tabela 8), pôde-se comprovar que estes nutrientes estavam presentes em abundância, não sendo limitantes para a produção primária e para o crescimento do fitoplâncton, como descrito pelos autores.

De acordo com Bitton (1994) e a Cetesb (2007), espera-se encontrar razão C:N:P, em esgotos, na proporção de 100:5:1 para processos aeróbios e 350:7:1 para processos anaeróbios. Porém esta, proporção pode variar de acordo com cada sistema. No presente estudo, de acordo com a relação citada, pode-se observar alternância dos processos anaeróbios e aeróbios, pois as razões obtidas variaram entre 172:7:1 e 
1034:21:1, em Pariquera-Açu; 141:17:1 e 791:37:1 em Jacupiranga. Altos valores de carbono são esperados em lagoas de estabilização devido à grande quantidade de matéria orgânica provinda dos esgotos domésticos.

Apesar das concentrações de $\mathrm{N}$ e $\mathrm{P}$ serem menores que as de $\mathrm{C}$, estes também não foram limitantes para a produção primária e para o crescimento do fitoplâncton , pois segundo RHEE (1982); TILMAN e KILHAM (1976) estes nutrientes só se tornam limitantes para as cianobactérias e bacilariofíceas, quando as razões forem menores que a variação de 7 a 15 N/P; e para a clorofíceas quando a razão for menor que 15 a 30 N/P.

A produção primária fitoplanctônica está relacionada diretamente com a disponibilidade de radiação solar e de nutrientes, e com a densidade fitoplanctônica. Corroborando os resultados obtidos por Weatherell et al. (2003), foi observada, em setembro, na lagoa de Pariquera-Açu, produção primária bruta em todas as profundidades, às 7 e 10h. Nestes horários, a transparência da coluna de água foi maior $(0,45$ e $0,65 \mathrm{~m})$ e a radiação solar fotossinteticamente ativa, variou de 63,5 a 430,0 $\mu \mathrm{E} . \mathrm{m}^{-}$ ${ }^{2} \cdot \mathrm{s}^{-1}$ (sub-superfície), se comparada aos outros. Na lagoa de Jacupiranga, em janeiro, às $13 \mathrm{~h}\left(0,60 \mathrm{~m}\right.$ e $\left.322,9 \mu \mathrm{E} \cdot \mathrm{m}^{-2} \cdot \mathrm{s}^{-1}\right)$ e em abril, às 10 e $16 \mathrm{~h}(0,60$ e $0,70 \mathrm{~m} ; 220,3$ e 109,2 $\left.\mu \mathrm{E} \cdot \mathrm{m}^{-2} \cdot \mathrm{s}^{-1}\right)$.

Foram observados altos valores de produção primária bruta na interface águasedimento, em todos os horários de amostragem, principalmente em setembro, em Pariquera-Açu e em janeiro, em Jacupiranga. Estes valores de PPB na interface águasedimento estão relacionados, provavelmente, com os padrões de mistura turbulenta da coluna de água provocado pelo vento, já que nestes períodos ocorreram as maiores velocidades de vento (2,68 $\mathrm{m} . \mathrm{s}^{-1}$; janeiro, Pariquera-Açu e $0,72 \mathrm{~m} . \mathrm{s}^{-1}$; janeiro, Jacupiranga).

De acordo com Ichimura (1960) ${ }^{1}$ apud Calijuri (1988), em ambientes bem misturados e rasos haverá pouca diferenciação das características fotossintéticas no sentido vertical da coluna de água. Isto ocorre por que o fitoplâncton, que está adaptado à superfície e responde à alta luminosidade, sedimenta por ação da mistura da coluna de água e continua realizar fotossíntese até se ajustar fisiologicamente às condições de escuro. Como o tempo de incubação nesta pesquisa foi pequeno (30 $\mathrm{min}$ ); se comparado ao citado por Ichimura (1960) apud Calijuri (1988), o fitoplâncton incubado não teve tempo suficiente para que ocorresse o ajuste fisiológico e, assim, foram obtidos valores

1 ICHAMURA, S. (1960) Photosyntesis pattern of natural phytoplankton relating to light intensity. Bot. Mag. Tokyo. v. 73, p.458-476. 
de PPB maior na interface água sedimento do que na sub-superfície, mesmo não tendo disponibilidade de RSFA.

Calijuri (1985), em estudos realizados na represa do Lobo (SP), mostrou a nítida variação da produtividade primária fitoplanctônica ao longo do fotoperíodo, e percebeu que há picos mais altos de atividade nas primeiras horas do fotoperíodo e picos menores próximos às 16h; entre 12 e 15h ocorrem períodos de inibição. Na lagoa facultativa de Pariquera-Açu, pôde ser observado o pico de PPL às $7 \mathrm{~h}$, em setembro, às $10 \mathrm{~h}$, em janeiro e abril, porém não ocorreu inibição às $13 \mathrm{~h}$, em nenhum dos períodos amostrados, provavelmente devido à abundância de nutrientes. Em abril e setembro, os valores de PPL às $13 \mathrm{~h}$ estiveram muito próximos aos das $16 \mathrm{~h}$, e em janeiro e julho foram maiores (Tabela 27).

$\mathrm{Na}$ lagoa facultativa da ETE de Jacupiranga também foram observados picos de PPL às $10 \mathrm{~h}$, em todos os períodos, exceto em janeiro. Neste período, observou-se PPL semelhante às 7,13 e $16 \mathrm{~h}\left(4280 ; 3560\right.$ e $5920 \mathrm{mgO}_{2} \cdot \mathrm{m}^{-3} \cdot \mathrm{h}^{-1}$; respectivamente). Nesta lagoa também não foi observada inibição da atividade fotossintética às $13 \mathrm{~h}$, como era esperado de acordo com autora citada anteriormente. Esta inibição não foi observada, pois a concentração de nutrientes neste sistema não foi limitante para a produção, como ocorreu em Pariquera-Açu.

De acordo com Talling (1966) $)^{2}$ apud Calijuri (1985) uma das possíveis explicações para a inibição da produção primária está relacionada com o tempo muito longo de exposição do fitoplâncton a alta radiação solar durante o período experimental (4 horas). Como no presente estudo o período de incubação foi menor (30 minutos), não expondo a célula por muito tempo a radiação e à falta de nutrientes evitando assim a inibição da produção.

De acordo com Konig (1984), a máxima concentração de clorofila nem sempre coincide com a máxima produção primária fitoplanctônica. A autora sugere o efeito de auto-sombreamento do fitoplâncton. O presente estudo corrobora com o que foi observado pela autora, pois na lagoa de Jacupiranga, os picos de PPL ou PPB não coincidiram com os de clorofila $a$.

Em setembro, nesta lagoa, obteve-se a maior concentração de clorofila a às $13 \mathrm{e}$ 16h porém não houve produção primária líquida no primeiro horário e no segundo foi obtida produção mais baixa que nos outros horários $\left(3065 \mathrm{mgO}_{2} \cdot \mathrm{m}^{-2} \cdot \mathrm{h}^{-1}\right)$. No entanto, na lagoa de Pariquera-Açu, o auto-sombreamento não foi observado, pois as maiores

\footnotetext{
${ }^{2}$ TALLING, J.F.; LEMOALLE, J. (1998) Ecological dynamics of tropical inland waters. Cambridge, University Press, UK. 441p.
} 
concentrações de clorofila foram obtidas em janeiro e coincidem com os maiores valores de PPL (13660 e $8980 \mathrm{mgO}_{2} \cdot \mathrm{m}^{-2} \cdot \mathrm{h}^{-1}$; respectivamente às 10 e $13 \mathrm{~h}$, na sub-superfície).

Elevados valores da respiração da comunidade são esperados em ambientes com altas concentrações de matéria orgânica e, portanto, maior decomposição. Segundo Goniak et al. (2003) e Azevedo, Duarte e Bordalo (2006), respiração maior que produção indica predominância de processos heterotróficos, comuns em lagoas de estabilização. Isto foi observado na lagoa de Pariquera-Açu, em abril, às 7, 10 e 16 h; em julho, às 16 h; e em setembro, às 10, 13 e $16 \mathrm{~h}$; e na lagoa de Jacupiranga, em janeiro, às 7, 10 e $16 \mathrm{~h}$; em julho, às 13 e $16 \mathrm{~h}$; e em setembro, às 10 e $13 \mathrm{~h}$. Porém nos outros períodos a PPB foi maior que a Rc.

Goniak et al. (op cit) observaram que o rápido aumento na respiração é seguido pelo aumento na concentração de carbono orgânico dissolvido (COD). Os dados apresentados na presente pesquisa corroboram esta afirmação, pois em setembro, em Jacupiranga, as concentrações de COD foram mais elevadas no horário em que a respiração da comunidade também foi maior (13 h). Os autores sugerem que este aumento da respiração, seguido do aumento de COD é, provavelmente, efeito do intensivo desenvolvimento do bacterioplancton utilizando sulfeto como fonte de energia

Joseph e Joseph (2001) também determinaram a produção primária fitoplanctônica, através do método do oxigênio dissolvido, em um sistema de lagoas para tratar efluente de uma refinaria de óleo e obtiveram entre 15480 e $117000 \mathrm{mgO} \cdot \mathrm{m}^{-2} \cdot \mathrm{h}^{-1}$ para PPB e entre 9630 e $7119 \mathrm{mgO}_{2} \cdot \mathrm{m}^{-2} \cdot \mathrm{h}^{-1}$ para a Rc. Segundo estes autores, é possível avaliar o nível de estabilização da água residuária e o potencial eutrofizante do efluente final, através da comparação entre a produção primária bruta e a respiração da comunidade. De acordo com os autores, PPB maior que a Rc indica, claramente, que a estabilização do efluente final não foi completa e confirma o seu potencial eutrofizante.

Esta relação pode ser analisada no presente estudo, nas duas lagoas facultativas estudadas. A PPB foi maior que a Rc em janeiro (10,13 e 16h), abril (7, 10 e 13h) e julho (13h), na lagoa facultativa de Pariquera-Açu; e em janeiro (7, 13 e 16h), abril (10 e 13h), julho (13 e 16h) e setembro (16h) na de Jacupiranga. Hoeppner (2007) estudou a eficiência das lagoas de Pariquera-Açu e Jacupiranga no mesmo período em que esta pesquisa foi realizada. A autora encontrou reduções de sólidos suspensos totais, com mínimas de $58,9 \%$ e $54,4 \%$, respectivamente, ambas em julho; de fósforo total, com mínimas de $15,8 \%$ e $37,3 \%$ em janeiro, respectivamente; de nitrogênio total e amoniacal com mínimas de $38,2 \%$ em julho. Não houve eficiência de redução das formas nitrogenadas e houve aumento de clorofila a no efluente final, o que pode confirmar o potencial eutrofizante do mesmo. 
Joniak, Goldyn e Kozak (2003) observaram que os valores máximos de produtividade primária fitoplanctônica ocorreram na superfície de um reservatório na Polônia, raso e hipereutrófico, no período de maior intensidade de luz. Os picos de PPB e PPL observados em janeiro e julho, na lagoa de Jacupiranga, também coincidiram com os maiores valores registrados de RSFA. Julho também foi o período em que o TDH foi maior (49,7 dias), o que pode ter favorecido os maiores valores de PPL e as maiores concentrações de clorofila $a$. A alta radiação solar pode aumentar a temperatura da água, como foi observado em janeiro e, de acordo com Cerqueira (1995), a elevação da temperatura interfere indiretamente no aumento da produção primária, pois acelera o metabolismo dos organismos fitoplanctônicos.

De acordo com Kayombo et al. (2002) e Ramirez e Bicudo (2005), as variações de OD, C-inorgânico e pH são amplamente conectadas às atividades biológicas, especialmente a respiração e a fotossíntese. Segundo estes autores, é possível encontrar relação inversa entre a concentração de OD e o pH com a concentração de $\mathrm{CO}_{2}$. Porém, embora esta relação de $\mathrm{OD}$ e $\mathrm{CO}_{2}$ tenha sido observada nas lagoas, o pH manteve-se praticamente constante durante todos os períodos. Em Pariquera-Açu, esta relação ficou mais evidente em abril, quando as concentrações de OD estiveram entre 0,47 e $22,21 \mathrm{mg} \cdot \mathrm{L}^{-1}$ e as de $\mathrm{CO}_{2}$ entre 0,08 e $9,13 \mathrm{mg} \cdot \mathrm{L}^{-1}$. Em Jacupiranga, a relação de $\mathrm{OD}$ e $\mathrm{CO}_{2}$ foi mais evidente em setembro, quando as concentrações de OD estiveram entre 5,38 e 28,54 mg. $\mathrm{L}^{-1}$ e as de $\mathrm{CO}_{2}$ entre 0,23 e $46,69 \mathrm{mg} \cdot \mathrm{L}^{-1}$.

Apesar da diferença na configuração de projeto das estações de tratamento de esgoto de Pariquera-Açu (chicanas) e Jacupiranga (convencional), não pôde ser observada relação entre os valores de PPB e Rc, pois valores diferentes foram obtidos para cada lagoa nos diferentes períodos amostrados, bem como nos diferentes horários e profundidades, não sendo possível, portanto, definir qual configuração de projeto seria a mais adequada em relação à estabilização da matéria orgânica, já que tais ambientes estão sujeitos a diferentes condições externas e internas.

No entanto, o estudo da variabilidade temporal da estrutura da comunidade fitoplanctônica e da produção primária é considerado relevante nos sistemas de tratamento de esgoto, pois estes organismos são responsáveis por processos que, direta ou indiretamente, interferem na qualidade do efluente final e, conseqüentemente, na qualidade da água do corpo receptor do mesmo. Foi neste sentido que esta pesquisa pretendeu auxiliar no entendimento da dinâmica dos organismos fitoplanctônicos com respeito à estabilização da matéria orgânica, visto que esta abordagem tem sido ainda pouco estudada em ambientes tropicais. 


\section{Conclusões}

I. Nas lagoas de estabilização de Pariquera-Açu e Jacupiranga não foram observadas variabilidade temporal e heterogeneidade espacial na estrutura da comunidade fitoplanctônica, como é esperado em ambientes naturais. Apenas as clorofíceas foram dominantes, em setembro, na lagoa de Jacupiranga. Nos outros períodos, nos dois sistemas, as clorofíceas e cianobactérias foram abundantes ou predominantes.

II. Apesar dos dois sistemas de lagoas estabilização terem configuração diferente, a densidade e a diversidade de espécies fitoplanctônicas foram semelhantes, sendo encontrados 72 taxa na lagoa de Pariquera-Açu e 74 na de Jacupiranga.

III. A precipitação influenciou na concentração de nutrientes e na densidade fitoplanctônica. No período de maior precipitação, ou seja, em janeiro, foram observadas as menores densidades de organismos fitoplanctônicos e concentrações de nutrientes na lagoa de Jacupiranga. Em julho, período em que não ocorreu precipitação significativa, os valores obtidos para estas duas variáveis nas lagoas de Pariquera-Açu e Jacupiranga, foram maiores.

IV. A variação sazonal da densidade fitoplanctônica não esteve relacionada com os períodos de estratificação e mistura da coluna de água. Isto porque densidades semelhantes foram verificadas nas duas lagoas, independentemente da estrutura térmica da coluna de água, nos quatro períodos estudados.

V. Em Pariquera-Açu, a maior biomassa fitoplanctônica, considerando-se a densidade fitoplanctônica, esteve atribuída a Kirchneriella lunaris, Synechocystis aquatilis, Phormidium sp e Chlamydomonas sp, enquanto para o biovolume os organismos que mais contribuíram foram Phormidium $\mathrm{sp}$, Chlorella Kessleri, Monoraphidium contortum e Monoraphidium sp .

VI. Em Jacupiranga, a contribuição de biomassa, considerando-se o biovolume, alternou entre Phormidium sp, Eutetramorus planctonicus, Chlorella kessleri e Micractinium pusillum; quanto à densidade, foram importantes as espécies 
Synechocystis aquatilis, Chlorella kessleri, Kirchneriella lunaris, Monoraphidium sp e M. pusillum.

VII. Na lagoa de Jacupiranga foi observado, em setembro, os menores valores dos índices de riqueza e diversidade, e o maior de equidade, comparandose aos outros períodos estudados. Este fato deve-se a predominância e abundância de C. Kessleri e K. lunaris, respectivamente.

VIII. A máxima concentração de clorofila a não coincidiu com a máxima produção primária fitoplanctônica na lagoa de Jacupiranga, principalmente em setembro. A maior concentração de clorofila a na superfície pode ter causado sombreamento, diminuindo assim a atividade fotossintética e resultando em valores menores de produção primária fitoplanctônica nas camadas abaixo. Porém, na lagoa de Pariquera-Açu este fenômeno não foi observado, pois as maiores concentrações de clorofila a e de produção primária foram obtidas no mesmo período (janeiro, 10h).

IX. Os nutrientes (C. N, P) não foram limitantes para a produção primária e para o crescimento do fitoplâncton, pois foram observadas altas razões de $\mathrm{C}: \mathrm{N}: \mathrm{P}$, para as duas lagoas (172:7:1 a 1034:21:1, em Pariquera-Açu e 141:17:1 a 791:37:1, em Jacupiranga).

X. Elevados valores de produção primária foram observados na interface águasedimento das lagoas de Pariquera-Açu (setembro) e de Jacupiranga (janeiro). Estes valores ocorrem devido à mistura da coluna de água, provocada pelo vento, fazendo com que os organismos que estão na superfície sedimentam no fundo das lagoas. O tempo de incubação não deve ter sido suficiente para o ajuste fisiológico em condições de escuro.

XI. Nas lagoas de Pariquera-Açu e de Jacupiranga, em abril, julho e setembro, em alguns dos horários de amostragem, foram observados elevados valores de respiração da comunidade. Maiores valores de PPB do que Rc indicam que a estabilização da matéria orgânica não foi completa e que o efluente final deve apresentar potencial eutrófico. 


\section{Referências Bibliográficas}

ANAGNOSTIDIS, K.; KOMARÉK, J. (1986). Modern approach to the classification system of Cyanophytes. 2 - Chroococcales. Algological Studies, v. 73, p. 157-226.

ANAGNOSTIDIS, K.; KOMARÉK, J. (1988). Modern approach to the classification system of Cyanophytes. 3 - Oscillatoriales. Algological Studies, v. 50-53, p. 327-472.

ANAGNOSTIDIS, K.; KOMARÉK, J. (1989). Modern approach to the classification system of Cyanophytes. 4 - Nostocales. Algological Studies, v. 82, p. 247-345.

APHA - AMERICAN PUBLIC HEALTH ASSOCIATION (1999) Standard methods for the examination of water and wastewater Washington, Byrd Prepess Springfield.1134p.

ARAUZO, M.; COLMENAREJO, M.F.; MARTINEZ, E.; GRACIA, M.G. (2000) The role of algae in a deep wastewater self-regeneration pond. Water Research. v.34, n.14, p.36663674.

AZEVEDO, I. C.; DUARTE, P.M.; BORDALO, A.A. (2006) Pelagic metabolism of the Douro estuary (Portugal) e Factors controlling primary production. Estuarine, Coastal and Shelf Science. v.69, p.133-146.

BICUDO, C.E. de M.; MENEZES, M. (2005). Gêneros de algas de águas continentais do Brasil - chave para identificação e descrições. São Carlos: Rima.

BICUDO, C.E.M.; RESTREPO, J. J. R. ; TUCCI, A. ; BICUDO, D. C. (1999) Dinâmica de populações fitoplanctônicas em ambiente eutrofizado: o Lago das Garças, São Paulo. In HENRY, R. (org) Ecologia de Reservatórios: estrutura, função e aspectos sociais. Botucatu: Fapesp/Fundbio. p.451-507.

BITTON, G (1994) Wastewater microbiology. Wiley, John \& Sons, Inc., New York.

BLOMQVIST, P., PETTERSSON, A., HYENSTRAND, P. (1994) Ammonium-nitrogen: A key regulatory factor causing dominance of non-nitrogen-fixing cyanobacteria in aquatic systems. Archiv fur Hydrobiologie, 132 (2), pp. 141-164.

BOURRELY, P. (1972). Les algues d'eau douce - initiation à la systématique - les algues vertes. v. 1. Paris: N. Boubee. 
BOURRELY, P. (1981). Les algues d'eau douce - les algues jaunes et brunes. v. 2. Paris: N. Boubee.

BOURRELY, P. (2002). Les algues d'eau douce - les algues bleues et rouges - les eugléniens, péridiniens et cryptomonadines. v. 3. Paris: N. Boubee.

CALIJURI, M. C.; DOS SANTOS, A. C. A. (2001) Temporal variations in phytoplankton primary production in a tropical reservoir (Varra Bonita, SP- Brazil). Hydrobiologia. v.445, p. 11-26.

CALIJURI, M. C.; DOS SANTOS, A. C. A. (2004) A produção primária do fitoplâncton. In: BICUDO, C. E. M., BICUDO, D. C. (Org). Amostragem em Limnologia. São Carlos: Rima, p.321-341.

CALIJURI, M.C. (1985) Curvas de luz-fotossíntese e fatores ecológicos em ecossistema artificial e não estratificado, represa do Broa (Lobo), São Carlos, SP. Dissertação (mestrado)- Universidade federal de São Carlos, São Carlos. 280f.

CALIJURI, M.C. (1988) Respostas fisiológicas da comunidade fitoplanctônica e fatores ecológicos em ecossistema com diferentes estágios de eutrofização. Tese (Doutorado) Escola de Engenharia de São Carlos, Universidade de São Paulo. 293f.

CARLSON, R.E.; SIMPSON, J. (1996) A coordidinator's guide to volunteer lake monitoring methods. North American lake management society, 96p.

CAÑIZES-VILLANUEVA,R.O.; RAMOS, A.; CORONA, A.I.; MONROY, O.; DE LA TORRE, M.;GÓMEZ-LOJERO, G.; TRAVIESO, L. (1994) Phormidium treatment of anaerobically treated swine wastewater. Water Research, v. 28, n. 9, p. 1891-1895.

CASTRO, A. A. J.; BICUDO, C. E. M.; BICUDO, D.C. (1991). Criptogamos do Parque Estadual das fonts do Ipiranga, São Paulo, SP.Algas; 2 - Chryptophyceae. Hoehnea, v. 18 , p. $87-106$.

CERQUEIRA, M. B. (1995) Caracterização limnológica e produtividade primária em lagoas de estabilização de São Carlos, Estado de São Paulo, Brasil. Dissertação (Mestrado). Escola de Engenharia de São Carlos, Universidade de São Paulo, 121 p.

CETESB, (2007) Variáveis de qualidade das águas. Disponível em <http://www.cetesb.sp.gov.br/Agua/rios/variaveis>. Acesso em 27/03/2008. 
CIIAGRO - Centro Integrado de Informações Aagrometeorológicas. Disponível em: $<$ http://ciiagro.iac.sp.gov.br/ciiagroonline/>. Acesso em 30/10/2006.

CURTIS, T. P.; MARA, D. D.; DIXO, N. G. H.; SILVA, S. A. (1994) Light penetration in waste stabilization ponds. Water Research, v. 28, n. 5, p. 1031-1038.

CYANOSITE image gallery: banco de dados. Disponível em $<$ http://www.cyanosite.bio.purdue.edu/images/images.html>. Acesso em 10 de março de 2007.

DRAKARE, S.; BLOMQVIST, P.BERGSTRO, A.; JANSSON, M. (2002) Primary production and phytoplankton composition in relation to DOC input and bacterioplankton production in humic lake Ortrasked. Freshwater Biology. v.47, p.41-52.

DOKULIL, M. T.; TEUBNER, K. (2000). Cyanobacterial dominance in lakes. Hydrobiologia, v. 438, p. 1-12

DOS SANTOS, A.C.A.; CALIJURI, M.C.; MORAES, E.M., ADORNO, M.A.T., FALCO, P.B., CARVALHO, D.P.; DEBERT, G.L.B.; BENASSI, S.F. (2003) Comparison of three methods for Chlorophyll determination: Spectrophotometry and Fluorimetry in samples containing pigment mixtures and spectrophotometry in samples with separate pigments through High Performance Liquid Chromatography. Acta limnologica Brasiliensia. v.15, n. 3, p. 7-18.

FALCO, P. B. (2005) Estrutura da comunidade microbiana (algas e bactérias) em um sistema de lagoas de estabilização em duas escalas temporais: nictemeral e sazonal. Tese (Doutorado). Escola de Engenharia de São Carlos, Universidade de São Paulo. $137 f$.

GIBSON, C.E.; SMITH, R.V. (1982) Freshwater plankton. In: CARR, N.G.; WHITTON, B.A. (ed) The Biology of Cyanobacteria, Botanical Monographs. v. 19, p.463-491.

GLOYNA, E.T. (1973) Estanques de estabilización de aguas residuales. Organización mundial de la salud. Série monografias. N 60. Genebra. 192p.

GOLTERMAN, H.L.; CLYMO, R.S.; OHNSTAD, M.A.M. (1978) Methods for physical and chemical analysis of freshwater. 2. ed, IBP. Handbook n. 8, Blackwell Scientific Publications, Oxford, 213p. 
GÓMEZ, I.M.; SILVEIRA, J.A.H. (2006) Primary productivity dynamics in pristine groundwater influenced coastal lagoon of the Yucatan Peninsula. Continental Shelf Research. v. 26, p. 971-986.

GÓRNIAK, A.; GRABOWSKA, M.; RUDCZYK, E.J.; ZIELINSKI, P.; SUCHOWOLEC, T. (2003) Long-term variations of phytoplankton primary production in a shallow, polyhumic reservoir. Hidrobiologia. v. 506-509, p.305-310.

GRANADO, D. C. (2004) Variações nictemerais e sazonais na estrutura da comunidade fitoplanctônica num sistema de lagoas de estabilização (Novo Horizonte, SP). Dissertação (Mestrado). Escola de Engenharia de São Carlos, Universidade de São Paulo, $130 \mathrm{p}$.

GURUNG, T.B.; DHAKAL, R.P.; BISTA, J.D. (2006) Phytoplankton primary production, chlorophyll-a and nutrient concentrations in a water column of mountainous Lake Phewa, Nepal. Lakes \& Reservoirs and Management. v. 11, p.141-147.

HAI, T.; AHLERS, H.; GORENFLO, V.; STEINBUCHEL, A. (2000). Axenic cultivation of anoxygenic phototrophic bacteria, cyanobacteria, and microalgae in a new closed tubular glass photobioreactor. Applied Microbiology and Biotechnology. v. 53, p.383-389.

HAPPEY-WOOD, C. (1988) Ecology of freshwater planktonic green algae. In: SANDGREN, C.D. (ed). Growth and reproductive strategies of freshwater phytoplankton. Cambridge University Press. p. 175 - 226.

HENRY, R.; NOGUEIRA, M.G.; POMPEU, M.L.M.; MOSCHINI-CARLOS, V. (2006) Annual and short-term variability in primary productivity by phytoplankton and correlated abiotic factors in the Jurumirim reservoir (São Paulo, Brazil). Brazilian Journal of Biology. v.66, n.1B, p. 239-261.

HILLEBRAND, H.; DÜRSELEN, H.; KIRSCHTEL, D.; POLLINGHER, U.; ZOHARY,T. (1999) Biovolume calculation for pelagic and benthic microalgae. Journal of Phycology. v. 35, p.403-424.

HOEPPNER, A. F. S. (2007) Comportamento de variáveis físicas, químicas e da eficiência de sistemas de lagoas de estabilização em ambiente tropical (Vale do Ribeira de Iguape, SP). Dissertação (mestrado). Departamento de Hidráulica e Saneamento, Escola de Engenharia de São Carlos, Universidade de São Paulo. 284 p. 
HUISMAN, J.; RICHAJONKER, R.R.; ZONNEVELD, C.; WEISSING, F.J. (1999). Competition for Light between Phytoplankton Species: Experimental Tests of Mechanistic Theory. Ecology, v. 80, pp. 211-222.

HUSZAR, V. L. M.; SILVA, L.S.H.; MARINHO, M.; DOMINGOS, P.; SANT'ANNA, C.L. (2000). Cyanoprokaryote assembleges in eight productive tropical Brazilian waters. Hydrobiologia, v. 424, pp. 67-77.

HUTCHINSON, G.E. (1967) A treatise of limnology. $v^{\circ}$. II, Introduction to lake biology and the limnoplankton. New York. Wiley.

IBGE - INSTITUTO BRASILEIRO DE GEOGRAFIA E ESTATÍSTICA, (2002) Tabela das estimativas das populações residentes. Disponível em www.lbge.gov.br. Acesso em $18 / 08 / 2006$.

JONIAK, T.; GOLDYN, R.; KOZAK, A. (2003) The primary production of phytoplankton in the restored Maltañski reservoir in Poland. Hydrobiologia. v. 506-509, p. 311-316.

JOSEPH, V.; JOSEPH, A. (2001) Algae in the assessment of industrial wastewater holding ponds. Water, Air, and Soil Pollution. v.132, p.251-261.

KAYOMBO, S.; MBWETTE, T.S.A.; MAYO, A.W.; KATIMA, J.H.Y.; JORGENSEN, S.E. (2002) Diurnal cycles of variation of physical-chemical parameters in waste stabilization ponds. Ecological Engineering. v. 18, p. 187-291.

KELLNER, E.; PIRES, E. C. (1998) Lagoas de estabilização: projeto e operação. Rio de Janeiro. ABES. 242 p.

KELLNER, E.; PIRES. E.C. (2002) The influence of thermal stratification on the hydraulic behavior of waste stabilization ponds. Water Science and Technology, v. 45, n. 1, p. 41 48.

KOMÁREK, J.; ANAGNOSTIDIS, K. (1998). Cyanoprokaryota I. Teil Chroococcales. In: ETTL, H. et al. SüBwasserflora von Mitteleuropa. G. Fischer: Verlag Jena.

KOMÁREK, J.; FOTT, B. (1983). Chlorophyceae (Grünalgen). Ordiniung: Chlorococcales, In: HUBER-PESTALOZZI, G. Das phytoplankton des süsswasers; systematik und biologie, v. 7(1), E. Schwiezerbat'sche Verlagsbuch - handlung: Stuttgart, 1044p.

KONIG, A. (1984) Ecophysiological studies on some algae and bactéria of waste stabilization ponds. Thesis. University of Liverpool. 174p. 
KÖNIG, A. (1990). Biologia das lagoas: algas. In: Mendonça, S.R. (ed). Lagoas de estabilização e aeradas mecanicamente: novos conceitos. João Pessoa, PB. 388p.

KÖNIG, A.; CEBALLOS, B. S. O.; SOUSA, M. S. M. (1994) Variación estacional de la composición del fitoplâncton el ciclo nictemeral de una laguna facultativa secundaria. I Congreso y III Reunión Argentina de Limnologia, Tankay, 43-47.

MACKERETH, F.J.H.; HERON, J.; TALLING, J.E. (1978) Water analysis: some revised methods for limnologists. Freshwater Biological Association. Sci. Pub.. n.36, Wilson and Sons LTDA. 117p.

MENDONÇA, S.R. (2000) Lagunas de estabilización. In: Mendonça, S.R. (ed). Sistemas de lagunas de estabilización - como utilizar aguas residuales tratadas en sistemas de regadio. McGraw-Hill. Colombia. 370p.

MIWA, A. C. P. (2007) Avaliação do funcionamento do sistema de tratamento de esgoto de Cajati, Vale do Ribeira de Iguape (SP), em diferentes épocas do ano. Tese (doutorado). Departamento de Hidráulica e Saneamento, Escola de Engenharia de São Carlos, Universidade de São Paulo. 194 p.

MUNÕZ, R.; GUIEYSSE, B. (2006) Algal-bacterial process for the treatment of hazardous contaminants: A review. Water Research. v.40, p.2799-2815.

NANDINI, S. (1999) Variations in physical and chemical parameters and plankton community structure in a series of sewage-stabilization ponds. Revista de Biologia Tropical. v.47, p.149-156.

NEDERLANDSE NORM. NEN 6520. Netherlands. 1981.

NÕGES, T.; KANGRO, K. (2005) Primary production of phytoplankton in a strongly stratified temperate lake. Hydrobiologia. v.547, p.105-122.

$\mathrm{NUSH}$, E. A. (1980) Comparison of different methods for chlorophyll and phaepigment. Arch. Hydrobiolol.Bech. Stuttgart. v. 14. p. 14-36.

ODUM, E.P. (1988) Ecologia. Rio de Janeiro: Guanabara Koogan, p.434.

OLIVEIRA, H.T. (1988) Utilização da vinhaça como meio de cultura para Chlorella vulgaris (CCAP-211/11b). Dissertação (Mestrado) - Universidade Federal de São Carlos, São Carlos. 
PARRA, O.O.; GONZALEZ, M.; DELLAROSSA, V. (1980). Manual taxonômico del fitoplâncton de águas continentales com especial referencia al fitoplancton de Chile. Classe Euglenophyceae. Concepcion: Universidad de Concepcion. 98p.

PARRA, O.O.; GONZALEZ, M.; DELLAROSSA, V. (1983). Manual taxonômico del fitoplâncton de águas continentales com especial referencia al fitoplancton de Chile. Classe Chlorophyceae (parte 1 e 2). Concepcion: Universidad de Concepcion. 151p.

PARRA, O.O.; GONZALEZ, M.; DELLAROSSA, V.; RIVERA, P.; ORELLANA, M. (1982). Manual taxonômico del fitoplâncton de águas continentales com especial referencia al fitoplancton de Chile. Classe Cyanophyceae. Concepcion: Universidad de Concepcion.

PEARSON, H. W.; MARA, D. D.; KONIG, A.; OLIVEIRA, R. de; MILLS, S. W.; SMALLMAN, D. J.; SILVA, S. A. (1987) Water column sampling as a rapid and efficient method of determining effluent quality and the performance of waste stabilization ponds. Water Science and Technology, v. 19, n. 12, p. 109-113.

PROTIST: banco de dados. Disponível em <http://protist.i.hosei.ac.jp>. Acesso em 25 de novembro de 2006.

RAMIREZ, J.J.; BICUDO, C.E.M. (2005) Diurnal and spatial (vertical) dynamics of nutrients (N,P,Si) in four sampling days (summer, fall, winter, and spring) in a shallow reservoir and their relationships with the phytoplankton community. Brazilian Journal Biology. v.65, n.1, p.141-157.

RATCHFORD, I.A.J.; FALLOWFIELD, H.J. (2003) The effect of light:dark cycles of medium frequency on photosynthesis by Chorella vulgaris and the implications for waste stabilization pond design and performance. Water Science and Technology. v.48, n. 2, p. $69-74$

REYNOLDS, C. 2006. Ecology of phytoplankton. Cambridge University Press. 535p.

REYNOLDS, C.S. (1988) Functional morphology and the adaptive strategies of freshwater phytoplankton. In: SANDGREN, C.D. (ed). Growth and reproductive strategies of freshwater phytoplankton. Cambridge University Press. p. 388 - 433.

REYNOLDS, C.S. (1996) The plant life of the pelagic. Verh. Internat. Verein. Limmol. v.26, p.97-113. 
REYNOLDS, C.S.; HUZAR, V.; KRUK, C.; NASELLI-FLORES, L.; MELO, S. (2002) Towards a functional classification of the freshwater phytoplankton. Jornal of plankton research. v.24, p.417-428.

RHEE, G.Y. (1982) Effects of environmental factors on phytoplankton growth. In: MARSHALL, K.C. (ed). Advances in microbial ecology. New York, Plenum Press, p. 33 74.

ROBSON, B.J (2005) Representing the effects of diurnal variations in light on primary production on a seasonal time-scale. Ecological Modelling. v. 186, p. 358 - 365.

SANT'ANNA, C.L. et al. (2006). Manual ilustrado para identificação e contagem de cianobactérias planctônicas continentais brasileiras. Rio de Janeiro: Interciência, 58p.

SHAPIRO, J. (1990) Current beliefs regarding dominance by blue-greens: The case for the importance of $\mathrm{CO}_{2}$ and pH. Verh. Internat. Verein. Limmol. v.58, p.94-144

SILVEIRA, J.A.H.; GOMEZ, I.M.; COLLI, R. (2002) Trophic status based on nutrient concentration scales and primary producers community of tropical coastal lagoons influenced by groundwater discharges. Hydrobiologia. v. 475/476, p.91-98.

STAEHR, P.A.; JENSEN, K.S. (2006) Seasonal changes in temperature and nutrient control of photosynthesis, respiration and growth of natural phytoplankton communities. Freshwater Biology. v. 51, p. 249-262.

TADESSE, I.; GREEN, F.B.; PUHAKKA, J.A. (2004) Seasonal and diurnal variations of temperature, $\mathrm{pH}$ and dissolved oxygen in advanced integrated wastewater pond system treating tannery effluent. Water Research. v.38, p.645-654.

TILMAN, D.; KILHAM, S.S. (1976) Phosphate and silicate uptake and growth kinetics of the diatoms Asterionella Formosa and Cyclotella meneghiniana in batch and semicontinuos culture. Journal of Phicology. v. 12, p.375-383.

UTHERMÖHL, H. (1958) On the perfecting of quantitative phytoplankton method. Inst.Ass. Theor. Commum. Vol 9.

VASCONCELOS, V.M.; PEREIRA, E. (2000) Cyanobacteria diversity and toxicity in a wastewater treatment plant (Portugal). Water Research. v. 35, n.5, p.1354-1357. 
VENRICK, E.L.; BEERS, J.R.; HEINBOKEL, J.L. (1977) Possible consequences of containing microplankton for physiological rate measurements, Journal of Experimental Marine Biology and Ecology. v.26, p.55 - 76.

von SPERLING, M. (1996) Lagoas de estabilização Belo Horizonte: Departamento de Engenharia Sanitária e Ambiental (DESA), Universidade Federal de Minas Gerais (UFMG), 140 p (Princípios do tratamento biológico de águas residuárias, v. 3).

WEATHERELL, C.A.; ELLIOTT, D.J.; FALLOWFIELD, H.J.; CURTIS, T.P. (2003) Variable photosynthetic characteristics in waste stabilization ponds. Water Science and Technology. v. 48, n. 2, p. 219-226.

WETZEL, R. G. (1993) Limnologia. Lisboa. Fundação Calouste Gulbenkian, 919 p. 


\section{ANEXO 1}

Densidade dos gêneros e espécies fitoplanctônicas mais freqüentes encontrados nas lagoas facultativas dos sistemas de Tratamento de Esgoto de Pariquera-Açu e Jacupiranga. 


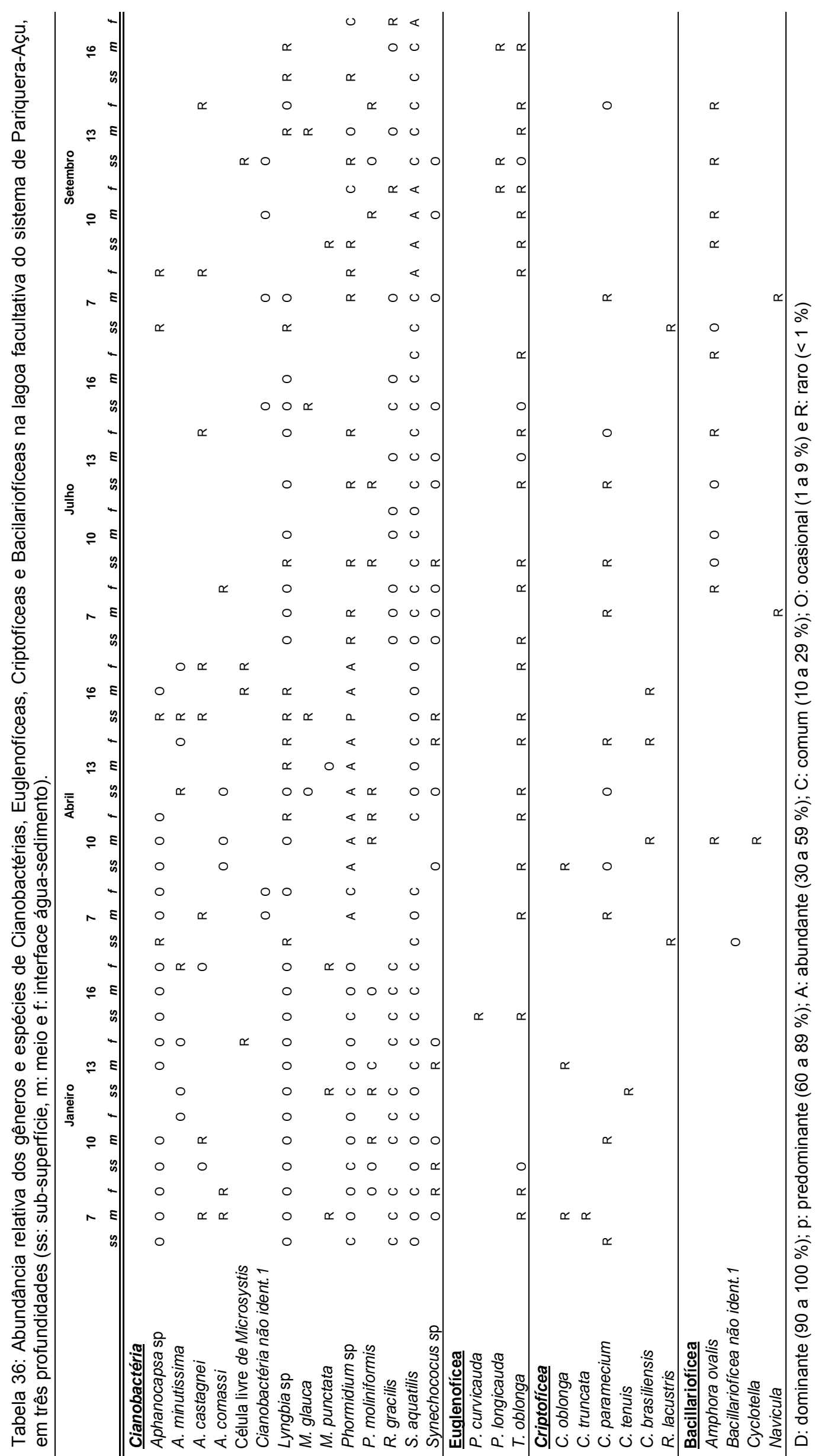




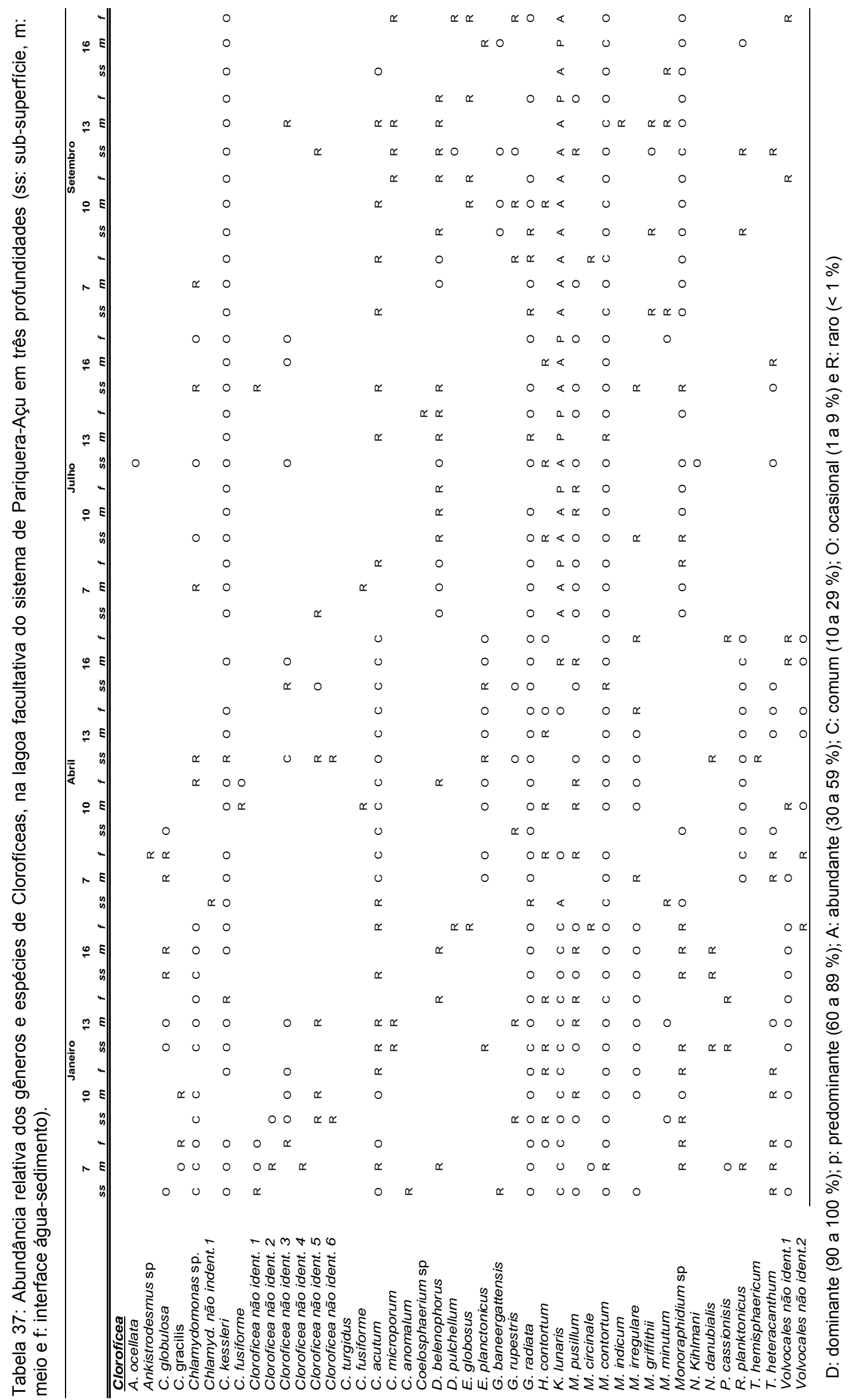




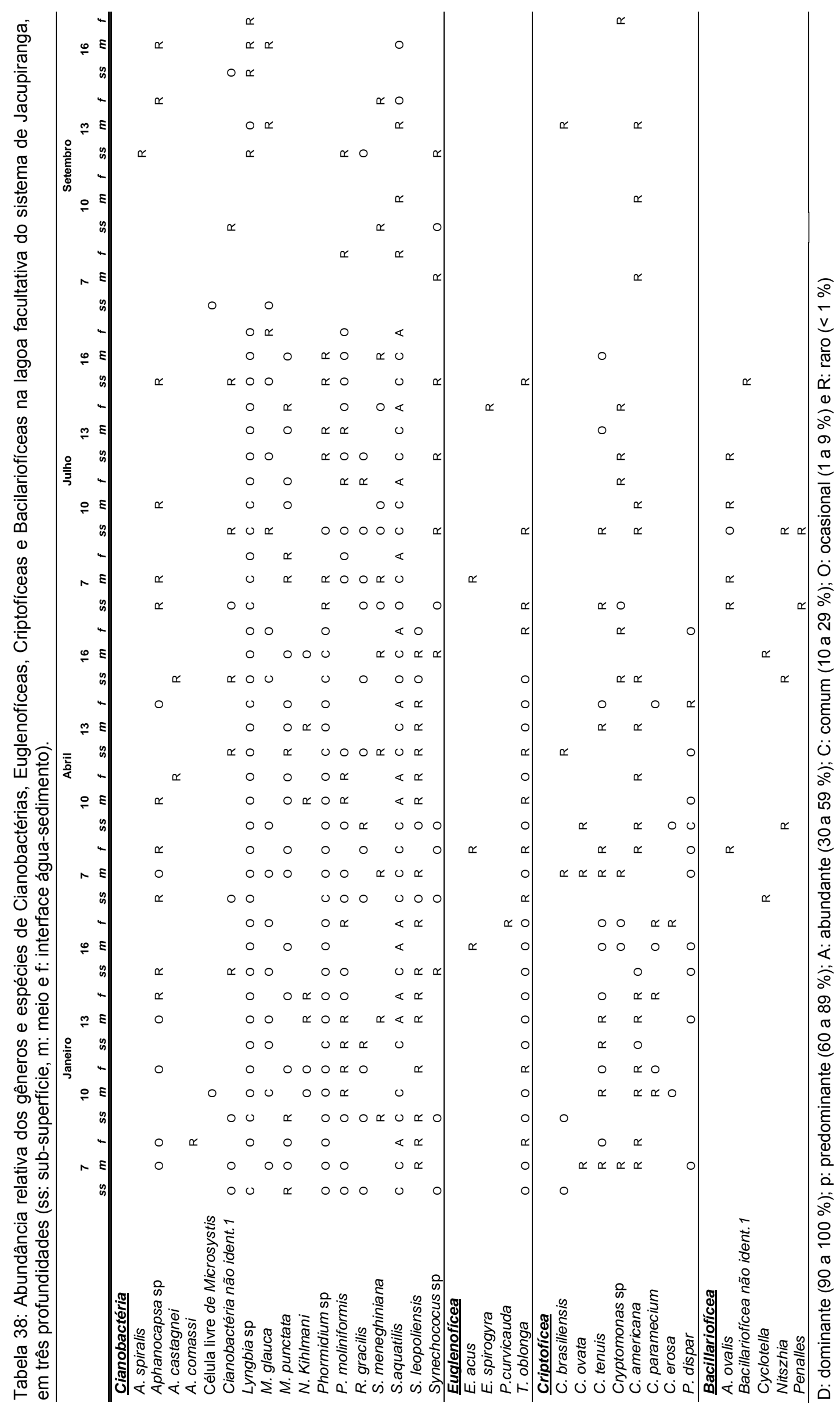




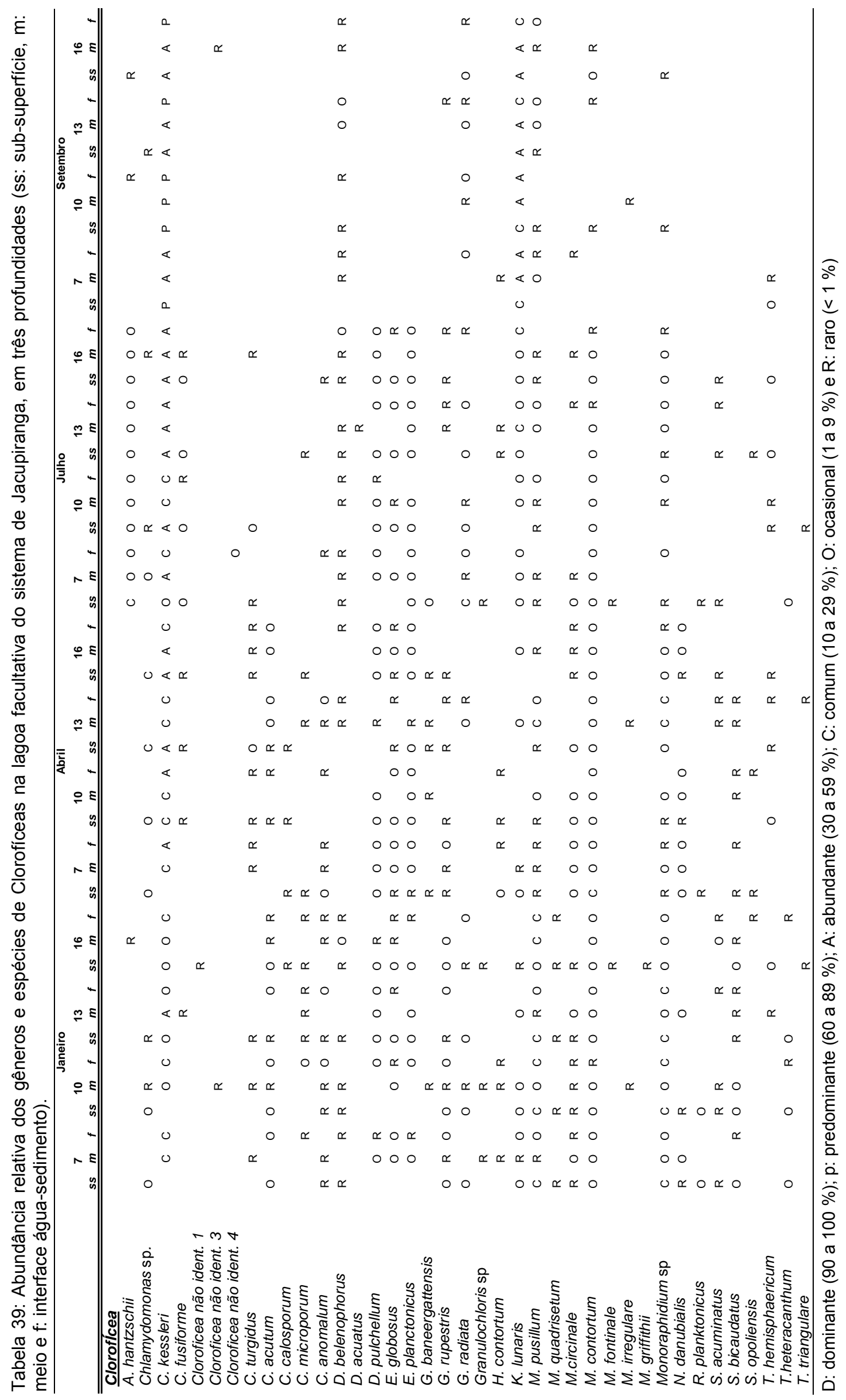

